\title{
Integrating Participatory GIS and political ecology to study flood vulnerability in the Limpopo Province of South Africa
}

Nthaduleni S. Nethengwe

West Virginia University

Follow this and additional works at: https://researchrepository.wvu.edu/etd

\section{Recommended Citation}

Nethengwe, Nthaduleni S., "Integrating Participatory GIS and political ecology to study flood vulnerability in the Limpopo Province of South Africa" (2007). Graduate Theses, Dissertations, and Problem Reports. 2581.

https://researchrepository.wvu.edu/etd/2581

This Dissertation is protected by copyright and/or related rights. It has been brought to you by the The Research Repository @ WVU with permission from the rights-holder(s). You are free to use this Dissertation in any way that is permitted by the copyright and related rights legislation that applies to your use. For other uses you must obtain permission from the rights-holder(s) directly, unless additional rights are indicated by a Creative Commons license in the record and/ or on the work itself. This Dissertation has been accepted for inclusion in WVU Graduate Theses, Dissertations, and Problem Reports collection by an authorized administrator of The Research Repository @ WVU.

For more information, please contact researchrepository@mail.wvu.edu. 
Integrating Participatory GIS and Political Ecology to study Flood Vulnerability in the Limpopo Province of South Africa

\author{
Nthaduleni S. Nethengwe \\ Dissertation submitted to the \\ Eberly College of Arts \& Sciences \\ at West Virginia University \\ in partial fulfillment of the requirements \\ for the degree of \\ Doctor of Philosophy \\ in Geography
}

Daniel Weiner, PhD., Chair Steven J. Kite, PhD. Brent McCusker, PhD. Ann Oberhauser, $\mathbf{P h D}$. Peter H. Omara-Ojungu, PhD.

Department of Geology and Geography

Morgantown, West Virginia 2007

Key words: Floods, Flood Vulnerability, Coping Strategies, PGIS, Political Ecology, Limpopo Province, Thulamela Municipality, Milaboni, Dzingahe 


\begin{abstract}
Integrating Participatory GIS and Political Ecology to study Flood Vulnerability in the Limpopo Province of South Africa
\end{abstract}

\author{
Nthaduleni S. Nethengwe
}

This dissertation research examines differential flood vulnerability in the Thulamela municipality of the Limpopo Province of South Africa. The study employs a triangulation of methods within a Participatory GIS methodology. Political ecology is the conceptual framework. The main premise of this research is that household flood vulnerability is socially constructed in that it is mediated by locally contingent political, socio-economic and environmental factors. As a result, conventional solutions that focus mainly on the physical event are ineffective and costly because they ignore local knowledge about flood hazards and flood coping mechanisms that have been disrupted or destroyed. The study integrates historical and contemporary flood experiences into a traditional GIS to study differential household flood vulnerability. The research seeks answers to four core questions: 1) what are the major historical and contemporary household flood coping strategies in the study area sites?; (2) how and why have historical household flood coping strategies changed?; (3) what are the critical factors that have produced differential household flood vulnerability?; and (4) how might a Participatory GIS methodology contribute to a political ecology analysis of differential flood vulnerability?

The study combines a quantitative spatial analysis using household survey and traditional GIS data with qualitative methods -- mental mapping, interviews, GPS-based transect walks, oral narratives and focus group discussions -- to examine the local dynamics of flood vulnerability at Milaboni and Dzingahe villages. PGIS provides the framework to include socially differentiated local knowledge while political ecology focuses the analysis on how power relations impact household flood vulnerability. The integration of local and expert knowledges comes together as a PGIS database for flood vulnerability analysis.

The main research findings are: 1) historical flood coping strategies have shifted from resource to income dependence; 2) physical factors such as rainfall, topography and geology are triggering factors of flood hazards. Notwithstanding this triggering role, flood vulnerability is socially constructed and it is shaped by differential household resources including land, income, housing quality, social networks of reciprocity and political resources; 3 ) the integration of local and expert knowledge has demonstrated the interaction of critical physical and socio-economic factors that have produced differential flood vulnerability. In this way, local and expert knowledges have been found to fulfill complementary roles towards the assessment of flood vulnerability; and 4) linking PGIS and political ecology provides a unique methodological and conceptual framework for representing and analyzing differential social and spatial flood vulnerability which takes into account historical processes, community perceptions, personal experiences and unequal power relations. 


\section{ACKNOWLEDGEMENTS}

It would have been impossible to see this project through without the support of the respondents at Milaboni and Dzingahe villages who formed the sample of the household survey and cognitive mapping workshops. The success of the project is accredited to my Chair and advisor, Dr. Daniel Weiner, for his unfailing willingness to critique my efforts, for his persistence in exhorting me to proceed with the work and invaluable advice and assistance. I wish to acknowledge the effort and guidance I received from other members of the dissertation committee: Drs. Steven Kite, Brent McCusker, Ann Oberhauser and Peter Omara-Ojungu.

I would also like to send my gratitude to the Department of Geology and Geography, Eberley College of Arts and Sciences, Office of the International Programme (WVU) and the University of Venda (Staff Development) for jointly provided funding and other logistical assistance during the course of this project. On the same note, I wish to thank my student colleagues, faculty and staff at West Virginia University and at the Department of Geography and Geo-information Sciences, School of Environmental Sciences (University of Venda) whose assistance and advice at various stages helped to set the pattern for this project. There are many others including my research assistants, who in their various ways have provided help and guidance. Among these are, Dr. Chifundo Lemani, Rueben Ramudzuli, Paddington Hodza, Steve McClelland, Sue Burgerson and Dr. Tirelo Moroka for advice and encouragement.

Finally, but not the least, I would like to thank my wife, Rofhiwa Nethengwe, my son, Khonani and my daughter, Tshinakaho who endured loneliness while I was away in the USA. I also want to thank my mother, Lydia Tshinakaho Nethengwe for the great work she did to raise me and my parents in-law, Mr. Jonathan and Mrs. Rosemary Siphuma for supporting my educational efforts to finish this doctorate program. To all these people, my thanks are due. 


\section{CONTENTS}

\section{Page}

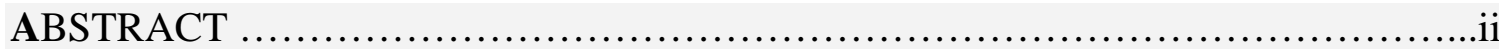

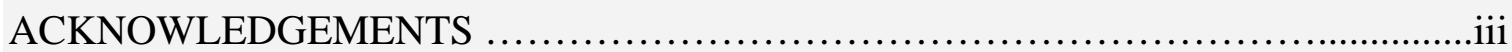

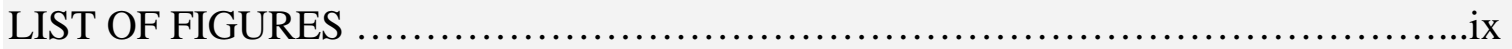

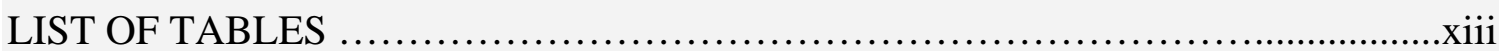

LIST OF ACRONYMS AND ABBREVIATIONS .................................

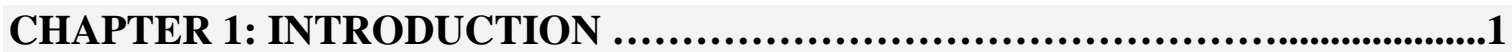

1.1 Research Background..........................................1

1.2 Statement of the Research Problem ..................................4

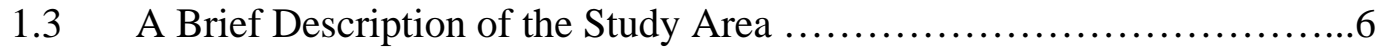

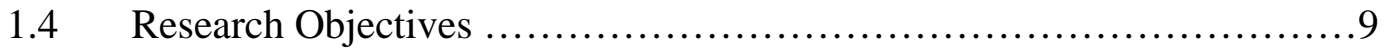

1.5 A Synopsis of the Research Methodology and Methods .................10

1.6 Contribution of this Research .......................................10

1.7 Dissertation Outline............................................12

\section{CHAPTER 2: THEORETICAL AND CONCEPTUAL FRAMEWORK.................13}

$2.1 \quad$ Introduction....................................................... 13

2.2 Theoretical Approaches to Flood Vulnerability........................14

2.2.1 Geography and Natural Hazards .............................16

2.2.1.1 The Choice Model......................................16

2.2.1.2 The Choice Constraint Model...........................19

2.2.2 Political Ecology and Flood Vulnerability .....................20

2.2.2.1 An Overview........................................20

2.2.2.2 The Concepts of Power, Human agency, Environment and Scale........................................23

2.3 Geographic Information Systems and Society $\ldots \ldots \ldots \ldots \ldots \ldots \ldots \ldots \ldots . .27$

2.4 Participatory Geographic Information Systems ......................28 
2.5 Integration of PGIS and Political Ecology for Flood Vulnerability

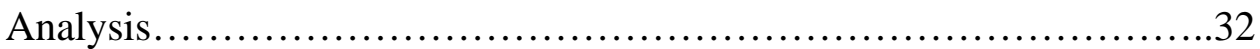

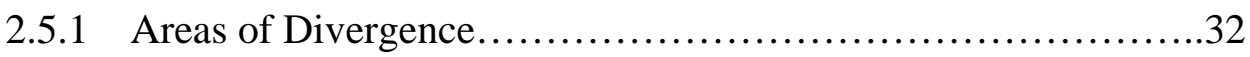

2.5.2 Common Ground............................................32

2.5.2.1 Geographic Context.................................32

2.5.2.2 Differential Access to Data, Technology \& Knowledge...34

2.5.2.3 Landscape of Power and Politics.......................35

2.6 Conceptual Framework ..........................................36

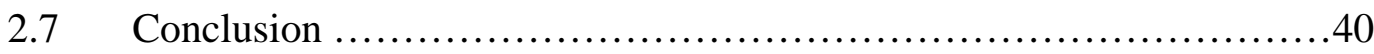

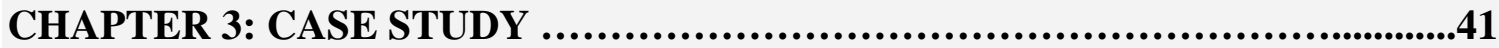

$3.1 \quad$ Introduction.......................................................41

3.2 Physical and Human Characteristics of the Limpopo Province and Case

Study Area..................................................45

3.2.1 Physical Characteristics.....................................45

3.2.1.1 Rainfall Distribution.............................45

3.2.1.2 Hydrology ......................................47

3.2.1.3 Vegetation Cover...................................47

3.2.1.4 Geology........................................47

3.2.1.5 Soil Property and Types...........................52

3.2.2 Socio-economic Characteristics.............................53

3.2.2.1 Demographic Characteristics........................53

3.2.2.2 Livelihood Activities...............................54

3.2.2.3 Land Use Activities.....................................55

3.3 The Apartheid Geographies and Political Ecology...........................56

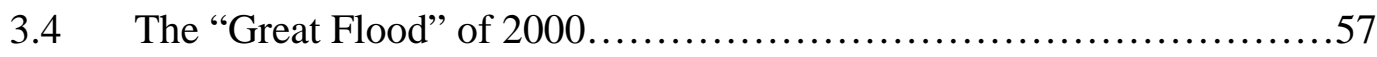

3.5 Conclusion...................................................63 


\section{CHAPTER 4: RESEARCH QUESTIONS, METHODOLOGY AND}

METHODS....................................................................64

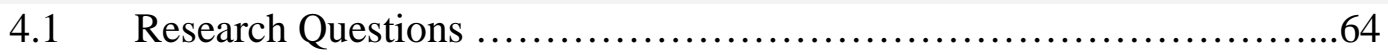

4.2 Research Methodology ............................................67

4.2.1 Setting up a PGIS in the Study Area.............................67

4.2.1.1 Conceptual Approach.....................................67

4.2.1.2 Methodological Approach................................69

4.2.1.2.1 Problem Definition...............................69

4.2.1.2.2 Data Requirements..................................71

4.2.1.2.3 Cartographic Model............................71

4.2.2 Study Sites and Means of Access.................................71

4.2.3 Context, Population Identification and Sampling Procedures.......72

$4.3 \quad$ Research Methods............................................... 74

4.3.1 Methods for Data Collection....................................74

4.3.1.1 Literature /Archival Search.............................74

4.3.1.2 Existing Socio-economic Survey.........................76

4.3.1.3 Household Survey......................................76

4.3.1.4 Individual Interviews, GPS Transect Walks and Participant

Observation.......................................... 77

4.3.1.5 Focus Group Discussions (FGDs) and Participatory Mental Mapping ........................................................78

4.3.1.6 Geographic Information Systems.......................80

4.3.2 Methods of Data Analysis.........................................81

\section{CHAPTER 5: A COMPARATIVE ANALYSIS OF HOUSEHOLD FLOOD}

COPING MECHANISMS ..........................................................................83

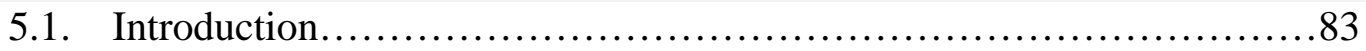

5.2. Historical Flood Coping Mechanisms in the Study Area.............................84

5.3. Crisis of Historical Forms of Flood Coping and Agents of Change......88

5.4. Current Flood Coping Mechanisms: A Comparative Perspective .........91

5.4.1. Borrowing of Financial Resources.........................92 
5.4.2. Reliance on Remittances ...............................100

5.4.3. Engagement in Informal Businesses..........................101

5.4.4. Evacuation to Places of Safety ..............................104

5.4.5. Asset Disposal .............................................106

5.4.6. Wage Labor .........................................108

5.4.7. Bank Savings............................................109

5.4.8. Flood Disaster Aid from Local Businesses and Government..109

5.4.9. Levees and Terraces .....................................110

5.5. Aggregated Measures of Differential Flood Coping Mechanisms........111

5.6. Conclusion...........................................................113

\section{CHAPTER 6: SOCIO-ECONOMIC AND POLITICAL DIMENSIONS OF} DIFFERENTIAL HOUSEHOLD FLOOD VULNERABILITY ....................115

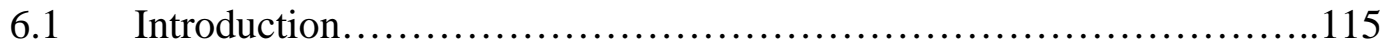

6.2 Household Resources and Flood Vulnerability........................116

6.2.1 Economic and Material Resources.............................117

6.2.1.1 Households Income..................................117

6.2.1.2 Housing type and Quality...........................126

6.2.1.3 Household Assets.......................................131

6.2.1.4 Perceived Economic Pressure............................133

6.2.2 Human and Personal Resources..................................139

6.2.2.1 Health Status of Householders..........................139

6.2.2.2 Household Living Arrangements........................141

6.2.3 Social Capital.................................................143

6.2.3.1 Family and Social Networks...........................143

6.2.3.2 Perceived Social Capital Measure........................145

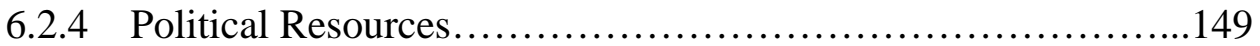

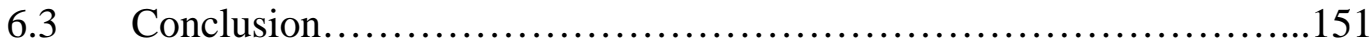




\section{CHAPTER 7: PGIS REPRESENTATIONS OF DIFFERENTIAL}

FLOOD VULNERABILITY ....................................................... 153

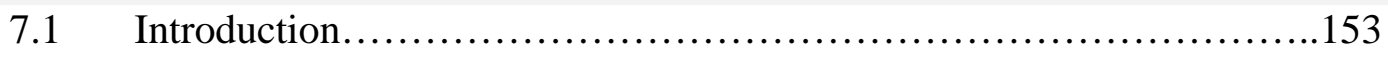

7.2 Community Perspectives on Flood Vulnerability in the Study Sites......154

7.2.1 The Historical Geography of Forced Removals and Insecurity of Land- tenure..............................................155

7.2.2 Perspectives on Contested Spaces.............................159

7.2.3 Perspectives on Flood-prone Areas...................................163

7.2.4 Perspectives on Historical and Contemporary Resource Access and Use ...................................................166

7.3 Integration of Local and Expert Knowledge...........................169

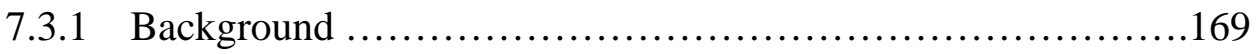

7.3.2 The Construction of Flood Vulnerability Surfaces ...............171

7.3.3 Analyzing Differential Flood Vulnerability for the Study Sites..174 7.3.3.1 Background .......................................174

7.3.3.2 Physical and Human Geographies of Differential Flood Vulnerability ...........................................175

7.4 A Composite Landscape of Flood Vulnerability ......................183

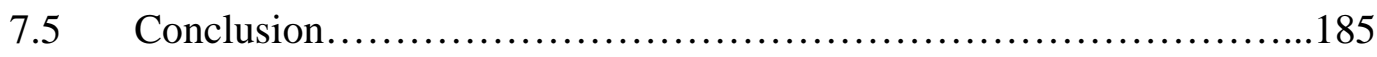

CHAPTER 8: SUMMARY AND CONCLUSIONS .................................187

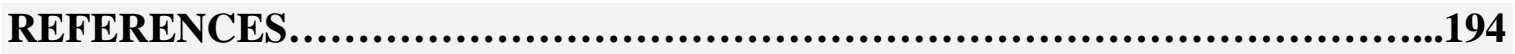

APPENDIX A: Confidentiality Statement........................................212

APPENDIX B: Questionnaire ......................................................................213

APPENDIX C: Focus Group Discussion Check List .....................................227 


\section{LIST OF FIGURES}

Page

1.1: An Orientation Map of Limpopo Province of South Africa...........................

1.2: Thulamela Municipality Case Study Area in Vhembe District Municipality..........8

1.3: Elevation and Hydrology of Dzingahe and Milaboni Study Sites in Thulamela

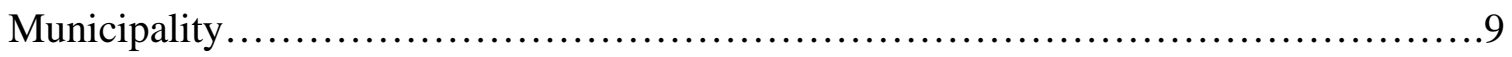

2.1: Political Ecology and PGIS conceptual framework of flood vulnerability...........38

2.2: Relationship between Coping Capacity, Exposure and Vulnerability.................39

3.1(a): Thulamela Municipality Case Study Area and Sites in the Vhembe District,

Limpopo Province of South Africa................................................43

3.1(b): A Map of Milaboni and Surrounding Villages................................44

3.1(c): A Map of Dzingahe and a Neighboring, Ngudza Village.........................44

3.2: Rainfall Distribution and Hydrology in Thulamela Case Study Area and Sites.....46

3.3: Young Girls and Boys Collecting Fuel-wood...................................48

3.4: Geological Map of Thulamela Municipality......................................50

3.5 (a): 3D View of Topography: Milaboni and its Environs...........................51

3.5 (b): 3D View of Topography: Dzingahe and its Environs...........................51

3.6: A House Crumbled under Unstable Soil conditions at Milaboni Village after the

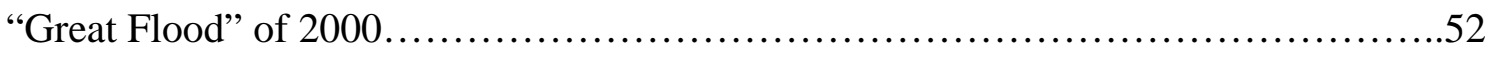

3.7: Cyclone Eline Approaches the Limpopo Province in February 2000...............59 
3.8: Flood inundated Petrol/Gas Station near Dzingahe Junction (March 2000)..........60

3.9: Roads damaged and Bridges washed away by 'Great Floods' of $2000 \ldots \ldots \ldots \ldots . . .61$

3.10: People crossing the Damaged Nzhelele Bridge using the Makeshift Bridge .......62

4.1: PGIS and Political Ecology Integration Model for Differential Social and Spatial

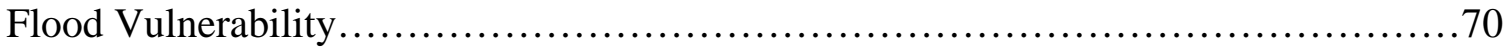

5.1: Fuel-wood stored as a Protective Fence in a Household.........................87

5.2: Households Borrowing by Income Quintiles: Milaboni and Dzingahe Villages .....95

5.3: Household Borrowing by Age: Milaboni and Dzingahe Villages..................98

5.4: An Example of an Incontestable Informal Trading Space at Milaboni...............102

5.5: A Sub-standard (derelict) Primary School at Milaboni Village...................105

6.1: Annual Household Income Quintiles: Milaboni and Dzingahe Villages............118

6.2 (a): Distribution of Annual Household Income Quintiles by Education: Dzingahe.119

6.2 (b): Distribution of Annual Household Income by Education: Milaboni.............121

6.3: Annual Household Income Distributions by Gender of Householders...............124

6.4(a): Annual Household Income Distributions by Marital Status of Householders:

Dzingahe. 125

6.4(b): Annual Household Income Distributions by Marital Status of Householders:

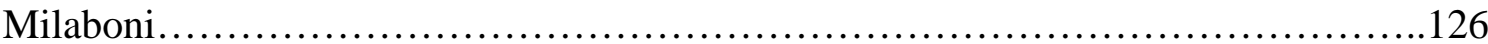

6.5 (a): A Grass thatched Hut at Milaboni Village...............................128

6.5 (b): A Poor Quality Housing Structure with Metallic Sheets at Milaboni Village...129 
6.5 (c): A Housing Option for some Residents at Milaboni Village.

6.6: A Typical RDP Housing Structure. 130

6.7 (a): Means, Standard Deviations, Skewness and Kurtosis of Perceived Household Economic Pressure: Dzingahe Village. ...

6.7 (b): Means, Standard Deviations, Skewness and Kurtosis of Perceived

Household Economic Pressure: Milaboni Village. .138

6.8 (a): Age Distribution by Health Status of the Householder: Milaboni Village......140

6.8 (b): Age Distribution by Health Status of the Householder: Dzingahe Village.....140

6.9: Children Distribution at Dzingahe and Milaboni Households....................142

6.10: Perceived Flood-related Assistance from Relatives and Friends...................144

6.11 (a): Means, Standard Deviations, Skewness and Kurtosis of Perceived

Household Social Capital: Dzingahe Village....................................148

6.11 (b): Means, Standard Deviations, Skewness and Kurtosis of Perceived Household Social Capital: Milaboni Village 149

7.1: Mental Map of Forced Removals at Dzingahe and Milaboni Villages.............158

7.2(a): Mental Map of Contested Spaces at Milaboni Village.......................160

7.2(b): Mental Map of Contested Spaces at Dzingahe Village.......................162

7.3(a): Cognitive Map of Flood-prone Areas at Dzingahe Village....................164

7.3(b): Cognitive Map of Flood-prone Areas at Milaboni Village...................165

7.4 (a): Historical and Contemporary Natural Resource Use at Dzingahe Village......167

7.4 (b): Historical and Contemporary Natural Resource Use at Milaboni Village......168 7.5 (a): Raster Interpolated Flood Vulnerability Surfaces: Scenarios 1-3 at Milaboni..172 
7.5 (b): Raster Interpolated Flood Vulnerability Surfaces: Scenarios 1-3 at Dzingahe.173

7.6 (a): Flood Vulnerability at Milaboni Village.....................................176

7.6 (b): Flood Vulnerability at Dzingahe Village............................................178

7.7 (a): Distribution of Households by Gender and Income of Householders:

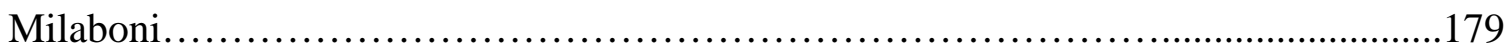

7.7 (b): Distribution of Households by Gender and Income of Householders:

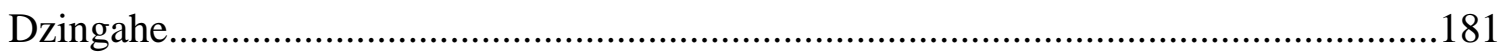

7.8 (a): A Composite Map of Household Flood Vulnerability: Milaboni Village........183

7.8 (b): A Composite Map of Household Flood Vulnerability: Dzingahe Village.......184 


\section{LIST OF TABLES}

Page

3.1: Access to Water at Thulamela Municipality...................................55

4.1: A Summary of Research Questions, Tasks, Variables and Data Collection

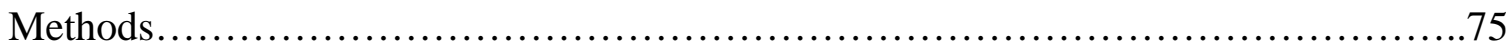

5.1: A Summary of Historical Forms of Flood Coping at Dzingahe and Milaboni

Villages.................................................................. 85

5.2(a): Multiple Response Ranking (R) of Household Flood Coping Strategies in

Dzingahe Village [scale 1 (most preferred) through 11 (least preferred)]

5.2(b): Multiple Response Ranking (R) of Household Flood Coping Strategies

in Milaboni Village [scale 1 (most preferred) through 11 (least preferred)]....

5.3 (a): Expected and Observed Values of Flood Coping Strategies by Income:

Milaboni. .96

5.3 (b): Expected and Observed Values of Flood Coping Strategies by Income:

Dzingahe 97

5.4 (a): Bivariate Tabular Analysis of Employment Type and Flood Coping Strategies:

Dzingahe Village.

5.4 (b): Bivariate Tabular Analysis of Employment Type and Flood Coping Strategies:

Milaboni Village............................................................. 100

5.5: Multiple Response Table of Household Flood Coping Strategies by Gender......103

5.6(a): Bivariate Analysis of Education and Flood Coping Strategies:

Dzingahe Village. 107 
5.6 (b): Bivariate Tabular Analysis of Education and Flood Coping Strategies:

Milaboni Village. 108

5.7: Pearson’s Chi-square $\left(\chi^{2}\right)$ Tests and Cramer's V Correlations between Listed Variables and Household Flood Coping Strategies.

6.1: Main source of Annual Household Income by Income quintiles: Dzingahe and Milaboni

6.2 (a): Housing Quality Index (Building materials) for the main dwelling unit:

Dzingahe \& Milaboni villages

6.2 (b): Housing Quality Index (Access to Amenities) for the main dwelling unit:

Dzingahe \& Milaboni villages

6.3: Multiple Response Table of Household Assets by gender.......................132

6.4 (a): Likert Scale Response Table of Perceived Household Economic Pressure......135

6.4 (b): Means and Standard Deviations of Perceived Household Economic Pressure..136

6.5(a): Likert Scale Response Table of Perceived Household Social Capital...........146

6.5 (b): Means and Standard Deviations of Perceived Household Social Capital.......147

7.1: Attribute Data for Households at Risk: Milaboni Village.......................180

7.2: Attribute Data for Households at Risk: Dzingahe Village.......................182 


\section{LIST OF ACRONYMS AND ABBREVIATIONS}

PGIS - Participatory Geographic Information System

GIS - Geographic Information Systems

GPS - Global Positioning System

CiGIS - Community Integrated Geographic Information System

PLA - Participatory Learning Actions

HDI - Human Development Index

ITCZ - Inter-Tropical Convergence Zone

IDP - Integrated Development Planning

ENSO - El Nino - Southern Oscillation

FGDs - Focus Group Discussions

HQI - Housing Quality Index

SPSS - Statistical Package for Social Sciences

DEM - Digital Elevation Model

NGOs - Non-Governmental Organizations

RDP - Reconstruction and Development Programme 


\section{CHAPTER 1}

\section{Introduction}

\subsection{Research Background}

This dissertation research conceptualizes flood vulnerability as a pre-existing condition (Cutter, 1996) which is characterized by differential loss since not all households, individuals and groups exposed to floods are equally vulnerable (Blaikie et al.,1994; Blaikie, 2004). Increasing and intensifying differential flood vulnerability in developing and developed countries has caused deaths, property and livelihood losses, damage to public infrastructure and environmental degradation all over the world (Ahmed, 1992; Dymon, 1993, 1999; Burby, 1998; Tierney, 1998; Mileti, 1999; Du Plessis, 2000; Mamun \& Amin, 2000). In developed and developing regions, there are differential flood impacts to people, livelihoods and their property. With the exception of rather unusual cases where floods are sometimes perceived as beneficial for the maintenance of livelihoods (e.g. in Bangladesh and in Egypt), floods are typically destructive in nature. In South Africa and elsewhere, river and flash flooding is an environmental problem decisionmakers have to deal with. This is because flooding causes more death, economic loss and social destruction than any other type of natural hazards worldwide (Burby, 1998; Tierney, 1998; Mileti, 1999; Messner \& Myer, 2006).

Several approaches and tools including GIS have been used to appraise flood damage and to develop solutions to flood problems (Du Plessis, 2000). Until recently, scholarly attention has privileged the characterization and the modeling of floods (i.e. magnitude and frequency) over the study of the interaction of physical and social processes that create flood vulnerability. This research employs political ecology to study the interaction of the physical and the social processes which create and distribute material resources, wealth and power in society (Blaikie, 2004). Society's daily living conditions are 
important indicators of differential flood vulnerability across different scales of analysis. In this research, the household, intra-household and the village constitute the units of analyses and specific attention is drawn to how households with differential human and material resources earn a livelihood in a poor rural village and how households cope, mitigate and recover from flooding. Using a Participatory Geographic Information System (PGIS), two rural case studies of Milaboni and Dzingahe villages illustrate differential flood vulnerability from a political ecology perspective.

When assessing household flood vulnerability, this dissertation research took into account the totality of primary and secondary flood impacts. Flood impacts involve damages that are caused by flooding and those caused by the disruption and malfunctioning of services and systems associated with flooding. Primary effects include injury and loss of life, and damages caused by floods to homes, communication networks and buildings. Secondary impacts may include short-term pollution of rivers, hunger, and the disease and displacement of people who have lost their homes (Keller, 2001). For most of the surveyed households at Dzingahe and Milaboni villages, flood impacts were associated with the damaged bridge that prevented them to go to the informal market in town; the destroyed huts that rendered them homeless; or the death of a relative that demanded their energies and resources. These direct and indirect flood impacts are important in the assessment of household flood vulnerability.

In South Africa, there are numerous factors that impact flood management. Three primary factors are the geography of apartheid, the emergence of a democratic South Africa in 1994, and, the increasing and differentiated trends in flood vulnerability. The geography of apartheid provides the historical context of flood vulnerability while the democratic dispensation has the responsibility of dealing with the legacy of a degraded environment and the poor socio-economic conditions of the majority of rural South Africans. In particular, the emergence of a democratic South Africa has to deal with the legacy of landlessness and inability by the majority of people to maintain a sustainable livelihood. Throughout many parts of the world, as well as in South Africa, governments and individuals tend to pursue land-use management approaches that skew land use 
decisions toward intensive development of flood zones (Mileti, 1999; Du Plessis, 2000). This trend together with rural poverty has encouraged settlement patterns that inhabit flood risk areas such as flood plains, areas of higher topography and poor vegetation cover. As Ellis (2000:118) wrote: "Those who are poor and hungry will often destroy their immediate environment in order to survive: they will cut down forests; their livestock will overgraze grasslands; they will overuse marginal land.” In turn, these poor people often settle and degrade fragile environments which are their only hope for providing protection from flooding (Burby, 1998; Mileti, 1999).

This argument is consistent with the major thesis of this research - that flood hazards are socially constructed because they arise out of the social and economic circumstances of everyday life. Flood vulnerability is also increasingly differentiated. Growing flood vulnerability results partly from the fact that the area's capital stock in both rural and urban areas is expanding in flood-prone areas, but they also stem from the fact that both the physical and social systems and their interactions are becoming more complex with each passing year (Burby, 1998). More importantly, it is the socio-economic, political and demographic characteristics that enhance communities' flood vulnerability. Evidence from this research indicates that there is a transition from a resource-dependent economy to income-dependent economy and this has dramatically changed the dynamics of vulnerability.

In February 2000, the Limpopo Province of South Africa experienced the worst floods in living memory. This flood event caused extensive damage to public and private infrastructure, costing up to one billion Rand (US\$165m). Most schools in the province were closed and up to 300,000 were left homeless due to almost 50,000 traditional dwellings that were damaged. More than 80 rural villages reported being spatially cut off and trapped since major roads were damaged and bridges destroyed (Zoutpansberger, March, 2000). Communities experienced water and food shortages as basic necessities like bread and maize-meal escalated in price (Mail and Guardian, 10 February, 2000; Sowetan, 18 February, 2000). 
A preliminary study conducted by the researcher in the study area sites --- Dzingahe and Milaboni --- found that these communities ranked the flood of 2000 higher than any flood that previously occurred in the area. Reoccurring floods (1976-7; 1978 and $1999-2000)^{1}$ in the Limpopo Province support the notion that flood hazards are not random events, but instead, they are part of political, economic and ecological processes which make communities differentially vulnerable to floods (Blaikie et al., 1994; Bryant \& Bailey, 1997).

\subsection{Statement of the Research Problem}

The large and rapidly growing academic literature on floods reveals three interesting perspectives about flood hazards. First, flood hazards are often seen as uncontrollable 'natural events' and 'acts of God' and blame is often difficult to cast (Blocker et al., 1991). Second, poor land-use planning, floodplain encroachment and unsuitable cultivation practices by the poor are cited as major factors contributing to flood hazards (Mitchell, 1992). Finally, policy makers at both global, national and local levels have unjustly viewed the poor as passive, naïve victims (Anderson \& Woodrow, 1991) and flood causing 'agents' through environmental degradation (Blaikie, 1985, 2004; Blaikie et al., 1994). These three perspectives, though shifting, have greatly influenced the conceptualization of flooding in developed and developing countries. Such perspectives are consistent with the conventional explanation of flood hazards whose main shortcoming is that it masks socio-economic and political dynamics, and, power relations that enhance flood vulnerability. Wijkman \& Timberlake (1984:18) asserted that "natural hazards as forces of nature are triggered into disasters by the acts of man.”

In South Africa, government interventions to address the problem of flooding over the years have not produced desired results. This is partly because of the government's conventional conceptualization and analysis of the flood problem that has ignored local perceptions and experiences and historical processes as triggering factors of flood vulnerability. Consequently, mitigation strategies have ignored traditional flood coping

\footnotetext{
${ }^{1}$ See Christie \& Hanlon, 2001.
} 
mechanisms. Within the context of South Africa, an examination of how colonialism and the geography of apartheid contributed to flood vulnerability becomes crucial. Yet despite their global significance, such historical processes have until recently been ignored in flood studies involving the use of GIS. In South Africa and the whole African continent, researchers have made enormous contributions to flood analysis using GIS (du Plessis \& Viljoen, 1999; du Plessis, 2001). However, such studies have privileged ahistorical and quantitative approaches over historical and qualitative analyses.

Understanding household flood vulnerability is a complex task that must transcend conventional approaches that emphasize physical processes. Such approaches often provide conventional engineering solutions (e.g. building of dams and levees) that focus mainly on the physical event, and are costly and ineffective because, among other reasons, they are likely to ignore local knowledge about flood hazards as well as socioeconomic inequalities as main determinants of flood vulnerability. Engineering solutions associated with the conventional approach often create a sense of false security to communities in hazard prone-areas (Mileti, 1999). In addition, traditional flood coping mechanisms can be disrupted or destroyed. It would be wrong, however, to argue that traditional coping mechanisms have been in ecological balance over the years. Such traditional coping strategies have been adaptive to an extent that they permitted fairly large populations to exploit fragile environments in a sustainable manner.

This conceptualization of the research problem demands the need for a unique methodological framework for integrating local knowledge with geo-spatial information to study flood vulnerability. Hence, this study integrates Participatory GIS and political ecology to study social, economic and spatial flood vulnerability. 


\subsection{A brief description of the study area}

The study area sites - Dzingahe and Milaboni villages - are located in the Thulamela Municipality in the Vhembe District of the Limpopo Province, South Africa (Figures 1.1 and 1.2). In local dialects, Dzingahe means "a place of stones" and Milaboni "a place of rivers.” These toponyms present interesting contrasts of these two villages. In addition to their different sizes, these villages have different physical and social landscape characteristics. Milaboni is a small village whose population in 2001 was 537 (Statistics South Africa, 2001). It has a rugged terrain (Figure 3.5a) with meager social infrastructure; the latter includes one primary school, two churches and one business site. In contrast, Dzingahe is relatively larger and has a 2001 population size of 3 641, and an undulating terrain (Figure 3.5 b) with a well-developed social and business infrastructure for a rural homeland village. It has one secondary and two primary schools, a community crèche, six churches and several small formal and informal businesses. However, subsistence agriculture and informal activities are important livelihoods in these villages.

These two villages were purposively sampled on the basis of their persistent flood problem, their different physical and social landscape characteristics, and, differential impacts from the great floods of 2000. Dzingahe village is more progressive while Milaboni shows characteristics of traditional patriarchal relations. Dzingahe and Milaboni villages are drained by Mutshindudi and Mutangwi Rivers respectively (Figures $3.1 \mathrm{a}, \mathrm{b}$ ). Other non-perennial streams traverse the study sites, especially during rainy seasons which normally start from October to the end of March. While these study sites are situated within the same physiographic region (i.e. Limpopo Belt) and in a similar rainfall regime, Milaboni is $900 \mathrm{~m}$ above sea level, while Dzingahe village is $500 \mathrm{~m}$ above sea

level (Figure 1.3). With different elevations come local variations in climate and exposure to floods. Similarly, variations in flood exposure are likely associated with major shifts in coping flood strategies. A comprehensive description of these study sites is given in Chapter 3. 


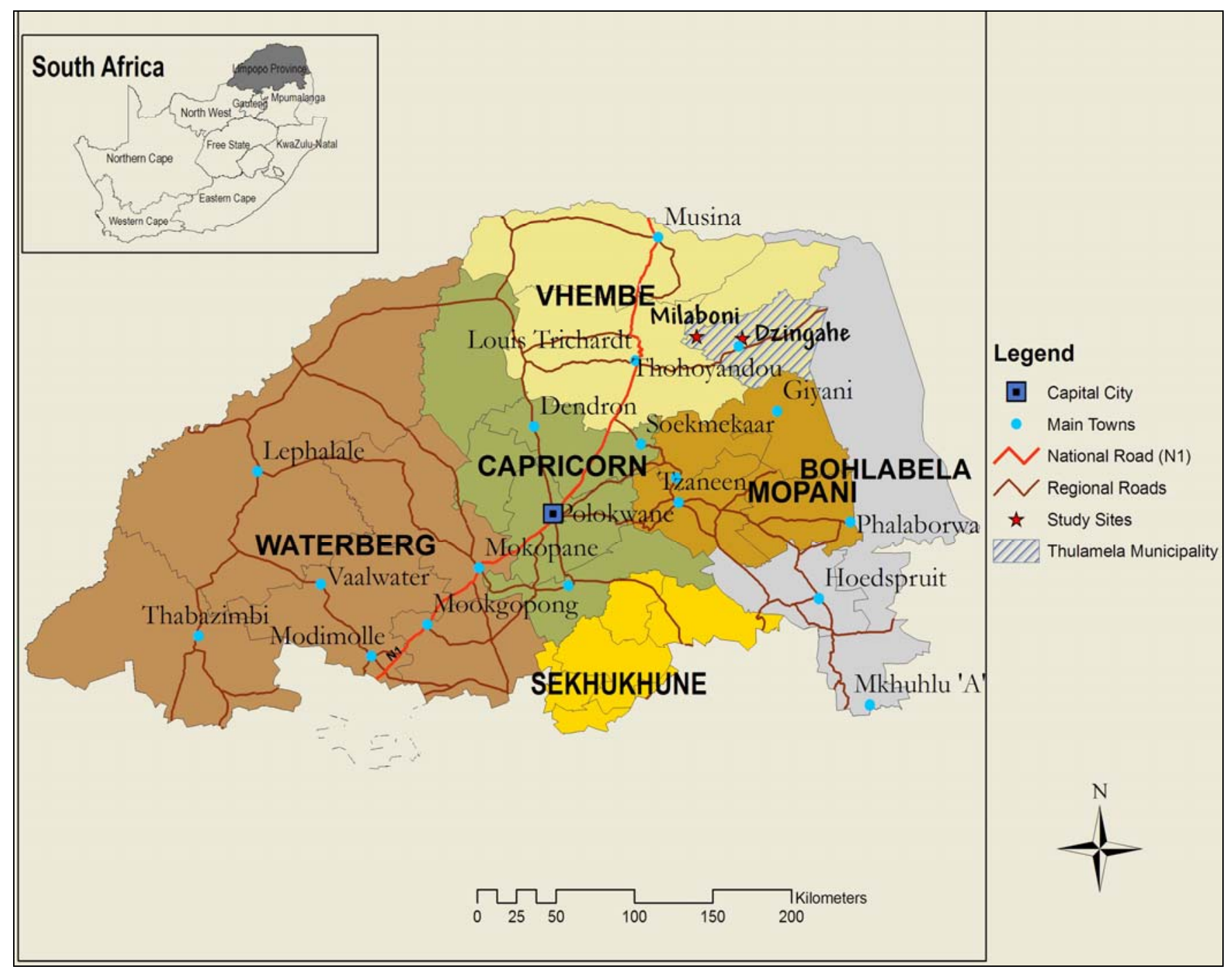

Figure 1.1: An Orientation Map of Limpopo Province of South Africa 


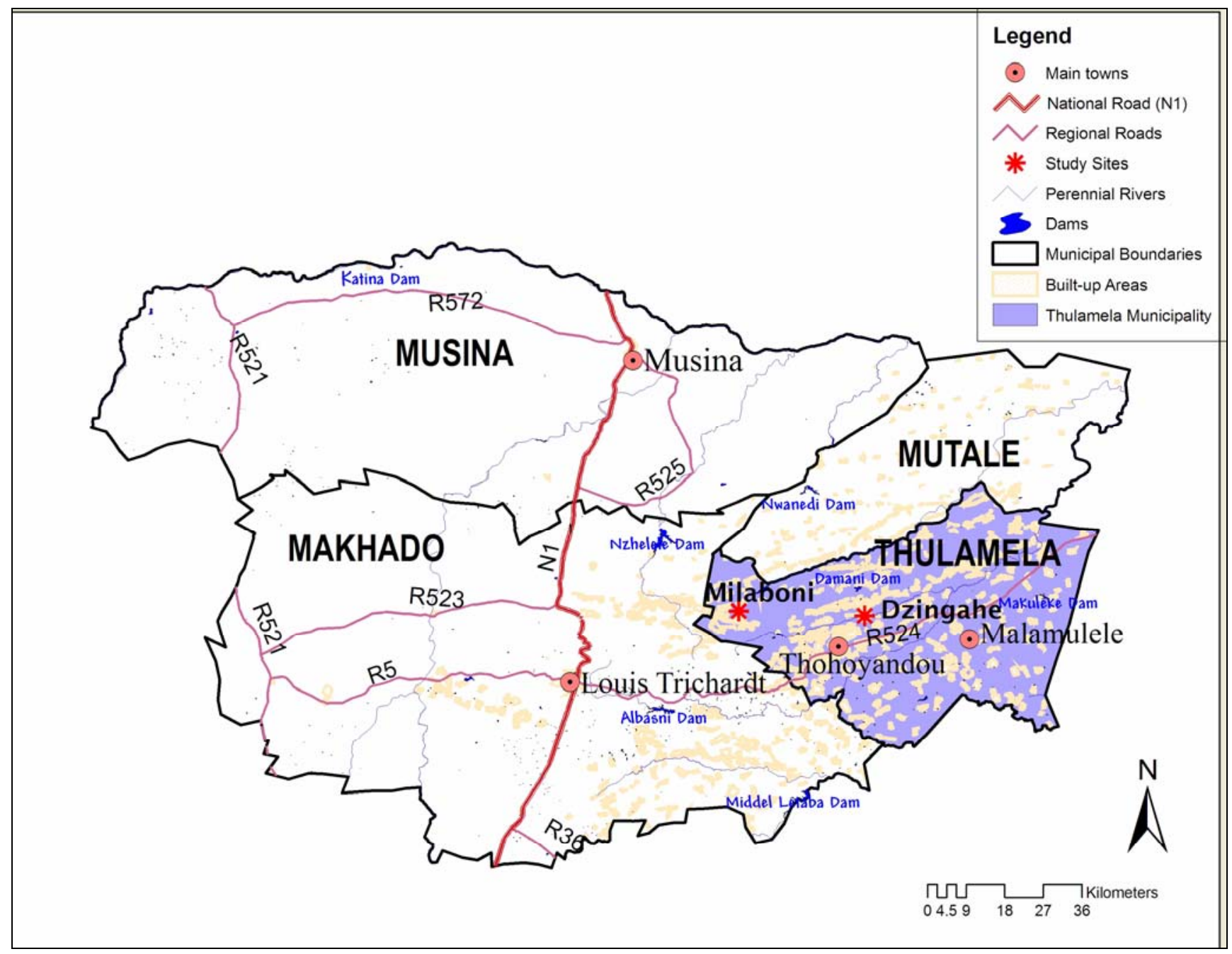

Figure 1.2: Thulamela Case study area in Vhembe District Municipality 


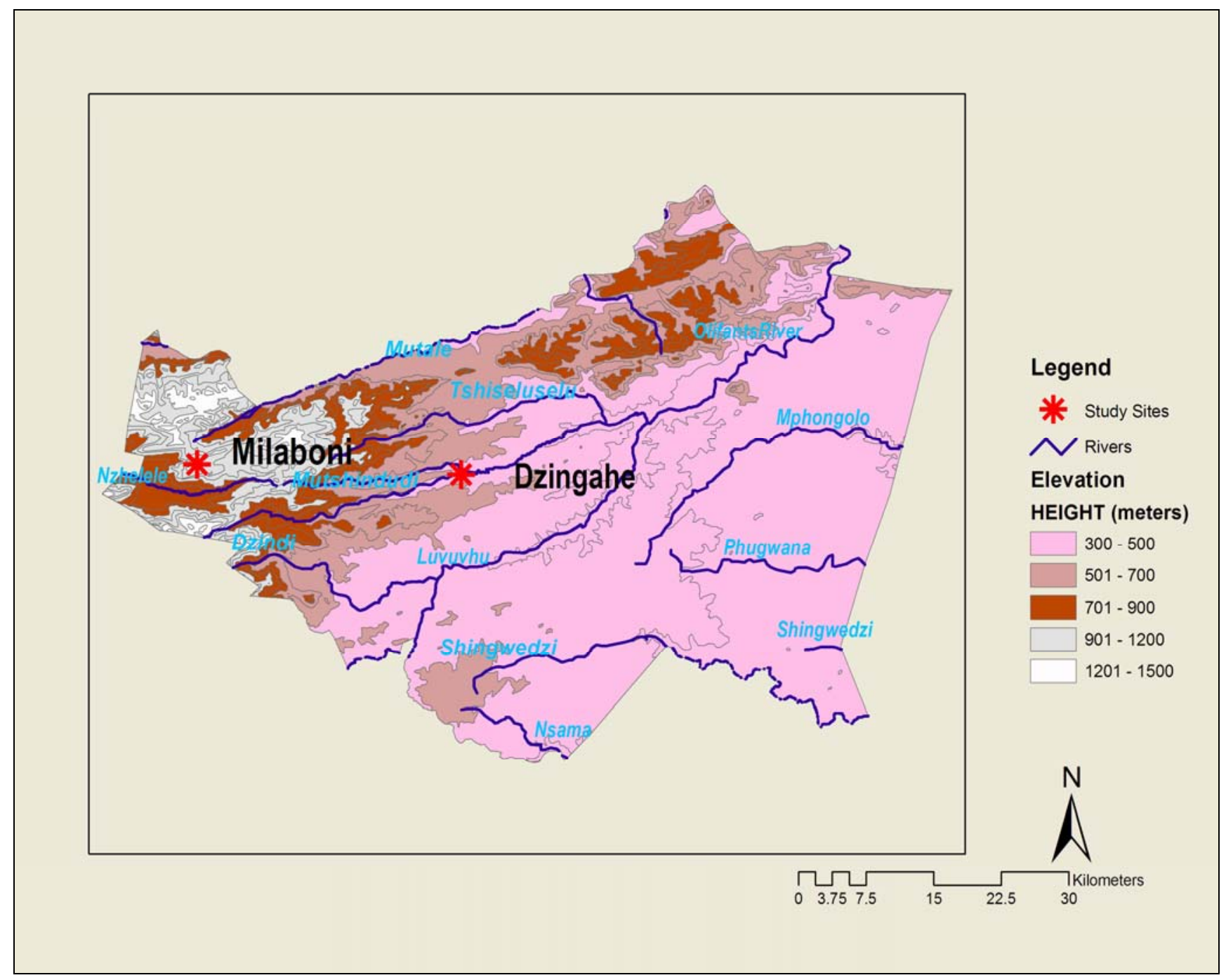

Figure 1.3: Elevation and Hydrology of Dzingahe and Milaboni Study sites in Thulamela Municipality

\subsection{Research Objectives}

The overall goal of this research is to examine social, economic and spatial differentiation of flood vulnerability from a PGIS and political ecology framework. To achieve this goal, the objectives of this dissertation research are to:

(1) identify and evaluate key historical and contemporary household flood coping 
strategies in the study area sites;

(2) examine how and why have these household flood strategies changed;

(3) assess the critical factors that have produced differential household flood vulnerability in the study area; and

(4) represent differential flood vulnerability using a Participatory Geographic Information System.

\subsection{A Synopsis of the Research Methodology and Methods}

To achieve the above-mentioned objectives, this research employs a triangulation of methods within a PGIS methodology with political ecology as the conceptual framework. PGIS brings in the participatory dimension of flood vulnerability assessment. It also helps document and map local knowledge. The research combines a household survey and quantitative spatial analysis using traditional GIS data with qualitative methods -mental mapping, individual interviews and focus group discussions -- to examine the local dynamics of flood vulnerability in the Limpopo Province study sites of Dzingahe and Milaboni. PGIS provides the framework to include socially differentiated local knowledge in a GIS database; while political ecology focuses the analysis on how socioeconomic and power relations impact household flood vulnerability. Traditional GIS spatial data sets were integrated with community mental maps and digital orthophotos. Critical attribute data from the household survey were integrated with spatial data points representing the sampled households in the study area. Overall, data from household surveys, individual interviews and focus group discussions augmented the PGIS database.

\subsection{Contribution of this Research}

Research about differential flood vulnerability is of academic and political importance because it emphasizes the participatory dimensions of flood vulnerability analysis and flood disaster management. This research dissertation will contribute in several ways. First, it will contribute to the integration of Participatory GIS and political ecology. This integration offers an innovative methodological framework for incorporating local 
knowledge with traditional geo-spatial information to study flood vulnerability in a former South African homeland. Issues of local knowledge production, context, local politics and power relations addressed in this research are major concerns in the application of PGIS to geographic research and in other disciplines. Hence, this study uses a PGIS methodology which brings in the participatory tools and techniques that are engaged within the context of political ecology to study household flood vulnerability. PGIS and political ecology place vulnerable people at the center of this research.

The second level of contribution relates to the conceptualization of flood vulnerability as key in linking participatory methodologies with quantitative analysis to understand spatial and social differentiation of flood vulnerability in terms of livelihood resilience, access to resources and gender inequality. Third, the study employs a triangulation of methods and this in turn contributes to the ongoing debate about the integration of qualitative and quantitative information and methodologies. Fourth, PGIS situates GIS and related technologies more effectively within their social and public context. Local communities in the study area are part of GIS production of local knowledge about flood perceptions and experiences and coping strategies that were included in a PGIS database.

Finally, the study employs political ecology to understand the dynamics of power and local politics for an assessment of flood vulnerability in the study area. With increasing recognition of the vulnerability of modern society to floods, a political ecology approach emerged to offer an alternative explanation of flood vulnerability. A political ecology conceptual framework challenges conventional explanations of disasters by bringing in the political-economic and ecological context in the analyses of flood vulnerability. Future policies and plans are likely to incorporate power dynamics and people's perceptions and experiences when dealing with flooding. 


\subsection{Dissertation Outline}

This dissertation is divided into eight chapters. The focus of this first Chapter is to provide the background, research problem, objectives and brief statement on the methodology used and the contribution of the study. Chapter 2 provides a theoretical and conceptual framework for the research by drawing from literature on natural hazards, political ecology, GIS and Society, and the integration of PGIS and political ecology.

Chapter 3 provides an environmental and socio-economic profile of the Limpopo case study area and a brief description of apartheid geographies, political ecology and the appraisal of the great floods of 2000. Chapter 4 outlines the research questions, methodology, sampling strategy and methods of data collection and analysis.

Chapter 5 identifies key household flood coping strategies and how they have evolved over time. The chapter concludes by providing a comparative analysis of the contemporary household flood coping strategies at Dzingahe and Milaboni villages and how these have produced differential flood vulnerability. Chapter 6 examines the socioeconomic characteristics that are likely to cause differential household flood vulnerability in the study area. The main argument of this chapter is that flood hazard is socially constructed while the physical characteristics operate as triggering factors.

Chapter 7 demonstrates the contribution of PGIS to a political ecology analysis of differential household flood vulnerability in the study area. This is done by documenting and analyzing through mental maps, narratives of people impacted by flooding. In addition, the chapter integrates "local" and "expert" knowledges about the understanding of flood vulnerability. Composite maps are developed to demonstrate the interaction of physical and socio-economic parameters of flood vulnerability. Finally, Chapter 8 reflects on the entire study and offers conclusions and research issues for future consideration. 


\section{CHAPTER 2}

\section{Theoretical and Conceptual Framework}

\subsection{Introduction}

The theoretical framework for this research draws from literature on natural hazards, GIS and Society, and Participatory GIS. Political ecology forms the main conceptual basis. Theories on this body of literature guided the empirical investigation of flood vulnerability in the study area. The aim of this chapter is to provide a theoretical, conceptual and empirical foundation to highlight insight into critical ways of representing “local” and “expert” knowledges on differential flood vulnerability.

The organization of this chapter is as follows: the first section describes the evolution of the field of natural hazards with emphasis on the critique of the conventional approach to natural hazards. The second section examines the relationship between political ecology and flood vulnerability. This is followed by the conceptual and methodological contributions of GIS and Society debates. The fourth section examines the methodological implications of Participatory GIS to the study of flood disasters and PGIS integration with political ecology. In addition, the concept of risk is addressed in terms of its importance for understanding vulnerability as a result of natural hazards including floods. The last section explicitly describes the conceptual framework of this study. 


\subsection{Theoretical Approaches to Flood Vulnerability}

This section focuses on two broadly defined theoretical approaches to study vulnerability to floods, namely, the geographic and the political ecology approaches. The geographic approach has provided the basis for characterizing hazardous events and for describing impacts and responses. The political ecology approach emerged out of the political economy perspective and has brought in socio-economic and political context to the analysis of the determinants of flood vulnerability.

In attempting to describe approaches to vulnerability, the concept of flood vulnerability needs to be defined, and its relationship to the concept of risk described. Cannon (1994) defined flood vulnerability as a measure of risk combined with the level of social and economic ability to cope with a flood event. This definition refers to the personal or group characteristics in terms of their capacity to anticipate, and cope with the impact of floods (Scoones, 1999; Smith, 1996). Susman et al. (1983: 264) defined vulnerability as the "degree to which different classes [groups] in society are differentially at risk, both in terms of the probability of occurrence of an extreme physical event, and the degree, which the community absorbs the effects of extreme physical events and helps different classes to recover.”

Similarly, Dow (1992) and Cutter (1996) have provided reviews of the development of the concept of vulnerability over the years. Despite differences in the definition of the term "vulnerability," two main views have emerged (e.g., Wu et al., 2002; Adger et al., 2004). The first view treats vulnerability as a pre-existing condition and focuses on potential exposure to hazards (Cutter, 1996). The second major perspective on vulnerability suggests that not all individuals and groups exposed to a hazard are equally vulnerable; rather, people display patterns of differential vulnerability (Wu et al., 2002, Blaikie, 2004). This differential vulnerability depends on exposure and on the coping ability of those affected and their resilience levels (Anderson and Woodrow, 1991; Dow, 1992; Watts and Bohle, 1993; Cutter, 1996; Clark et al., 1998; Wu et al., 2002). 
Cutter (1996) asserts that a third major theme is emerging in vulnerability literature. The concept of vulnerability as a "hazard of place" combines elements of differential vulnerability and vulnerability as a pre-existing condition. This approach - called the vulnerability of places framework by Wu et al. (2002) - treats vulnerability as both a biophysical risk and a social response within a specific geographic domain. Researchers such as Yarnal (1994), Clark et al. (1998), and Wu et al. (2002) have employed this approach; however, this research has relied most on the first two perspectives of vulnerability.

Flood vulnerability is thus not merely proximity to flood zones, but it is the product of the flood as a physical, political and socio-economic phenomenon (Alexander, 1993; 1997). Hence, strategies that emphasize the removal of people or activities in a floodplain only deal with the risk component of vulnerability and do not address effectively flood vulnerability. The concept of risk is important in understanding vulnerability to flood hazards. The process of risk profiling often identifies discrepancies between people's perceptions of risk and personal harm caused by a flood event and the statistical probability that such events will harm them (Miller, 1997). The statistical evidence of risk is based on the frequency and damage caused by previous events of similar character. This risk statistic often assists in the development of plans and policies to reduce the initial risks or managing events if they do occur (Kates \& Kasperson, 1993).

The notion of risk, however, tends to homogenize disaster impacts. It may provide quantitative justification for not addressing differential factors that have produced flood vulnerability, especially when the most vulnerable people are perceived as grouped in a homogenous population. This research, therefore, privileges vulnerability over risk and hence the analysis of vulnerability is not only restricted to flood zones proximity but to the broader territory within the bounds of the two study area villages. The following subsections focus on the geographic and political ecology approaches to study flood risk and vulnerability. 


\subsubsection{Geography and Natural Hazards}

The geographic approach to natural hazards stems from the work of Barrows in the 1920s whose focus was on the human ecological adaptation to the environment ${ }^{2}$. This was followed by the work of Gilbert White during 1945 as a consequence of increasing flood damage in the United States (Burton et al., 1993). The work of Huntington (1945) on storms based on environmental determinism was also instrumental in the conceptualization of hazards in the mid-1940s. These classical works on natural hazards were couched within the human-environment tradition, which theorizes the impact of nature on society. However, Huntington's work was heavily criticized because it regarded man as a passive being, controlled solely by the environment. Nevertheless, the work of White and others (e.g. Burton \& Kates, 1964; Burton et al., 1993) contributed significantly to hazard research (Chapman, 1994, Hewitt, 1997). More recently, this approach has been criticized as geographic research incorporated different perspectives to interpret how human systems interact with the natural and human-made hazards. Within the context of the geographic approach, two models could be identified, namely, the choice and choice constraint models.

\subsubsection{The Choice Model}

The choice approach is sometimes known as the conventional view of natural hazards. According to Hewitt (1983:4) dominance of this approach is evident in the "allocation of resources, the number of trained personnel, its influence on mitigation strategies and its close attachment to the most powerful funding institutions associated with this perspective”. The main tenet of the choice model is that people have choices regarding the degree of risk they will bear and the adjustment they will make. Burton et al. (1993) concurred by arguing that people analyze their choices of acceptable risk and adjustments

\footnotetext{
${ }^{2}$ A natural hazard is defined as a potentially damaging physical event, phenomenon that may cause the loss of life or injury, property damage, social and economic disruption or environmental degradation (von Kotze \& Holloway, 1996).
} 
based on their knowledge, beliefs and value systems. In this way, people would choose adjustments based on "the expected utility, subjective utility and bounded rational methods" (Burton, et al., 1993:62). For example, those that choose adjustments on the basis of all the expected outcomes (probabilities) use the expected utility method. Those that choose not on the basis of probable outcomes use the subjective expected utility method. Lastly, the person who chooses the best course of action by subjective assessment of utility with the aim of choosing some form of adjustment less than that of maximizing returns uses the bounded rationality method (ibid.). The choice model has several shortcomings. First, it bases individual choice on the concept of 'rationality'. Second, it relies on the questionable assumption that individuals have access to and capacity to process full information in appraising natural hazards or alternative course of actions. Third, individuals may have quite different goals of adjustments from those of maximizing the expected utility. The bounds of rational choice in dealing with natural hazards are numerous.

Critics of the choice model have reservations about its general straightforward acceptance of hazard vulnerability as a result of extremes in geophysical processes (Hewitt, 1983; Watts, 1983a; Palm, 1990). Defined by Burton \& Kates (1964:413) as "those elements of the physical environment harmful to man and caused by forces extraneous to him" traditionally, hazards have been seen as 'acts of God' and external forces against which man had no defense (Wijkman \& Timberlake, 1984). This perspective regards people vulnerable to hazards including floods as passive victims. It is in this similar context where the geography of flood risk is treated as synonymous with the distribution of floods and with natural features associated with them such as flood plains. Instead, it is the combination of physical factors (e.g. flood plains) and the human factors (e.g. inability to cope) that define the geography of flood risk.

With regard to the role of society in mitigating flood disaster impacts, the choice model placed much emphasis on "public policy backed by most advanced geophysical, geotechnical and managerial capability" (Hewitt, 1983:6). In other words, engineering solutions to flood problems were emphasized. Exceptions to this emphasis were the 
works of Gilbert White (1958) and White \& Haas (1975). White's main argument was that structural measures (dams, levees) of flood control might worsen rather than control the hazard itself. In 1975, White and Haas advanced the idea that hazard research needed to take economic, social and political aspects into account (ibid.). These socio-economic and political factors were however, relegated to the appraisal of flood impacts and government intervention, and not regarded as major causes of flood vulnerability.

The other critique of the choice approach is that it emphasizes geophysical processes as key determinants of flood vulnerability and suggests that the best way to reduce flood vulnerability is to either modify the biophysical environment or move out of marginal areas (Liverman, 1990). This conceptualization regards the physical environment as the major causal agent of vulnerability (Hewitt, 1997). Thus, societies are seen to be at flood risk or vulnerable because they reside in areas of high flood hazard frequency such as floodplains and coastal zones (Burton et al., 1978). Such societies (according to this perspective) have a choice to stay or move out of the danger zones. In addition, this approach assumes that disasters represent a departure from "normal" functioning of society, yet it is these daily 'normal' conditions that make people vulnerable in the first place (Blaikie et al., 1994). The critique of the choice model does not outplay the importance of natural forces as important triggering mechanisms of flood vulnerability. However, they emphasized the social construction of flood disasters.

Another strand of the choice approach that has been used to study hazards is the cognitive (perception) or behavioral approach. According to this theory, factors such as personal histories and psychological dispositions, local histories, media reporting of events, expertise, and availability of information influence the perception of risk (Burton \& Kates, 1964; Burton et al., 1993). These factors interact with the physical event (e.g. flood) to influence people's perceptions and actions in ways that vary greatly from statistical risk and may contribute to either increasing or reducing vulnerability. In addition, the behavioral approach views flood impacts as a result of the interaction of natural hazards and vulnerable facets of society. Burton et al. (1978) stress the importance of values, attitudes, and beliefs as motivators of behavior, and illustrate how 
people's perception of risk affects their decision. The proponents of the behavioral approach (ibid.) also suggest that individuals have a range of choices from which to select their responses to hazards or risks.

In summary, the choice approach has concentrated on the application of measuring and monitoring techniques to understand geophysical processes. The immediate goal has been that of flood prediction. Planning and managerial activities have been to contain geophysical processes through flood control works. This involves zoning, building codes (i.e. physical planning) and the assessment of flood risk. The last area of emphasis has been on emergency measures, involving disaster plans and the establishment of organizations for relief and rehabilitation (Hewitt, 1983). In its current form of analysis, the choice model lacks explanation of how flood vulnerability is produced and distributed as well as the role of the politics, economy, culture, and institutions of governance and NGOs in flood vulnerability assessment. These factors are important indicators of societal differential flood vulnerability.

\subsubsection{The Choice Constraint Model}

The choice constraint model was the beginning of the alternative geographic approach to the study of hazards and flood vulnerability in particular. The early critics of the choice model (e.g. Waddell, 1977; Torry, 1979; Walker, 1979; Hewitt, 1983; Watts, 1983a; Emel \& Peet, 1989; Palm, 1990) pointed out its insensitivity to social and economic constraints and how such constraints limit the choice of people and governments. The widespread use of the choice model and the focus on individual perceptions and behavior implied that humans are masters of their fate to a much greater extent than is valid. The emphasis on choice of adjustment seemed to ignore the reality of economic and political constraints and structures (such as patriarchy) that limit the decision-making processes, especially in the developing world. The choice constraint model has eventually contributed insight to the political ecology approach to flood vulnerability. 
Nevertheless, the choice and choice constraint models have characterized past geographical enquiry to hazards research. Currently, the evolving hazard paradigm is more interdisciplinary and still incorporates aspects of both. Within geography, hazard paradigm has always been in the state of flux. For example, the path it took has evolved from the study of sudden to slow and cumulative events such as soil erosion (Blaikie, 1985), social causes of land degradation (Blaikie \& Brooksfield, 1987) and deforestation (Hecht et al., 1988). These slow and cumulative events affect millions of people in the developing world. Similarly, geographic analysis of natural hazards has continued to shift from the study of geophysical to biological hazards including the study of diseases (Howe, 1980; Burton, 1990; Foster, 1992).

The two most important paradigm shifts in hazards research that relate remarkably well with this research are the move in terms of vulnerability analysis from the individual to the social group (Hewitt, 1983; Watts, 1983b; Susman, et al., 1983; Wijkman \& Timberlake, 1986; Wisner, 1989) and from the empirical to theoretical debates about the causes of hazard vulnerability (Kates, 1980; Palm, 1990; Alexander, 1991). It is out of these two shifts that political economy and later on political ecology perspectives draw their main tenets. In particular, political ecology has its origin from the intersection of cultural and political economy perspectives and has developed further to include ecological processes, agency, power and the concept of scale.

\subsubsection{Political Ecology and Flood Vulnerability}

\subsubsection{An overview}

Political ecology is defined as the approach that "integrates political, economic and ecological issues as the basis for effective response to contemporary environmental problems” (Bryant \& Bailey 1997:1). This conceptual framework evolved out of the political economy approach during the 1970s (Stott \& Sullivan, 2000). In the 1980s, academic researchers began to emphasize the political context of environmental problems (Peet \& Watts, 1996). The 1970s saw an emergence of political ecologists such as Wolf 
(1972), who emphasized ownership regimes and political ecology. Ensenberger (1974) emerged to focus mainly on the critique of political ecology. The book of Cockburn \& Ridgeway (1979) was the first to carry "Political Ecology" as its title (see Morse \& Stocking, 1995). In the 1980s, the works of Blaikie (1985) and Blaikie \& Brookfield (1987) revolutionized the field of political ecology. Blaikie (1985) identified political circumstances that forced people into livelihood activities that were environmentally degradative. He strongly challenged narratives that have always associated environmental degradation with population pressure, the survival activities of the poor and their practices that are unfriendly to the "serene' environment. These issues have significant implications for this research because they highlight the divergence between political ecology and the conventional approach to flood vulnerability. This divergence is an important milestone towards the development of flood mitigation strategies at local, national and global scales.

The relationship between political ecology and disasters was advanced by the early work of human geographers O’Keefe (1975) and Wisner (1976, 1978). These pioneers embarked on a research agenda that focused on the interaction of political-economic structures with ecological processes. Their initial agenda developed as a main critique of neo-Malthusian theory and then diffused into disaster and hazards research (Bryant \& Bailey, 1997). O' Keefe et al. (1976) and (Emel \& Peet, 1989) argue that vulnerability is determined largely by local and national socio-economic institutions that shape how individuals in society perceive hazards and risk. Instability in social structures is viewed as the cause of vulnerability because it reduces the ability of individuals to cope with hazards including floods. As a result, individuals' risk of being adversely affected by a hazard increases.

Similarly, Susman et al. (1983) argued that hazard vulnerability is closely tied to the lack of action by local, national, and international institutions to improve the coping skills of the most vulnerable individuals such as the poor, elderly and women. Their perspective in contrast to the conventional approach earlier discussed emphasizes how human systems become vulnerable to natural hazards. It specifically focuses on understanding both the 
evolution of social conditions that affect an individual's ability to cope with extreme events and the physical events as triggering mechanisms (Cutter, 1996).

Within the political ecology framework, individuals are seen not as powerless victims, but as active agents whose inputs count in the development of hazard mitigation strategies (Kelly \& Adger, 1999). Their coping capacity is however, constrained by institutional and social structures, especially class and gender (Blaikie \& Brookfield, 1987; Watts \& Bohle, 1993). In this perspective, vulnerability is regarded as an interaction of vulnerable groups of society and a physical event. In his study of poverty and famines, Sen (1981) argued that the ability of individuals and social institutions to cope with hazards was determined by their capacity to compete for access to rights, resources and assets. At the global scale, Tierney (1989) concurred by describing political ecology and hazards in terms of the role of global economic structures in creating hazards and promoting disasters.

In the political ecology approach, flood vulnerability occurs as a lack of resilience to external forces caused by societal relations that constrain or restrict individual decisionmaking. In this regard, the concept of power becomes important. For example, those social groups that are least able to influence their own situation due to poverty, lack of education, race, gender or religion become more vulnerable irrespective of the hazard frequency or its magnitude. Blaike et al. (1994) argue that social structures themselves are responsible for societal vulnerability to natural hazards because they determine who is entitled to resources and how resources are distributed.

Pelling (1998:250) summarizes this view as follows: "Decision-making power is central to the distribution of differential vulnerabilities, and is negotiated between institutions, which differ in their scales of influence, access to information and resources, and legal and cultural rights and responsibilities." Pelling's view reinforces the idea that society is responsible for creating vulnerable individuals and groups, and that the latter will continue to be susceptible to a wide range of hazards because of their inability to change their economic, political or social situation. However, Blaikie et al. (1994) vulnerability 
model was critiqued on its emphasis on the linear progression of vulnerability since in policy practice the challenge is to deal with non-linear relations of socio-economic and political factors influencing vulnerability (Frenks \& Bender, 2004).

Through the lens of political ecology, human factors (political, social, economic, and cultural) as well as human characteristics (demography, location, resource access, institutions) of the human - environment system becomes more important in flood vulnerability assessment. It is therefore important to relate the concepts of power, environment, human agency and scale to the assessment of differential social and spatial flood vulnerability.

\subsubsection{The Concepts of Power, Human agency, Environment and Scale}

The concepts of power and scale are two of the most contested terms in human geography. This is partly because of the fact that they incorporate a very complex understanding of how place is constructed and mobilized in politics (Wolf, 1999; Staeheli, 2003). The conceptual disagreement relates to whether power should be viewed as an "attribute or a relation, as a capacity or a commodity” (see Bernhagen, 2002: 1). Other issues are about the relationship between power on one hand, and its associated concepts such as autonomy, responsibility and freedom on the other. Furthermore, the definitional scope of power, capacity, influence, force, coercion, authority and domination are far from clear (ibid.). These disagreements about what constitutes power clearly indicate the complexity of power as a concept.

This dissertation research has adopted the relational definition of power. Bernhagen (2003:2) defines power as "a relational phenomenon both in the sense that persons exert power over others and in that the power (or capacity) of one person to do something constitutes social relationships”. This definition implies that power could be exercised inside and even outside the official domain of the state and government. In any case, human agency is restricted by what Bernhagen (2002: 17) referred to as 'structural

dominance'. According to him the analysis of power cannot be separated from the 
analysis of structural dominance. Bernhagen further argues that the very resources, on which individual or collective power is based, are subjective to a variety of structural constraints (such as gender, race) and opportunities. The concept of power, therefore, is based on human agency and hence, comprises both decision-making and non-decision making strategies.

Having defined the concept of power, the subsequent discussion relates to the role of power in flood vulnerability assessment. The political ecology approach emphasizes the role of different levels of power in influencing differential social and spatial vulnerability to flood hazards. According to this perspective, floods do not exist in a political or philosophical vacuum, but occur within power relations in which they share space and place. In the context of flood vulnerability, power manifests itself over defining the flood problem and the prescription of the solutions to it. The political ecology questions become who defines the flood problem (mental creations of the problem) and from what perspective? Who then prescribes flood solutions? There are power dimensions involved in the declaration of flooding as problem by governments. Similar difficulties are experienced in the bid to define national disasters as justification for intervention and call for international relief aid. Flood relief aid providers base their response to hazards on what they term 'humanitarian principles.' Power dimensions are also involved when flood solutions are prescribed. Very often, local variables and local agents (communities) are neglected since the latter are viewed as victims to be assisted or whose traditional coping strategies are not consistent with conventional engineering solutions. In all these cases the main agents of power are the state, parastatals, NGOs and powerful individuals in society. Hence, closer political and social affiliation with these power agents may achieve political success during and after flood disasters.

Power is also evident in the allocation of natural resources such as water and land. The unequal distribution of natural resources such as land and water connects remarkably well with the question of the environment. The concept of the environment is important in political ecology (Grossman, 1998). The fate of endangered species or the loss of soil and forests or the use of pesticides has significant consequences. Overall, a political ecology 
framework highlights issues on the use and misuse of the environment. It however, challenges concepts of conservation and preservation that perpetuate unequal access to environmental resources. In this respect, political ecology seeks ways in which “environmental knowledge and politics can co-evolve dynamically” (Forsyth, 2003:103).

Political ecology insists that disasters are preventable, and people are not helpless victims, but rather, are active agents who cope in different ways when disaster strikes (Anderson \& Woodrow, 1991). The issues of social and spatial justice are often highlighted. Literature on social justice regards the most vulnerable groups as "women, old and very young, those of low social status and with poor access to appropriate resources and reserves" (Blaikie, 2004:300). Hence, these groups' perceptions and experiences are important in understanding flood vulnerability and seeking solutions thereof. Spatial justice refers to the notion that development benefits and burdens (externalities of development) are not equally distributed and consequently, spatial entities are likely to depict differential flood impacts.

The element of scale in political ecology is very important in analyzing vulnerability to disasters including floods (Zimmerer \& Bassett, 2003; McCusker \& Weiner, 2003). Scale and location are key issues to geographical analysis of hazards. Howitt (2003:151) argues that scales are "relational as well as socially and politically constructed". In this way, the global scale of interaction between core and peripheral countries have created socioeconomic and political conditions in the latter that make people vulnerable to natural hazards.

There are important trade-offs with respect to scale. For example, while a global scale may help identify the root and dynamic causes of flood vulnerability, this is offset by its lack of sensitivity to variation at the national or local scale. This explains why local agency, the flood victim, might not be aware of the fact that socio-economic and historical processes beyond the local area are likely to account for their vulnerability to floods. For example, local communities might not link the role of global forces towards flood vulnerability. In addition, local context is not considered when "experts" define 
flood vulnerability and as such local perceptions are ignored in defining the problem and seeking solutions. Thus, social and spatial differentiation is best understood at the local scale. The recent tendency has been to move away from global scale, national or provincial to the community, household and individual scale to develop flood mitigation policies based on local dynamics. The reference scale of the conceptual framework in Figure 2.1 ranges from the individual to global levels. This is possible because political ecology has the ability to connect different scales of analysis. However, the limitations of a particular scale chosen needs to be clearly identified. Issues at the national and global scales are important in explaining local dynamics of flood vulnerability.

The spatial extent of damage, regional similarities or variations in the impact of flood hazards depends on the issue of scale. Spatial extent of damage also influences the magnitude of relief and recovery aid afforded to disaster areas. For example, the extent of Tsunami damage in 2004 and the consequent huge amount of humanitarian aid given to Southeast Asia is a good example of this. The important question is how actions and processes operating at one scale relate to actions and processes at another scale. This question emphasizes that vulnerability has to be understood as a dynamic phenomenon, changing in space and time, and is often better understood at a local scale (Aysan, 1993; Blaikie et al., 1994) but still incorporating the effects of global and national scale to the analysis of local dynamics of flood vulnerability.

Flooding ceases to be just a physical event when it is viewed as part of the political, economic, social and power relations. Such seemingly 'natural' phenomena as floods for example, are a consequence of unequal power relations among individuals (Zimmerer \& Bassett, 2003). This idea emphasizes the centrality of politics in flood vulnerability assessment. 


\subsection{Geographic Information Systems and Society}

Geographic Information Systems have assumed various definitions over time. For example, Burrough defined GIS as a "powerful set of tools for storing and retrieving, transforming and displaying spatial data collected from the real world for different purposes” (1986:6). His definition implies that GIS is a tool for geographic analysis. This is often called the toolbox definition of GIS, because it stresses a set of tools each designed to solve specific problems. Authors such as Maguire et al., (1991), Thomson \& Laurini (1992), and Clarke (1995) defined GIS in terms of what it does --- a functional definition of GIS. For example, Clarke defines GIS as a "computerized system (organized collection of computer hardware, software and geographic data and expertise) for capturing, storing, updating and displaying geographic data” (1995:13).

The participation of society in local decision-making is a significant means of safeguarding their interests in the development process. In light of this, care should be taken to precisely define what society means to avoid ambiguous interventions in terms of empowering people. Meanwhile, society is defined as an extended social group having a distinct cultural, political and economic organization. Of significant importance here, is that society is not a homogenous entity. In most modern societies, key social issues are relegated to the periphery in favor of individual concerns. Such relegations are a significant barrier to community empowerment, especially when there is a disconnect between societal and individual goals.

Until recently, the diffusion of traditional GIS technology took place in the context of celebrating its capabilities and positive social impacts (Dobson, 1993a; 1993b; Goodchild, 1993; Cowen, 1995; Obermeyer \& Pinto, 1994). Discussions on the social impacts of GIS have been limited to the analysis of the techniques and methodologies of GIS. Such discussions cover issues such as improving accuracy, extending capabilities and widening the scope of GIS applications. In contrast, the social theory critiques of GIS amongst others asserted that GIS technology carries with it inherent societal values, which has significant impact on target communities. These critiques focus the analysis on 
the power relations embedded within traditional GIS and social implications associated with its use. Such hegemonic power relations inherent in traditional GIS are transformed through differential access to GIS and data (Taylor, 1990, 1991; Openshaw, 1991, 1992; Taylor \& Overton, 1991, 1992; Smith, 1992; Abler, 1993; Lake, 1993; Aitken \& Michel, 1995; Pickels, 1995; Taylor \& Johnston, 1995; Kwan, 2002). Overall, traditional GIS technology was critiqued based on its tendency to privilege “expert” knowledge over “local” knowledge (Talen, 2000). This elitist top down representation of knowledge tends to filter and hence, structural local knowledge distortion results (Taylor, 1991; Harris et al., 1995; Weiner et al., 1995).

Another important contribution of the GIS and Society debate relates to the potential role of GIS as a democratizing or a disenfranchising force (Obermeyer \& Pinto, 1994; Harris et. al., 1995; Rundstrom, 1995; Obermeyer, 1998). The democratizing-disenfranchising nexus has significant implications in South Africa because GIS technology is still in the hands of the government, institutions and agencies controlled by South African elites. Democratizing GIS in the form of Participatory Geographic Information System (PGIS) in this context implies reshifting of power scales in local and national politics. For example, communities may be empowered while traditional holders of power (e.g. chiefs, white farmers) may feel disenfranchised.

\subsection{Participatory Geographic Information Systems}

Participatory GIS developed out of the social theory critiques of GIS. PGIS is a term that was coined to express the adoption of GIS to empower indigenous and local communities in Africa and other parts of the world (Obermeyer, 1998; Harris \& Weiner, 2002; Kyem, 2002). The term originated from the GIS and Society debate in the late 1980s. The main emphasis of the debate revolves around GIS structural deficiencies and societal implications of its use. Such deficiencies include its positivist nature, differential data access and commodification of information as well as its empowerment-marginalization capabilities, representation, and geo-demographics and surveillant capabilities of GIS (Onsrud, 1992; Goss, 1995; Harris \& Weiner, 1996, 1998). Since then, there has been a 
growing interest in using GIS in a participatory mode (Craig et al., 2002; Harris et al., 2002; Kyem, 2002; Laituri, 2002) using participatory tools and methods such as ephemeral mapping (drawing maps on ground), sketch mapping, scale mapping, 3D modeling, photomaps, the use of GPS, map-linked multimedia information systems, and integration of GIS (Rambaldi et al., 2006). In this context, PGIS is viewed as a guide to the design of alternative forms of GIS uses, access, production and representation (Weiner \& Harris, 1999). PGIS maps designed from a community perspective have the ability to depict what community members themselves regard as important. These might include local resource management issues, local conflicts pertaining to land claims and issues pertaining to floods.

The advocates of PGIS (Obermeyer, 1995, 1998; Abbot et al., 1998; Elwood \& Leitner, 1998; Harris \& Weiner, 1998, 2002; Kyem, 2001, 2002; Koti \& Weiner, 2006; Rambaldi et al., 2006; Sieber, 2006) see this application as a double-edged sword with the capability to empower and also marginalize communities. Yapa (1991) identified this contradiction in a GIS study for grassroots communities in Brazil. Similarly, Laituri in her case studies involving indigenous peoples in New Zealand and in the USA argued for cultural sensitivity and innovative strategies, integrating western and indigenous knowledge systems (Laituri, 2002). In certain contexts, PGIS can cause conflicts that affect local politics. Kyem (2001) identified such local power politics in his participatory study in Ghana. He argued that despite support from external agents, local structures might not exist to support high levels of participation such as power sharing. In some cases PGIS projects might give power to people unprepared to use it and hence abuse of power might result. Nevertheless, in the context of Participatory GIS, power levels in decision-making, problem solving and knowledge production are shifting in favor of previously marginalized societies. For example, in San Francisco Parker and Pascual (2002) argued that PGIS has successfully scaled the community's concerns that gentrification of the city would privilege market-driven development over sensitivity to culture of existing neighborhoods. In contrast, Elwood (2002) in her study of neighborhood revitalization in Minneapolis argued that factors such as limited time, inadequate training and financial resources are significant barriers of GIS implementation 
in this community. In many PGIS projects, effective participation is crucial to the success of community development. However, participation can be manipulated to legitimize topdown decision-making process (Craig et al., 2002). Still, non-participation often results in distancing local community from decision-making process (Tripathi \& Bhattarya, 2004). In any case, PGIS provides an opportunity for the local community to produce, control and document their local knowledges.

As a democratizing force PGIS is argued to have the potential to broaden the access base to digital spatial information technology and data. Harris \& Weiner (1996; 2002) in their implementation of a community-integrated GIS (CiGIS) in Mpumalanga Province of South Africa, argued that "spatial decision-making using CiGIS remains a significant challenge, particularly in the context of socially differentiated knowledge, perceptions about landscapes and uneven access to GIS resources” (Harris \& Weiner, 2002:257). A disenfranchising effect of GIS results when GIS changes local power relations in favor of the traditionally marginalized groups in society. Hence, GIS practice is as much political as it is technological (Lupton \& Mather, 1996).

Setting up a PGIS in South Africa is constrained by the complex nature of the concepts of empowerment and participation as well as the locally contingent socio-economic and political factors. Like in other parts of Africa, PGIS implementation in South Africa is also limited by the legacy of apartheid, patriarchal traits that discourage participation of women, and lack of resources (Hastings \& Clark, 1991). Attempts to deal with these problems are always hampered by the problems of poverty and provision of basic necessities such as water, food and electricity (Harris \& Weiner, 2002). However, the process of empowerment is a complex process and is often misunderstood or used for functions other than empowering the community (Kyem, 2002). Very often, there is a mismatch between community and individual goals. The complexity is heightened because empowerment is conceived in terms of local leaders transferring power, authority or responsibility to less powerful groups in society. There are difficulties in public officials relinquishing power (Kyem, 2002). 
This dissertation research uses a PGIS methodology to study people's vulnerability to flood within a political ecology conceptual framework. The study acknowledges that PGIS can empower communities (Jordan \& Shrestha, 1999) and also marginalize them. The empowerment-marginalization nexus as discussed above reflects serious challenges when setting up a Participatory GIS in these poor communities. In such communities full implementation of community-controlled PGIS has been restricted by limited resources and fundamental political and cultural differences among stakeholders. In addition, the issue of how community participation can be properly incorporated into a GIS is important to enhance the bottom-up decision-making processes. In this research, the application of PGIS was aimed at uncovering social and spatial differentiation of household flood vulnerability and consequently to develop strategies to reduce social vulnerability to flood hazards.

Participatory Learning and Actions (PLA) methods inherent in a PGIS framework, have offered community members the opportunity to voice issues about flood vulnerability and capacity assessment. In mental mapping workshops, community members used themselves and their own community as a reference point to discuss issues pertaining to resource use, distribution, access and control. Communities also used maps to explore their geographic area and to observe how the area they know is represented on the map. PGIS practice was mainly in map reading and interpretation as well as mental mapping exercises. There are potential opportunities for PGIS to overcome empowerment limitations but complete empowerment would take place over a much longer time in these poor communities. Due to cost and time, a dissertation project of this nature could not claim to bring complete empowerment to households and communities at large. A more longitudinal and a collaborative community development PGIS project needs to be conducted in these communities in future. The application of PGIS methodology in this dissertation was a research attempt to understand, locate and map social processes and power relations behind flood vulnerability in the study area. 


\subsection{Integration of PGIS and Political Ecology for Flood Vulnerability Analysis}

\subsubsection{Areas of divergence}

Participatory Geographic Information Systems and political ecology seem to be far from being integrated. The two originated from different theoretical heritage and assumptions. More importantly, their areas of focus were quite different with PGIS pertaining to the use of GIS to broaden public involvement in spatial decision-making processes (Harris \& Weiner, 1996) while political ecology brought in the political dimension to the study of

environmental problems in the developing countries (Blaikie \& Brookfield, 1987). The proponents and methodological orientation of these two approaches are quite different, although changing trends point to some strides towards convergence (Harris et al., 1995; McCusker \& Weiner, 2003). For the most part, PGIS and political ecology have remained unconnected and directed geographic research in different directions. In particular, their applications to the study of flooding are still limited in South Africa, especially in the Limpopo Province. However, PGIS and political ecology share some commonalities. Hence, the following section explores the connection between PGIS and political ecology to the study of flood vulnerability in the Limpopo Province of South Africa.

\subsubsection{Common ground}

The integration of PGIS and political ecology is played out in four themes: geographic context; differential access to data, technology and knowledge; and landscape of power and politics. These are the common themes that connect PGIS and political ecology.

\subsubsection{Geographic context}

Both PGIS and political ecology approaches highlight the importance of geographic context. Context according to Sarah McLafferty (2002:256) means the "grounding of 
human experiences and interactions in space and place.” In her framework for a coproduced PPGIS (an earlier conceptualization of PGIS), Renee Sieber (2006:494) reiterated the argument of Laituri (2002) and Kyem (2004) that PPGIS projects are not implemented in a void but are context-dependent, i.e. the laws, cultures, politics and histories within a community influence their implementation. PGIS provides the tools for representing and visualizing the geographical contexts of flood affected communities. Political ecology draws attention to the socio-economic and political context of flood vulnerability as well as the social construction of hazards. Culture, patriarchy and local institutions shape PGIS. For example the application of PGIS may be broadly accepted by all stakeholders in one community but may fail in another because of different cultural regimes in these communities. According to Renee Sieber (2006:495) "legal regimes restrict access to critical data, and culture and politics limit the type of participants to specific gender, class or caste.”

Local influence, scale and geographic extent are important elements in the context of PGIS. Kyem (2001:7) finds that whereas PGIS was judged by researchers to be successful in most villages in Ghana, "the marginalization and continued oppression of the people were achieved through the same institutions and structures which the project was designed to transform.” Similarly, the role of local context is highlighted in political ecology of flood hazards. Flood vulnerability is recognized to be mediated by local politics and the existing socio-economic conditions of the community (Anderson, 1994; Varley, 1994). These include the "on-going social order, its everyday relations and historical circumstances” (Hewitt, 1983:25).

Carver (2003) argues that people‘s connections with local issues strengthens as they become closer to the problem. Similarly, the concept of scale is very important in political ecology of hazards. Within the context of flood hazards political ecology brings the connections between local, regional and global scale. Differential flood vulnerability becomes more evident at the local scale, although there are forces at the regional and global scales that make local communities vulnerable to floods. PGIS and flood hazards are socially constructed in terms of scale, data and geographic context. 


\subsubsection{Differential access to data, technology and knowledge}

Integrating PGIS and political ecology challenges us to think about GIS technology, geographic data and the creation of new knowledge in innovative ways. Unequal access to GIS technology ensures unequal benefits to stakeholders. For example, elderly people may be marginalized while the youth and young adults are empowered. Currently, most PGIS activity is cartographic so map reading may be one essential skill in many communities (Sieber, 2006). Hence, data input and output devices might be appropriate technology for most communities.

The integration of PGIS and political ecology in the context of disaster research promotes a broader and a more critical view of flood vulnerability. People's perceptions and experiences of floods are able to be populated in a PGIS database and issues about access to and control of resources being mapped in a PGIS environment. In other words, both easily measurable (quantitative) and difficult to measure objectively (quantitative) features are represented and captured. PGIS highlights the importance of qualitative data such as narratives, photographs, mental maps, videos and oral histories. Case studies in South Africa (Harris \& Weiner, 1998), Ghana (Kyem, 2002; 2004) and in New Zealand and the United States (Laituri, 2002) have increasingly demonstrated the integration of qualitative and quantitative geographic information.

PGIS literature addresses the issue of differential access to GIS technology and data as a growing concern. Lack of access to spatial data and GIS technology by community members make it impossible for communities to own and house Community GIS projects. Political ecology on the other hand, addresses differently the issue of resource access and control. Literature on community vulnerability to hazards highlighted the significant relationship between resource access and control and increased hazard risk (Morrow, 1999). Technology, data and local knowledge acquisition connect PGIS and political ecology, especially with regards to differential access and control of resources. 


\subsubsection{Landscape of power and politics}

The final commonality between PGIS and political ecology concerns the issue of power and politics. PGIS has potential as a tool for community empowerment and disempowerment (Sheppard et al., 1999). Power dynamics permeate social relations that underpin PGIS and its development. Currently, public agencies, researchers and private corporations are directing PGIS development, since the ability to shape GIS practice to community needs presumes technical knowledge and power to influence (Sieber, 2000:779). PGIS practice might empower some and marginalize others.

It has been stated elsewhere in this chapter that the concept of power is a critical element in political ecology. Power in political ecology of flood disasters precludes strong connections with politically powerful decision-makers. This strong political affiliation with powerful structures becomes useful when scarce resources are allocated. For example, when disaster aid is administered, usually the more affluent, well-organized with strong connections to political leaders tend to benefit. Marginalized poor communities are unlikely to benefit significantly from flood relief funds. Power also means the ability to access resources such as land and to control its appropriation.

Understanding the changing patterns of power that underlie PGIS development and political ecology of flood hazards present important opportunities for using a PGISpolitical ecology conceptual framework to study flood vulnerability. The following section presents the elements of such a framework. Despite few areas of divergence stated above, there exists strong connection between PGIS and political ecology approaches. 


\subsection{Conceptual Framework}

This research is based on a conceptual framework of political ecology and PGIS methodological framework. Thus, the analytical framework developed for this study links the ecological processes of flood vulnerability to issues of power, human agency and scale. How these key concepts relate to this study is discussed earlier on in this chapter.

The conceptual framework for this study which is described and illustrated in Figure 2.1 below is informed by the work of Hewitt, 1983; Susman et al., (1983); Watts, 1983a; Watts \& Bohle, 1993; Blaikie et al., (1994); Ellis, (2000); Craig et al. (2001); Blaikie, 2002; McCusker \& Weiner, 2003 and Sieber (2006). The purpose of the diagram is to organize themes and identify critical historical processes and factors that make people vulnerable to flood events. The major limitation of such a two dimensional representation of processes that bring about flood vulnerability are recognized at the outset. It is difficult in such a diagram to capture the complete picture of the complex dynamic interaction between biophysical and human factors. However, some key dynamic processes are identified and discussed. This conceptual framework is applicable at different units of analysis and is broadly consistent with the general themes described in the preceding sections of the chapter. However, in the study the framework is confined to the analysis of flood vulnerability at the household and community levels.

Figure 2.1 presents the interaction between the human (social, economic and political) and the biophysical factors (climate, hydrological and geophysical) with increasing sociospatial marginalization as the main root cause of vulnerability. Such an interaction impacts both the exposure and coping capacity of households. Within the context of the study area, spatial and social marginalization is associated with historical processes of colonialism and more importantly, the geography of apartheid. These historical processes have created the "marginals" who have been either forced off the land or onto very poor or insufficient land. This has consequently created the marginalized population with little political power and a poor standard of living. Hence, the landless poor people have consequently resorted to means of survival, which has led to the degradation of the 
environment. When extreme flood events come in contact with marginalized people operating in a deteriorating physical environment, flood disasters occur. This claim is consistent with the notion of disasters as the interaction of physical factors that induce hazard types (e.g. floods) and the root causes, dynamic pressures, and unsafe conditions (Blaikie et al., 1994; Blaikie, 2002). The role of human factors in creating vulnerability is important for this research. Hence, specific themes that are addressed in the conceptual framework reflect a combination of both physical and human factors in the analysis of vulnerability.

As shown in Figure 2.1, the concept of flood vulnerability consists of two components: exposure and coping capacity. The term exposure is defined as the act of leaving subject to risk (Oxford English Dictionary). Mitchell \& Cutter (1999) define exposure as the state of being physically at risk from a hazard. In this research exposure refers to the susceptibility and degree to which people are physically at risk from flooding. Exposure to floods is an interaction of both physical and human factors. The exposure component of vulnerability includes the assessment of the physical forces that act as stimuli on the human-environment system. Political ecology, therefore, focuses the analysis on the interaction of human factors and physical factors and how they enhance exposure as an important component of vulnerability (Clark et al., 1998; Blaike, 1994).

Historical experience, choice of location, demography, resource use, access, control, political structure, institutional organizations and economic status are factors that influence the exposure of an individual or group to floods (Potter-Gibson, 2000). For example, poor people might have a higher exposure to floods than other groups of people due to their inability to provide shelter and income (Wisner, 1999). This example also illustrates how coping capacity influences flood vulnerability. 


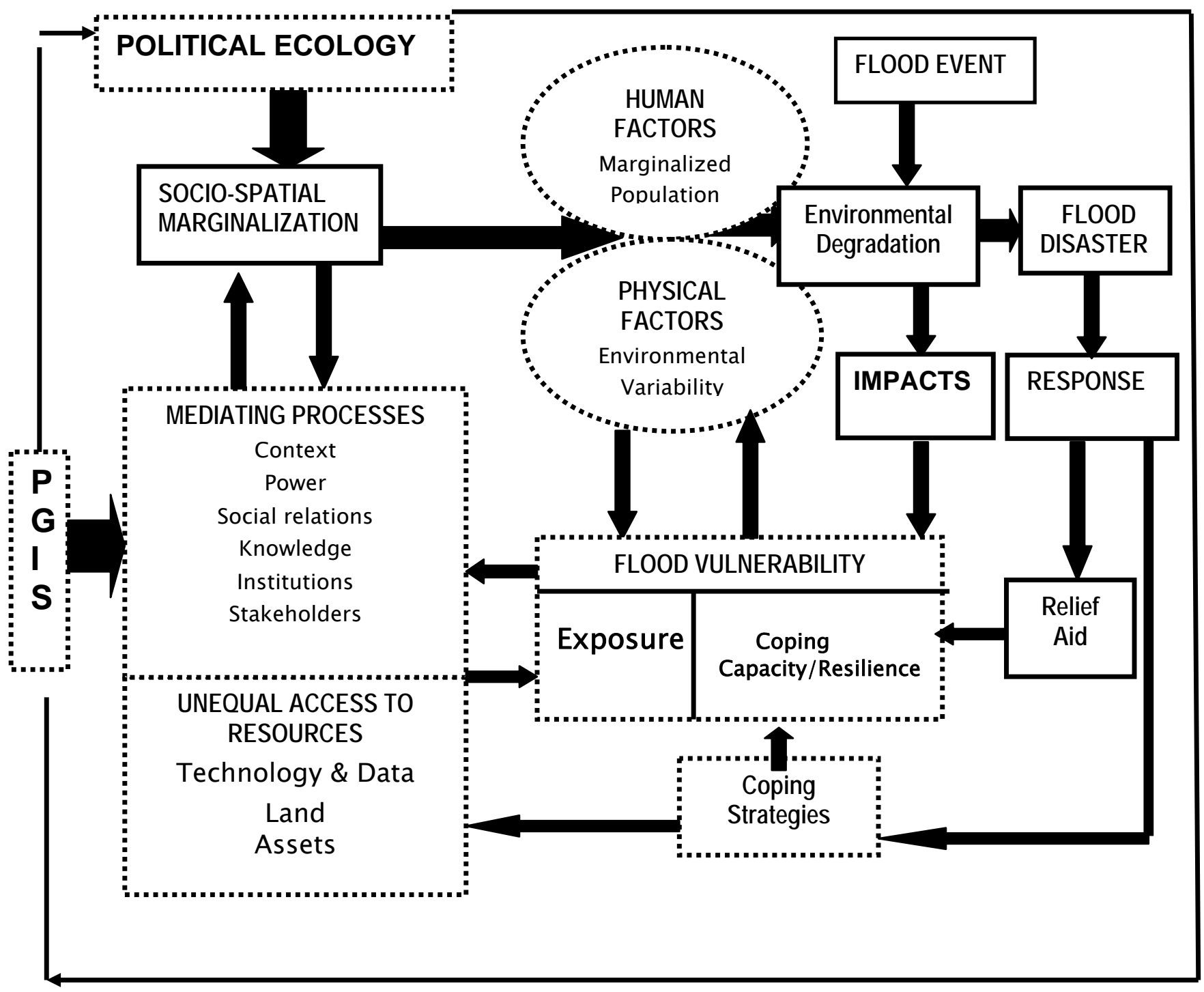

Figure 2.1: Political Ecology and PGIS conceptual framework of flood vulnerability.

Coping capacity refers to the preparedness or the ability of an affected system to absorb, manage, or respond to a stimulus and effects associated with it (Smit et al., 1999). This component of vulnerability encompasses the response of systems to external stimuli. In this case, extreme climatic events coupled with low levels of preparedness and poor resilience can affect people's coping ability. Figure 2.2 illustrates conceptually how 
coping capacity and exposure interact to create vulnerability. The graph indicates that there is high exposure and vulnerability when coping capacity is low. Conversely there is low exposure and vulnerability if coping capacity is high.

Relief aid as a loss-sharing mechanism can also enhance household's coping capacity. However, in most cases relief aid enhances vulnerability in that there are unequal power relations embedded in relief aid. Such power relations are manifested in the unequal distribution of relief aid and its role in undermining local expertise and coping strategies.

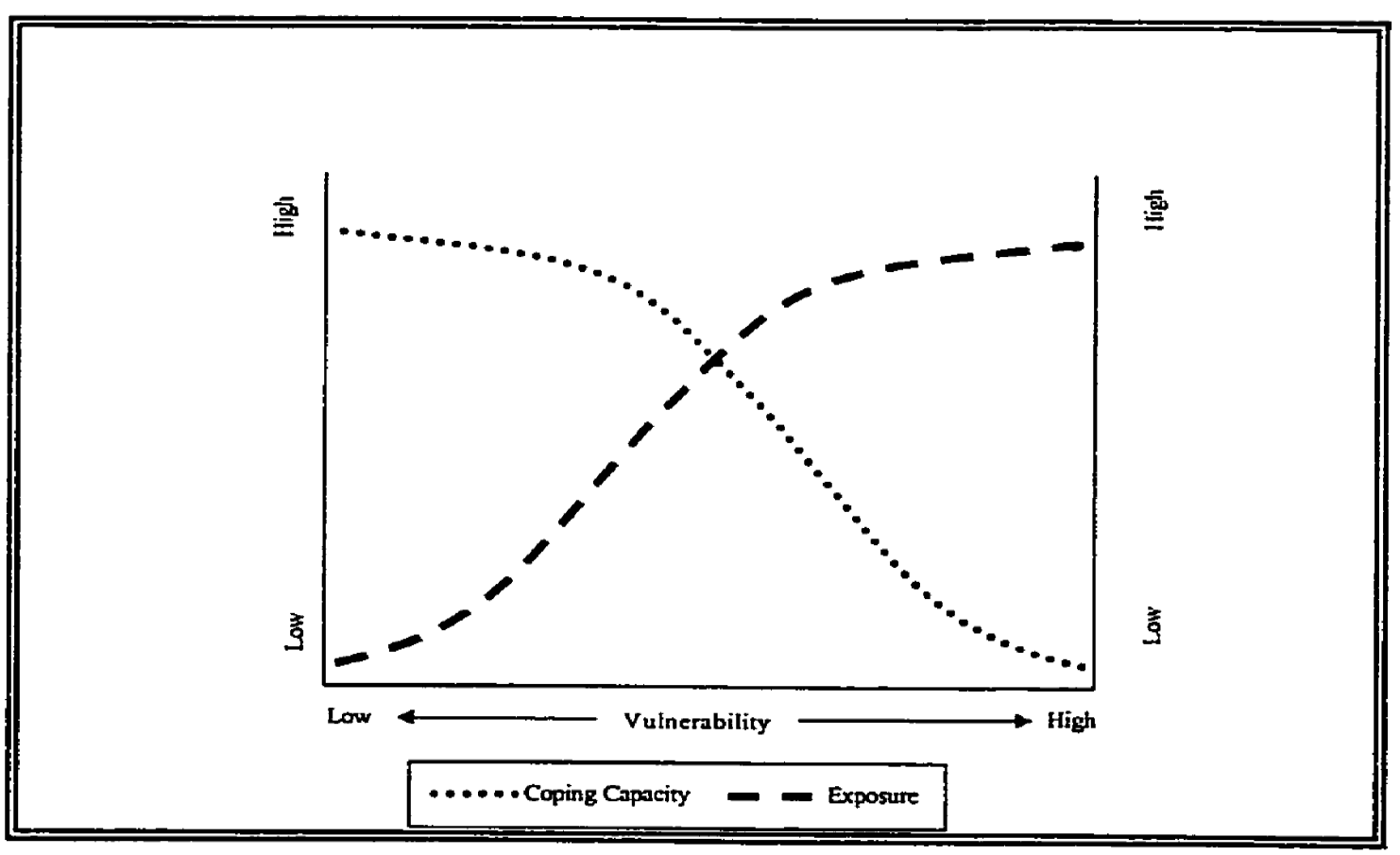

Figure 2.2: Relationship between Coping Capacity, Exposure, and Vulnerability.

Social relations, institutions, power and geographic context mediate access to resources. Unequal access to resources often impacts households and individuals' exposure to floods and their coping capacity. The political question of access and allocation of resources involves unequal social and power relationships. Other social institutions such 
as culture and social structure are important components of resource allocation. For instance, culture-specific patriarchal practices about gender roles and social norms all play an important role in how resources are allocated and managed. The allocation of resources represents unequal power relations and in turn, influences differential social and spatial vulnerability to flood hazards. In this way, power relations influence differential social and spatial vulnerability to flood hazards. For example, such seemingly 'natural' phenomena as floods are a consequence of unequal power relations among individuals (Zimmerer \& Bassett, 2003). This example emphasizes the centrality of political power in flood vulnerability assessment.

\subsection{Conclusion}

Political ecology provides key concepts that form the basis for analyzing flood vulnerability in this research. It also identifies the political and economic circumstances that are likely to force people into activities that contribute to environmental degradation (Bryant \& Bailey, 1997). This perspective recognizes complex social relations that involve the exercise of influence, leadership and power, mediating the relations between communities and their natural environment (ibid). Political ecology critiques many common assumptions of the conventional explanation of disasters (e.g. rationality, choice) to acknowledge socio-economic and political forces that cause vulnerability to floods. In this framework, community local knowledge can augment 'scientific' knowledge to study flood vulnerability. A PGIS and political ecology link enhances

participatory dimensions about the power and politics of resource use, access, ownership and distribution. Household and local communities are encouraged to engage themselves in socio-economic and political issues affecting their daily lives. 


\section{CHAPTER 3}

\section{Case Study}

\subsection{Introduction}

The case study area - Thulamela Municipality - is situated in the Vhembe District of the Limpopo Province of South Africa (Figure 1.2). This municipality has incorporated the Greater Thohoyandou and Malamulele regions, which respectively, were within the jurisdiction of the former Venda and Gazankulu homelands. Two study sites, namely, Milaboni and Dzingahe villages are located in Thulamela municipality (Figures 1.3; 3.1 a, b). Historically, these villages are within the jurisdiction of the former Venda homeland. Both villages derive most of their social and commercial services from Thohoyandou and Louis Trichardt, which are some of the main towns in the Vhembe district.

Notwithstanding its commercial function, Thohoyandou, the former capital of Venda homeland, is now the administrative seat of the Vhembe District of the Limpopo Province. Similarly, it is where the head office of Thulamela municipality is located and the Vhembe District Disaster Centre is to be built as well. The choice of this location for the establishment of the Centre and head office is largely related to recurrence of flood disaster in the area as well as the availability of redundant office space left during the dawn of a democratic South Africa in 1994. Immediately after 1994, Thohoyandou's political power shifted, resulting in massive flights of government departments and personnel to Polokwane, the capital city of the province (Figure 1.1). Despite this flight, the commercial sector continued to flourish due to the presence of the University of Venda as a support base. Consequently, the massive flight was reversed a few years later when office space in the capital became extremely limited which in turn pushed up rental levels. As a result, provincial government departments of Education, Labor, Home 
Affairs and Statistics with their associated personnel were deployed back to Thohoyandou town.

Administratively, the Limpopo Province is divided into 6 districts and 26 local municipalities (Figure 1.1). Polokwane is the capital city of the province and the centre of government and commerce ${ }^{3}$. As such, the capital city serves as the regional service hub for the whole province including the neighboring countries of Zimbabwe and Botswana. South Africa's Human development index (HDI) is not the worst in the world and it ranges between 0.6 and 0.69 (Statistics South Africa, 2001). The Limpopo Province has low life expectancy, low levels of educational attainment especially that of women, and low per capita income. With the HDI of less than 0.4 the Limpopo Province is one of the poorest provinces in South Africa with about 2453 rural and urban settlements housing approximately 1180000 households (ibid.).

Most of these settlements are rural and very few have developed a sustainable local economic base. In fact, the majority of these settlements are in the former homeland areas which were established on lands that are ecologically sensitive, marginal and relatively unproductive (Levin \& Weiner, 1997; Omara-Ojungu, 1999). Most of the available productive land is taken up by large-scale commercial farms and forest plantations. Coupled with this ecologically fragile environment are problems of deforestation, erosion, overstocking and poor farming methods (Muzila, 1999). Many of these problems have their origin in the overcrowding associated with apartheid policies.

In addition, the energy and forest policies of the colonial and apartheid regimes have confined people to the use of fuel-wood and subsistence agricultural activity practiced on land that is susceptible to erosion. Hence, these policies are regarded as the main causes of deforestation which consequently has increased flood vulnerability in the province. Furthermore, the apartheid regime was effective in limiting access to natural resources, a phenomenon reversed by the current government (McCusker \& Oberhauser, 2006).

\footnotetext{
${ }^{3}$ Polokwane is formerly known as Pietersburg
} 


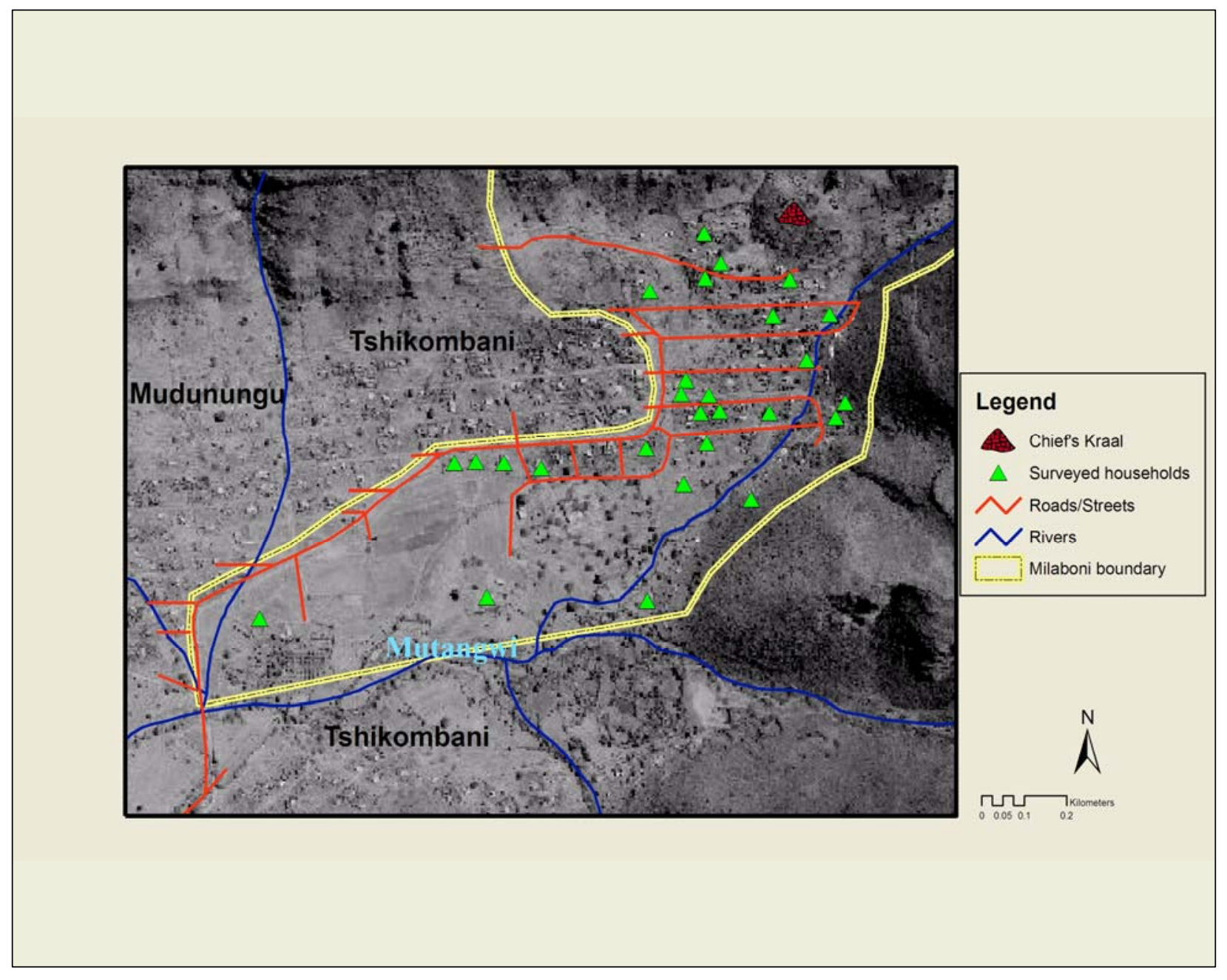

Figure 3.1(a): A map of Milaboni and surrounding villages

This chapter, therefore, locates the Thulamela case study area and research sites within the socio-economic and environmental context of the Limpopo Province of South Africa. It should be stated from the outset that the socio-economic and environmental context is largely integrated. This integrated human-environment context is situated within a political ecology framework and is best understood and analyzed most effectively at the village and the household scales. Political ecology has been employed in this chapter to 
illustrate how this particular 'context' has over time contributed to flood vulnerability and restricted choices and opportunities for the majority of people in the Thulamela municipality of the Limpopo Province.

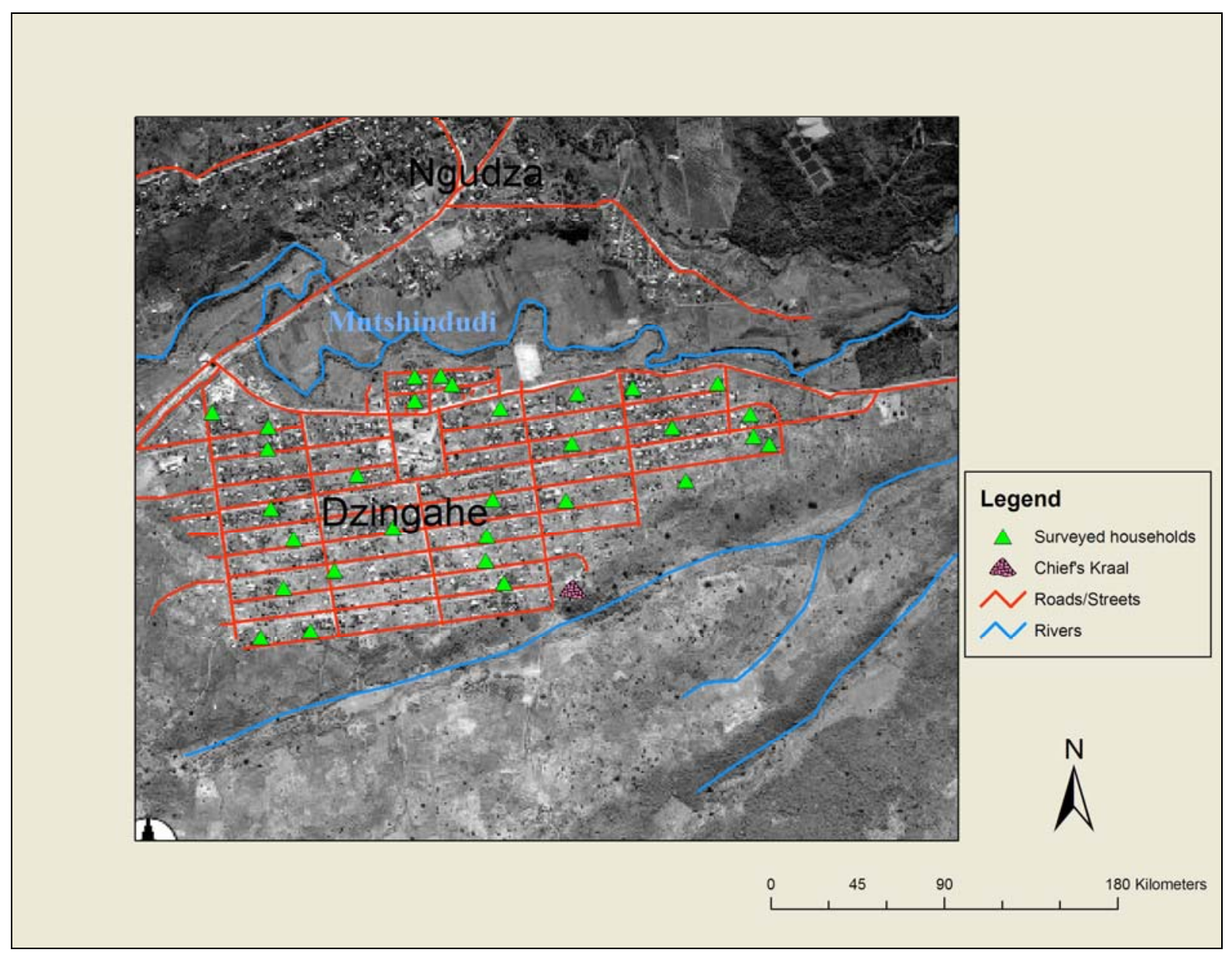

Figure 3.1(b): A map of Dzingahe and a neighboring, Ngudza village 


\subsection{Physical Characteristics and Social Profile of the Limpopo Province and Case Study Area}

\subsubsection{Physical characteristics}

Physical characteristics refer to natural aspects of an area such as its climate, soil and its terrain features. These physical landscape attributes provide the setting within which human occupation takes place. They help shape - but do not dictate - how people live. For example, people modify the environment of a given place by generally occupying it. Physical landscape characteristics overlaid with social characteristics define flood hazards in an area. This section will describe rainfall, hydrology, vegetation cover, geology and soils as physical parameters that are likely to amplify flood vulnerability if overlaid on the area's demographic characteristics and social processes.

\subsubsection{Rainfall distribution}

Rainfall as one of the climatic variables plays a major role as a triggering mechanism of flood disaster across the globe. The Limpopo Province falls in the summer rainfall region with the western part semi-arid, and the eastern part largely sub-tropical. Mean annual rainfall in the province ranges between $400 \mathrm{~mm}$ in the semi arid western region and 800 $\mathrm{mm}$ in the eastern subtropical part of the province (Mufamadi, 2003).

The Vhembe district is situated in the eastern subtropical region and it is generally hot and humid, receiving the bulk of its annual rainfall from November through March as the Inter Tropical Convergence Zone (ITCZ) moves south (Kabanda, 2004). Hence, the Vhembe district is generally subjected to high rainfall and consequently flooding due to its maritime influence and its complex topography, especially the effects of the Soutpansberg mountain range. This mountain range also exerts large impacts on the weather and climate of the Makhado and Thulamela municipalities (Mufamadi, 2003; Kabanda, 2004). The orographic effects of the Soutpansberg are most evident when its 
influence on the rainfall patterns of Milaboni and Dzingahe villages are examined. The mountains receive exceptional high rainfall due to orographic effects and as such Milaboni village experiences higher rainfall than Dzingahe village.

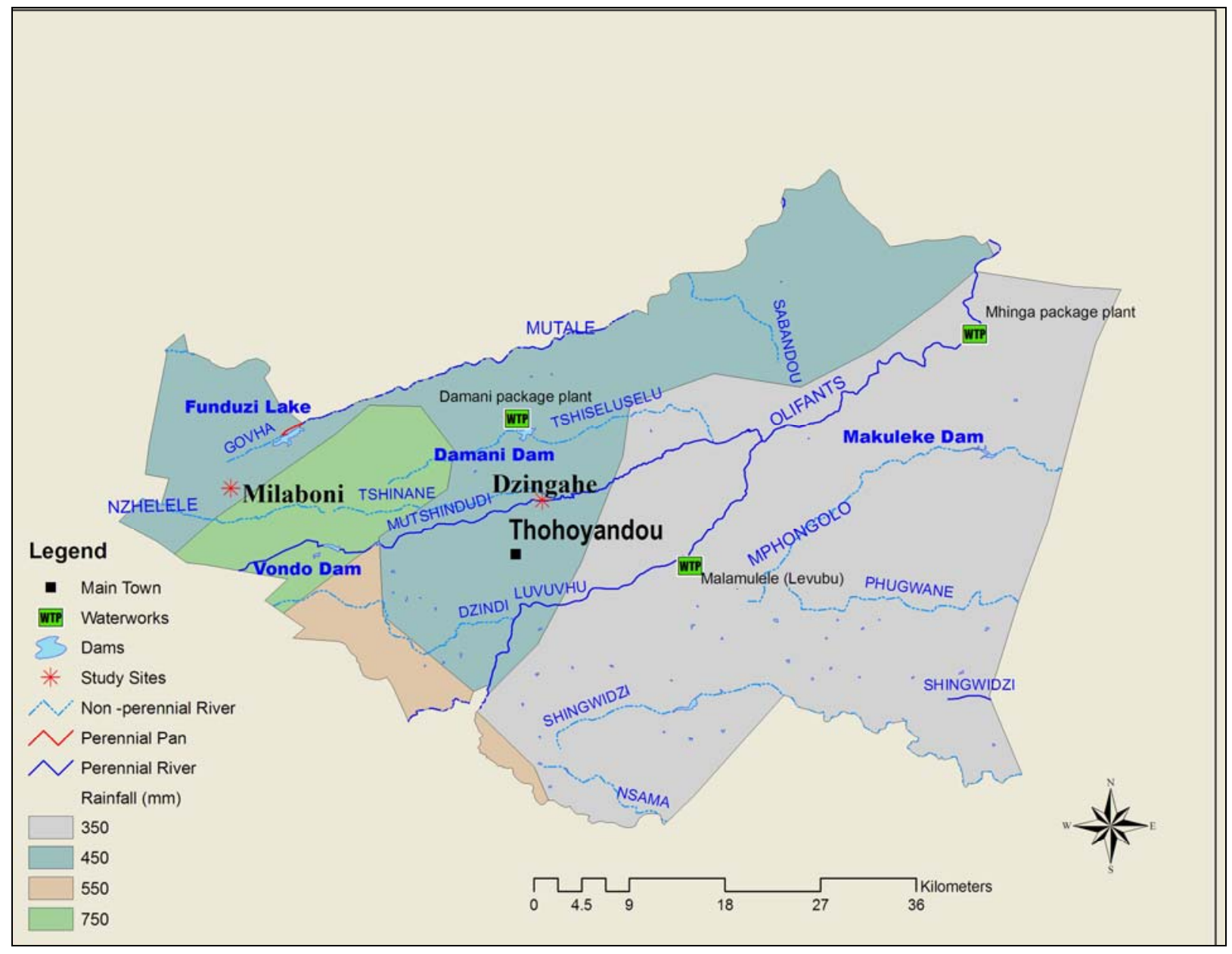

Figure 3.2: Rainfall distribution and hydrology in Thulamela Case study area and sites

Figure 3.2 indicates hydrology and rainfall distribution in the Thulamela case study area. Generally, the south-eastern part of Thulamela municipality is relatively drier than the north-eastern and southwestern parts. The annual mean rainfall in this municipality ranges from 350 to $750 \mathrm{~mm}$. The two study sites --- Dzingahe and Milaboni villages are in a similar rainfall belt with an annual mean rainfall of $450 \mathrm{~mm}$. Due to topographical differences, Milaboni generally experiences higher rainfall and geological instability than 
Dzingahe village ${ }^{4}$. Nevertheless, local spatial variations in rainfall patterns impact households in these study sites because they rely on rainfall for water supply and their subsistence agriculture. For example, households in Dzingahe village often receive good rains which enable them to grow crops and keep domestic animals.

The problem, however, is that most of these high rainfall areas across the Thulamela municipality are taken up by commercial farms, tea and pine plantations. Pine species dominate the Vhembe district, especially the Thulamela municipality. Milaboni village is situated immediately adjacent to these plantations. Dominant species such as eucalyptus, pine and wattle disrupt species richness and diversity by invading indigenous plants in the area (Kabanda, 2004).

\subsubsection{Hydrology}

The Limpopo River is the largest catchment in the Vhembe district and Thulamela municipality. It forms the border between South Africa and Botswana and Zimbabwe before flowing through Mozambique to the Indian Ocean. Within the study area there are several streams, some perennials and others that are intermittent. Generally the drainage pattern in Thulamela municipality is largely dendritic. Streams such as Mushindudi, Mutale, and Tshinane are perennial and flow into the Luvuvhu River catchment, another important river within the case study area (Figure 3.2). Two most important streams within the study sites are the Mutshindudi and Mutangwi Rivers. Mutshindudi River drain Dzingahe village while Mutangwi flows in the south westerly direction through Milaboni village (Figures $3.1 \mathrm{a}, \mathrm{b}$ ).

\subsubsection{Vegetation cover}

Although the Thulamela municipality is installing electricity in rural areas, most villages still have no electricity (Thulamela Municipality IDP Review 2006/7). For those villages with electricity, like Dzingahe village, most households are failing to keep up with

\footnotetext{
${ }^{4}$ Landslides and seismic activity are usually experienced in addition to floods at Milaboni village.
} 
electric bills. Hence, as a cost cutting measure they usually resort to using wood as a cheaper alternative. Other households use a combination of wood, gas and paraffin for cooking and heating purposes. As a result, vegetative material (i.e. wood) is still a major source of energy for domestic purposes. Figure 3.3 shows how the burn for fuel-wood collection is on children both girls and boys.

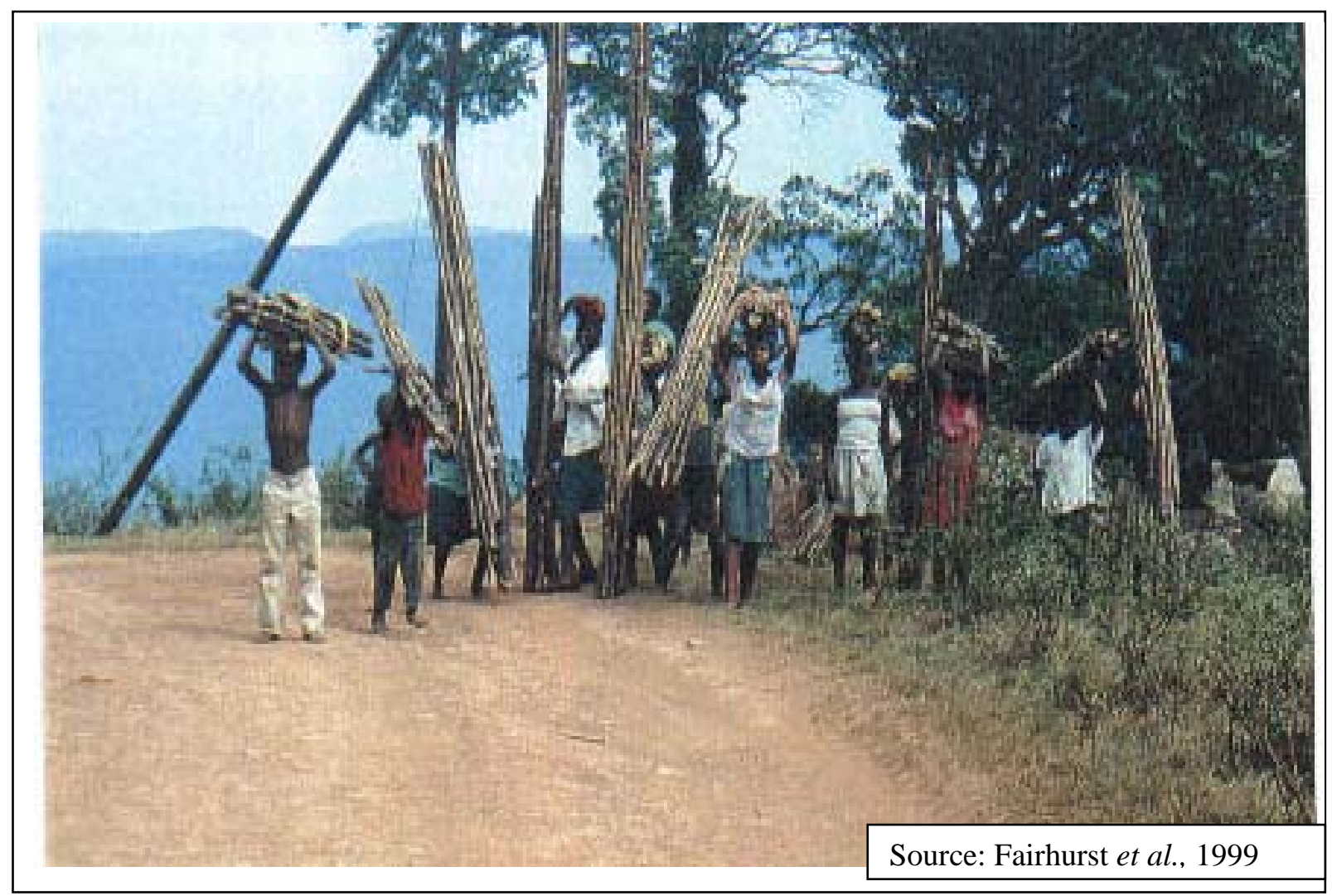

Figure 3.3: Young girls and boys seen collecting fuel-wood

Deforestation or forest clearing is a major cause of increased flood runoff in the Milaboni and Dzingahe villages and an associated decrease in channel capacity due to sediment deposition. Forest vegetation, in general, increases rainfall and reduces evaporation while it absorbs moisture and lessens run-off. Deforestation and logging practices have reduced the vegetation and the forest absorption capacity, thus increasing run-off in the study 
sites. Overgrazing in both study sites has decreased vegetation cover and exposed soil to erosion as well as increased runoff. The clearing of forests strips the land of its natural shield against soil erosion (Muzila, 1999).

\subsubsection{Geology}

Geology has strong control over flood related parameters such as topography, soil types, soil infiltration, general hydrology and vegetation cover (Kabanda, 2004). Hydrology and vegetation cover have been dealt with in the preceding sections. In terms of geology, the Limpopo Province has a diverse geological composition whose broad terrain patterns are characterized by intrusive igneous and metamorphic rocks especially in the Soutpansberg and the Waterberg complex (Mufamadi, 2003; Kabanda, 2004). These rocks are fairly resistant to weathering. Generally, Thulamela municipality is composed of granite gneiss of the Precambrian age which is referred to as “Goudplaats” or golden plate gneiss. This is a high grade metamorphic rock which is not easily eroded. The central Soutpansberg is interspersed with Fundudzi and Willies Poort geological formations (see Figure 3.4).

The structural geology of Dzingahe and Milaboni is characterized by the rocks of the Soutpansberg groups which dominate the central region. Figures 3.5 (a; b) show the 3D view of rugged terrains of these villages. Milaboni village is surrounded by the Nzhelele, Fundudzi and Willies Poort formations. The "Goudplaats" and Fundudzi formation surround Dzingahe village. Milaboni village experienced high earthquake activity that has shifted houses during the "great” flood of 2000. The importance of geology in respect to this research is that rock outcrops of the Soutpansberg especially in Milaboni village are also inhabited due to scarcity of land. Such settlement of denudated rock outcrops promotes run off and consequently permits a higher percentage of a large flood discharge downhill. Similarly, geological composition of Milaboni is attributed to occasional seismic activity experienced in this area. 


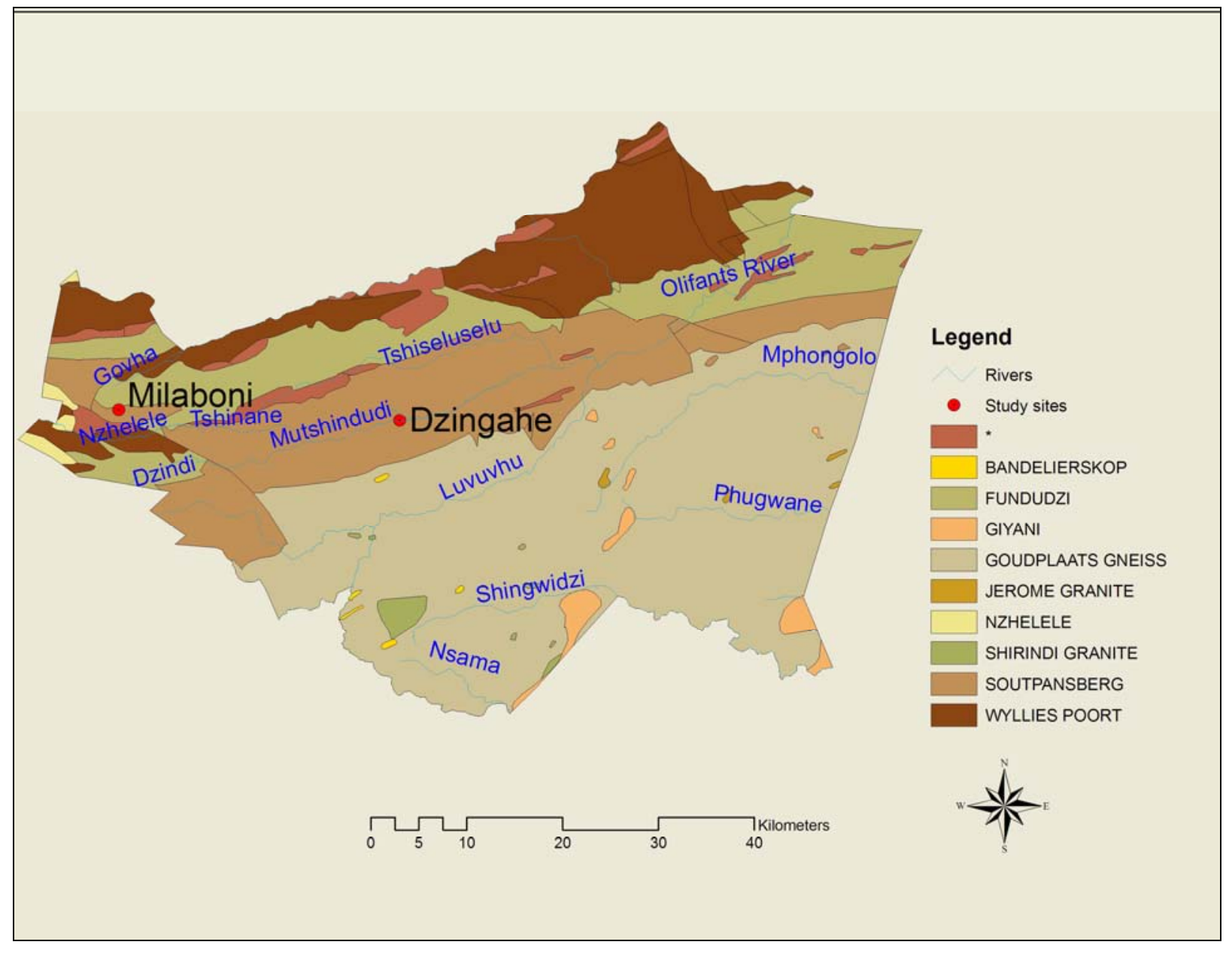

Figure 3.4: The Geological map of Thulamela Municipality 


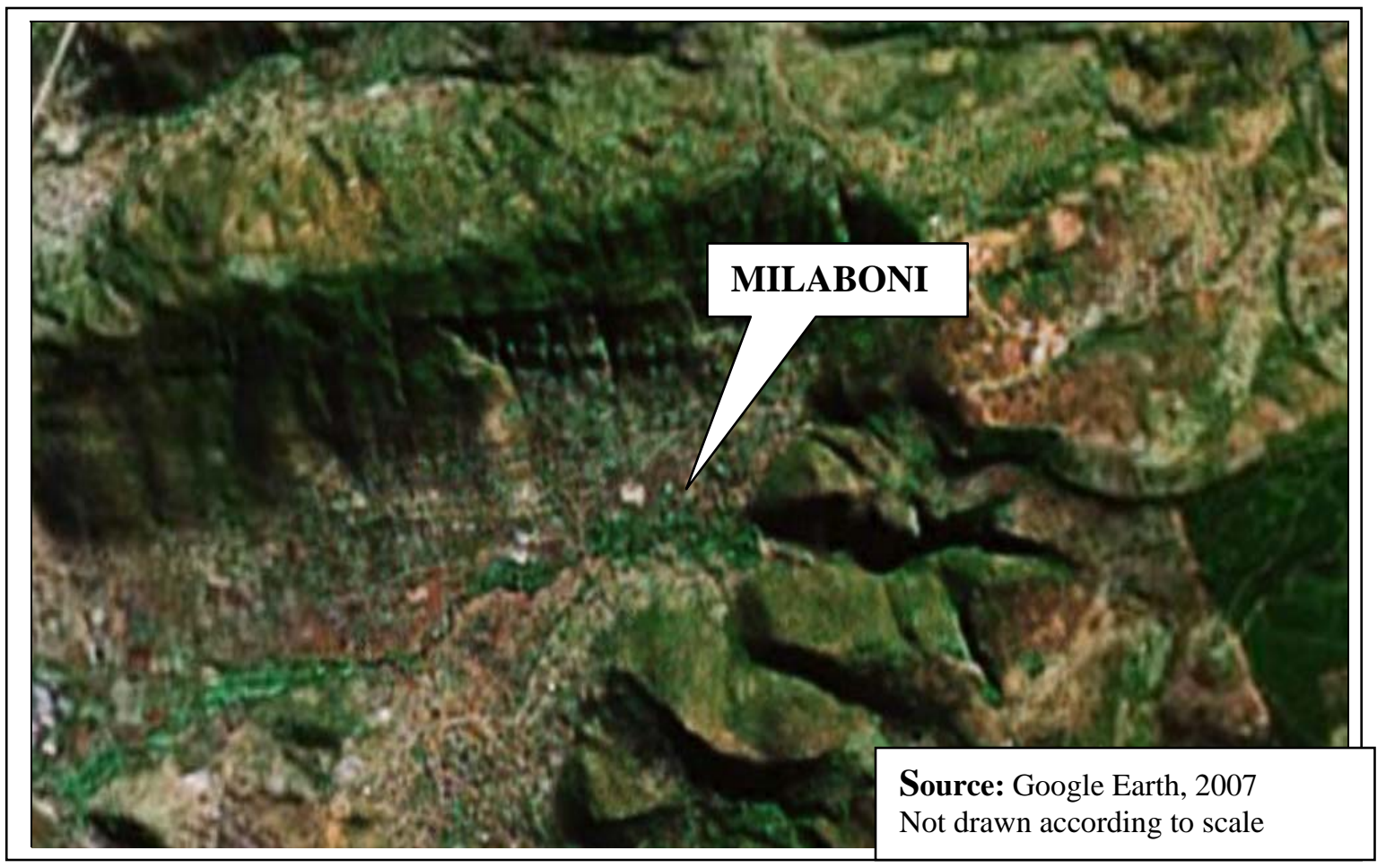

Figure 3.5 (a): 3D View of Topography: Milaboni and its environs

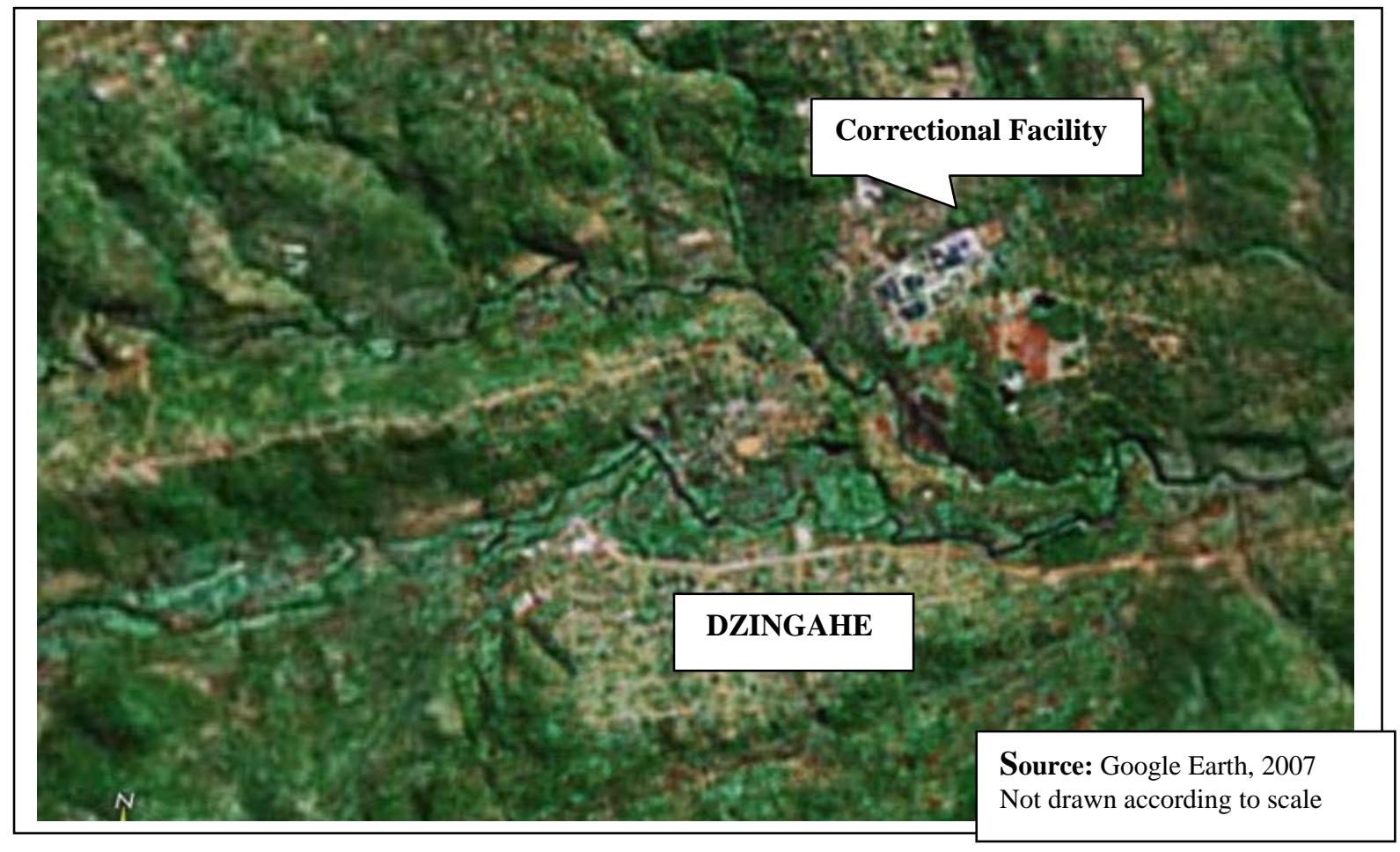

Figure 3.5 (b): 3D View of Topography: Dzingahe and its environs 


\subsubsection{Soil property and types}

Soil types and soil infiltration capacity play important roles in the run-off of surface water that contributes to flooding. Soil soaks rain water before releasing the excess as surface run-off. Soil texture and depth determine how much water can be held after it rains. The Vhembe district and in particular, Thulamela municipality, is characterized by different soil types which include sandy soils, clay soils and sandy-loam soils. These types of soils are not massive but sparsely distributed across the district, and are easily eroded by major erosive agents such as rain and wind.

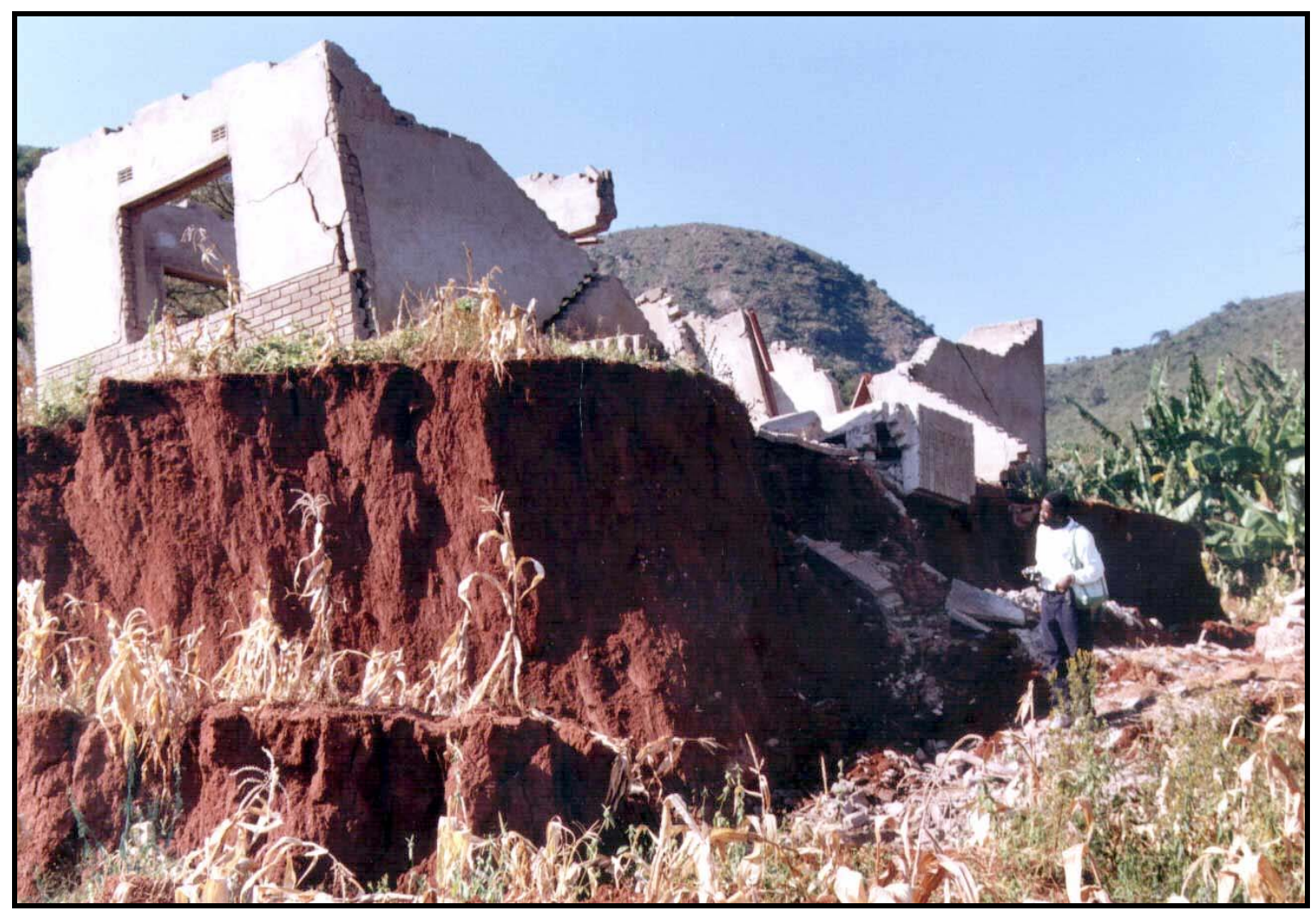

Figure 3.6: A house crumbled under unstable soil conditions at Milaboni village after the "great flood" of 2000. 
The soil type at Milaboni and Dzingahe villages is fertile red loam, which often suffers from excessive drainage or runoff. This soil type has higher water holding capacity that can create a barrier to water drainage. Water logging and flooding due to local rainfall is common in red loam soil. Not only do heavy rains cause flash floods, subsistence agricultural production in these study sites increases the risk of soil erosion. Figure 3.6 shows the effect of unstable red loam soil on structural foundation after heavy rains during the great floods of 2000. For us to understand this situation better, we need to factor in human-environment interaction, individual experiences and social processes affecting decisions made by the house owner.

\subsubsection{Socio-economic characteristics}

The geography of apartheid is more apparent when the social profiles of the Limpopo Province and the case study area are examined ${ }^{5}$. This section is divided into the following headings: demographic characteristics; socio-economic profile; economic activities and land-use; apartheid legacy and the impacts of the great floods in 2000 in the Limpopo Province.

\subsubsection{Demographic characteristics}

The Limpopo Province of South Africa has a population of over 5 million, which constitutes about 13 percent of South Africa's population. The majority of these people reside in the rural areas of former homelands of Venda, Gazankulu and Lebowa. The province covers an area of approximately $124000 \mathrm{~km}^{2}$ and this accounts for $10.2 \%$ of the total land area of the Republic of South Africa (Statistics South Africa, 2001). The population density of the Limpopo Province fluctuates amongst plains and mountainous terrain and averages 39 people per square kilometers. This makes the province the third most densely populated province in South Africa (Statistics South Africa, 2001).

\footnotetext{
${ }^{5}$ Apartheid (literally "apartness" in Afrikaans and Dutch) was a system of racial segregation that was enforced in South Africa from 1948 to 1994. South Africa had long been ruled by whites and apartheid was designed to form a legal framework for continued economic and political dominance by people of European descent.
} 
Population density is particularly high in the former homelands. Such a high population density in these areas is largely attributed to past apartheid policies, which amongst other things, prevented the African population from migrating out of the designated homeland areas. Thulamela municipality has a population of 584563 with 261304 males and 323 259 females (Statistics South Africa, 2001). This comprises 126688 households (ibid.). The 2001 population figures of Dzingahe and Milaboni were 3641 and 537 respectively (Statistics South Africa, 2001).

\subsubsection{Livelihood activities}

The Limpopo Province is second poorest of the nine provinces (Statistics South Africa, 2001). This economic status is attributed to high unemployment rates (30.8\%) and poverty levels (48\%), unequal access to basic amenities (such as water and electricity) and unequal distribution of land resources (McCusker, 2002). The household sector wealth is relatively lower in the Limpopo Province than in other adjacent provinces (Aaron \& Muelbauer, 2006a). Households survive mainly on government grants, remittances from breadwinners who migrate to urban centers and on income generated from working in farms or towns. Most of the household purchasing takes place in the towns and commuter destinations outside of rural communities. The majority of households (69\%) in the province live in formal houses of brick structures while a significant portion (20\%) lives in traditional houses. A relatively small number of households live in informal dwellings (about 7\%), while the rest (4\%) of the households live in other forms of housing (Statistics South Africa, 2001).

In-house piped water is available to $11 \%$ of households while $34 \%$ have taps inside their yards. Communal taps within $200 \mathrm{~m}$ of dwellings serve about 19\% of households while $28 \%$ of households are served by water taps that are further than $200 \mathrm{~m}$ away from dwellings (Statistics South Africa, 2001). The rest of the households obtain water from other sources such as boreholes, springs, rivers and dams. In terms of sanitation, the majority of households (59\%) use pit latrines for sanitation. Flush toilets are available to $16 \%$ of households most of which are connected to municipal sewage systems. A large 
number of households (23\%) do not have access to in-house/yard toilet facilities. The rest use either bucket latrines or portable toilets (ibid.). Similarly, the water provision is not so different in Thulamela municipality and the study areas sites of Milaboni and Dzingahe. Table 3.1 shows the statistics of access to water in the case study area. Over 7000 people still receives water from fountains and boreholes, with over 4000 household getting water from rivers (see Table 3.1).

Table 3.1: Access to Water at Thulamela Municipality

\begin{tabular}{|c|c|}
\hline TYPE OF SERVICE & NUMBER OF HOUSEHOLDS \\
\hline Pipe water (in dwelling or yard) & $\mathbf{5 0 ~ 8 6 0}$ \\
Within 200 meters & $\mathbf{2 0 ~ 7 9 9}$ \\
More than 200 meters & $\mathbf{3 6 ~ 0 5 3}$ \\
Boreholes & $\mathbf{3 6 6 2}$ \\
Fountain spring & $\mathbf{4 5 5 0}$ \\
Rainwater tank & $\mathbf{1 5 4}$ \\
Dam, Pool, Stagnant water & $\mathbf{6 5 9}$ \\
River & $\mathbf{4 0 9 7}$ \\
Other & $\mathbf{5 4 2 0}$ \\
\hline \multicolumn{2}{|c|}{ Source: Thulamela Municipality IDP Review, 2006/7 } \\
\hline
\end{tabular}

\subsubsection{Land-use activities}

Despite water shortages, the Limpopo Province is renowned for commercial agriculture, especially its production of tea, citrus and deciduous fruit. However, these commodities are produced in large commercial farms with blacks providing the necessary labor power. A closer observation at the province's agricultural sector makes apparent the stark dualism between large-scale commercial farming and smallholder subsistence farming. The impact of this dualism becomes evident when $70 \%$ of land is apportioned to minority white farmers while 30\% to majority black smallholder subsistence farmers (McCusker, 2004). These characteristics have significant implications in terms of the social causes of flood vulnerability in the area. 
Tshikondeni, Burgersfort and Lephalale are centres closely associated with mining activities, while Levubu and Tzaneen are encircled by subtropical fruit, tea and coffee plantations. The towns of BelaBela, Modimolle, Mookgopong, Groblersdal and Marble Hall are associated with mixed wet and arid agriculture. Mokopane is cattle country while Vaalwater is fast becoming a major service centre for a growing eco-tourism industry in the Waterberg Biosphere Reserve. Musina, Makhado, Thohoyandou and Giyani are important towns that service vast areas of rural and urban settlements in the Vhembe district of the Limpopo Province. Farming is the predominant activity in the Thulamela municipality and the study sites. However, the majority of black people do not have access to land after they were forcefully removed from such lands to make way for agriculture and the development of towns and planned urban residential areas.

In Dzingahe and Milaboni villages, subsistence farming on small household plots is the main economic activity interspersed with informal sector activity. In these study sites, grazing is an important land use activity and this has often resulted in localized degradation (e.g. overgrazing) since herder mobility and access were restricted (Saidi, 1999; Omara-Ojungu, 1998). Overgrazing in grassland areas decreases the vegetation cover and exposes soil to erosion as well as increased runoff (Cooper, 1991). Forest vegetation, in general, increases rainfall and evaporation while it absorbs moisture and lessens run-off. Eventually, frequent floods lead to soil erosion and this promotes run-off and impedes infiltration.

\subsection{The Apartheid Geographies and Political Ecology}

Apartheid geographies in South Africa represented the mechanisms of control over people, relationships and resources, especially land. The political, economic and social legacy of the past apartheid policy in South Africa is evident in the Limpopo Province and particularly in the Thulamela municipality. Forced removals to make way for Kruger National, Makuya Parks, and commercial farms at Levubu, displaced black people to fragile ecosystems (Tapela, 1999; Tapela \& Omara-Ojungu, 1999). Land-use practices and legislations have also restricted people’s right of access to land and use and offered 
few alternative means of livelihood (McCusker, 2004). These legal institutions have contributed to the widening of wealth disparities in the province, the district and the municipality. At the scale of the study sites of Dzingahe and Milaboni, the historical policies of the former Venda homeland government contributed to environmental degradation. For example, changes in land-tenure practices by the homeland governments, such as the privatization of commonly held lands in an effort to provide orchards and irrigation schemes alienated people from resources they had depended on for many years.

Within the study sites, differentiation exists regarding the effects of apartheid on communities. The general economic legacy though not simple, is characterized by unstable employment, inadequate housing, lack of access to technology and training for growth and development, poor transportation infrastructure, poverty and consequent poor standard of living. The political legacy of apartheid is manifested in disputed land claims and lack of government solutions to economic and flood problems affecting communities in the study area. Lack of adequate health care, sanitation, clean water, education issues with lack of permanent residence, quality of life, lack of access to technology, and hygiene issues are some of the features of the social legacy of apartheid at the village level.

\subsection{The "Great Flood" of 2000}

The Limpopo Province has regular cycles of floods. Before the devastating floods of February 2000, the province has experienced floods in 1976-78 and 1999 (Christie \& Hanlon, 2001). This flood recurrence supports the argument that flooding in the province is not an unexpected and random event. Floods are meteorologically caused by weather phenomena and events. These events often deliver more precipitation to a drainage basin than can be readily absorbed or stored within the basin. On February, 2000 torrential rains and the water from dams that collapsed or their sluice gates opened, hit the Limpopo province resulting in flash floods that wrecked havoc in the province. The kinds of weather phenomena and events that cause floods in the province include a combination 
of the effects of El Nino/La Nina (ENSO phenomena), tropical cyclones, cut-off lows and the Intertropical Convergence Zone (Triegaardt et al., 1988; Kabanda, 2004). The Inter Tropical Convergence Zone (ITCZ) is situated close to the equator and is identified by massive rain bearing clouds that form during the convergence of the South East Trade Wind and the North East Monsoon Winds (Crimp et al., 1997). The ITCZ changes position during the year, moving between the Equator and the Tropic of Capricorn. Its southward movement usually marks the beginning of a rainy season (Taljaard, 1994). In summer the ITCZ is identified by large convective cloud structures, moves southwards to approximately $17^{\circ} \mathrm{S}$ (Taljaard, 1994) bringing tropical weather to South Africa's northern regions. Karoly \& Vincent (1998) suggested that during this time of the year tropical weather systems invade Southern Africa in the form of tropical cyclones, tropical lows and easterly waves.

In February 2000, it was tropical cyclone Eline that caused heavy continuous rains. In the lowveld areas about $200 \mathrm{~mm}$ of rain fell within forty-eight hours (de Villiers, 2000; (Khandlhela \& May, 2006). Heavy rains continued throughout the following week in most parts of the Limpopo Province as cyclone Eline continues to approach the province (see Figure 3.7). This is unusual as compared to the annual average of less than $400 \mathrm{~mm}$ in the Limpopo Province. The high rainfall caused flooding in most parts of South Africa, but the most affected area was the Limpopo Province that witnessed disastrous flooding particularly, the Thulamela municipality in the Vhembe District. Milaboni and Dzingahe villages were within the eye of Tropical Cyclone Eline which also caused flooding in Mozambique. Further intermittent heavy rains which caused damage to public infrastructure and houses fell during March 2000. Heavy rains caused the water levels in Vondo, Funduzi, Damani and Makuleke dams to rise to a dangerous level and Thulamela authorities were forced to open flood gates to prevent dams from bursting.

Reports from the South African Weather Service and print media estimated the flood damage in the province at one billion Rand (US\$165m) ${ }^{6}$. According to this report, nearly

\footnotetext{
${ }^{6}$ Sowetan, 18 February, 2000; Mail and Guardian, 10 February, 2000.
} 
R880 million was required just to repair roads, bridges and drainage systems. It was also estimated that almost 120000 families in the Limpopo Province were in short supply of food stuffs (Agricultural News, 2000). Most of the commercial farmers have lost more than $50 \%$ of the crops that were destined for export (ibid.). Limpopo floods damaged property, disrupted social interaction, health care facilities and caused considerable damage to the environment in terms of soil erosion.

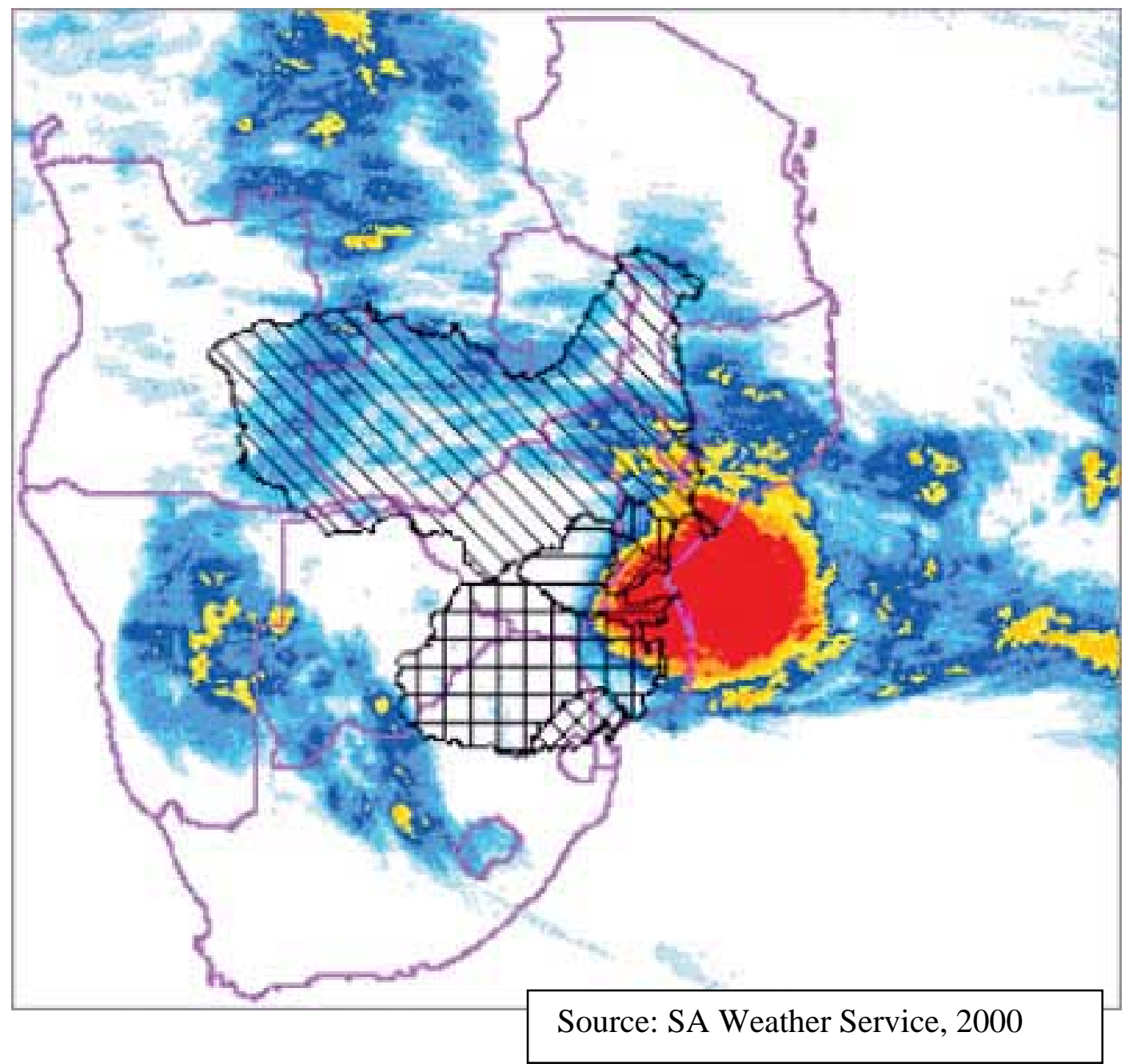

Figure 3.7: Cyclone Eline approaches the Limpopo Province in February 2000 
At Dzingahe village agricultural crops such as maize and ground nuts which were grown along the river were washed away by floods in March 2000. Figure 3.8 shows the devastating of floods near Dzingahe village. A gas/petrol station was damaged by floods when Mutshindudi River which was rechannelled during road construction, reverted to its original course.

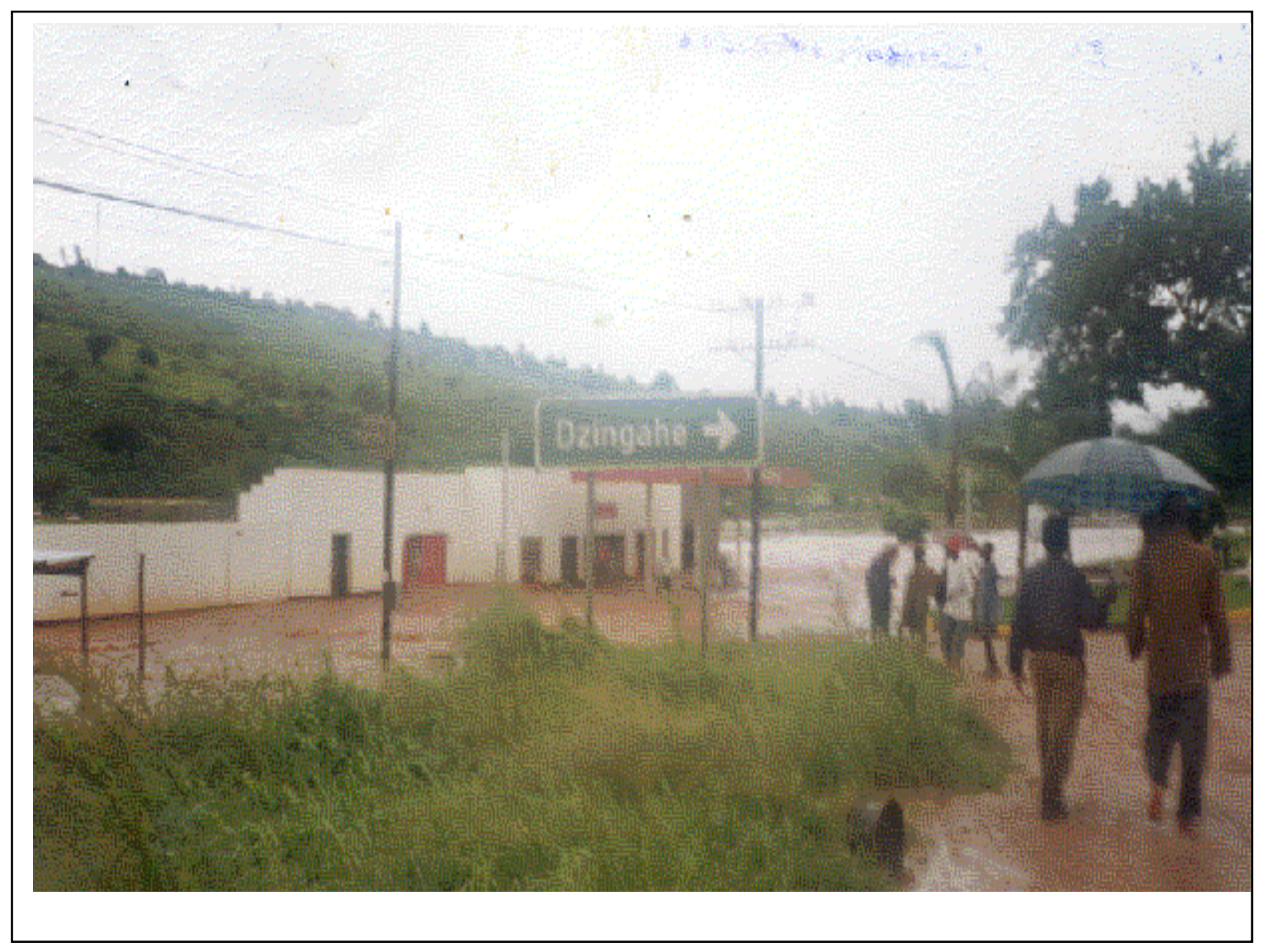

Figure 3.8: Flood inundated Petrol/Gas Station near Dzingahe junction (March 2000) 
Other businesses in the village sustained significant physical damage as well the washing away of mini buses (taxis) that were parked at the gas station. Estimates vary on the number of homes flooded and families impacted by floods at the village. Milaboni village was cut off and remained without water when basic infrastructure such as roads and water pipes were destroyed in 2000. Figure 3.9 illustrates the disruption of spatial interaction and connectivity between Thohoyandou and the surrounding areas of Levubu, Elim, Vleifontein, Bandelierkop, Makhado, Nzhelele, Waterpoort and Musina.

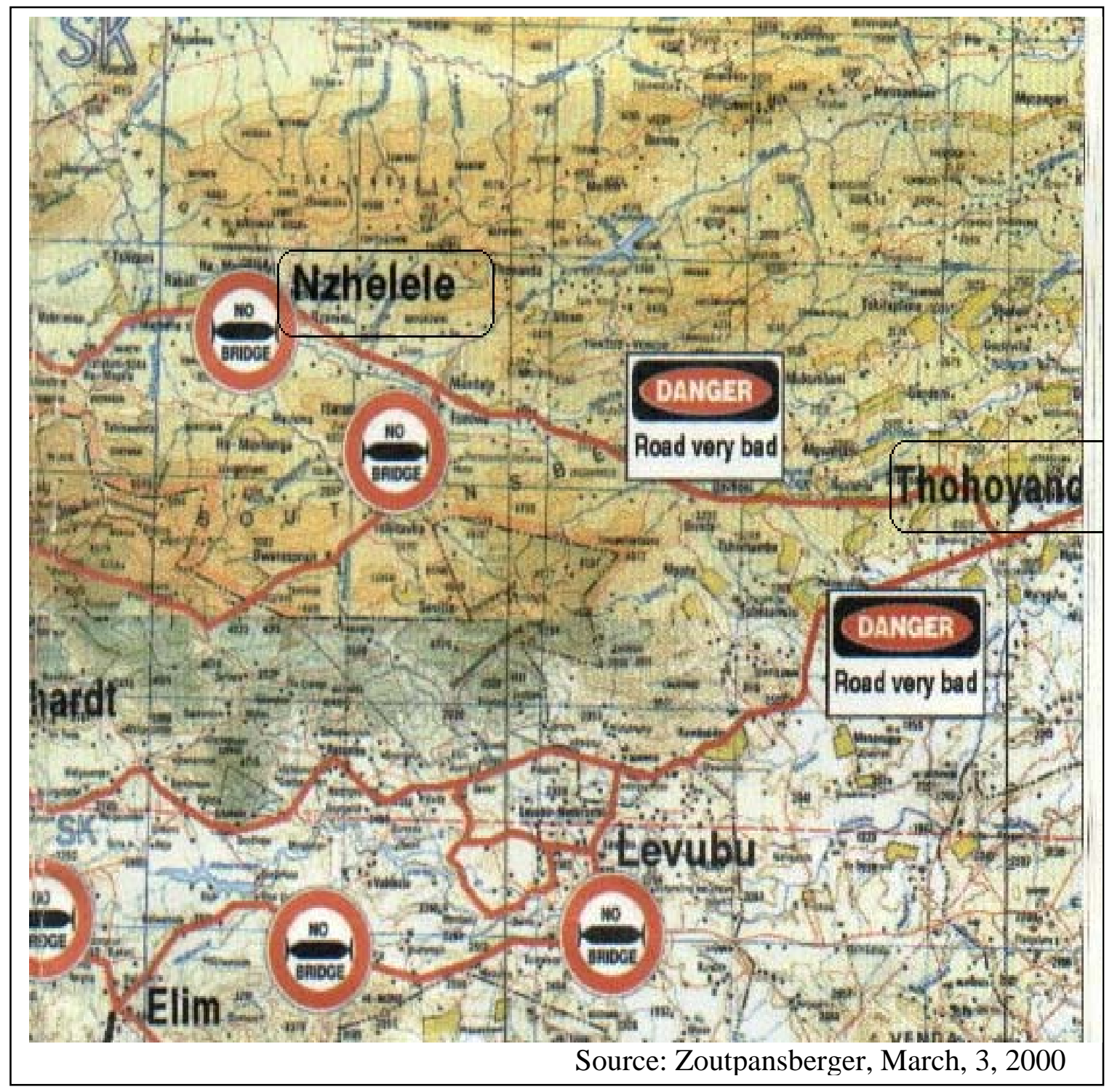

Figure 3.9: Roads damaged and bridges washed away by 'great floods' of 2000 
The roads linking these places were eroded and bridges washed away. The major cause of bridges being washed away was the effect of a bad drainage around the bridge or the bridge may have not been constructed properly. The accumulation of debris, collected by flooding rivers, in front of the bridge openings was the other cause of bridge damage. In Nzhelele area where Milaboni is located, the community had to construct a makeshift bridge to cross over the Nzhelele River (Figure 3.10). It was reported in Zoutpansberger (March 3, 2000:1) that "from dusk to dawn, hundreds of people from all over Nzhelele area form long lines on both sides of the damaged Nzhelele bridge where they take turns in crossing the makeshift bridge".

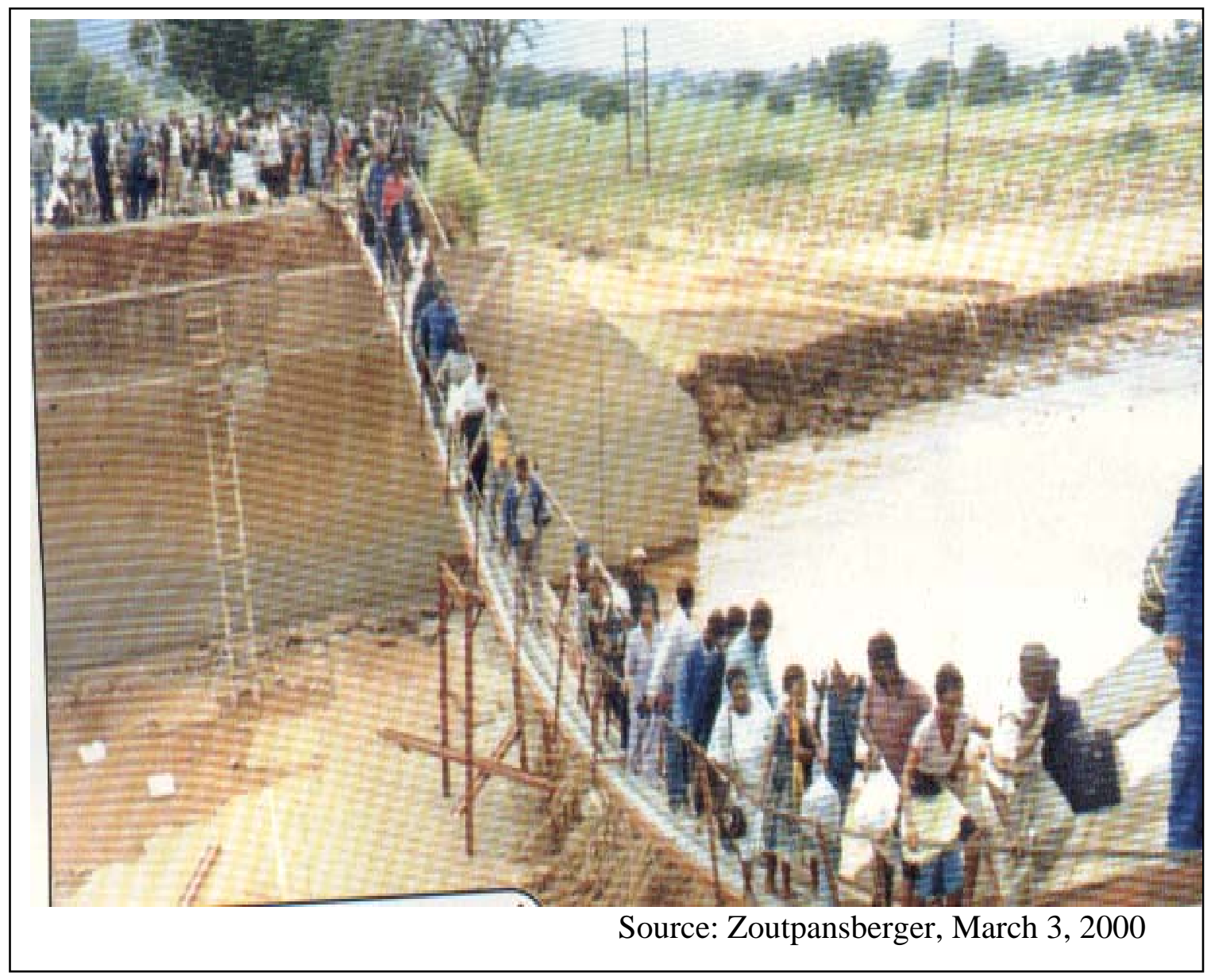

Figure 3.10: People crossing the damaged Nzhelele Bridge using the makeshift bridge 
The damage to the roads and bridges has resulted in severe disruptions to the social and economic activities of the people in the two study sites and the municipality as a whole. This has had serious consequences for economic development at the district and the provincial levels.

\subsection{Conclusion}

This chapter introduced the context of the study within Limpopo Province of South Africa which supports the view that flood hazards are socially constructed and that an interaction of physical and social processes defines vulnerable people and the spatial location of flood impacts. In South Africa, the geography of apartheid has expressed itself (though in complex ways) through environmental degradation, landlessness, unemployment and poor sanitation. Political, historical and economic as well as ecological processes have for so long made people vulnerable both at the provincial, municipal and local levels. Export orientated economy, commercial logging (forest policy) and coffee plantations have created deforestation and consequently make majority of people landless. Political ecology provides concepts of power, agency, scale, environment, which are useful in the analysis of vulnerability in South Africa and the Limpopo Province. 


\section{CHAPTER 4}

\section{Research Questions, Methodology and Methods}

\subsection{Research Questions}

This research integrates Participatory Geographic Information Systems and political ecology to study social and spatial differentiation of flood vulnerability in the Thulamela municipality of South Africa’s Limpopo Province. PGIS is a methodological approach embedded within a GIS and society conceptual framework. Within this context, flood hazards are socially constructed. This research seeks answers to four core questions:

\section{Question 1: What are the major historical and contemporary household flood coping strategies in the study area sites?}

This question concerns key historical and contemporary household flood coping strategies in order to highlight how these strategies shape our understanding of differential flood vulnerability in general and household flood coping mechanisms in particular. Ecological, socio-economic and cultural factors influencing the choice of a particular strategy are examined.

\section{Question 2: How and why have historical household flood coping strategies changed?}

This question provides a historical analysis of how household flood coping strategies evolved and the consequent emergence of contemporary flood coping strategies. The assumption here is that as household flood vulnerability changes the nature of flood coping strategies also change. Similarly, shifts in the physical, socio-economic and cultural factors shaping particular coping strategies, are likely to cause significant changes in household flood vulnerability. 


\section{Question 3: What are the factors that have produced differential household flood vulnerability in the study area sites?}

Flood vulnerability varies over space, time and among groups of people depending on both the physical exposure and human-environmental characteristics of a household (e.g. coping capacity). This question therefore, examines physical and human factors as key determinants of differential flood vulnerability. There has been an increasing recognition of the need to understand the nature of human resource systems, institutional structures and changes in the physical environment as critical factors that produce differential household flood vulnerability. For example, the interaction of the human factors and the physical factors such as rainfall patterns, hydrology, geology, and soil characteristics might increase flood vulnerability at the household level. Changes in the physical environment brought about by land use activities such as grazing, cultivation and building, become very important. In other words, socio-economic conditions of households interacting with physical factors produce flood vulnerability.

Similarly, the role of social networks, institutions and organizations become critical in influencing community's ability to cope with floods since such interventions measure social capital that is or not available to such a community. People's coping capacity determines their ability to recover and rebuild their lives after flood disasters.

\section{Question 4: How does a Participatory GIS methodology contribute to a political ecology analysis of flood vulnerability?}

This question involves the role of PGIS and political ecology in locating and understanding flood vulnerability in the study area. PGIS with its participatory dimension provides an opportunity for local communities to voice and document their experiences and knowledges about flood vulnerability in their area. Political ecology offers historical and contemporary analyses of social and power relations that produce differential flood vulnerability. PGIS provides an opportunity for local representations of power, politics and resource management in the study area. Communities have a clear understanding of 
social and economic factors that influenced a change in flood coping mechanisms. Hence, their perspectives are important for flood vulnerability assessment. The following issues drawn on local knowledge demonstrated PGIS contribution to a political ecology analysis of flood vulnerability:

- $\quad$ PGIS representation through mental mapping, of historical geography of forced removals and contested spaces within the two communities;

- $\quad$ Mental mapping of flood-prone areas; and

- Community resource mapping of historical and contemporary resource access and distribution.

These conceptual issues are not exhaustive of PGIS contribution to political ecology analysis of flood vulnerability. Nevertheless, they represent an important contribution towards the integration of local and expert knowledges for vulnerability analysis. PGIS in this context offers opportunities for communities to generate and document local knowledge about flood vulnerability.

The four core research questions identified above capture the research problem of this study. By developing a greater understanding of changing household coping strategies and mapping communities' perceptions of critical forces that have produced flood vulnerability, there is potential to understand differential nature of flood vulnerability in the study area. Local knowledge could augment "expert” knowledge about flood vulnerability for complementary outcomes. Furthermore such integration could promote the development of flood mitigation strategies based on the integration of local and other types of knowledges. Flood coping mechanisms might incorporate such strategies within an overall livelihood strategy. The integration of PGIS with political ecology provides insight on differential flood vulnerability and some guidelines towards the development of appropriate flood mitigation policies for the municipality and the province as a whole. 


\subsection{Research Methodology}

To answer the research questions identified above, this study employs a triangulation of methods within a participatory GIS methodology and a political ecology conceptual framework. As a research methodology, PGIS promotes the use of a variety of quantitative and qualitative methods with an emphasis on active involvement of research participants. The main goal of the study is to examine differential social and spatial flood vulnerability and how to represent this in a PGIS. Therefore, PGIS is employed within the context of political ecology and has offered fresh perspectives in terms of addressing the limitations of traditional GIS and the conventional approach to flood vulnerability assessment. In order to address social and spatial differentiation, challenges pertaining to the setting up of a PGIS, how participants are accessed and chosen and maintaining a good rapport with research participants, become very important methodological issues.

\subsubsection{Setting up a PGIS in the Study Area}

\subsubsection{Conceptual Approach}

Conceptually, the general approach for setting up a PGIS begins with the choice of an appropriate model for its implementation and the identification of the users within a participant community. The choice of an appropriate model depends on the both the socio-economic and political conditions prevailing in the target community. Leitner et al. (2002:41) identified six models for making PGIS available to communities. These are:

- $\quad$ Community-based GIS;

- $\quad$ University-community partnerships;

- GIS facilities in universities and public libraries;

- Map Rooms;

- Internet Map Servers; and

- $\quad$ Neighborhood GIS center. 
Models for implementing PGIS in developing regions and Africa in particular, should consider the effects of PGIS on other cultural systems that produce geographic knowledge and should consequently be adapted to local cultural, political and economic African context (Rundstrom, 1995). In addition, certain models of PGIS implementation do not take into account cultural contexts and as such they promote epistemological assimilation as an essential tool for destroying indigenous culture and ways of knowing (ibid.). Although community-based (in-house) PGIS can be tailored to local needs and made available directly to communities, difficulties in raising funds and long-term maintenance of PGIS due to monetary problems and community skills, rule this out as an appropriate model for PGIS implementation in South African rural areas.

Against this background, a University Community partnership is an appropriate model for implementing PGIS in the study area. The socio-economic, political and environmental context in the Limpopo Province and the study area supports this as an appropriate model for three main reasons. First, South Africa's apartheid geography has created economic and political disparities that make it difficult for the majority of poor rural communities to be effectively involved in spatial decision-making processes (Harris, et al., 1995). Hence, poor rural communities would need comprehensive PGIS training to be able to manage an in-house PGIS project. In addition, projected costs of procuring PGIS equipment, software, data and training would make it virtually impossible for these poor communities to run an in-house community PGIS. Second, the social positioning (through gender, class, ethnicity and race) of individuals and households in the Limpopo Province has created limited access to resources for survival and hence, the in-house option of PGIS technology is not appropriate in terms of such poor communities being able to afford and maintain it. Finally, the University of Venda can utilize some of its links already forged with its neighboring communities to implement the University Community partnership model. This study therefore presents an initial attempt to practically foster this partnership. However, the meaningful implementation of this partnership would require more support and planning than could be achieved during the duration of this research. Follow-up mechanisms need to be made with the affected communities in future. 


\subsubsection{Methodological Approach}

Methodologically, setting up a PGIS in the study area sites has involved several steps such as problem definition, data requirement and the conceptual implementation of the cartographic model. These steps are described below.

\subsection{Problem Definition}

The development of a PGIS database demonstrates how PGIS integrates local community perceptions and experiences (i.e. local knowledge) with traditional GIS data to understand differential social and spatial flood vulnerability. This problem is broken down into a series of tasks to be executed in a PGIS environment. These are:

- $\quad$ Mental mapping of dynamic pressures (e.g. forced removals);

- $\quad$ Cognitive mapping of contested spaces;

- Mental mapping of flood-prone areas;

- Mapping historical resource access, distribution and compare with current spatial strategies;

- $\quad$ Mapping of geographic space and analyzing land use patterns; and;

- Characterization and mapping of households based on the socio-economic data to identify households at flood risk; 


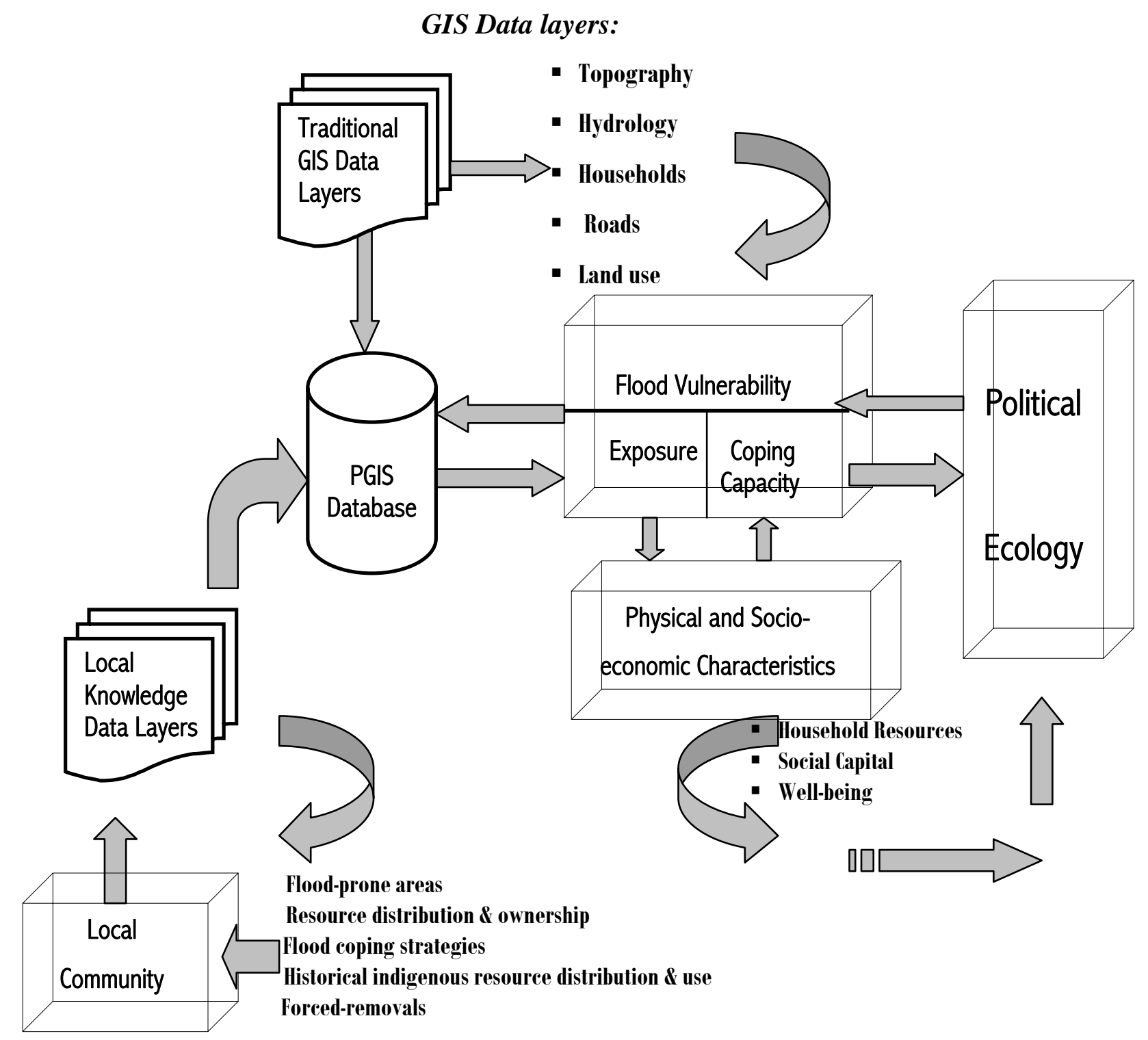

Figure 4.1: PGIS and political ecology integration model for differential social and spatial flood vulnerability. 


\subsection{Data Requirements}

The review of existing digital data sets for incorporation within the proposed GIS is a first step towards database development. Quantitative data requirements included household survey and GIS data layers such elevation, geology, rainfall, rivers, dams, roads, land use/cover, physical/social infrastructure and the year 2000 flood damage data. These data sets were obtained from the Department of Water Affairs in Polokwane South Africa. Qualitative data collected from interviews, archival searches, focus group discussions and mental maps are also important data sets for this project. A combination of qualitative and quantitative data sets has populated the PGIS database for this research.

\subsection{Cartographic model}

A cartographic model is defined as a step-by step flow diagram, which basically organizes the data inside an information system. Its main purpose is to identify data required for a GIS study to organize the analytical procedures that are performed. Figure 4.1 is a cartographic model showing an integration of PGIS and political ecology for flood vulnerability analysis.

\subsubsection{Study Sites and Means of Access}

Fieldwork was conducted for a period of nine months from August 2005 to April 2006 within the communities of the two identified study sites (see Figures $3.1 \mathrm{a}$; b). Access to Milaboni and Dzingahe villages was gained via the Civic organization and the local headman. Research assistants from these two villages facilitated access and consequently permission was granted to administer a household survey, individual interviews, focus group discussions and mental mapping workshops.

A case study approach was used to explore differential social and spatial flood vulnerability among two communities in the study area. Participatory approaches inherent in a PGIS framework were employed to reveal people's perceptions and 
experiences about floods --- their coping strategies and how they changed over time. Central to this research is an examination of differential social and spatial flood vulnerability, which reflects the impact of colonial and apartheid policies in South Africa and post-apartheid landscape changes. The nature of differential flood vulnerability currently poses several economic, social and political questions with regard to the problem of floods in the study area.

\subsubsection{Context, Population Identification and Sampling procedures}

Thulamela municipality in the Limpopo Province provides an ideal context for a study about flood vulnerability, especially examining the impact of apartheid geographies on differential social and spatial vulnerability to floods. Floods devastated the municipality and the province in the year 2000. The nature of devastation in the municipality provided an important rationale for the choice of this study area. Similarly, historical processes such as colonialism and apartheid at the study area sites also make them ideal for this research.

The basic tenet of the concept of social differentiation is that a community is not homogenous (Bob, 1997). In terms of gender, women`s experiences and perceptions of flooding might differ from those of men not because of an essentialist conception of gender differences but because women have restricted access to a range of opportunities from paid employment to services (McCusker \& Oberhauser, 2006). Their access to land is achieved through their husbands (Levin \& Weiner, 1997). These characteristics make them more vulnerable to floods. Hence, in choosing research participants, the focus was not on the local communities as a group but in different social groups and sub-groups that comprise it. In addition, to intra-household and village scale, the primary unit of analysis was the household head in the two study sites surveyed. This provided a household perspective regarding hardships, coping capacity and experiences of those impacted by flooding. Mental mapping workshops were conducted at the village level while intrahousehold scale provided gender dynamics of flood vulnerability. The primary household survey provided a snapshot of the overall community socio-economic profile, flood 
coping strategies and vulnerability. Individual interviews with key informants and focus group discussions provided a platform where historical processes and structures (social, cultural, economic, political and environmental) that have produced and maintained flood vulnerability are deliberated upon.

The population in this study included all households at Milaboni and Dzingahe villages. Apart from households in these two communities, local government structures also formed a vital part of the population that was surveyed. The sample of the study was selected randomly and purposively from the population specified above to include thirty households in each village (a total of 60), a group of ten individuals from each village (a total of 20), six elderly key respondents and two senior officials from Thulamela municipality, disaster management center. All the sixty household dwelling points were collected with a GPS in order to know the location of each household that was interviewed so that information from the survey could be attached to these shape files as attribute tables.

Both snowball and random sampling methods were employed in two different contexts. Snowball sampling, being non probabilistic offers a practical advantage for gaining access to research subjects that may otherwise be difficult to access (Hendricks et al., 1992). This type of sampling was used to select key elderly informants who were knowledgeable about the history of flooding in both villages. The snowball sampling method has been used to identify the elderly key respondents who provided information on flood prone areas, historical flood coping strategies and historical forces enhancing flood vulnerability. These issues were also the subject matter for individual interviews and focus group discussions.

Random sampling on the other hand, was applied when a sample of the household survey was made. This form of sampling ensured that the population had an equal opportunity to appear in the sample. In addition, random sampling is one of the requirements for a Chi square statistical analysis which was used to measure socio-economic differentiation of household flood vulnerability. Chi square analysis was also used to test the statistical 
significance of the results reported in bivariate tables (crosstabs) about household differentiation in flood coping strategies and coping capacity. The snowball sampling procedure has allowed some flexibility in selecting the research subjects while random sampling has provided some form of generalizing from samples to populations in both villages.

\subsection{Research Methods}

\subsubsection{Methods for Data Collection}

A variety of qualitative and quantitative research methods were used to elicit primary and secondary data, and were guided by the PGIS methodology. Table 4.1 provides an integration of research questions, research activity and data collection methods. Five data collection methods used in this research are:

- $\quad$ Literature / Archival search;

- $\quad$ Existing Socio-economic Survey;

- $\quad$ Household Survey;

- Individual interviews, GPS transect walks and Participant Observation;

- $\quad$ Focus Group Discussions and Participatory mental mapping.

- Geographic Information Systems

The section below describes how these methods were used in this research.

\subsubsection{Literature / Archival Search}

A literature survey in the form of books and research journals has contributed criteria for identifying flood zones and conceptual understandings of flood coping strategies, role of institutions during flooding and the theoretical background on the role of socio-economic and political factors in flood vulnerability assessment. 
Table 4.1: Summary of research questions, tasks, variables and data collection methods

\begin{tabular}{|c|c|c|c|}
\hline RESEARCH QUESTIONS & RESEARCH TASKS & VARIABLES & DATA COLLECTION METHOIDS \\
\hline $\begin{array}{l}\text { 1. What are the major } \\
\text { historical and } \\
\text { current } \\
\text { household flood coping } \\
\text { strategies? }\end{array}$ & $\begin{array}{l}\text { - Identify key historical and current } \\
\text { household flood coping strategies. } \\
\text { - Explain different factors influencing } \\
\text { the choice of a particular strategy. }\end{array}$ & $\begin{array}{l}\text { - Household flood } \\
\text { coping strategies } \\
\text { - Measuring differential } \\
\text { forms of coping with } \\
\text { flood:- (gender, age, } \\
\text { income, employment, } \\
\text { assets, health, } \\
\text { education }\end{array}$ & $\begin{array}{ll}\text { - } & \text { Household Survey. } \\
\text { - } & \text { Focus Group Discussions } \\
\text { - } & \text { (FGDs). } \\
\text { - } & \text { Interviews with key } \\
\text { - } & \text { informants. } \\
\text { - } & \text { Literature. } \\
& \text { Newspapers }\end{array}$ \\
\hline $\begin{array}{l}\text { 2. How and why have these } \\
\text { household flood coping } \\
\text { strategies changed? }\end{array}$ & $\begin{array}{l}\text { - Explain change in flood coping } \\
\text { strategies by comparing household } \\
\text { flood coping strategies for two study } \\
\text { sites. } \\
\text { - } \quad \text { Relate change in household flood } \\
\text { coping strategies to the physical } \\
\text { and social environment. } \\
\text { Map change in flood coping } \\
\text { mechanisms. }\end{array}$ & $\begin{array}{l}\text { - Agents of change in } \\
\text { flood coping strategies:- } \\
\text { - apartheid spatial } \\
\text { planning; } \\
\text { - commercialization } \\
\text { of social capital; } \\
\text { - integration of local } \\
\text { knowledge with } \\
\text { other knowledges }\end{array}$ & $\begin{array}{ll}\text { - } & \text { Household Survey. } \\
\text { - } & \text { FGDs } \\
\text { - } & \text { Interviews with key } \\
\text { - } & \text { informants } \\
\text { - Literature }\end{array}$ \\
\hline $\begin{array}{l}\text { 3. What are the factors that } \\
\text { have produced differential } \\
\text { household flood } \\
\text { vulnerability? }\end{array}$ & $\begin{array}{l}\text { - Examine and analyze both physical } \\
\text { and human factors that have } \\
\text { produced differential flood } \\
\text { vulnerability. } \\
\text { - Mapping of physical components of } \\
\text { vulnerability (topography- drainage, } \\
\text { elevation and aspect), rainfall, } \\
\text { hydrology, soils and land cover and } \\
\text { natural resource endowment). } \\
\text { Mapping of household components } \\
\text { of flood vulnerability: } \\
\text { - household resources/ } \\
\text { - livelihood resilience; } \\
\text { - } \quad \text { well / societal protection; } \\
\text { - } \quad \text { social capital. } \\
\text { Mapping of historical and current use } \\
\text { of natural resource, access and } \\
\text { ownership as indicators of flood } \\
\text { vulnerability; } \\
\text { Construct a composite map of } \\
\text { physical and human components of } \\
\text { vulnerability. }\end{array}$ & $\begin{array}{l}\text { - Topography, soil } \\
\text { properties, hydrology; } \\
\text { land cover } \\
\text { - } \quad \text { Land-use activities } \\
\text { - Household } \\
\text { resources:- } \\
\text { - Economic \& } \\
\text { material and } \\
\text { Human and } \\
\text { personal } \\
\text { - Family \& social } \\
\text { (social capital) } \\
\text { - Institutional } \\
\text { - Political } \\
\text { - Location of home and } \\
\text { livelihood } \\
\text { - Housing Quality } \\
\text { Index } \\
\text { - Initial well-being - } \\
\text { physical \& mental } \\
\text { health (proxy for } \\
\text { capacity for self- } \\
\text { reliance) }\end{array}$ & $\begin{array}{ll}\text { - } & \text { GIS data (elevation, } \\
\text { - } & \text { drainage \& land-use) } \\
\text { - } & \text { Digital Elevation Models } \\
\text { (DEMs) } \\
\text { - } \quad \text { Satellite imagery } \\
\text { - } \quad \text { Photographs } \\
\text { - } \quad \text { Household Survey } \\
\text { - } \quad \text { FGDs } \\
\text { - } \quad \text { Participant Observation } \\
\text { - } \quad \text { GIS data (socio economic } \\
\text { - } \quad \text { and infrastructure) } \\
\text { Socio-economic survey } \\
\text { (Statistics South Africa, } \\
\text { Census 2001) }\end{array}$ \\
\hline $\begin{array}{l}\text { 4. How does a PGIS } \\
\text { methodology contribute to a } \\
\text { political ecology analysis of } \\
\text { flood vulnerability? }\end{array}$ & $\begin{array}{l}\text { - Mental mapping of:- } \\
\text { - } \quad \text { forced removals and } \\
\text { contested spaces; } \\
\text { - } \quad \text { flood-prone areas; } \\
\text { - } \quad \text { natural resource use \& } \\
\text { ownership. }\end{array}$ & $\begin{array}{l}\text { - Historical processes } \\
\quad \text { of:- } \\
\text { - Forced removals } \\
\text { - Betterment } \\
\quad \text { planning } \\
\text { - } \text { Flood-prone areas } \\
\text { - } \quad \text { Resource use \& } \\
\text { ownership. }\end{array}$ & $\begin{array}{ll}\text { - } & \text { FGDs / Mental Mapping } \\
& \text { Workshop } \\
\text { - } & \text { PGIS } \\
\text { - } & \text { GPS transect walks } \\
\text { - } & \text { GIS data and Cartographic } \\
& \text { model. }\end{array}$ \\
\hline
\end{tabular}


The archival search of year 2000 newspaper editions of the Zoutpansberger, Sowetan and Mail and Guardian also provided historical flood data and experiences of floods during February to March 2000. This period is consistent with the flood disasters that hit the Limpopo Province. These newspapers were chosen because they often report the majority of local news in the study area. These newspaper articles initiated focus group discussions in the study sites.

\subsubsection{Existing Socio-economic Survey}

A thorough understanding and evaluation of the demographics of vulnerable people and other socio-economic characteristics (e.g. poverty levels, per capita income, literacy, and population density) is imperative to evaluate spatial and social differentiation of flood vulnerability. Similarly, insight into the services and infrastructure that communities have access to is also significant. At the municipality level, the database that was used to evaluate the communities' socio-economic characteristics is the government socioeconomic database. This was accessed from the South African Census conducted in 2001,

provided by Statistics South Africa. Socio-economic survey from Census 2001 was an excellent source of socio-economic data that provided the context of this study. However, socio-economic data particular to households in the study sites were not part of the Census 2001 database and these were obtained through household survey.

\subsubsection{Household Survey}

Flood vulnerability is differentiated according to social, economic and physical factors. As a function of coping capacity, flood vulnerability also reflects gender differentiation within a household. Hence, an intra household perspective is useful to understand a full range of vulnerability indicators such as gender, class, income, house value and size and power relation within the community and household. Thus, a socio-economic household survey was administered to a total of 60 randomly selected households, 30 in each of the two villages (Milaboni and Dzingahe) [see Appendix B for a survey]. In administering the survey, the head of household was requested to participate. Defining household and 
household headship has always been problematic during household surveys. A household is defined in this research as a unit consisting of one person or a group of people who usually live in the same dwelling and make common provision for living essentials. Some researchers have defined headship based on socio-economic parameters such income share, authority and age (Schultz, 1995). Varley (1996) has contested the economic definitions of headship in that they are not better than those based on cultural parameters. In this research, headship is self-defined by respondents rather than by objective criteria. This form of definition is supported by Posel (2001) who asserted that in South Africa subjective criteria determines householders in surveys. The conventional definition which normally assigns headship to a senior male becomes problematic in situations where men migrate to urban areas and women are left with all the social and economic responsibilities of the household.

The survey provided the demographic and socio-economic profile of the households. It also measured the household flood coping capacity, which is a function of household's income-generating ability, access to natural resources (e.g. land, water and wood), housing quality index, and household assets. The asset status of the head of households was used to measure social differentiation (see Table 4.1).

\subsubsection{Individual Interviews, GPS transect walks and Participant Observation}

Merriam (1991:72) defines an interview as the "conversation with a purpose that is necessary when we cannot observe behavior, feelings, or how people interpret the world around them. It is also necessary to interview when we are interested in past events that are impossible to replicate”. In this study, flexibly structured interviews were conducted with three elders in each village (six in total) and two senior municipal officials as the key research informants. Flexibly structured interviews were used to enhance flexibility in terms of questioning which elicited information about flood experiences, coping strategies and overall causes of flooding. More importantly, it allowed for some exploratory data collection. With the exception of government officials, the key 
informants were identified through snowball sampling procedure during focus group discussions.

Individual interviews also provided key historical flood coping strategies, historical socio-economic and political forces enhancing flood vulnerability, and perceptions of flood prone areas. They were also helpful in delineating areas of historical resource management whose demarcation was done during GPS transect walks with these key research participants (i.e. elders). The demarcated areas in both villages were then overlaid on the respective base maps provided during FGDs. Lastly, the transect walks also provided information on the physical characteristics and human activity profile of the study sites.

Participant observation and orthophoto interpretation also played a very important part of data collection, particularly with regard to qualitative assessment of the physical landscape characteristics and the human activity profile of the broad flood plains of the study area sites. The spatial information about historical resource management was compared with information from mental map workshops and focus group discussions. This information was in turn compared with contemporary resource management strategies in the area. Interviews conducted with key informants and administered household survey documented issues of flood risk perceptions, experiences and key historical and contemporary flood coping mechanisms.

\subsubsection{Focus Group Discussions (FGDs) and Participatory Mental Mapping}

Focus group discussions involve "a small group of people discussing a topic or issues defined by a researcher" (Cameroon, 2000:84; 2005:116). In this research, focus group discussions (FGDs) were conducted in three sessions that lasted between one and two hours. Each session was tape-recorded and participants (with their permission) were photographed. In contrast to the interview method, interaction between members of the group is one of the main strengths of this method (Cameroon, 2005). FGDs elicited information about people's coping strategies and capacity, role of social networks, 
institutions and organizations of community's ability to cope with floods. The other strength of focus group discussion is that it permitted individuals to challenge the interpretation or assumption of other group members (ibid.). This characteristic is very important in this context, because patriarchy dominates social relations.

Participatory mental mapping and spatially encoded surveys were used to incorporate social and spatial differentiation into a PGIS database. These methods are said in the literature to minimize inherent power relations and structural knowledge distortion by involving local communities in GIS knowledge production, representation and use (Harris \& Weiner, 2002). Participatory mental mapping workshops involved three tasks:

- Task 1 entailed the mapping of areas in the study sites that are prone to floods (e.g. proximity to flood plains, etc.). A small group of four or five men and women carried out this task, together in each of the two study sites.

- Task 2 involved mapping dynamic pressures particularly forced removals and contested spaces in order to make sense of flood vulnerability issues affecting their lives.

- Task 3 involved mapping of historical and contemporary resource access and ownership. The exercise was to document where the people used to get resources such as wood, water and wild vegetables before and where they get them now. Identifying what and where resources exist, who has access to such resources, and who controls them, is important for capacity building and for planning flood vulnerability reduction strategies.

In all these situations, a 1:10 000 digital Orthophoto image (year 2004) of the respective villages and relevant GIS data layers prepared in advance, were provided to each group in Dzingahe and Milaboni villages. Digital Orthophoto images were used rather than a 1:50 000 topographic maps because they are a photographic image of the terrain - but more importantly, they are relatively true to scale and therefore accurate distances and areas can be measured. Training in map reading skills was also conducted with the participants 
to put them at ease when working with maps. Mental maps generated from the workshops were geo-referenced and integrated into the PGIS database.

\subsubsection{Geographic Information Systems}

The use of GIS in this research is consistent with the PGIS methodology within a political ecology framework to study flood vulnerability. As discussed in the literature review, flood hazards occur in social, political and economic space as well as in geographic space. These four dimensions are used to define flood vulnerability in the study sites. Thus, the power of GIS in this dissertation research has been its ability to bridge types of data sets associated with these dimensions, by incorporating not only the traditional "expert” data sets, but also the so-called "layman” subjective mental maps. In order to accomplish this task, GIS has captured, organized and managed conventional data sets such as elevation, drainage, land-use and socio-economic data which were colleted through the household survey. Orthophotos (1:10 000), of Dzingahe and Milaboni villages, elevation, road and drainage data have been acquired by mail from the Chief Directorate: Surveys and Mapping, in Mowbray, Cape Town. Land use data were digitized from the orthophoto of Dzingahe and Milaboni villages obtained from Statistics South Africa's map server through ArcIMS. Mental maps from the community workshops were geo-referenced and integrated into a PGIS database.

On the basis of mental maps and ground inspection, physical flood vulnerability surfaces for both villages were created using 3D Analyst Raster Interpolation function of ArcGIS. This together with proximity analysis created surfaces that were then populated with households and other land use data to identify elements at risk. Surveyed households were further characterized on the basis of socio-economic information acquired through the household survey. These socio-economic vulnerability indicators such as access to income, housing conditions and land are cast in spatial context, by linking them with household data points colleted through Global Positioning Systems. House quality index (HQI) was used to assess housing conditions of the households in both villages. Similarly, socio-economic capacity was also measured using the household survey. 
Vulnerability is also a function of power hierarchies within the social, political and economic spheres, and not merely proximity to flood zones. These power hierarchies expressed through local politics were represented in terms of the mental maps of contested spaces pertaining to the way in which tribal authorities fragment a village to belong to two contesting power authorities. For example, at Dzingahe village, there is Dzingahe that falls under the jurisdiction of chief Tshivhase and the one under Mphaphuli tribal authority. However, power as a variable can only be mapped to the extent that it is manifested in issues of access to wealth, income and resource distribution, ownership and social relations.

The comprehensive data requirements and the cartographic model of populating GIS data in this research are already described elsewhere in this chapter. The model in Figure 4.1 represents an integration of PGIS with political ecology and how the former is populated with traditional and local information data to study social and spatial differentiation of flood vulnerability. Understanding how flood damage correlates not only with proximity to a flood zone such as the floodplain, but also with housing value and size for example, allows us to closely examine the effects of social differentiation on the distribution of flood damage. PGIS allows us to integrate social and geographic data in order to understand social and spatial differentiation of flood vulnerability. Both the conventional GIS and local information data layers came together to constitute a PGIS database. In this case, local knowledge and 'expert' GIS data are brought together to fulfill complementary roles.

\subsubsection{Methods of Data Analysis}

The research design of this study constitutes a triangulation of quantitative and qualitative methods to study social and spatial differentiation of household flood vulnerability. Both research perspectives have generated a lot of raw data sets which were grouped in order to make initial sense of it. Qualitative data sets from individual interviews and focus group discussions were transcribed and transcripts processed in $\mathrm{NVivo}{ }^{7}$ software to

\footnotetext{
${ }^{7}$ A qualitative software package used to code and analyze qualitative data.
} 
identify themes and narratives revolving around research questions as identified in Table 4.1. The collected qualitative data were reported in tabular form, picture and map format, and as narratives to evaluate and interpret the quantitative results. The purpose here was not to generalize from the samples to the population, but to examine how the interviews and focus group discussions inform our understanding of household flood vulnerability.

Quantitatively, the data analysis was done using SPSS. This statistical package was chosen because it is user-friendly, yet powerful and does not have much restricted data management capabilities. Household survey data sets were also presented under major themes as reflected in the questionnaire (see Appendix A). The results were reported as raw data, percentages and were displayed as contingency frequency tables and graphs. Bivariate analysis, statistical significance tests using Chi-square and correlation using Cramer's V were conducted to further analyze quantitative data. A Chi-square is a nonparametric test of statistical significance for bivariate tabular analysis while Cramer's V represents a percentage portion of the total behavior of variables accounted for by Chisquare. This measure implies that there are still undetected variables which account for the remaining percentage.

Qualitative data sets were selectively integrated (as a local information layer) into a PGIS database to set the context for flood vulnerability analysis. These data sets included mental maps about historical processes of forced removals, contested spaces, flood-prone areas, and resource distribution, use and access. Digital orthophotos of year 2004 for both villages were analyzed to uncover physical and social factors that might have produced flood vulnerability in the study sites. Similarly, quantitative data sets from the household survey were linked with the GPS location of the sampled households in the study area villages for further analysis on a DEM surface created from study sites' elevation data. Proximity and overlay analyses on the interpolated three raster surfaces based on three scenarios were conducted. The estimated pixel values and buffer distance for each scenario were informed by local community experiences of historical flood represented in the form of mental maps. Finally, two composite maps of flood vulnerability based on physical and socio-economic parameters are produced for the study sites. 


\section{CHAPTER 5}

\section{A Comparative Analysis of Household Flood Coping Mechanisms}

\subsection{Introduction}

The primary unit of analysis in this dissertation research is the household as a social institution around which members pool their diverse resources together to respond to flood impacts ${ }^{8}$. One of the objectives of this chapter is to identify and review historical and contemporary household flood coping strategies at Milaboni and Dzingahe villages. Household flood coping strategies are mechanisms or means that households use to maintain their diverse livelihoods in times of stress including flood hazards (Ellis, 2000). Householders often deal with such stress within the range of their available resources. As such, households tend to cope with the effects of flooding differently because of their varied levels of coping capacity and resilience (Bovin \& Manger, 1990; Blaikie, 2004).

Thus, a closer analysis of how households in the study area live and maintain their livelihoods is crucial to understanding their differential flood coping mechanisms and vulnerability. Qualitative and quantitative results of this research indicate that household flood coping strategies in the study area have changed and were shaped by factors such as access to (or lack of it) local environmental resources, differential socio-economic characteristics of households, household ecological knowledge, and other types of knowledge and skills. It is important to note that as flood coping strategies change so does the nature and level of flood vulnerability. Flood vulnerability as a function of

\footnotetext{
${ }^{8}$ Resource in this context is used to denote wealth, strength, labor, entrepreneurial skills, knowledge, assets, cultural attributes and household stability (Johnston, et.al., 2000:706)
} 
exposure and household coping capacity is dealt with in greater detail in the next chapters.

This chapter, therefore, aims to comparatively:

- identify and evaluate key historical household flood coping strategies at Milaboni and Dzingahe villages;

- discuss how the historical forms of household flood coping changed and to isolate agents of change; and

- identify and analyze differential current household flood coping strategies at Dzingahe and Milaboni villages based on income, employment type (formal and informal), education and other variables listed in Table 5.7.

\subsection{Historical flood coping mechanisms in the study area}

Households at Dzingahe and Milaboni villages have experienced flooding for a long time. Empirical studies recently conducted continue to confirm that South Africa is prone to flood hazards (Khandlhela \& May, 2006). People in the study sites have differentially experienced and coped with flooding over the years. Individual interviews with the elders together with Focus Group Discussions (FGDs) in the study area indicate that historical forms of flood coping mechanisms have been largely related to the environment. For example, an evacuation to the upland terrain for weeks as a flood coping mechanism had always been related to available and accessible land. In this dissertation research, the term "historical” is preferred to "indigenous" because the latter assumes that knowledge is static while the former is sensitive to constant changes associated with flood coping strategies. Table 5.1 provides a summary of eight historical flood coping strategies identified by the interviews of key informants and FGDs at Milaboni and Dzingahe villages. 
Table 5.1: A Summary of Historical Forms of Flood Coping at Dzingahe and Milaboni Villages

\author{
Change cropping patterns \\ Change eating habits \\ Natural resource extraction ( wild fruit and vegetables) \\ Livestock disposal \\ Consume stored fencing wood \\ Faith in God (Mudzimu/Nwali) \\ Temporary relocation to higher grounds \\ Hanging maize and other household items on trees
}

The 2000 flood disaster and others before, destroyed agricultural crops in the study area villages where riparian cultivation is predominant. In most cases this subjected households to food insecurity for the whole season especially in cases where food surpluses from the previous harvest could not sufficiently sustain households. The situation became acute as precautionary savings in the form of food stocks which were stored in the surface and underground granaries were exposed to flood waters. In the short-term, the head of the household would ensure that food supply is pro-longed by changing the eating behavior of the household. In the long-term the household or the whole village might change the cropping patterns as one of the mechanisms to cope. A change of cropping patterns would involve, for example the planting of flood-resistant crops. In identifying the problem of flood resistant crops, one of the key respondents at Dzingahe village observed: "The problem with planting flood resistant seeds is that it is a short-term solution and that such crops might not survive our soil conditions. People shall not prefer them because they are not the usual staple food" (Individual Interview, October 2005). 
A change in eating habits as another form of household coping occurred when household food security was threatened by the flood crisis. This strategy involved a reduction in the number of meals in a day as well as a limit imposed on the portions at meal times. Adults, especially women used to give up their daily ration to young kids and their husbands. The frequency and the success of this meal skipping strategy was contingent upon the availability of supplements in the form of wild fruits and vegetables. Hence, the change of eating behavior was related to natural resource extraction as a coping strategy. These three interrelated strategies are linked to household food insecurity and were historically shaped by local resource endowments.

The fourth historical flood coping strategy identified was the disposal of assets especially livestock such as chickens, goats and cattle. Livestock disposal was performed according to a particular order. For example, chicken and goats were usually disposed first and cattle later if the household crisis persisted. Asset disposal as a form of coping was shaped by the asset holding capacity of the household. Historically, cattle in these villages were not commonly sold (unless during drought) because wealth and social status were associated with the number of cattle one had. To substantiate this point one respondent in a focus group discussion at Dzingahe village reported: "My relative could walk without shoes or sandals, but he might not sell any cattle to buy them, even when his kraal is full of livestock” (Focus Group Discussion, October 2005). This narrative shows that cattle ownership alone could not in the past guarantee successful recovery from flood impacts. However, this type of thinking has undergone major shifts

The fifth historical coping strategy was the consumption of wood stored in the yard as fencing. In the past, for heating and cooking needs, rural households often consumed wood that was temporarily stored in the yard as a protective fence. Consumption of such fencing wood was done when the gathering of forest woods was not possible, partly because of the regulatory environment in place and because of the flooding river which might make it impossible to cross over to places where wood was available. Figure 5.1 shows how wood resources are normally stored for such contingencies. 


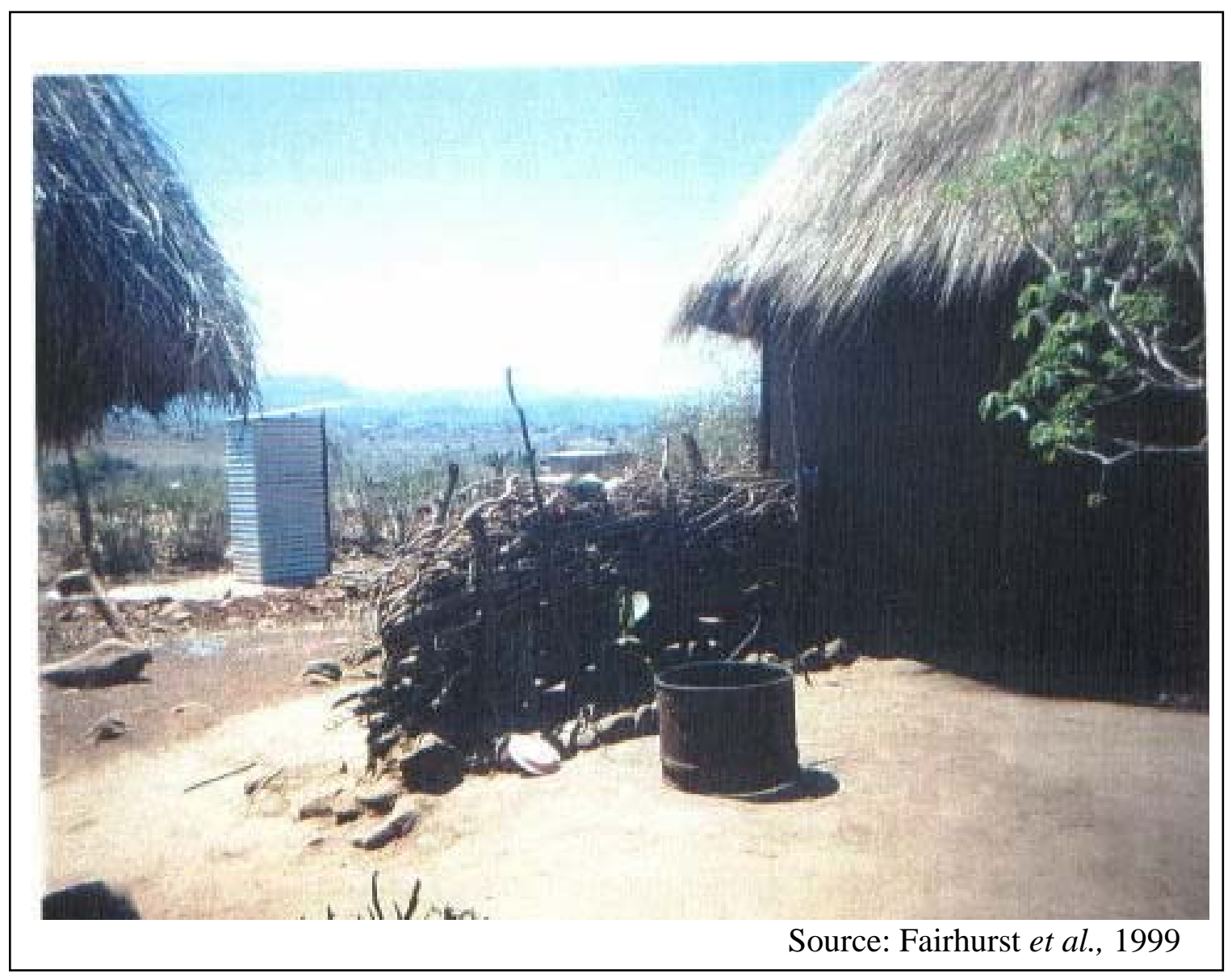

Figure 5.1: Fuel-wood stored as a protective fence in a household

It was not uncommon for households in these villages to both blame supernatural forces for flood disasters and in turn rely on gods and ancestors for help. Faith in God or "Nwali/Mudzimu" in the vernacular was a flood coping strategy that was related to people’s belief systems and their levels of spirituality. Historically, people preferred associating recovery from a flood crisis with faith in God. Centering belief systems on these deities should not be equated with complacency and passivity but with an inherent need to trust in a supreme being in times of trouble. This strategy implies a clear integration of nature and culture. More importantly, trusting these deities was not performed in isolation but integrated in the whole range of other flood coping strategies. 
Another historical strategy identified by the elders in these villages is that of evacuating to non-flooded upland where temporary shelters were built. This strategy was related to the availability of upland resources. As one of the elderly key informant at Milaboni reported:

Mountainous areas used to be like our second home during a flood crisis. We often come back to permanent dwellings down slope after flooding had subsided. Nowadays, this is no longer possible because no one will allow you to inhabit such areas because of the pine plantations and the agricultural fields over there (Individual Interview, September 2005).

It was in these temporary mountainous shelters where households tended to float or hang maize and other household items on trees. Floating of maize and other household items was done when dwelling units and grain storage facilities were inundated with flood waters. In summary, historical flood coping strategies at Milaboni and Dzingahe villages are relatively similar because of spatial proximity and the fact that these two communities share similar cultural contexts. In addition, both strategies are related to the environment and social organization. However, the difference in local resource endowments in these villages determined the local success or failure of a particular flood coping strategy. People at Milaboni village tended to be more attached to the environment than those at Dzingahe village who more inclined to urban lifestyles. In both villages historical flood coping strategies tend to overlap with contemporary ones. Nevertheless, many of the traditional forms of coping have undergone significant changes to respond to modern lifestyles and the dwindling natural resource base.

\subsection{Crisis of historical forms of coping and agents of change}

Household flood coping strategies are dynamic and in the study sites there are several interrelated factors that are responsible for change in such flood coping mechanisms. Of significant importance is apartheid spatial planning, particularly betterment planning, which negatively impacted historical forms of flood coping. The scheme was designed to 
transform land use patterns in the homelands by dividing rural areas into residential, arable and grazing lands. Grazing lands were fenced off leading to drastic livestock reductions by culling (McAllister, 1989). Consequently, homesteads were grouped into villages. Betterment planning included noble plans to conserve soil and forest resources. However, coupled with forced removals, the implementation of betterment planning disrupted socio-political organization and resulted in overcrowding, landlessness, deforestation, soil erosion and the development of major pine plantations in the homeland areas. In short, betterment planning through its zoning by-laws has alienated the majority of people from their traditional use of land as well as their spiritual and functional attachment to it. For example, a respondent at Dzingahe village asserted that before 1994 "The homeland government would not allow settling on both sides of the road. You have to be on its preferred side" (Focus Group Discussion, October 2005). Consequently, betterment schemes declared major historical coping strategies such as the extraction of natural resources which involved the gathering of wild fruit and vegetables obsolete.

Draconian measures during the apartheid era denied people the access rights to exploit such resources. For example, temporary relocation to higher grounds could no longer be possible as land became a scarce and inaccessible resource. Reduced livestock and arable land meant that other alternative ways of coping including the commodification of labor needed to be sought to maintain sustainable livelihoods. This has resulted in migration of young men to cities leaving a feminized labor force to till the land and herd livestock. As a consequence, many households are under the headship of women for the most part of the year. The development of a migrant labor system continued to put pressure on local knowledge because of integration into the wider economic and political systems of the urban areas. Formal education as another agent of change continued to challenge the relationship between local ecological knowledge and other types of knowledge people need in order to adapt. For example, through education and labor migration, people's traditional values and coping strategies changed to incorporate other values beyond their immediate environment. 
These developments though not all negative, have brought changes in the traditional sharing and redistribution mechanisms that characterized the traditional people of Milaboni and Dzingahe villages for so long. In other words, social capital became commercialized and the extended family system weakened since incomes derived from labor could no longer be able to support more than a nucleated family. The following quote documents some of these changes:

In our family, if you slaughter a chicken or goat, we used to distribute meat to neighbors and relatives nearby. Relatives far away were considered if a cow or bull is killed. Nowadays, it is not done anymore (Milaboni Focus Group Discussion, September 2005).

Another important agent of change in historical forms of coping was based on information about the comparative value of other coping strategies. In particular, people began to value wages much higher than possible income through local cultivation. Hence, reliance on the environment as the only source of livelihood was no longer feasible, since coping resources needed to survive were also coming from other areas rather than from the local environment. This line of argument does not relegate the role of common property resources like land to a lesser degree. Land has always maintained its status in these villages as an important resource for the previous and the current generation. As another respondent at Dzingahe village reported: "Cultivating crops these days is not as profitable. Hence, one would prefer working for a wage somewhere in town or sell goods there” (Focus Group Discussion, October, 2005).

Finally, changes in traditional flood coping strategies have transformed how contemporary flood coping strategies are conceptualized. Current forms of coping should not only be looked upon as a relationship between local people and nature. Instead, they should be viewed as they are emerging from the interaction between nature and the social, political and economic dynamics in the larger region. For example, remittances and wage labor as coping strategies extend territorial boundaries. 


\subsection{Current flood coping mechanisms: a comparative analysis}

This section outlines current flood coping strategies as identified by the household survey, individual interviews and focus group discussions at Dzingahe and Milaboni villages. Household heads in each of the two villages were firstly asked to identify flood coping strategies they previously employed in the event of a flood crisis. Secondly, they were then asked to choose one key flood coping strategy they would employ in the event of a flood hazard. Finally, the discussion of flood coping mechanisms identified by the interviews and the household survey was then taken to the FGDs workshops. Table 5.2 below summarizes the multiple response ranking results of the household survey on flood coping strategies in these two communities that were affected by the great floods of 2000 . In interpreting the table, note that the counts (frequencies) in the second and the fifth columns do not add up to 30 but rather to 113 and 105 respectively. These figures represent the total number of responses about flood coping strategies in each village. Since each of the 30 respondents could make up to eleven responses, the total number of responses is expectedly greater than the actual number of respondents. The third and sixth columns in the table report the percentages relative to the number of respondents $(\mathrm{N}=30)$ in each site.

Bivariate analysis of household survey results grounded by qualitative data sets and analysis indicate a shift from heavy reliance on the extraction from the environment to emphasize the importance of financial capital as a contemporary means towards recovery from flood crises. The considerable majority of contemporary household flood coping strategies have more economic than social and environmental dimensions. Table 5.2 shows the heterogeneous patterns of household rankings of flood coping strategies described below. 


\subsubsection{Borrowing of financial resources}

Within the sample, one key popular flood coping strategy adopted by households at Dzingahe and Milaboni villages is the borrowing of financial resources. $70 \%$ of households at Milaboni and 60\% at Dzingahe villages mentioned borrowing money from friends, neighbors, relatives and informal lenders as the main flood coping strategy. ${ }^{9}$ Despite $10 \%$ difference in the proportions of households employing the strategy, both villages have ranked this strategy as the most preferred one in the event of flood disaster (see Tables 5.2 a; b).

To add depth to statistical generalization, focus group discussions on flood coping mechanisms confirmed that during flood events, households borrow money from diverse sources. However, borrowing money from neighbors, relatives, and friends presupposes previous networking and reciprocity. In particular, stable relationships with others provide a positive context to deal with flood crisis. The positive context might be affected when individuals fail to repay their debts. As such, people without this form of social support prefer borrowing money from informal lenders instead. This strategy is sometimes referred to as 'informal insurance' since households borrow money from informal lenders whose collateral requirements are informal and show more leniency than those of the formal financial institutions. Informal lenders subject males and females to the same collateral requirements but with the hidden cost of higher interest rates. A respondent at Dzingahe village added:

These 'sharks' [referring to informal lenders] charge higher interest rates and when you fail to repay, they take your ID and your bank card so that they will be able to withdraw the monthly installments themselves. If you close your bank account, they send you to debt collectors. You will never borrow money again (Dzingahe Focus Group Discussion, October, 2005).

\footnotetext{
${ }^{9}$ Popularly known as "Matshonise” a Zulu word, meaning (financial) helpers"
} 
What this respondent implied was that because of irresponsible borrowing patterns, households are often trapped in debt and this in turn negatively impacts social spending on food and other basic necessities. Consequently, their overall creditworthiness is affected and the resultant negative social and economic implications go beyond the postdisaster phase to intensify flood vulnerability.

Table 5.2 (a): Multiple Response Ranking (R) of Household flood coping strategies in Dzingahe villages [scale $\mathbf{1}$ (most preferred) through 11 (least preferred)]

\begin{tabular}{|l|c|c|c|}
\hline & \multicolumn{3}{|c|}{ DZINGAHE VILLAGE } \\
\hline (N = 30 CASES) \\
\hline Coping Strategies Employed & $\begin{array}{r}\text { Number of } \\
\text { responses } \\
\text { (f) }\end{array}$ & of cases & Rank \\
\hline - Borrowing money from friends, neighbors \& relatives & 18 & 60 & 1 \\
\hline - Engaging in informal sector/ businesses & 17 & 56.7 & 2 \\
\hline - Remittance from family member working elsewhere & 16 & 53.3 & 3 \\
\hline - Access savings from the bank & 15 & 50 & 4 \\
\hline - Disaster aid from local business and government & 15 & 50 & 4 \\
\hline - Asset disposal & 13 & 43.3 & 5 \\
\hline - Evacuating to places of safety & 7 & 23.3 & 6 \\
\hline - Wage labor in nearby farms, towns or elsewhere & 3 & 10 & 7 \\
\hline - Do nothing & 3 & 10 & 7 \\
\hline - Levees and terraces & 2 & 6.7 & 8 \\
\hline - Other & 4 & 13.3 & 8 \\
\hline TOTAL & 113 & 376.7 & \\
\hline \hline
\end{tabular}


Table 5.2b: Multiple Response Ranking (R) of Household flood coping strategies in Milaboni villages [scale 1 (most preferred) through 11 (least preferred)]

\begin{tabular}{|l|c|c|c|}
\hline & \multicolumn{2}{|c|}{$\begin{array}{l}\text { MILABONI } \\
\text { (N =30 CASES) }\end{array}$} \\
\hline Coping Strategies Employed & $\begin{array}{c}\text { Number of } \\
\text { responses } \\
\text { (f) }\end{array}$ & $\begin{array}{c}\text { Rank } \\
\text { of cases }\end{array}$ & \\
\hline - Borrowing money from friends, neighbors \& relatives & 21 & 70 & 1 \\
\hline - Remittance from family member working elsewhere & 14 & 46.7 & 2 \\
\hline - Engaging in informal sector/ businesses & 13 & 43.3 & 3 \\
\hline - Evacuating to places of safety & 11 & 36.7 & 4 \\
\hline - Asset disposal & 11 & 36.7 & 4 \\
\hline - Wage labor in nearby farms, towns or elsewhere & 9 & 30 & 5 \\
\hline - Access savings from the bank & 9 & 30 & 5 \\
\hline - Disaster aid from local business and government & 8 & 26.7 & 6 \\
\hline - Levees and terraces & 7 & 23.3 & 7 \\
\hline - Do nothing & 2 & 6.7 & 8 \\
\hline - Other & $-\cdots----$ & $-\cdots---$ & 9 \\
\hline TOTAL & 105 & 350 & \\
\hline
\end{tabular}

A bivariate tabular analysis of borrowing strategies intersected by annual household income in both case studies indicates a positive relationship between these two variables in both villages. What needs to be further tested is the combined statistical significance of flood coping strategies by household annual income. A Chi-square test $\left(\chi^{2}\right)$ against income, age, health, assets, employment and gender and the results are summarized in Table 5.7 


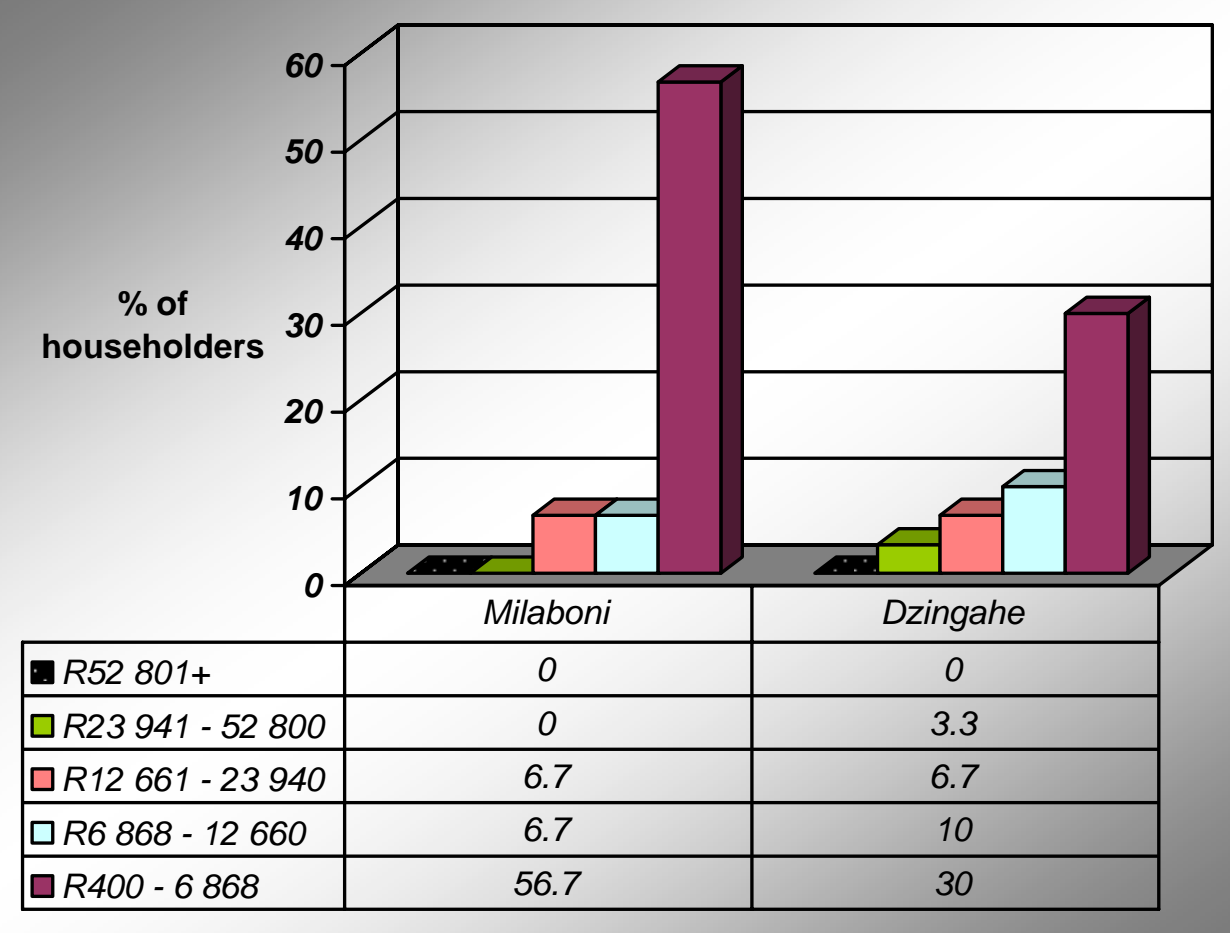

Figure 5.2: Households borrowing by income quintiles: Milaboni and Dzingahe villages

Figure 5.2 shows that at Milaboni village, $57 \%$ of households employing borrowing as a flood coping strategy were among the poorest fifth, compared with nearly one third (30\%) of those at Dzingahe village. Furthermore, an analysis of Tables 5.3 (a, b) confirms the finding from FGDs that households with lower annual income (category, R400 - 6 868) in both study sites tend to borrow more than is expected by almost four points higher (residual values $=3.8 \& 3.9$ respectively). The general trend observed from the above tables is that people who are wealthier borrow less (R52 801+) and this suggests an important relationship between income and household vulnerability to flood hazards. The gap between the poorest fifth and the wealthiest fifth is wider at Milaboni than at Dzingahe village (see Figure 5.2). Income differentials among households are more pronounced at Milaboni than at Dzingahe village. 
Table 5.3 (a): Expected and Observed values of Flood Coping strategies by income: Milaboni

\begin{tabular}{|c|c|c|c|c|c|c|c|c|c|c|}
\hline & & \multicolumn{8}{|c|}{ Household Flood Coping Strategies } & \multirow[b]{2}{*}{ Total } \\
\hline \multicolumn{2}{|l|}{$\begin{array}{l}\text { Income } \\
\text { Quintiles }\end{array}$} & $\begin{array}{c}\text { Money } \\
\text { Borrowing }\end{array}$ & $\begin{array}{c}\text { Bank } \\
\text { Savings }\end{array}$ & Evacuate & $\begin{array}{l}\text { Wage } \\
\text { labor }\end{array}$ & $\begin{array}{c}\text { Informal } \\
\text { sector }\end{array}$ & $\begin{array}{l}\text { Levees \& } \\
\text { terraces }\end{array}$ & Remittances & Local Aid & \\
\hline \multirow[t]{4}{*}{ R400 - 6868} & Observed & 11 & 0 & 2 & 0 & 4 & 0 & 0 & 1 & \multirow{4}{*}{$\begin{array}{c}18 \\
18.0 \\
60.0 \%\end{array}$} \\
\hline & Expected & 7.2 & 4.2 & 1.2 & 6 & 3.0 & 6 & 6 & .6 & \\
\hline & \multirow{2}{*}{$\begin{array}{l}\% \text { of Total } \\
\text { Residual }\end{array}$} & $36.7 \%$ & $.0 \%$ & $6.7 \%$ & $.0 \%$ & $13.3 \%$ & $.0 \%$ & $.0 \%$ & $3.3 \%$ & \\
\hline & & 3.8 & -4.2 & .8 & -.6 & 1.0 & -.6 & -.6 & .4 & \\
\hline \multirow[t]{4}{*}{ R6 $869-12660$} & Observed & 0 & 2 & 0 & 1 & 0 & 0 & 1 & 0 & \multirow{4}{*}{$\begin{array}{c}4 \\
4.0 \\
13.3 \%\end{array}$} \\
\hline & Expected & 1.6 & .9 & .3 & .1 & .7 & .1 & .1 & .1 & \\
\hline & \multirow{2}{*}{$\begin{array}{l}\% \text { of Total } \\
\text { Residual }\end{array}$} & $.0 \%$ & $6.7 \%$ & $.0 \%$ & $3.3 \%$ & $.0 \%$ & $.0 \%$ & $3.3 \%$ & $.0 \%$ & \\
\hline & & -1.6 & 1.1 & -.3 & .9 & -.7 & -.1 & .9 & -.1 & \\
\hline \multirow[t]{4}{*}{ R12 661-23940 } & Observed & 1 & 1 & 0 & 0 & 1 & 1 & 0 & 0 & \multirow{4}{*}{$\begin{array}{c}4 \\
4.0 \\
13.3 \%\end{array}$} \\
\hline & Expected & 1.6 & .9 & .3 & .1 & .7 & .1 & .1 & .1 & \\
\hline & $\%$ of Total & $3.3 \%$ & $3.3 \%$ & $.0 \%$ & $.0 \%$ & $3.3 \%$ & $3.3 \%$ & $.0 \%$ & $.0 \%$ & \\
\hline & Residual & -.6 & .1 & -.3 & -.1 & .3 & .9 & -.1 & -.1 & \\
\hline \multirow[t]{4}{*}{ R23 941-52 800} & Observed & 0 & 3 & 0 & 0 & 0 & 0 & 0 & 0 & \multirow{4}{*}{$\begin{array}{c}3 \\
3.0 \\
10.0 \%\end{array}$} \\
\hline & Expected & 1.2 & .7 & .2 & .1 & .5 & .1 & .1 & .1 & \\
\hline & $\%$ of Total & $.0 \%$ & $10.0 \%$ & $.0 \%$ & $.0 \%$ & $.0 \%$ & $.0 \%$ & $.0 \%$ & $.0 \%$ & \\
\hline & Residual & -1.2 & 2.3 & -.2 & -.1 & -.5 & -.1 & -.1 & -.1 & \\
\hline \multirow[t]{6}{*}{ R52 $801+$} & Observed & 0 & 1 & 0 & 0 & 0 & 0 & 0 & 0 & \multirow{3}{*}{$\begin{array}{c}1 \\
1.0 \\
3.3 \%\end{array}$} \\
\hline & Expected & .4 & .2 & .1 & .0 & .2 & .0 & .0 & .0 & \\
\hline & $\%$ of Total & $.0 \%$ & $3.3 \%$ & $.0 \%$ & $.0 \%$ & $.0 \%$ & $.0 \%$ & $.0 \%$ & $.0 \%$ & \\
\hline & Residual & -.4 & .8 & -.1 & .0 & -.2 & .0 & .0 & .0 & \\
\hline & Observed & 12 & 7 & 2 & 1 & 5 & 1 & 1 & 1 & 30 \\
\hline & Expected & 12.0 & 7.0 & 2.0 & 1.0 & 5.0 & 1.0 & 1.0 & 1.0 & 30.0 \\
\hline TOTAL & $\%$ of Total & $40.0 \%$ & $23.3 \%$ & $6.7 \%$ & $3.3 \%$ & $16.7 \%$ & $3.3 \%$ & $3.3 \%$ & $3.3 \%$ & 100 \\
\hline
\end{tabular}


Table 5.3 (b): Expected and Observed values of Flood Coping strategies by income: Dzingahe

\begin{tabular}{|c|c|c|c|c|c|c|}
\hline \multirow{2}{*}{$\begin{array}{l}\text { Income } \\
\text { Quintiles }\end{array}$} & & \multicolumn{5}{|c|}{ Household flood coping strategie! } \\
\hline & & $\begin{array}{c}\text { Money } \\
\text { Borrowing }\end{array}$ & $\begin{array}{l}\text { Bank } \\
\text { Savings }\end{array}$ & $\begin{array}{c}\text { Asset } \\
\text { disposal }\end{array}$ & $\begin{array}{c}\text { Remittance } \\
\mathrm{s}\end{array}$ & Total \\
\hline R400 - R6 868 & $\begin{array}{l}\text { Observed } \\
\text { Expected } \\
\% \text { of Total } \\
\text { Residual }\end{array}$ & $\begin{array}{c}9 \\
5.1 \\
30.0 \% \\
3.9\end{array}$ & $\begin{array}{c}0 \\
4.8 \\
.0 \% \\
-4.8\end{array}$ & $\begin{array}{c}1 \\
.7 \\
3.3 \% \\
.3\end{array}$ & $\begin{array}{c}1 \\
.4 \\
3.3 \% \\
.6\end{array}$ & $\begin{array}{c}11 \\
11.0 \\
36.7 \%\end{array}$ \\
\hline R6 869 - R 12660 & $\begin{array}{l}\text { Observed } \\
\text { Expected } \\
\% \text { of Total } \\
\text { Residual }\end{array}$ & $\begin{array}{c}3 \\
2.8 \\
10.0 \% \\
.2\end{array}$ & $\begin{array}{c}2 \\
2.6 \\
6.7 \% \\
-.6\end{array}$ & $\begin{array}{c}1 \\
.4 \\
3.3 \% \\
.6\end{array}$ & $\begin{array}{c}0 \\
.2 \\
.0 \% \\
-.2\end{array}$ & $\begin{array}{c}6 \\
6.0 \\
20.0 \%\end{array}$ \\
\hline R12 661 - R23 940 & $\begin{array}{l}\text { Observed } \\
\text { Expected } \\
\% \text { of Total } \\
\text { Residual }\end{array}$ & $\begin{array}{c}2 \\
2.3 \\
6.7 \% \\
-.3\end{array}$ & $\begin{array}{c}3 \\
2.2 \\
10.0 \% \\
.8\end{array}$ & $\begin{array}{c}0 \\
.3 \\
.0 \% \\
-.3\end{array}$ & $\begin{array}{c}0 \\
.2 \\
.0 \% \\
-.2\end{array}$ & $\begin{array}{c}5 \\
5.0 \\
16.7 \%\end{array}$ \\
\hline R23 941 - R52 800 & $\begin{array}{l}\text { Observed } \\
\text { Expected } \\
\% \text { of Total } \\
\text { Residual }\end{array}$ & $\begin{array}{c}0 \\
2.8 \\
.0 \% \\
-2.8\end{array}$ & $\begin{array}{c}6 \\
2.6 \\
20.0 \% \\
3.4\end{array}$ & $\begin{array}{l}0 \\
.4 \\
.0 \% \\
-.4\end{array}$ & $\begin{array}{c}0 \\
.2 \\
.0 \% \\
-.2\end{array}$ & $\begin{array}{c}6 \\
6.0 \\
20.0 \%\end{array}$ \\
\hline R52 801+ & $\begin{array}{l}\text { Observed } \\
\text { Expected } \\
\% \text { of Total } \\
\text { Residual }\end{array}$ & $\begin{array}{c}0 \\
.9 \\
.0 \% \\
-.9\end{array}$ & $\begin{array}{c}2 \\
.9 \\
6.7 \% \\
1.1\end{array}$ & $\begin{array}{l}0 \\
.1 \\
.0 \% \\
-.1\end{array}$ & $\begin{array}{l}0 \\
.1 \\
.0 \% \\
-.1\end{array}$ & $\begin{array}{c}2 \\
2.0 \\
6.7 \%\end{array}$ \\
\hline & $\begin{array}{l}\text { Observed } \\
\text { Expected }\end{array}$ & $\begin{array}{c}14 \\
14.0\end{array}$ & $\begin{array}{c}13 \\
13.0\end{array}$ & $\begin{array}{c}2 \\
2.0\end{array}$ & $\begin{array}{c}1 \\
1.0\end{array}$ & $\begin{array}{c}30 \\
30.0\end{array}$ \\
\hline TOTAL & $\%$ of Total & $46.7 \%$ & $43.3 \%$ & $6.7 \%$ & $3.3 \%$ & $100.0 \%$ \\
\hline & & & & & & \\
\hline
\end{tabular}




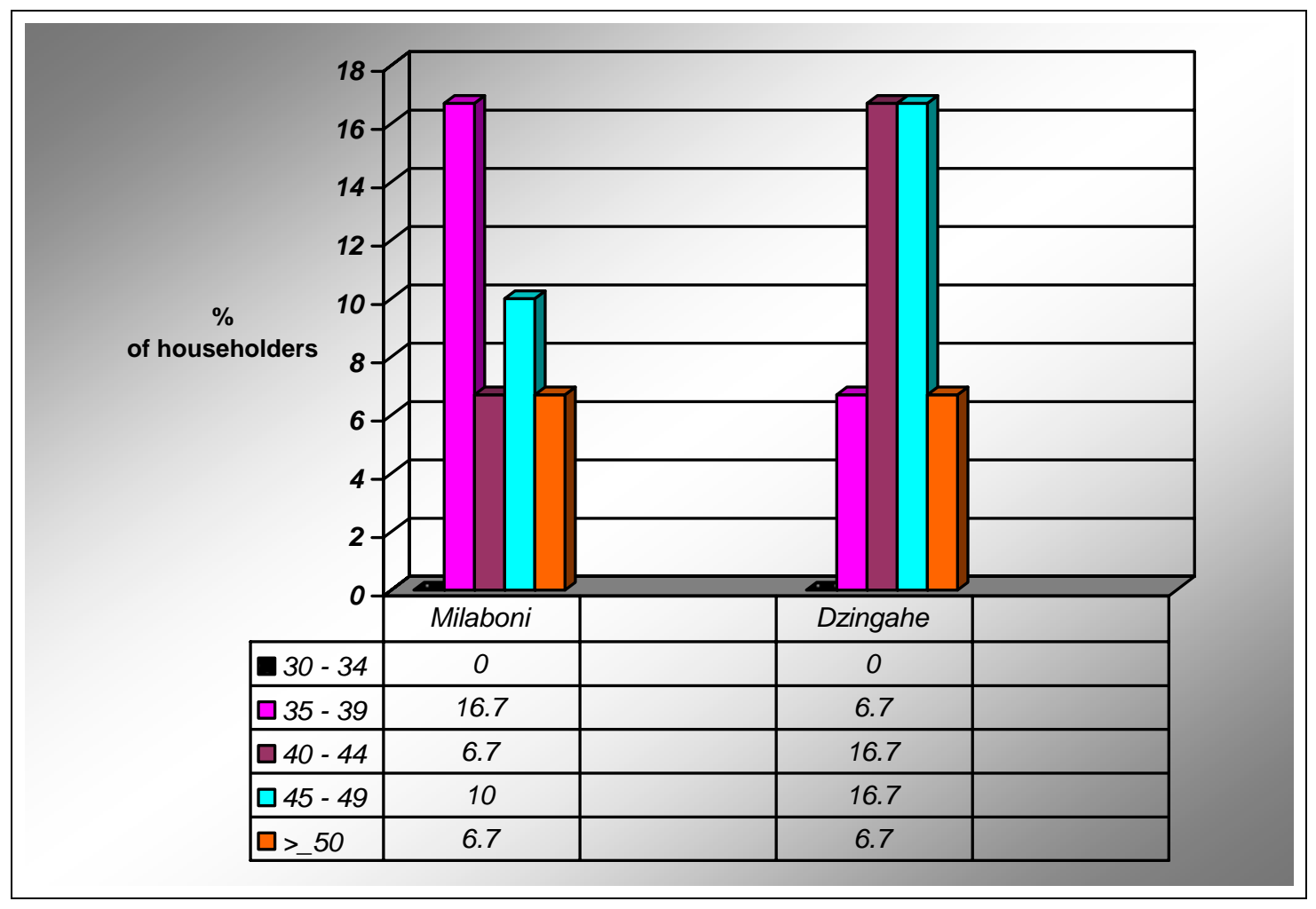

Figure 5.3: Household borrowing by age: Milaboni and Dzingahe villages

Household borrowing was also correlated with the age of the head of household. Figure 5.3 shows that at Dzingahe village, $40 \%$ of households heads of age category 30 - 49 rely more on borrowing than those at Milaboni (33\%) village within the same age group. Householders 50 years and above show a tendency to rely on this strategy for coping with floods. It is not uncommon for this age group that includes pensioners to embark on borrowing that leave them trapped in debt. Emerging informal businesses have strategic marketing campaigns to lure them into irresponsible borrowing. Tables 5.4 (a; b) indicate borrowing by employment type. In both villages those that are formally employed tend to borrow more than is expected. Regarding education, those with five years or less of formal education tend to borrow more (Table 5.4a, b). 
It is evident from Table 5.5 that household flood coping strategies in these two villages are not differentiated by gender. Male- and female- headed households show similar patterns of borrowing as a flood coping strategy. Similarly health, assets, skills and age do not show any significant correlation with borrowing (Table 5.7). Hence, no significant conclusions can be inferred from them. However, it can be inferred that class seems to be more important than gender in this case.

Table 5.4 (a): Bivariate Tabular Analysis of Employment type and flood coping strategies: Dzingahe village

\begin{tabular}{|c|c|c|c|c|c|c|}
\hline \multicolumn{7}{|c|}{ Household flood coping strategies } \\
\hline $\begin{array}{c}\text { Employment } \\
\text { Type }\end{array}$ & Counts & Borrow money & $\begin{array}{c}\text { Bank } \\
\text { Savings }\end{array}$ & $\begin{array}{c}\text { Asset } \\
\text { disposal }\end{array}$ & Remittances & Total \\
\hline Formal & $\begin{array}{l}\text { Observed } \\
\text { Expected } \\
\% \text { of Total } \\
\text { Residual }\end{array}$ & $\begin{array}{c}3 \\
6.1 \\
10.0 \% \\
-3.1\end{array}$ & $\begin{array}{c}10 \\
5.6 \\
33.3 \% \\
4.4\end{array}$ & $\begin{array}{c}0 \\
.9 \\
.0 \% \\
-.9\end{array}$ & $\begin{array}{c}0 \\
.4 \\
.0 \% \\
-.4\end{array}$ & $\begin{array}{c}13 \\
13.0 \\
43.3 \%\end{array}$ \\
\hline Informal & $\begin{array}{l}\text { Observed } \\
\text { Expected } \\
\% \text { of Total } \\
\text { Residual }\end{array}$ & $\begin{array}{c}10 \\
6.5 \\
33.3 \% \\
3.5\end{array}$ & $\begin{array}{c}3 \\
6.1 \\
10.0 \% \\
-3.1\end{array}$ & $\begin{array}{c}1 \\
.9 \\
3.3 \% \\
.1\end{array}$ & $\begin{array}{c}0 \\
.5 \\
.0 \% \\
-.5\end{array}$ & $\begin{array}{c}14 \\
14.0 \\
46.7 \%\end{array}$ \\
\hline $\mathrm{N} / \mathrm{A}$ & $\begin{array}{l}\text { Observed } \\
\text { Expected } \\
\% \text { of Total } \\
\text { Residual }\end{array}$ & $\begin{array}{c}1 \\
1.4 \\
3.3 \% \\
-.4\end{array}$ & $\begin{array}{c}0 \\
1.3 \\
.0 \% \\
-1.3\end{array}$ & $\begin{array}{c}1 \\
.2 \\
3.3 \% \\
.8\end{array}$ & $\begin{array}{c}1 \\
.1 \\
3.3 \% \\
.9\end{array}$ & $\begin{array}{c}3 \\
3.0 \\
10.0 \%\end{array}$ \\
\hline TOTAL & $\begin{array}{l}\text { Observed } \\
\text { Expected } \\
\% \text { of Total }\end{array}$ & $\begin{array}{c}14 \\
14.0 \\
46.7 \%\end{array}$ & $\begin{array}{c}13 \\
13.0 \\
43.3 \%\end{array}$ & $\begin{array}{c}2 \\
2.0 \\
6.7 \%\end{array}$ & $\begin{array}{c}1 \\
1.0 \\
3.3 \%\end{array}$ & $\begin{array}{c}30 \\
30.0 \\
100.0 \%\end{array}$ \\
\hline
\end{tabular}


Table 5.4 (b): Bivariate Tabular Analysis of Employment type and flood coping strategies: Milaboni village

\begin{tabular}{|c|c|c|c|c|c|c|c|c|c|c|}
\hline \multicolumn{10}{|c|}{ Household flood coping strategies } & \multirow[b]{2}{*}{ Total } \\
\hline $\begin{array}{c}\text { Employment } \\
\text { Type }\end{array}$ & Counts & $\begin{array}{l}\text { Borrow } \\
\text { Money }\end{array}$ & $\begin{array}{c}\text { Bank } \\
\text { Savings }\end{array}$ & Evacuate & $\begin{array}{l}\text { Wage } \\
\text { Labor }\end{array}$ & $\begin{array}{l}\text { Informal } \\
\text { Sector }\end{array}$ & $\begin{array}{l}\text { Levees \& } \\
\text { terraces }\end{array}$ & Remittances & $\begin{array}{l}\text { Local } \\
\text { Aid }\end{array}$ & \\
\hline \multirow[t]{3}{*}{ Formal } & Observed & 2 & 7 & 1 & 1 & 0 & 1 & 1 & 0 & 13 \\
\hline & Expected & 5.2 & 3.0 & .9 & .4 & 2.2 & .4 & .4 & .4 & 13.0 \\
\hline & $\begin{array}{l}\% \text { of Total } \\
\text { Residual }\end{array}$ & $\begin{array}{l}6.7 \% \\
-3.2\end{array}$ & $\begin{array}{c}23.3 \% \\
4.0\end{array}$ & $\begin{array}{c}3.3 \% \\
.1\end{array}$ & $\begin{array}{c}3.3 \% \\
.6\end{array}$ & $\begin{array}{l}.0 \% \\
-2.2\end{array}$ & $\begin{array}{c}3.3 \% \\
.6\end{array}$ & $\begin{array}{c}3.3 \% \\
.6\end{array}$ & $\begin{array}{l}.0 \% \\
-.4\end{array}$ & $43.3 \%$ \\
\hline Informal & $\begin{array}{l}\text { Observed } \\
\text { Expected } \\
\% \text { of Total } \\
\text { Residual }\end{array}$ & $\begin{array}{c}10 \\
6.4 \\
33.3 \% \\
3.6\end{array}$ & $\begin{array}{c}0 \\
3.7 \\
.0 \% \\
-3.7\end{array}$ & $\begin{array}{c}1 \\
1.1 \\
3.3 \% \\
-.1\end{array}$ & $\begin{array}{c}0 \\
.5 \\
.0 \% \\
-.5\end{array}$ & $\begin{array}{c}4 \\
2.7 \\
13.3 \% \\
1.3\end{array}$ & $\begin{array}{c}0 \\
.5 \\
.0 \% \\
-.5\end{array}$ & $\begin{array}{c}0 \\
.5 \\
.0 \% \\
-.5\end{array}$ & $\begin{array}{c}1 \\
.5 \\
3.3 \% \\
.5\end{array}$ & $\begin{array}{c}16 \\
16.0 \\
53.3 \%\end{array}$ \\
\hline \multirow[t]{2}{*}{$\mathrm{N} / \mathrm{A}$} & $\begin{array}{l}\text { Observed } \\
\text { Expected } \\
\% \text { of Total } \\
\text { Residual }\end{array}$ & $\begin{array}{c}0 \\
.4 \\
.0 \% \\
-.4\end{array}$ & $\begin{array}{c}0 \\
.2 \\
.0 \% \\
-.2\end{array}$ & $\begin{array}{c}0 \\
.1 \\
.0 \% \\
-.1\end{array}$ & $\begin{array}{c}0 \\
.0 \\
.0 \% \\
.0\end{array}$ & $\begin{array}{c}1 \\
.2 \\
3.3 \% \\
.8\end{array}$ & $\begin{array}{c}0 \\
.0 \\
.0 \% \\
.0\end{array}$ & $\begin{array}{c}0 \\
.0 \\
.0 \% \\
.0\end{array}$ & $\begin{array}{c}0 \\
.0 \\
.0 \% \\
.0\end{array}$ & $\begin{array}{c}1 \\
1.0 \\
3.3 \%\end{array}$ \\
\hline & $\begin{array}{l}\text { Observed } \\
\text { Expected }\end{array}$ & $\begin{array}{c}12 \\
12.0\end{array}$ & $\begin{array}{c}7 \\
7.0\end{array}$ & $\begin{array}{c}2 \\
2.0\end{array}$ & $\begin{array}{c}1 \\
1.0\end{array}$ & $\begin{array}{c}5 \\
5.0\end{array}$ & $\begin{array}{c}1 \\
1.0\end{array}$ & $\begin{array}{c}1 \\
1.0\end{array}$ & $\begin{array}{c}1 \\
1.0\end{array}$ & $\begin{array}{c}30 \\
30.0\end{array}$ \\
\hline TOTAL & $\%$ of Total & $40.0 \%$ & $23.3 \%$ & $6.7 \%$ & $3.3 \%$ & $16.7 \%$ & $3.3 \%$ & $3.3 \%$ & $3.3 \%$ & $100.0 \%$ \\
\hline
\end{tabular}

\subsubsection{Reliance on Remittances}

The importance of remittances from families or relatives living and working in urban areas cannot be overstated and is discussed widely in the literature (see Glewwe and Hall, 1998; Cox \& Jimerez, 1990; Ellis, 2000). Focus group discussions indicated that in times of crises, remittances are usually delivered in cash and in person contingent upon the ease of accessing the village by road. As a flood coping strategy, households at Dzingahe and Milaboni villages have rated this strategy differently. 
Table 5.2 shows that more than half (53\%) of the head of households in Dzingahe had relegated the strategy to the third position $(\mathrm{R}=3)$ compared to those at Milaboni (47\%) who allocated the second rank $(\mathrm{R}=2)$ to it. The difference in rank order though small, might be attributed to socio-economic variations inherent in these two villages. In addition, relative location and the distance to the main urban centers might also account for this variation. Urban centers are the main employers of relatives that remit some of their earnings back home. More importantly, the success of remittances as a flood coping strategy is a function of the family or relative working elsewhere who is ready to send some of their earnings home. These are usually family members who are nearby and have not severed their ties with their families back home. However, bivariate analysis of the household survey in both study sites has unexpectedly indicated no significant relationship between this strategy and its contribution to household income (Tables 5.3a; b). This implies that remittances from migrant laborers are increasingly irregular and intermittent.

\subsubsection{Engagement in Informal businesses}

Any approach to deal with flood vulnerability reduction in Thulamela Municipality that does not recognize the potential benefits of the informal sector is likely to fail. The cultural landscape of towns and villages in the municipality reflects markets and diverse goods of the informal economy. It is clear from Table 5.2 that more households (57\%) at Dzingahe than at Milaboni (43\%) have engaged in informal businesses as the coping strategy that enhances flood recovery and resilience. However, there are important functional differences that exist regarding the informal sector at Milaboni and Dzingahe villages. First, these villages do not share a common urban market. Dzingahe village is closer to the municipality head office in Thohoyandou, while Milaboni which is newly incorporated in Thulamela municipality is closer to Dzanani town (though outside its jurisdiction). Second, although their sense of belonging is still there, they are compelled to forsake their economic ties with Dzanani town to claim their share of the Thohoyandou market. 
Milaboni is almost $40 \mathrm{~km}$ while Dzingahe is just $5 \mathrm{~km}$ away from Thohoyandou town. The effect of distance is important because informal trading spaces in this town are available on a first-come-first serve basis. There is always a struggle over trading space and those who arrive earlier become over time permanently attached to a particular trading space and hence, the space becomes incontestable. Households engaged in informal businesses are therefore, faced with the problem of space. To this effect one respondent at Milaboni reported: "It is difficult to get a trading space at Sibasa or Thohoyandou, because the market is always full, no space available. It is always a fight to get the trading space there, even though we belong to the same municipality and pay taxes, we feel like orphans” (Focus Group Discussion, September 2005).

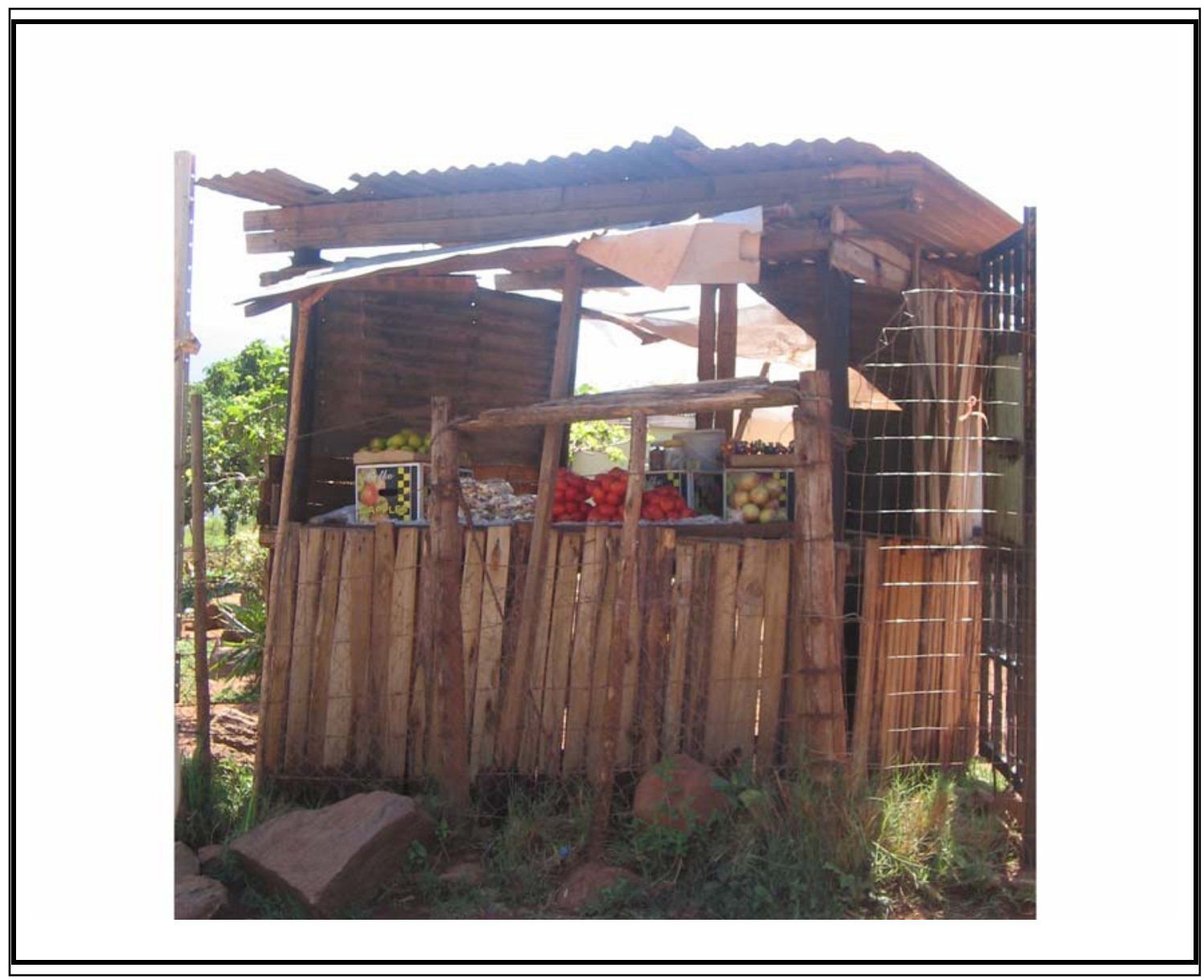

Figure 5.4: An example of an incontestable informal trading space at Milaboni. 
Households deal with the problem of contested trading space differently. Some of the informal traders at Dzingahe village reported that they contacted the town manager to solve the problem but in vain. Other households at Milaboni used their family ties to secure trading spaces at Dzanani town. The remaining group in both study sites tended to establish their informal businesses on their yard. In other words, informal trading spaces are attached to their fences. In this case, the trading spot is incontestable under current rural by-laws since it is attached to the owner of the stand. Figure 5.4 shows an example of those trading spaces which cannot be contested because they are part of the owners' stands. The disadvantage of this type of location is that it is limited in terms of the customers and the range of goods sold.

Table 5.5: Multiple Response Table of Household Flood Coping Strategies by Gender

\begin{tabular}{|c|c|c|c|c|}
\hline & \multirow{2}{*}{\multicolumn{2}{|c|}{$\begin{array}{c}\text { STUDY AREA } \\
\text { Dzingahe } \\
(\mathrm{N}=30 \text { cases })\end{array}$}} & \multirow{2}{*}{\multicolumn{2}{|c|}{$\begin{array}{l}\text { VILLAGES } \\
\text { Milaboni } \\
(\mathrm{N}=30 \text { cases })\end{array}$}} \\
\hline & & & & \\
\hline Coping Strategies Employed & $\begin{array}{c}\text { Male } \\
\text { Responses } \\
\text { (\% of Cases) }\end{array}$ & $\begin{array}{c}\text { Female } \\
\text { Responses (\% } \\
\text { of Cases) }\end{array}$ & $\begin{array}{c}\text { Male } \\
\text { Responses } \\
\text { (\% of Cases) }\end{array}$ & $\begin{array}{c}\text { Female } \\
\text { Responses } \\
\text { (\% of Cases) }\end{array}$ \\
\hline Borrowing money from friends, neighbors \& relatives & $7(23.3 \%)$ & $11(37 \%)$ & $10(33 \%)$ & $11(37)$ \\
\hline Remittance from family member working elsewhere & $7(23.3 \%)$ & $9(30 \%)$ & $8(26.7 \%)$ & $6(20 \%)$ \\
\hline Engaging in informal sector/ businesses & $5(16.7 \%)$ & $12(40 \%)$ & $6(20 \%)$ & $7(23.3 \%)$ \\
\hline Evacuating to places of safety & $4(13.3 \%)$ & $3(10 \%)$ & $5(16.7 \%)$ & $6(20 \%)$ \\
\hline Asset disposal & $10(33.3 \%)$ & $3(10 \%)$ & $9(30 \%)$ & $2(6.7 \%)$ \\
\hline Wage labor in nearby farms, towns or elsewhere & ------- & $3(10 \%)$ & $2(6.7 \%)$ & $7(23.3 \%)$ \\
\hline Access savings from the bank & $10(33 \%)$ & $5(16.7 \%)$ & $8(26.7 \%)$ & $1(3.3 \%)$ \\
\hline Disaster aid from local business and government & $10(33 \%)$ & $5(17 \%)$ & $7(23 \%)$ & $1(3 \%)$ \\
\hline Levees and terraces & $2(6.7 \%)$ & -------- & $5(16.7 \%)$ & $2(6.7 \%)$ \\
\hline Do nothing & $2(6.7 \%)$ & $1(3.3 \%)$ & $1(3.3 \%)$ & $1(3.3 \%)$ \\
\hline Other & $1(3.3 \%)$ & $3(10 \%)$ & -------- & -------- \\
\hline TOTAL & $58(192 \%)$ & 55 (184\%) & 59 (204\%) & $45(150 \%)$ \\
\hline
\end{tabular}


There are minor variations between female- and male- headed households regarding their involvement in informal businesses in both villages (see Table 5.5). However, significant variations exist regarding male - female participation ratio at Dzingahe village. Femaleheaded households were more likely (40\%) to engage in informal sector than maleheaded households (17\%). At Milaboni village, households in the poorest fifth (R400 R 6 868) tend to be more engaged in informal businesses (Table 5.3 b).

\subsubsection{Evacuation to places of safety}

The results of the household survey in Table 5.2 indicate that more households at Milaboni (37\%) have ranked evacuation to places of safety higher than those at Dzingahe village (23.3\%). This is not a prospective strategy at Dzingahe village when households were asked to choose the best strategies they would like to employ during times of flood disasters (see Table 5.3b). Evacuation mechanism presupposes the availability of places of safety elsewhere and that people would be ready to or be persuaded to leave. Places of safety include non-flooded upland areas and public spaces such as schools, churches and community halls where available. The findings of the focus group discussions in both villages indicated perceptual differences in terms of the conditions of places of safety.

As one elderly male respondent at Milaboni village said:

There are no schools and churches that are safe because there are in the valley floor. My family and I prefer to go to the mountains to settle during flooding. The problem is that we can no longer build any temporary structure there because the headman won't allow us since the land does not belong to us anymore (Focus Group Discussions, September 2005).

Similarly, a male respondent from Dzingahe village reported:

The living conditions of schools and churches as places of safety are worse than those of the affected dwellings. These facilities are always cold, overcrowded and noisy. I would rather stay home or go to my friends or relatives who are not affected by flooding (Focus Group Discussion, October 2005). 
These two narratives emphasize important differences and concerns regarding evacuation as a flood coping strategy. First and foremost, the respondents' ideas about evacuation are diverse since they were framed by their individual experiences and perceptions. A closer analysis of the first narrative reveals dissatisfaction of the elderly respondent at Milaboni village with lack of safe schools and churches, and lack of access to nonflooded highlands as problems of this strategy. Inherent in this narrative is the regulatory environment that disrupted upland settlement and cropping that are both shaped by the limited access to land. The respondent's inaccessibility to an upland environment is particular and therefore, cannot be generalized. On average the area of cultivated land on mountainous environment in Milaboni is nearly equal to that of the arable land on the valley floor. Hence, communities seem to be utilizing these mountainous resources for cultivation and pasture.

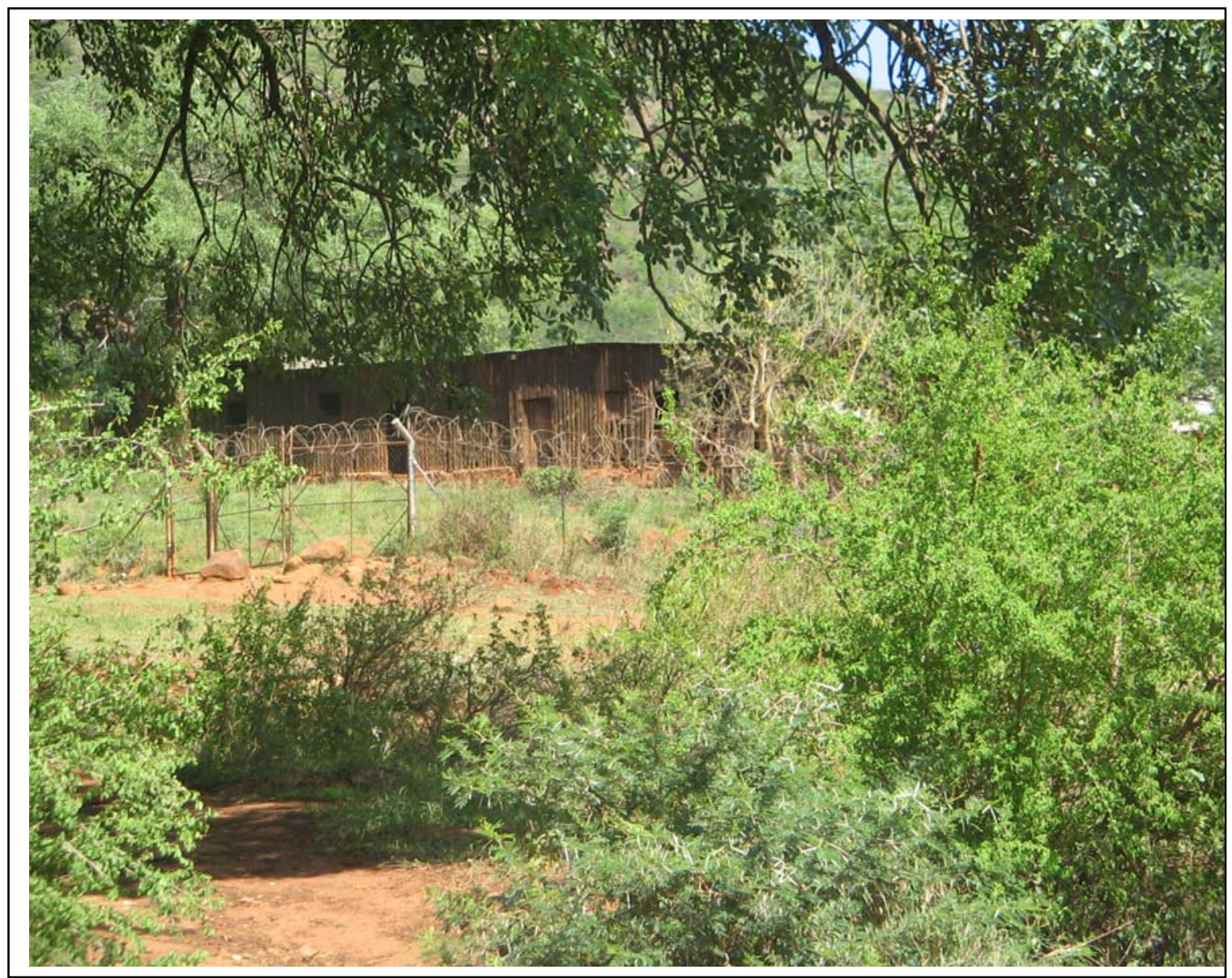

Figure 5.5: A sub-standard (derelict) Primary School at Milaboni village 
Regarding places of safety, there is one primary school and two churches at Milaboni village, both located in the valley floor. Due to its derelict nature, the school cannot qualify as a place of safety during flood disasters (see Figure 5.5). The second narrative points to the overcrowded, cold and noisy living conditions at both places of safety. Resistance to leaving or temporarily migrating to friends and relatives characterized the respondent's perception of evacuation as a flood coping strategy.

\subsubsection{Asset disposal}

Table 5.2 shows that over four in ten (43\%) of Dzingahe households compared to $37 \%$ of Milaboni, had identified disposal of their assets as one of their flood coping strategies. Assets identified in focus group discussions in these villages, range from electronic equipments (e.g. radios, cell-phones, TV, kettles, hot plates) to quasi-jewelry, toys, glassware and other household items. Clothing, especially leather goods are also the candidates for disposal during flood crisis. Some respondents particularly the elderly had made mentioned of livestock, especially chicken and goats as candidates for disposal. The nature of assets that are disposed is contingent upon the asset holding capacity of the households.

There is no significant difference between the two villages in terms of their asset disposal. However, gender differentials are evident at the level of this strategy in both villages. At Dzingahe village one third (33\%) of male-headed compared to one in every ten (10\%) of female head households had mentioned disposing some of their assets as one of their mechanisms to cope with flood disasters. Similarly, at Milaboni village, 30\% of male-headed compared to $7 \%$ of female-headed households have adopted this flood coping strategy in the event of floods. There are also weaker and insignificant relationship between education and asset disposal as a flood coping strategy in Dzingahe village [Tables 5.6 (a)]. This might be due to a small sample size. However, there is significant difference between remittances and borrowing, implying that people are relying less on remittances than borrowing as a coping strategy. 
Households were asked to identify only the most important flood coping strategies that they employed or were likely to employ. Tables $5.6(\mathrm{a} ; \mathrm{b})$ show the expected and the observed values for those strategies. Important observations emerge when one compares strategies identified by households in these two case studies. Households at Dzingahe case study have dropped asset disposal as a coping strategy while maintained by those at Milaboni village. This observation can be attributed to variations in asset holding capacity of households in these villages.

Table 5.6 (a): Bivariate analysis of Education and flood coping strategies: Dzingahe village

\begin{tabular}{|c|c|c|c|c|c|c|}
\hline \multicolumn{7}{|c|}{ Household flood coping strategies } \\
\hline $\begin{array}{c}\text { Education in } \\
\text { years }\end{array}$ & Counts & $\begin{array}{l}\text { Borrow } \\
\text { money }\end{array}$ & $\begin{array}{c}\text { Bank } \\
\text { Savings }\end{array}$ & $\begin{array}{c}\text { Asset } \\
\text { disposal }\end{array}$ & Remittances & Total \\
\hline$\leq 5$ & $\begin{array}{l}\text { Observed } \\
\text { Expected } \\
\% \text { of Total } \\
\text { Residual }\end{array}$ & $\begin{array}{c}4 \\
2.8 \\
13.3 \% \\
1.2\end{array}$ & $\begin{array}{c}1 \\
2.6 \\
3.3 \% \\
-1.6\end{array}$ & $\begin{array}{c}1 \\
.4 \\
3.3 \% \\
.6\end{array}$ & $\begin{array}{c}0 \\
.2 \\
.0 \% \\
-.2\end{array}$ & $\begin{array}{c}6 \\
6.0 \\
20.0 \%\end{array}$ \\
\hline $6-8$ & $\begin{array}{l}\text { Observed } \\
\text { Expected } \\
\% \text { of Total } \\
\text { Residual }\end{array}$ & $\begin{array}{c}3 \\
1.9 \\
10.0 \% \\
1.1\end{array}$ & $\begin{array}{c}0 \\
1.7 \\
.0 \% \\
-1.7\end{array}$ & $\begin{array}{c}1 \\
.3 \\
3.3 \% \\
.7\end{array}$ & $\begin{array}{c}0 \\
.1 \\
.0 \% \\
-.1\end{array}$ & $\begin{array}{c}4 \\
4.0 \\
13.3 \%\end{array}$ \\
\hline $9-13$ & $\begin{array}{l}\text { Observed } \\
\text { Expected } \\
\% \text { of Total } \\
\text { Residual }\end{array}$ & $\begin{array}{c}7 \\
6.1 \\
23.3 \% \\
.9\end{array}$ & $\begin{array}{c}5 \\
5.6 \\
16.7 \% \\
-.6\end{array}$ & $\begin{array}{c}0 \\
.9 \\
.0 \% \\
-.9\end{array}$ & $\begin{array}{c}1 \\
.4 \\
3.3 \% \\
.6\end{array}$ & $\begin{array}{c}13 \\
13.0 \\
43.3 \%\end{array}$ \\
\hline$\leq 14$ & $\begin{array}{l}\text { Observed } \\
\text { Expected } \\
\% \text { of Total } \\
\text { Residual }\end{array}$ & $\begin{array}{c}0 \\
3.3 \\
.0 \% \\
-3.3\end{array}$ & $\begin{array}{c}7 \\
3.0 \\
23.3 \% \\
4.0\end{array}$ & $\begin{array}{c}0 \\
.5 \\
.0 \% \\
-.5\end{array}$ & $\begin{array}{c}0 \\
.2 \\
.0 \% \\
-.2\end{array}$ & $\begin{array}{c}7 \\
7.0 \\
23.3 \%\end{array}$ \\
\hline TOTAL & $\begin{array}{l}\text { Observed } \\
\text { Expected } \\
\% \text { of Total }\end{array}$ & $\begin{array}{c}14 \\
14.0 \\
46.7 \%\end{array}$ & $\begin{array}{c}13 \\
13.0 \\
43.3 \%\end{array}$ & $\begin{array}{c}2 \\
2.0 \\
6.7 \%\end{array}$ & $\begin{array}{c}1 \\
1.0 \\
3.3 \%\end{array}$ & $\begin{array}{c}30 \\
30.0 \\
100.0 \%\end{array}$ \\
\hline
\end{tabular}


Table 5.6 (b): Bivariate Tabular Analysis of Education and flood coping strategies:

Milaboni village

\begin{tabular}{|c|c|c|c|c|c|c|c|c|c|c|}
\hline \multicolumn{11}{|c|}{ HOUSEHOLD FLOOD COPING STRATEGIES } \\
\hline $\begin{array}{c}\text { Education } \\
\text { in years }\end{array}$ & Counts & $\begin{array}{l}\text { Borrow } \\
\text { Money }\end{array}$ & $\begin{array}{c}\text { Bank } \\
\text { Savings }\end{array}$ & Evacuate & Wage labor & $\begin{array}{c}\text { Informal } \\
\text { sector }\end{array}$ & $\begin{array}{c}\text { Levees \& } \\
\text { terraces }\end{array}$ & Remittances & $\begin{array}{l}\text { Local } \\
\text { Aid }\end{array}$ & Total \\
\hline$\leq 5$ & $\begin{array}{l}\text { Observed } \\
\text { Expected } \\
\% \text { of Total } \\
\text { Residual }\end{array}$ & $\begin{array}{c}5 \\
2.8 \\
16.7 \% \\
2.2\end{array}$ & $\begin{array}{c}0 \\
1.6 \\
.0 \% \\
-1.6\end{array}$ & $\begin{array}{c}0 \\
.5 \\
.0 \% \\
-.5\end{array}$ & $\begin{array}{c}0 \\
.2 \\
.0 \% \\
-.2\end{array}$ & $\begin{array}{c}1 \\
1.2 \\
3.3 \% \\
-.2\end{array}$ & $\begin{array}{c}0 \\
.2 \\
.0 \% \\
-.2\end{array}$ & $\begin{array}{c}0 \\
.2 \\
.0 \% \\
-.2\end{array}$ & $\begin{array}{c}1 \\
.2 \\
3.3 \% \\
.8\end{array}$ & $\begin{array}{c}7 \\
7.0 \\
23.3 \%\end{array}$ \\
\hline $6-8$ & $\begin{array}{l}\text { Observed } \\
\text { Expected } \\
\% \text { of Total } \\
\text { Residual }\end{array}$ & $\begin{array}{c}2 \\
2.0 \\
6.7 \% \\
.0\end{array}$ & $\begin{array}{c}1 \\
1.2 \\
3.3 \% \\
-.2\end{array}$ & $\begin{array}{c}0 \\
.3 \\
.0 \% \\
-.3\end{array}$ & $\begin{array}{l}0 \\
.2 \\
.0 \% \\
-.2\end{array}$ & $\begin{array}{c}2 \\
.8 \\
6.7 \% \\
1.2\end{array}$ & $\begin{array}{c}0 \\
.2 \\
.0 \% \\
-.2\end{array}$ & $\begin{array}{c}0 \\
.2 \\
.0 \% \\
-.2\end{array}$ & $\begin{array}{c}0 \\
.2 \\
.0 \% \\
-.2\end{array}$ & $\begin{array}{c}5 \\
5.0 \\
16.7 \%\end{array}$ \\
\hline $9-13$ & $\begin{array}{l}\text { Observed } \\
\text { Expected } \\
\% \text { of Total } \\
\text { Residual }\end{array}$ & $\begin{array}{c}4 \\
4.0 \\
13.3 \% \\
.0\end{array}$ & $\begin{array}{c}0 \\
2.3 \\
.0 \% \\
-2.3\end{array}$ & $\begin{array}{c}2 \\
.7 \\
6.7 \% \\
1.3\end{array}$ & $\begin{array}{c}1 \\
.3 \\
3.3 \% \\
.7\end{array}$ & $\begin{array}{c}2 \\
1.7 \\
6.7 \% \\
.3\end{array}$ & $\begin{array}{c}0 \\
.3 \\
.0 \% \\
-.3\end{array}$ & $\begin{array}{c}1 \\
.3 \\
3.3 \% \\
.7\end{array}$ & $\begin{array}{l}0 \\
.3 \\
.0 \% \\
-.3\end{array}$ & $\begin{array}{c}10 \\
10.0 \\
33.3 \%\end{array}$ \\
\hline$\leq 14$ & $\begin{array}{l}\text { Observed } \\
\text { Expected } \\
\% \text { of Total } \\
\text { Residual }\end{array}$ & $\begin{array}{c}1 \\
3.2 \\
3.3 \% \\
-2.2\end{array}$ & $\begin{array}{c}6 \\
1.9 \\
20.0 \% \\
4.1\end{array}$ & $\begin{array}{c}0 \\
.5 \\
.0 \% \\
-.5\end{array}$ & $\begin{array}{c}0 \\
.3 \\
.0 \% \\
-.3\end{array}$ & $\begin{array}{c}0 \\
1.3 \\
.0 \% \\
-1.3 \\
\end{array}$ & $\begin{array}{c}1 \\
.3 \\
3.3 \% \\
.7\end{array}$ & $\begin{array}{c}0 \\
.3 \\
.0 \% \\
-.3\end{array}$ & $\begin{array}{c}0 \\
.3 \\
.0 \% \\
-.3\end{array}$ & $\begin{array}{c}8 \\
8.0 \\
26.7 \%\end{array}$ \\
\hline TOTAL & $\begin{array}{l}\text { Observed } \\
\text { Expected } \\
\% \text { of Total }\end{array}$ & $\begin{array}{c}12 \\
12.0 \\
40.0 \%\end{array}$ & $\begin{array}{c}7 \\
7.0 \\
23.3 \%\end{array}$ & $\begin{array}{c}2 \\
2.0 \\
6.7 \%\end{array}$ & $\begin{array}{c}1 \\
1.0 \\
3.3 \%\end{array}$ & $\begin{array}{c}5 \\
5.0 \\
16.7 \%\end{array}$ & $\begin{array}{c}1 \\
1.0 \\
3.3 \%\end{array}$ & $\begin{array}{c}1 \\
1.0 \\
3.3 \%\end{array}$ & $\begin{array}{c}1 \\
1.0 \\
3.3 \%\end{array}$ & $\begin{array}{c}30 \\
30.0 \\
100.0 \%\end{array}$ \\
\hline
\end{tabular}

\subsubsection{Wage labor}

Wage labor is a flood coping strategy that involves an attempt by the member of household to earn extra money for livelihood support. Participants in the focus group discussions in the study sites indicated that unemployed households and individual members sometimes engage in government/NGO organized temporary employment programs locally or elsewhere. This usually occurs after a member of household lost a job or had been unemployed before flood disaster struck. Female labor constitutes the 
majority of contingent employment programs (see Table 5.5). Program activities include road and bridge repair work, repairing damaged water pipes and other social infrastructure damaged in the Departments of Public Works and Education. Thirty percent of surveyed households at Milaboni village had indicated working in nearby farms and towns as a flood coping strategy. This compares with only $10 \%$ of households at Dzingahe village. Labor adjustment as a flood coping strategy is contingent upon the skills and health of a job seeker and job availability.

\subsubsection{Bank savings}

Households in the study area value the importance of financial savings in financial institutions such as banks and post offices. Focus group discussions confirmed this assertion, since most of the participants had one or two saving accounts either at the post office or the bank. However, the results from the household survey indicated differences between the two villages in bank savings as a flood coping strategy. Fifty percent of households at Dzingahe village compared to 30\% (see Table 5.2) at Milaboni reported having accessed their savings from the banks to cope with flooding. It is important to note that poor households value financial services that address risk coping motive while the value of wealthier households is placed on financial services that generate income and assets. This strategy is ranked lower $(\mathrm{R}=6)$ at Milaboni than at Dzingahe village (Rank = 4). Table 5.4 indicates gender differences inherent in this coping strategy. In both villages a greater proportion of male-headed households had reported accessing savings from the bank as a coping strategy during flood events.

\subsubsection{Flood disaster aid from local businesses and government}

In the event of flood disasters the local government and businesses play an important role in mobilizing resources to help flood victims. Fifty percent at Dzingahe village reported they had approached or would approach local businesses and government structures for help during a flood crisis (Table 5.5). However, focus group discussions emphasized the point that disaster aid is mostly hampered by delays. When households were asked if they 
were aware of policies or laws meant to enhance flood coping capacity, respondents in both villages denied the knowledge thereof. There are variations regarding whether households can survive a flood crisis or not. At the village level, an equal proportion of households at Dzingahe (47\%) and Milaboni (47\%) strongly agreed in a Likert scale of 1 to 5 that they could survive a flood crisis. Similarly, no local variations exist within the village itself regarding this strategy.

\subsubsection{Levees and terraces}

Almost $23 \%$ of households at Milaboni village compared to about $7 \%$ at Dzingahe indicated flood proofing in the form of levees around their homes and terracing systems in their fields as one of the structural flood coping measures employed. An orthophoto image of Dzingahe village does not indicate evidence of the use of terracing systems in fields. Flood-proofing mechanisms attempt to minimize flood damage and loss in respondents' homes and fields. A closer analysis of the terrain at Milaboni confirms the overwhelming use of terraces on steep slopes. Such ecological footprints of hastily constructed terraces are more evident.

The cultivation of steeper slopes explains why soil erosion has increased so much in this area. In addition, this mountainous terrain is also used for the grazing of livestock. Overgrazing strips the land of its natural shield against soil erosion since it decreases the vegetation cover and exposes the soil to increased runoff. With the exception of the residence of the chief of Milaboni, and few houses along the eastern slopes, most steep sloping terrains are left out of bounds to settlement. Finally, one might also infer from the "Other" category that households in both villages had a more limited range of household flood coping strategies especially those at Milaboni village. 


\subsection{Aggregated Measures of Differential Flood coping mechanisms}

The aggregated differential effects of variables in Table 5.7 and coping strategies were measured using a Chi-square and correlations using Cramer's V. Cramer's V is interpreted as a Pearson correlation coefficient $(r)$, with a shared variance $\left(r^{2}\right)$ indicating the percentage to account for the difference. Eight variables were used to measure the strength and the direction of relationship (if any) as described in the bivariate tabular analysis done in section 5.4. Chi-square is used to test statistical significance while Cramer's V was used to determine the strength and the direction of the relationships between the listed variables and household coping strategies.

A Pearson Chi-Square non-parametric test showed that no significant differential aggregated effects of gender on household flood coping strategies exist at Milaboni and Dzingahe villages (see Table 5.5). The gender related critical values at Milaboni (14.07) and Dzingahe (7.82) cleared by the scores of household coping strategies are larger than their respective chi-square $\left(\chi^{2}\right)$ values, with probability of error threshold $(\mathrm{p}=.05)$. This means that the data do not present a statistically significant relationship between gender and household flood coping strategies. In other words male- and female-headed households show similar distribution patterns on flood coping strategies within the sample. The statistical insignificance of the relationship between gender and coping strategies might be associated with a small sample size. Consistent with the literature (Fairhurst et al., 2000; Oberhauser \& Pratt, 2004; McCusker \& Oberhauser, 2006) gender is an important determinant of social relations and land ownership in the study sites where patriarchal institutions and relations dominate. Similarly, age, assets, health and personal skills are statistically not significant, although they all have positive weaker relationships. However, qualitative evidence from interviews and focus groups attest to the contrary. Income is positively correlated with household flood coping strategies. This implies that the type of household flood coping strategies is correlated with the household annual income, with a shared variance $\left(r^{2}=.368\right)$ at Milaboni and $\left(r^{2}=.238\right)$ at Dzingahe villages. 
Table 5.7: Pearson's Chi-square $\left(\chi^{2}\right)$ Tests and Cramer's V Correlations between Listed Variables and Household Flood Coping Strategies.

\begin{tabular}{|c|c|c|c|c|c|c|}
\hline Variables & $\chi^{2}$ & df & $\begin{array}{l}\text { Critical } \\
\text { Value }\end{array}$ & $\begin{array}{l}\text { Statistically } \\
\text { Significant? }\end{array}$ & $\begin{array}{l}\text { Cramer's } \\
\text { V (r) }\end{array}$ & $\begin{array}{l}\text { Shared } \\
\text { variance } \\
\mathbf{r}^{2}\end{array}$ \\
\hline \multirow[t]{2}{*}{ Gender } & 8.998* & 7 & 14.07 & No & .548 & .300 \\
\hline & $4.723 * *$ & 3 & 7.82 & No & .397 & .158 \\
\hline \multirow[t]{2}{*}{ Age } & 29.318* & 28 & 41.34 & No & .494 & .247 \\
\hline & $9.787 * *$ & 9 & 16.92 & No & .330 & .109 \\
\hline \multirow[t]{2}{*}{ Income } & $44.264 *$ & 28 & 28.87 & Yes & .607 & .368 \\
\hline & $21.453 * *$ & 12 & 21.03 & Yes & .488 & .238 \\
\hline \multirow[t]{2}{*}{ Assets } & $23.908 *$ & 28 & 41.34 & No & .446 & .199 \\
\hline & $10.591 * *$ & 12 & 21.03 & No & .343 & .118 \\
\hline \multirow[t]{2}{*}{ Health } & $11.967 *$ & 21 & 32.67 & No & .365 & .133 \\
\hline & $10.306 * *$ & 9 & 16.92 & No & .338 & .114 \\
\hline \multirow[t]{2}{*}{ Education } & $33.477^{*}$ & 21 & 32.67 & Yes & .610 & .372 \\
\hline & $18.147 * *$ & 9 & 16.92 & Yes & .449 & .202 \\
\hline \multirow[t]{2}{*}{ Employment } & $25.438 *$ & 14 & 23.69 & Yes & .651 & .424 \\
\hline & $22.810 * *$ & 6 & 12.59 & Yes & .617 & .381 \\
\hline
\end{tabular}

Notes: Probability of error threshold: $\mathbf{p}=.05 ; *=\chi^{2}$ values for Milaboni $* *=\chi^{2}$ values for Dzingahe

Interpretation of statistical significance: If $\chi^{2}$ value $=>$ Critical value $=$ statistically significant

$: \chi^{2}$ value $\leq$ Critical value $=$ statistically not significant

Low income households are likely to choose strategies that reflect limited financial reserves while medium to high income households prefer those coping strategies that increase their financial reserves. Although this assumption is accepted, at Milaboni village, income explains about $37 \%$ of the strategic differences compared to $24 \%$ at Dzingahe. The Cramer's V and the shared variance also imply that there are one or more variables still undetected which cumulatively account for $63 \%$ at Milaboni and $76 \%$ at Dzingahe. This means that income is merely one of many factors explaining the observed differentials. These results also demonstrate the importance of qualitative analysis. 
Table 5.7 also shows that both education and employment are correlated with household coping strategies. Education accounts for 37\% at Milaboni and 20\% at Dzingahe village, in explaining its correlation with household flood coping strategies. Similarly, employment accounts $43 \%$ and $38 \%$ at Milaboni and Dzingahe respectively. Both education and employment play a significant role in the choice of coping strategies. Higher education and employment could be viewed as desirable indicators for the ability to cope in times of crises. However, with higher patterns of borrowing, more people are trapped in debt and this cycle will affect effective recovery from hazards even when their educational levels and income rise.

\subsection{Conclusion}

This chapter began by identifying historical forms of flood coping and how they changed over time to incorporate contemporary coping mechanisms. In times of flood crises, some people are able to cope well while other people's coping mechanisms are stimulated by circumstances of desperation and loss. Those that cope well do so by maximizing their own capacities, resources and social networks. Such capacity building initiatives are socially constructed through social networks and power relations; hence, some people are more resilient than others.

In these villages, coping strategies have constantly evolved through homeland government historical processes and power struggles over environmental resources, including land. Historical forms of coping have been influenced in the study area by the geography of betterment planning which has negatively impacted those coping measures that are based on environmental endowment. Both historical and current coping strategies have ecological and socio-economic features. Comparative village analysis indicates that household flood coping strategies show minor variability in terms of ecological characteristics but significant variation in their socio-economic and socio-cultural contexts. Historical coping strategies at Milaboni and Dzingahe villages indicated versatility and innovation (ingenuity) and effective use of marginal resources and social networks. In both villages these strategies were mainly shaped by natural resource 
endowments and historical experiences. However, contemporary flood coping mechanisms relate remarkable well with the household resources in its broadest sense to include economic, political and social capital. However, these strategies overlap largely with historical forms of coping and hence they are not abandoned completely. For example, the disposal of livestock as assets is still an important contemporary flood coping strategy in the study area.

An interesting finding in these communities is that the emphasis is shifting away from coping mechanisms that rely heavily on environmental resources to those that privilege financial capital, political connections and social networks. This shift can be understood through an analysis of local political ecology. By the same token household reliance on remittances is shifting as more and more households begin to rely on borrowing of financial resources as flood coping strategies. One key reason for people not saving enough or at all was the level of debt that people have built up. High debts lead to no savings and hence no financial reserves to use during flood crises. This change in coping strategies indicates a shift from community to household and individual vulnerability, and this is discussed further in chapter 6.

In conclusion, a Chi-square measure of differential flood coping mechanisms, indicate income, education and employment as statistically significant in accounting for differences in household flood coping strategies. What this means is that households with differential employment opportunities, income and educational levels often adopt different types of flood coping strategies that are contingent upon their capacities, resources and social networks. The unexpected finding is that gender, age, assets and health do not significantly account for differential flood coping mechanisms. A small sample size in the study sites might account for this observation. More importantly, statistical aggregation often masks differential accounts of variables. Hence, the impact of gender, age and assets on flood coping mechanisms is obscured. Further evidence as presented in the next chapters will provide insight into this finding, especially the relationship between gender and flood vulnerability. 


\section{CHAPTER 6}

\section{Socio-economic and Political Dimensions of Differential Household Flood Vulnerability}

\subsection{Introduction}

The previous chapter demonstrated the relationship between flood vulnerability and coping mechanisms. This has been achieved by focusing on the historical and contemporary household flood coping mechanisms and how they evolved over time. A closer analysis of flood coping strategies highlighted major shifts from historical to contemporary flood coping strategies. These changes have both ecological and socioeconomic dimensions. Thus, this chapter examines critical factors that underlie the social, economic and political geographies of flood vulnerability at Milaboni and Dzingahe villages. Specifically, critical mechanisms and processes by which socio-economic and political factors contribute to flood vulnerability in these study sites are investigated. Particular attention is paid to processes through which households become resilient or vulnerable to flooding. The main argument in this chapter is that physical parameters are important triggering factors, but that flood hazards are socially constructed and highly differentiated. In other words, flood hazards impact people differently and their impacts arise out of the socio-economic circumstances of everyday life. Hence, the dynamics of household flood vulnerability are a result of historical processes (as demonstrated in previous chapter), current household capacities, resources and social networks. Combined, these factors are likely to indicate the extent to which households are resilient or vulnerable to flooding. 
Socio-economic dimensions of household flood vulnerability in this research are examined on the basis of household data obtained through a household survey and qualitative data from the focus group discussions and interviews. As a basis for understanding the nature and extent of differential flood vulnerability, household coping capacity and resilience levels are examined. These variables formed a basis for determining the extent to which socio-economic variables can explain overall patterns of differential household flood vulnerability. Empirical results of this study indicate that over half (53.3\%) of the surveyed households in both villages suffered direct losses from the flood of 2000. The remaining $47 \%$ did not suffer direct flood impacts, but reported suffering from indirect impacts. The critical question here is why certain households were directly impacted and others were less vulnerable? The answer lies with the complex intersection of physical and human factors. However, it is the purpose of this chapter to provide insights into socio-economic factors that produced differential household flood vulnerability in the study sites.

\subsection{Household Resources and Flood Vulnerability}

Household resources and political variables explain flood vulnerability patterns at Milaboni and Dzingahe villages. A household survey conducted at the two villages elicited information about demographic characteristics, livelihood earnings (income), living conditions, flood experiences and coping strategies, household location, and perceived family economic pressure and social capital. The extent to which household location plays in flood vulnerability analysis is examined in the next section. In addition, information about the role of local businesses, local government and NGOs in enhancing coping capacity and resilience was part of the survey, interviews and focus group discussions. The socio-economic determination of household levels of flood vulnerability was made on the basis of household resources defined in its broadest sense to include economic, personal, social capital and political resources. 


\subsubsection{Economic and material resources}

Economic and material resources, including land, are proxy indicators of socio-economic status and are good measures for flood coping capacity and household resilience to flood impacts. Various studies have used these indicators to map social vulnerability to hazards in general (Ahmed, 1993; Bolin, 1993; Morrow, 1999; Adger et al., 2004). These are important indicators for the assessment of household flood vulnerability, because they assess household capacity and resilience which are important components of flood vulnerability (see Figure 2.1). The relationship between household resources and flood vulnerability is that coping with and recovery from flood impacts demand financial reserves that can buffer the household from negative flood impacts. Hence, an examination of household position in terms of the economic and material resources such as income earnings, housing type and assets becomes critical. An analysis of survey data of Dzingahe and Milaboni households indicates differential capacity of household resources such as income and assets, within and between the two villages. Finally, an analysis is done of the perceived household economic pressure measured on a Likert scale of 1 (strongly disagree) to 5 (strongly agree).

\subsubsection{Household Income}

In terms of self-reported annual household income, ${ }^{10}$ households in the study area were divided into five groups of national income quintiles; from the poorest fifth of households to the wealthiest fifth. Specific income categories as indicated in Figure 6.1 are: lower income (R400 - 6 868), low income (R6 869 - 12 660); lower middle income (R12 661 23 940); upper middle income (R23 941 - 52 800) and high income groups (R 52801 and above). The national income quintile has been used to standardize income categories. In certain cases the researcher might determine the income categories that match the income profile of the study sites.

\footnotetext{
${ }^{10}$ Annual household income is here calculated as the sum of wages, salaries, old-age pension and proceeds from formal and informal businesses of the related members of the household, per year.
} 
Figure 6.1 indicates that at Milaboni village, only 3.3\% of households fell in the high income quintile (R52 801.00 and above) compared to 7\% at Dzingahe village. The considerable majority (60\%) of households at Milaboni village were in the lower income category compared to over a third (37\%) at Dzingahe village. This finding indicates that a great disparity exists between the poor and wealthy households at Dzingahe and Milaboni villages. However, in both villages more households are relatively poor. Reasons for income disparities might be associated with variations in educational levels, sources of income and gender of the householder. More importantly, the historical geography of development during the homeland government, has allocated more development resources at Dzingahe (a former dormitory village for blacks working at Sibasa) than at Milaboni, a small village whose surplus development space was taken up by the rapidly growing Tshikombani village. Inter-household analysis indicates income differentials between households throughout the income quintiles.

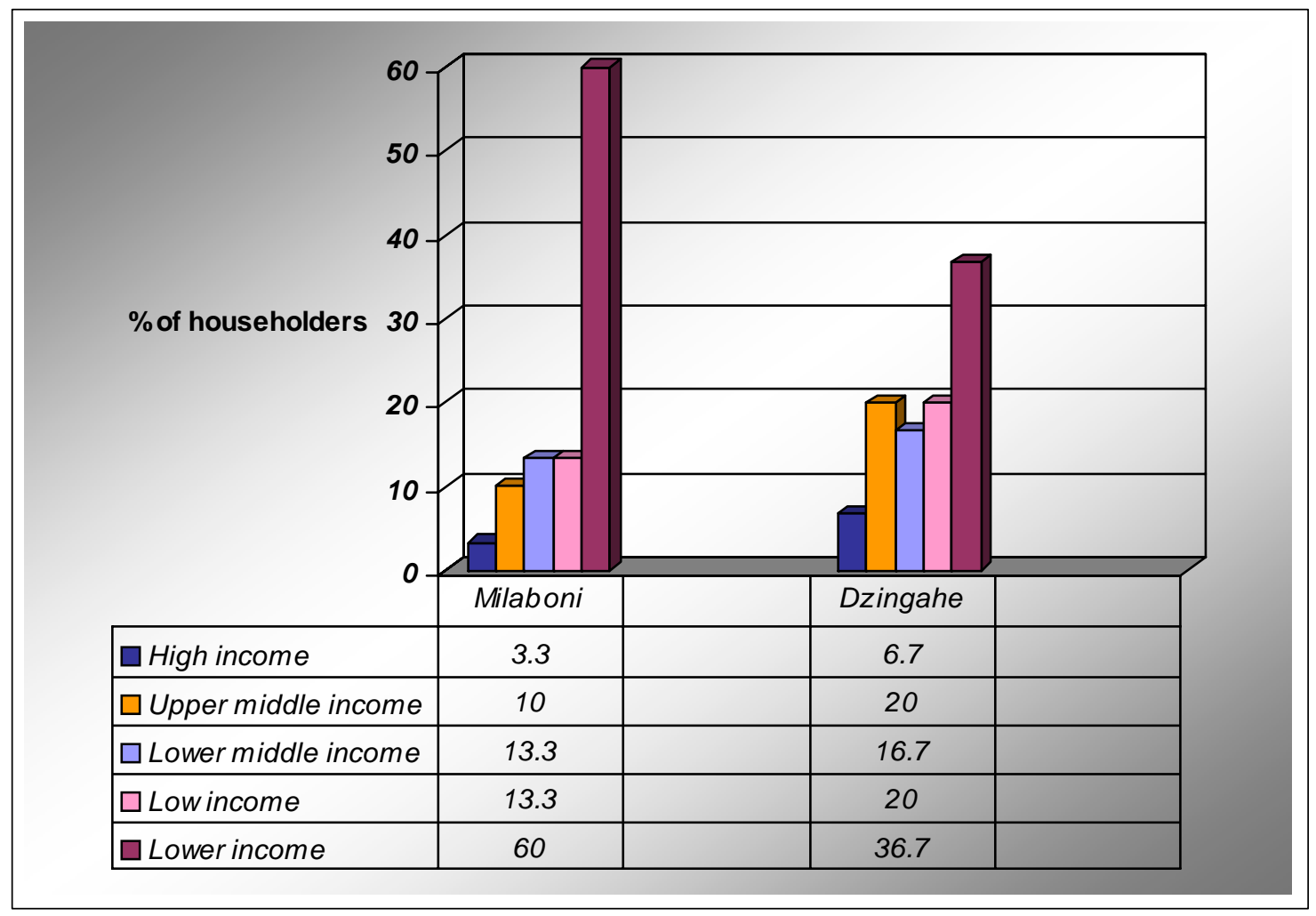

Figure 6.1: Annual household income quintiles: Milaboni and Dzingahe villages 
Within the sample, the relationship between education and annual household income is a complex one. Normally, one would expect a strong positive correlation between education and income, because it is a common trend that household income increases significantly with an improvement in educational qualification of the householder. Figures 6.2 (a; b) indicate the distribution of annual household income quintiles by education in the study sites.

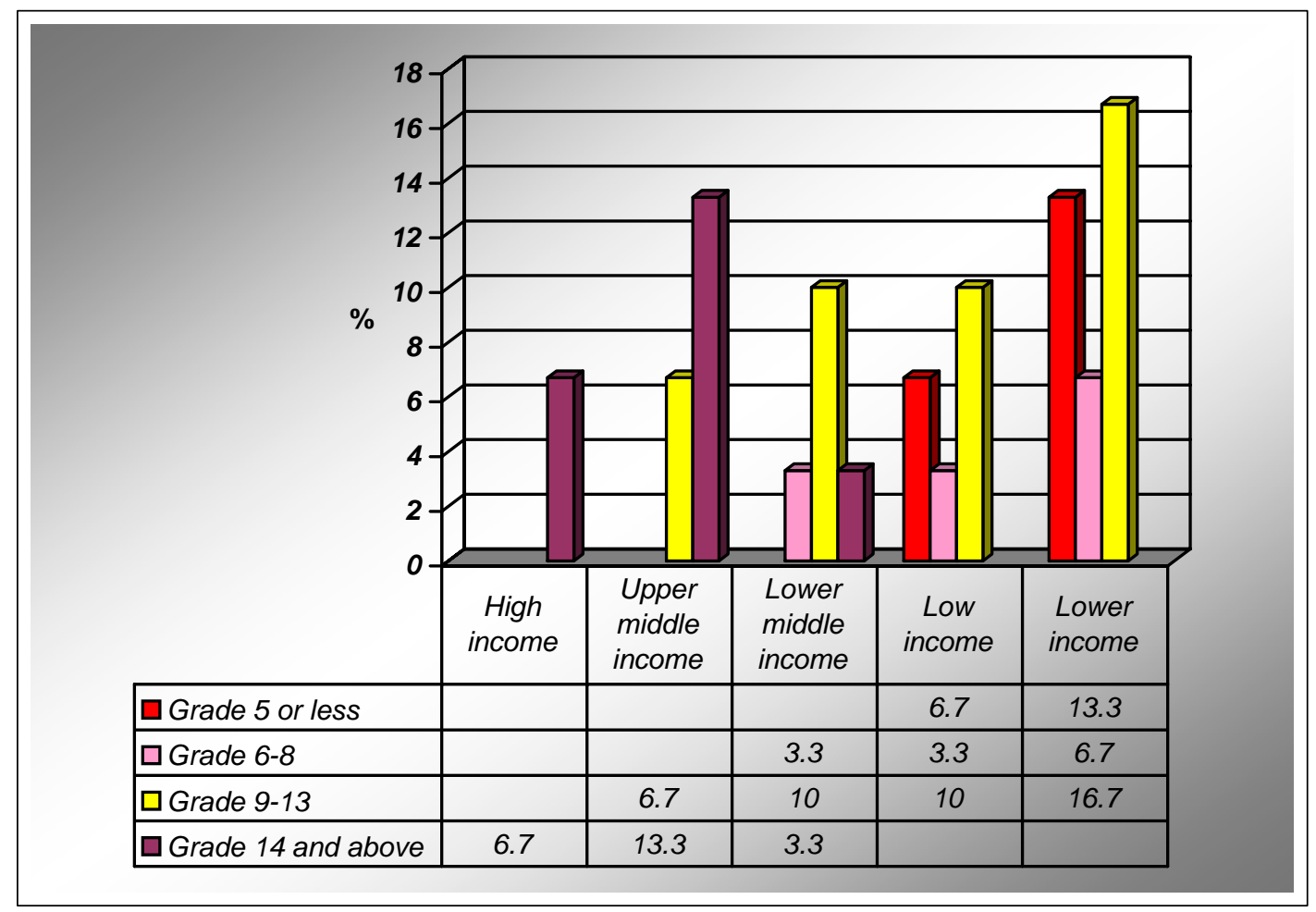

Figure 6.2 (a): Distribution of annual household income quintiles by education: Dzingahe

There is an observed cluster distribution of householders with diverse educational experience in the lower quintiles (low and lower income categories) in both villages. As one moves up the top quintile, educational attainment of the householders tend to determine their position in the income ladder. This implies that there are specific processes in operation that value formal education more than any other skill or ability not 
acquired through formal learning. This implication is backed up by qualitative evidence from the focus group discussions. For example, in a focus group activity where participants were asked to identify resources available for short-term flood risk reduction at the individual and household level, most participants considered their particular skills (e.g. weaving, wooden-spoon making, etc.) as not worth-mentioning. One respondent at Milaboni village explained: "My skills of making pot-holding stands and wooden spoons are part of me. I mean I'm born with these skills, but they are not so much important nowadays, because I could make little or no money out of them” (Focus Group Discussions, November, 2005).

This participant considered his/her particular skills as worthless partly because they are considered "natural" rather than acquired from formal institutions and as such they are perceived to have little economic value. A similar example is provided by a builder at Dzingahe village who explained:

I did not go to school to study building as a subject, but I can read plans [blueprints] and build houses and schools. I learned these skills when I was working with the "boers" 11 in Johannesburg. The problem with building schools is that I cannot get any tender from the government because I do not have a building Certificate (Focus Group Discussions, November, 2005).

Though the participant is emphasizing a different skill, this narrative supports the point stated earlier, that there are processes of power relations that validate certain skills as more valuable than others. This process of validation strips individuals of their power or ability to recognize valuable skills that are inherent in them which can be put to productive use.

\footnotetext{
${ }^{11}$ Boers (farmers) or "Afrikaans" refer to white South Africans of Dutch descent. The word, "Afrikaans," means "African" and was first used to indicate white reluctance to leave Africa, because they identified themselves as Africans.
} 
High unemployment rates of the graduates might provide some explanation pertaining to why the majority of householders, including those with Grade 14 and above is still in the lower income categories [see Figures 6.2 (a; b)]. Skills learnt in formal educational environments (i.e. certified skills) are considered valuable and are associated with white collar jobs and high social status. Households with these skills, however, tend to cope well during flood crises. Recognition of social status is pursued, especially by the young graduates to the extent that an individual may choose not to do any other job even if there are no vacancies in the formal employment sector. Adherence to this form of reasoning among the youth is gradually changing as more educated but unemployed youth are engaging in productive legal activities outside the formal sector.

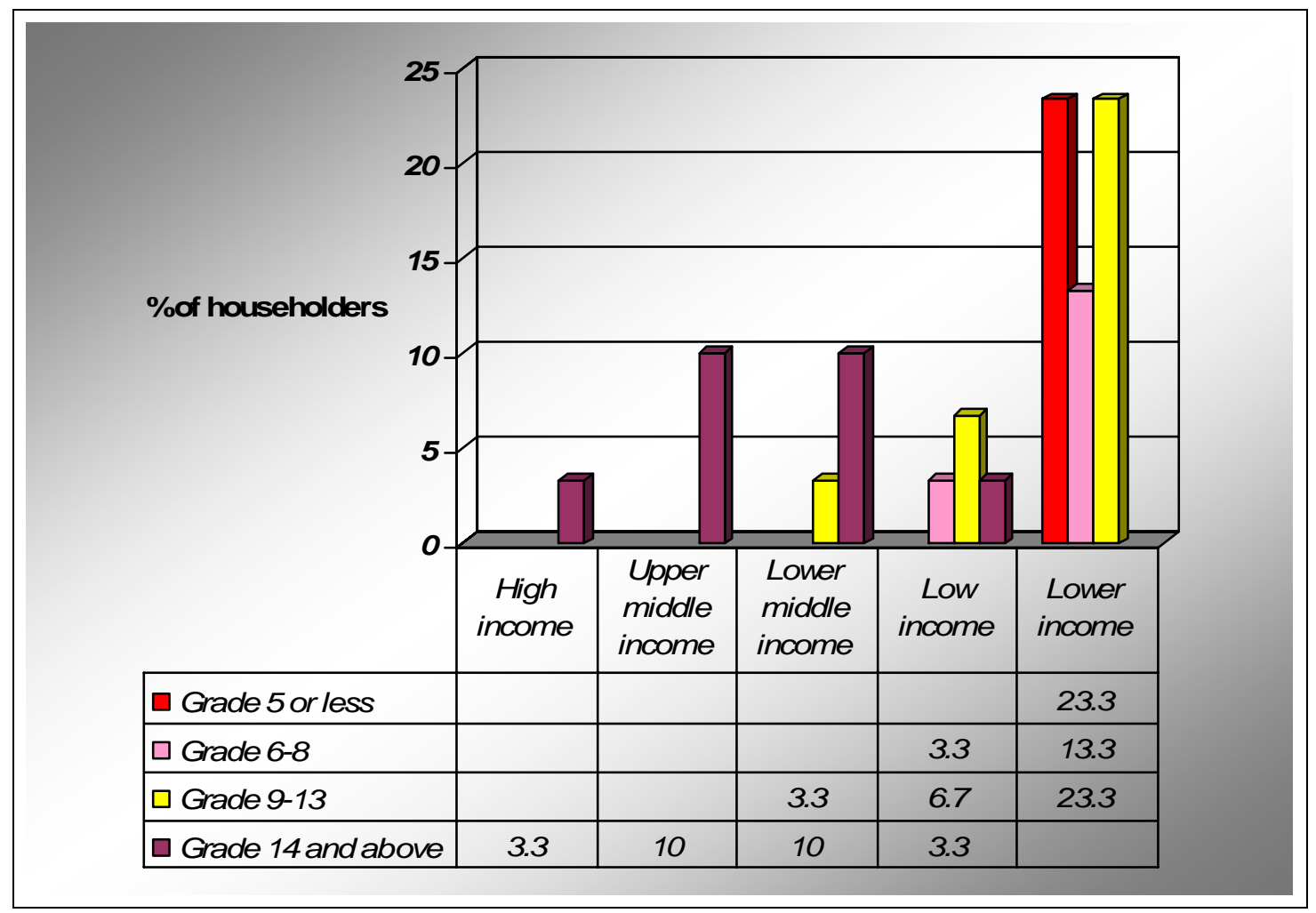

Figure 6.2 (b): Distribution of annual household income by education: Milaboni 
A bivariate analysis of annual household income by its main source puts the contribution to the lower income category, of the informal sector in both villages, at $27 \%$ of the total household annual income (see Table 6.1). The overall contribution of the informal sector in the study area is $40 \%$. This implies that considerable proportions of households depend on the employment opportunities offered by the informal sector. These employment opportunities are unstable and combined with poor income often mean that these households would have insufficient financial reserves to buffer them against the negative impacts of future flood hazards. Hence, the dependence on the informal sector might make it difficult for households to fully recover from flood impacts and thereby increasing their vulnerability to future hazards, especially when spatial interactions are disrupted. Furthermore, poor households whose main source of income was the informal sector were more vulnerable than those who relied on formal employment. Medium and high income households were less vulnerable because of higher levels of coping capacity and resilience.

Table 6.1: Main source of Annual Household Income by Income quintiles: Dzingahe and Milaboni

\begin{tabular}{|c|c|c|c|c|c|c|}
\hline \multirow[b]{3}{*}{ INCOME QUINTILES } & \multicolumn{3}{|c|}{ STUDY AREA } & \multicolumn{2}{|c|}{ VILLAGES } & \\
\hline & \multicolumn{3}{|c|}{$\begin{array}{l}\text { DZINGAHE (N= 30) } \\
\text { Source of Income }\end{array}$} & \multicolumn{3}{|c|}{$\begin{array}{l}\text { MILABONI }(\mathbf{N}=\mathbf{3 0}) \\
\text { Source of Income }\end{array}$} \\
\hline & $\begin{array}{c}\text { Informal } \\
\text { Business } \\
f(\%)\end{array}$ & $\begin{array}{c}\text { Old-age } \\
\text { Pension } \\
f(\%)\end{array}$ & $\begin{array}{c}\text { Formal } \\
\text { Employment } \\
f(\%)\end{array}$ & $\begin{array}{c}\text { Informal } \\
\text { Business } \\
\mathrm{f}(\%)\end{array}$ & $\begin{array}{l}\text { Old-age } \\
\text { Pension } \\
\mathrm{f}(\%)\end{array}$ & $\begin{array}{l}\text { Formal } \\
\text { Employment } \\
\mathrm{f}(\%)\end{array}$ \\
\hline Lower income (R400 - 6 868) & $8(26.7 \%)$ & $3(10 \%)$ & ---- & $8(26.7 \%)$ & $2(6.7 \%)$ & $8(26.7 \%)$ \\
\hline Low income (R6 869 - 12 660) & $2(6.7 \%)$ & $1(3.3 \%)$ & $3(10 \%)$ & $2(6.7 \%)$ & 1 (3.3\%) & $1(3.3 \%)$ \\
\hline Lower middle income (R12 661- 23 940) & $2(6.7 \%)$ & $-\cdots-$ & $3(10 \%)$ & ---- & $1(3.3 \%)$ & $3(10 \%)$ \\
\hline Upper middle income (R23 941 - 52 800) & ---- & $-\cdots$ & $5(16.7 \%)$ & $2(6.7 \%)$ & $-\cdots$ & $1(3.3 \%)$ \\
\hline High income (R52 8001 and above) & ---- & ---- & $2(6.7 \%)$ & --- & --- & $1(3.3 \%)$ \\
\hline TOTAL & $12(40.1 \%)$ & $\begin{array}{l}4(13.3 \%) \\
N=28\end{array}$ & $13(43.4 \%)$ & $12(40.1 \%)$ & $\begin{array}{l}4(13.3 \%) \\
N=30\end{array}$ & $14(46.6 \%)$ \\
\hline
\end{tabular}


However, in a provincial economy where the supporting systems and policies are skewed towards the development of the formal sector and where unemployment is at $31 \%$ (Statistics South Africa, 2001), this finding present serious challenges to the regulatory framework of the informal sector. In these poor rural communities the sampled economic contribution of the informal sector (40\%) and the old-age pension (13.3\%) to the overall annual household income is important. Table 6.1 supports the finding of the focus group discussions that there is a high dependency on social grants and pensions in these two villages. The importance of social grants in the study sites cannot be under-estimated in that they sustain household livelihoods and support educational endeavors of the disadvantaged youth in these villages. In this case, the elderly are regarded not as the usual vulnerable group (because of immobility and lack of resilience) but as a powerful community asset by providing the necessary productive resources and skills for households to cope and recover from flood impacts. In this case, power and vulnerability are sides of the same coin.

Household income is also differentiated by gender of the head of the household. An analysis based on Figure 6.3, shows that female-headed households in these two villages are poorer than the male-headed. However, there are important variations at the village scale of analysis. An aggregated income gap is more pronounced at Milaboni than at Dzingahe village, where the income gap seems narrower. For example, at Milaboni village, one-third (33\%) of the female-headed households were among the poorest fifth compared with $27 \%$ male-headed households. In contrast, a relatively small proportion of households (37\%) are in the lower quintile with minor variation (3\%) based on gender (see Figure 6.3). 


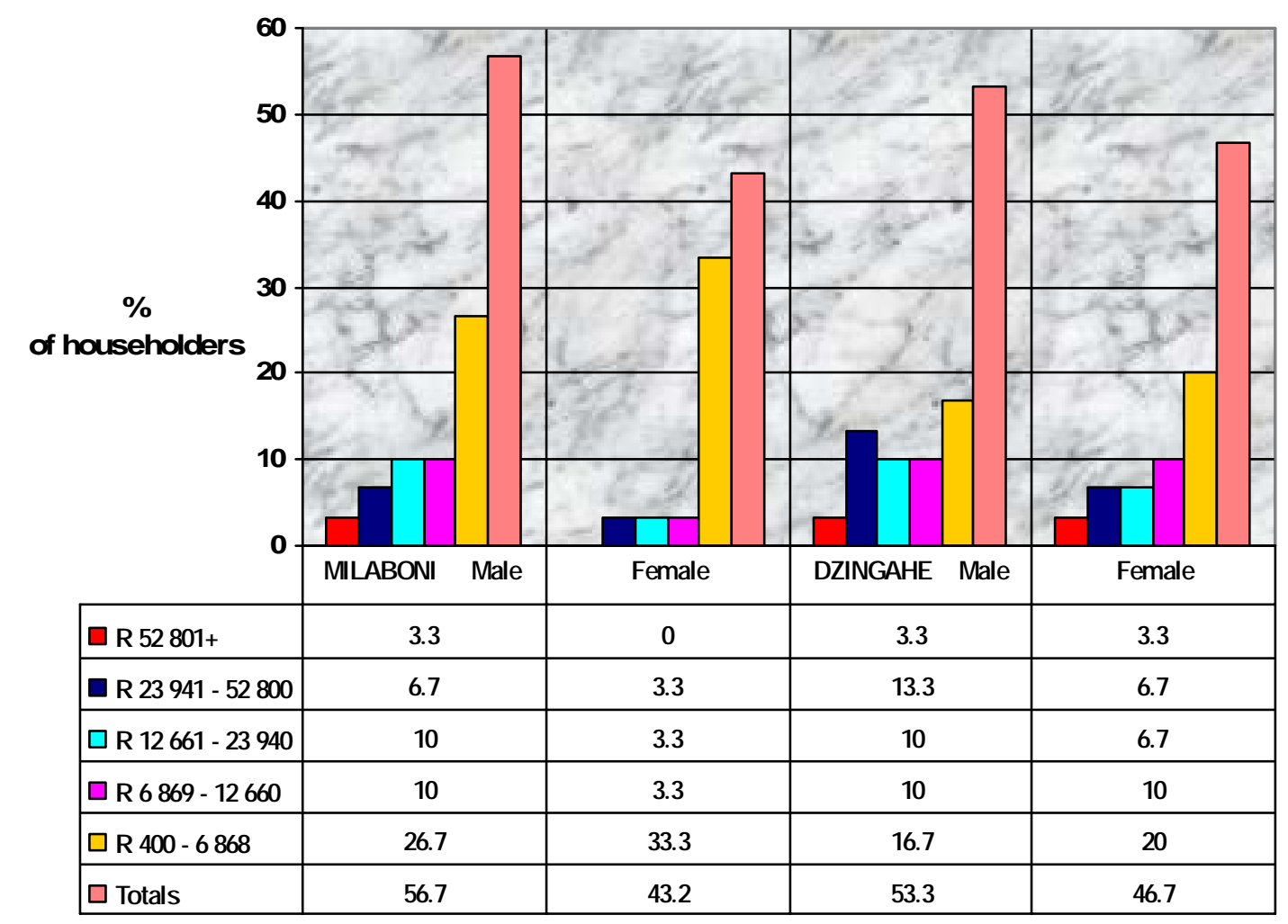

Figure 6.3: Annual household income distributions by gender of householders

Overall, the finding about household differentiation based on gender, has serious implications for flood vulnerability of these poor female-headed households. The recovery efforts of these households would be slow and difficult to accomplish, partly because of their limited access to resources. Furthermore, their poor economic status coupled with patriarchy would limit their access to post-disaster aid and more importantly, their access to land within these communities. Hence, on the basis on these findings, the poor female-headed households were more vulnerable to floods than the male-headed households. 


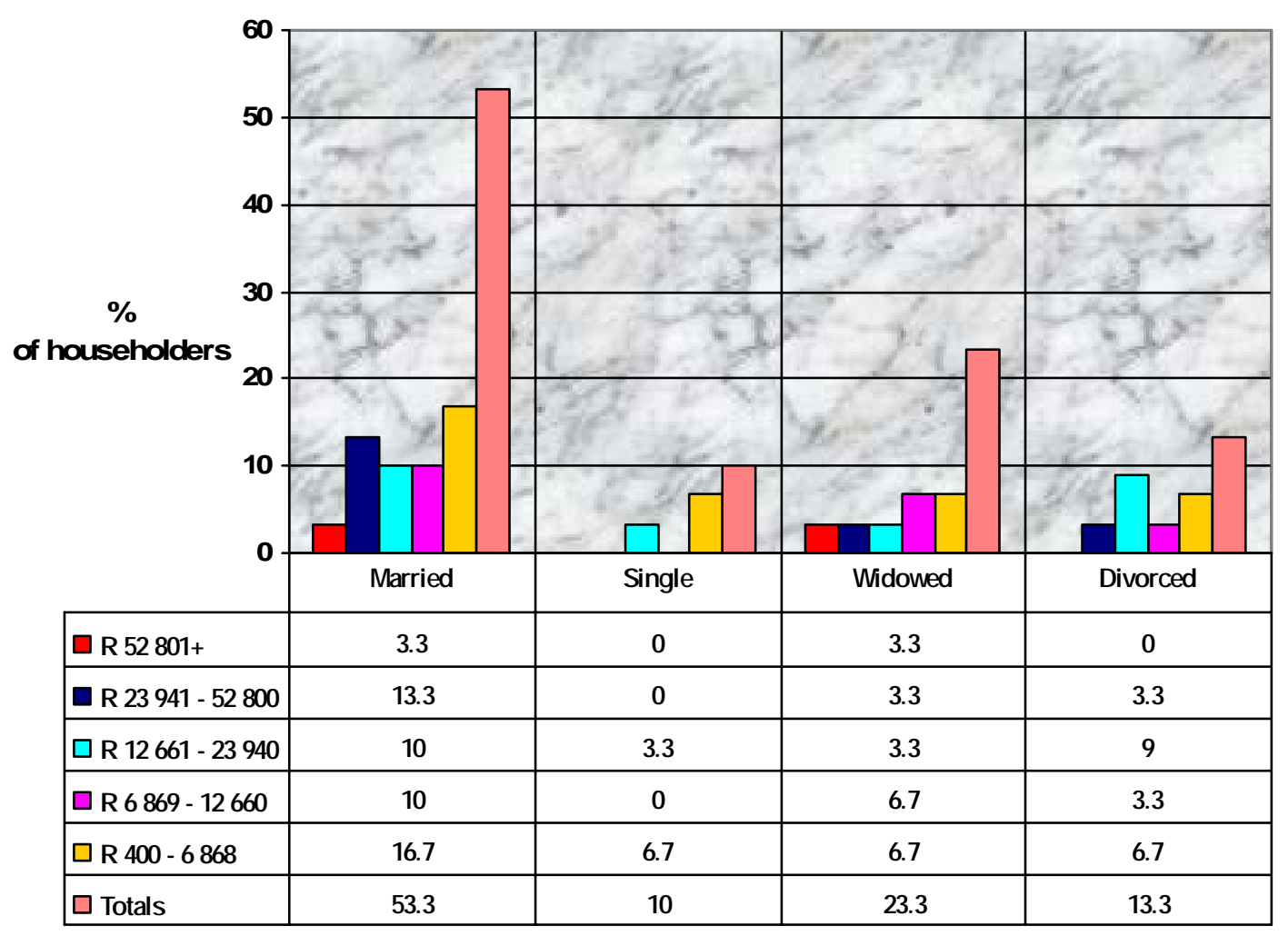

Figure 6.4(a): Annual household income distributions by marital status of householders: Dzingahe

Figures $6.4(\mathrm{a}$; b) show the distributions of annual household income by marital status. Considerable proportions of householders (67\%) at Milaboni are married compared to 53\% at Dzingahe village. Marital status seems to play an important role in determining flood vulnerability. At Dzingahe village, all the income quintiles are represented as compared to only two at Milaboni village. Depending on the form of marriage, spouses that are widowed at Dzingahe village tend to have access to more resources including land than those at Milaboni village. In this case, marital status serves as a buffer against negative flood impacts because it is associated with property or resource heritage. Hence, the householders' positionality in lineage, marriage and access to resources at Dzingahe enhance their levels of resilience or their vulnerability to flood crises. The situation is different at Milaboni village where traditional patriarchal practices seem dominant. 


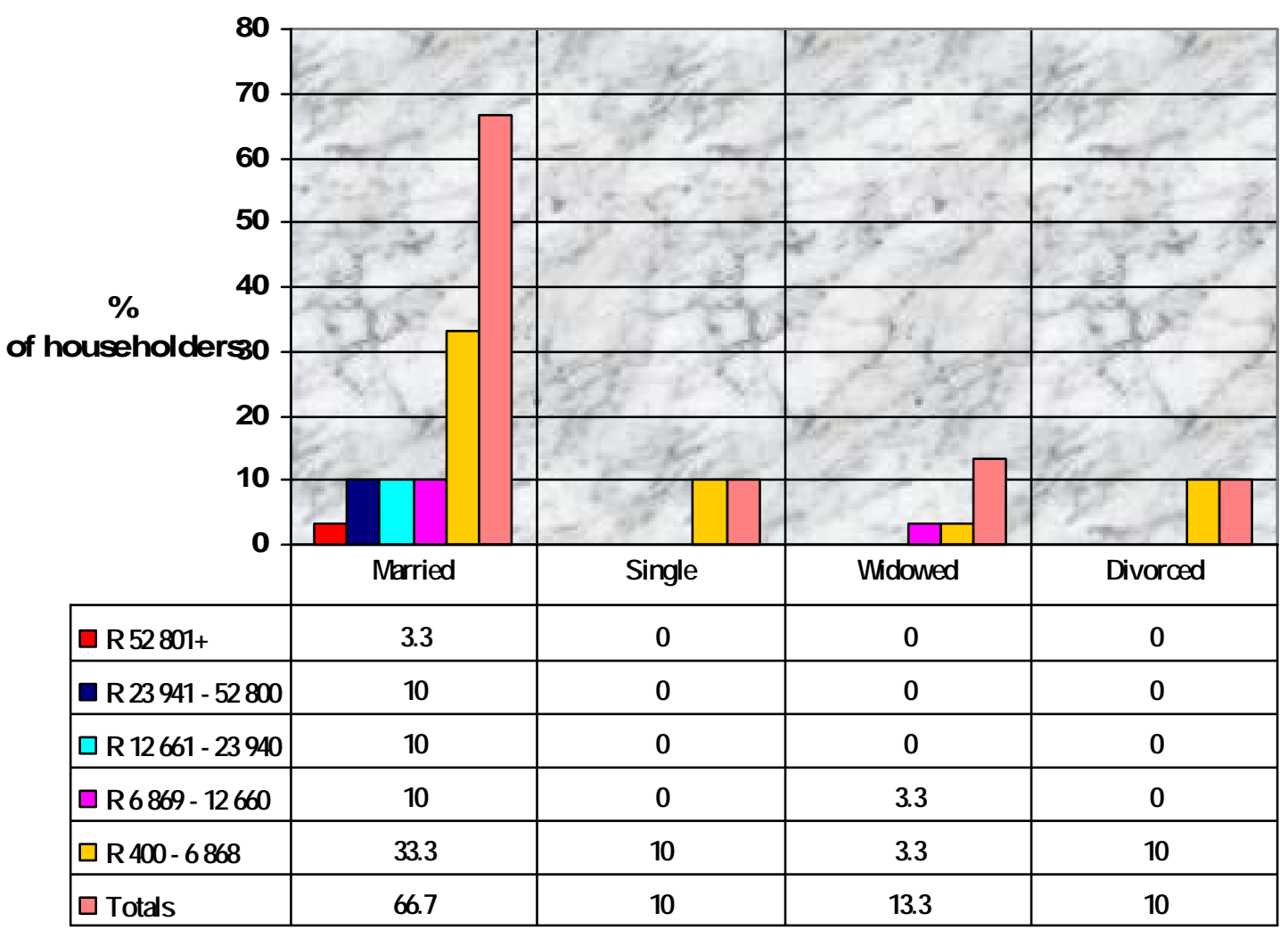

Figure 6.4(b): Annual household income distributions by marital status of householders: Milaboni

\subsubsection{Housing type and Quality}

Housing type and quality are important determinants of household flood vulnerability. A house in its most general sense is a human-built dwelling with enclosing walls, a floor, and a roof. As measures of flood vulnerability, the nature of building materials and the overall amenities associated with the house add to its quality. Housing quality determines whether the house would withstand or not the massive power of flood waters. In order to get a quick look-up of the housing conditions in the study area, a Housing Quality Index (HQI) was incorporated in the household survey administered at Dzingahe and Milaboni villages. The number of dwelling units within a household was recorded and the 
information about the housing type and quality was gathered for the main dwelling (house/hut) of the household. The results of the HQI are presented in Tables 6.2 (a; b).

Table 6.2 (a): Housing Quality Index (Building materials) for the main dwelling unit: Dzingahe \& Milaboni villages

STUDY AREA VILLAGES

\begin{tabular}{|c|c|c|c|c|c|c|}
\hline \multirow{2}{*}{ BUILDING MATERIALS } & \multicolumn{3}{|c|}{ DZINGAHE $(\mathrm{N}=30)$} & \multicolumn{3}{|c|}{ MILABONI $(\mathrm{N}=30)$} \\
\hline & $\begin{array}{c}\text { WALLS } \\
f(\%)\end{array}$ & $\begin{array}{c}\text { FLOORS } \\
f(\%)\end{array}$ & $\begin{array}{c}\text { ROOF } \\
f(\%)\end{array}$ & $\begin{array}{c}\text { WALLS } \\
f(\%)\end{array}$ & $\begin{array}{c}\text { FLOORS } \\
f(\%)\end{array}$ & $\begin{array}{l}\text { ROOF } \\
f(\%)\end{array}$ \\
\hline Mud /Dirt & $16(53.3 \%)$ & $14(46.7 \%$ & $-\cdots$ & $17(56.7 \%)$ & $15(50 \%)$ & \\
\hline Masonry (brick cement and block) & $14(46.7 \%)$ & ---- & ---- & $12(40 \%)$ & & \\
\hline Metallic sheets & ---- & $\cdots$ & $5(16.7 \%)$ & $1(3.3 \%)$ & & $4(13.3 \%)$ \\
\hline Cement & $\cdots---$ & $4(13.3 \%)$ & $\cdots$ & & $6(20 \%)$ & \\
\hline Tiles & $\cdots$ & $12(40 \%)$ & $8(26.7 \%)$ & & $9(30 \%)$ & $8(26.7 \%)$ \\
\hline Grass thatch & ---- & $-\cdots--$ & $17(56.7 \%)$ & & & $18(60 \%)$ \\
\hline TOTAL & $30(100 \%)$ & $30(100 \%)$ & $30(100 \%)$ & $30(100 \%)$ & $30(100 \%)$ & $30(100 \%)$ \\
\hline
\end{tabular}

Table 6.2 (b): Housing Quality Index (Access to Amenities) for the main dwelling unit: Dzingahe \& Milaboni villages

\begin{tabular}{|c|c|c|c|c|c|c|}
\hline \multirow[t]{2}{*}{ ACCESS TO AMENITIES } & \multicolumn{3}{|c|}{$\begin{array}{l}\text { DZINGAHE } \\
(\mathrm{N}=30)\end{array}$} & \multicolumn{3}{|c|}{$\begin{array}{l}\text { MILABONI } \\
(\mathrm{N}=30)\end{array}$} \\
\hline & $\begin{array}{c}\text { POWER } \\
f(\%)\end{array}$ & $\begin{array}{l}\text { WATER } \\
f(\%)\end{array}$ & $\begin{array}{c}\text { SANITATION } \\
f(\%)\end{array}$ & $\begin{array}{c}\text { POWER } \\
f(\%)\end{array}$ & $\begin{array}{c}\text { WATER } \\
f(\%)\end{array}$ & $\begin{array}{l}\text { SANITATION } \\
f(\%)\end{array}$ \\
\hline Wood & $6(20 \%)$ & ---- & ---- & $15(50 \%)$ & +--- & ----- \\
\hline Paraffin/Kerosene; candles/lamp & $11(36.7 \%)$ & $-\cdots--$ & $\ldots$ & $4(13.3 \%)$ & $-\cdots--$ & $-\cdots--$ \\
\hline Electricity & $12(40 \%)$ & ----- & ---- & $11(36.7 \%)$ & ---- & ---- \\
\hline Gas/Propane & $1(3.3 \%)$ & ---- & ---- & ---- & ---- & ---- \\
\hline Communal water tap on street & ---- & $22(73.3 \%)$ & ----- & ---- & $19(63.3 \%)$ & ---- \\
\hline Water tap in yard & ---- & $8(26.7 \%)$ & ---- & ---- & $10(33.3 \%)$ & ---- \\
\hline Boreholes or Fountains & ---- & ---- & ---- & ---- & $1(3.3 \%)$ & ---- \\
\hline Pit-toilet on yard & ---- & ---- & $30(100 \%)$ & ---- & ---- & $30(100 \%)$ \\
\hline TOTAL & $30(100 \%)$ & $30(100 \%)$ & $30(100 \%)$ & $30(100 \%)$ & $30(100 \%)$ & $30(100 \%)$ \\
\hline
\end{tabular}


As evident from Table 6.2 (a), a considerable majority of households in both villages have walls and floors of their main houses made up of mud or dirt compared to other building materials. From the many options available for roofing materials, grass thatch is the predominant roofing material followed by tiles and metallic sheets (also see Figures $6.5 \mathrm{a}$; b). Thatch roofing is becoming difficult to maintain in these villages since thatch grass is no longer readily available, because of drought. Huts with grass as roofing materials normally leak during rainy seasons and combined with muddy walls, the destruction by floods becomes great. An alternative housing options for the poor and the rich are represented by Figures 6.5 (b; c) respectively. These figures represent the spatial manifestation of poverty and wealth on the same cultural landscape. As evident in these figures, the housing quality index is an important indicator of flood vulnerability. For example, households in buildings structures such as those indicated in Figure 6.5 (a; b) are more vulnerable to floods than a household in Figure 6.5 (c), whose housing structure represents high coping capacity and more resilience to flood hazards. Similar observations were evident at Dzingahe village.

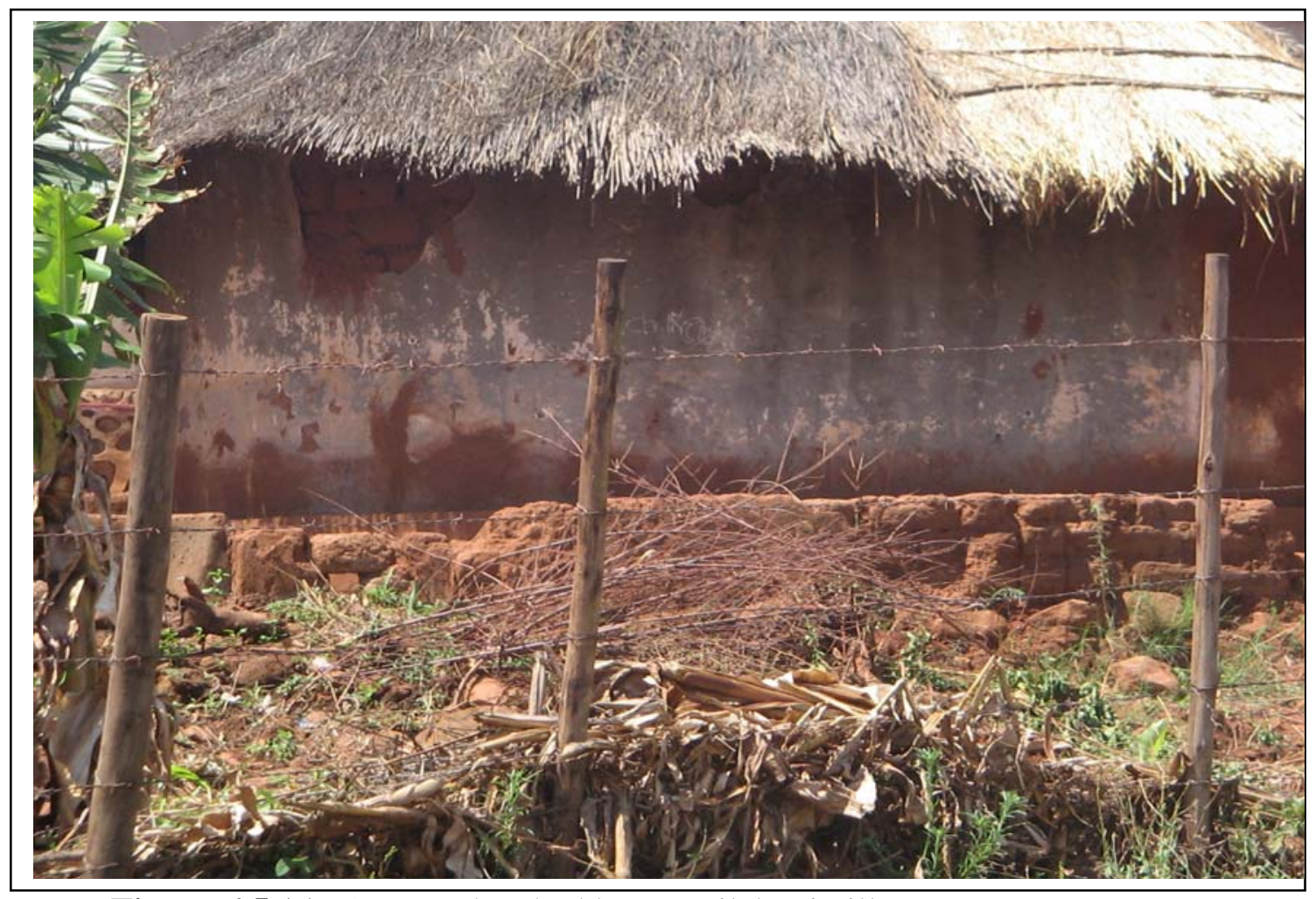

Figure 6.5 (a): A grass thatched hut at Milaboni village 


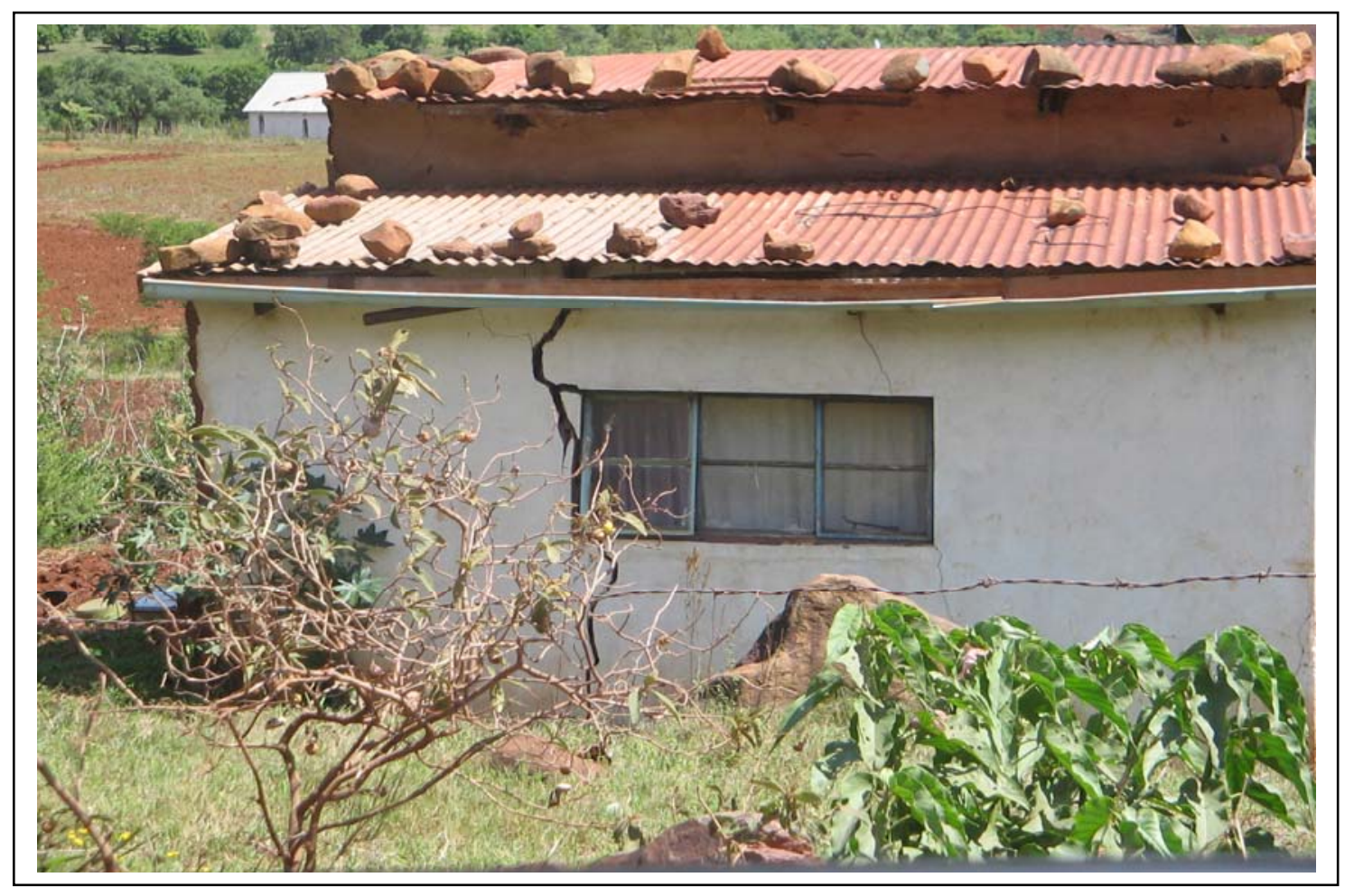

Figure 6.5 (b): A poor quality housing structure with metallic sheets at Milaboni village.

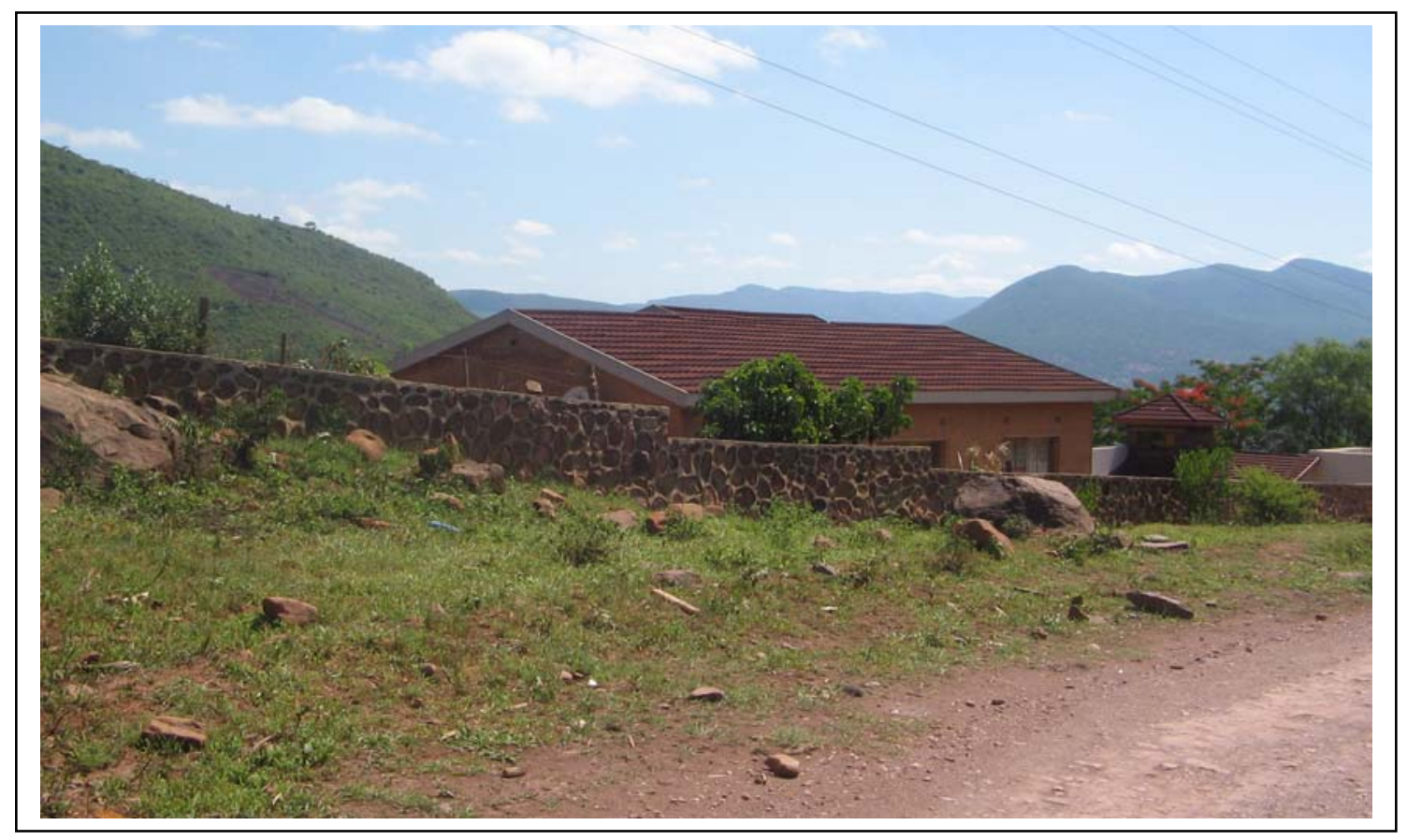

Figure 6.5 (c): A housing option for some residents at Milaboni village. 
Correlating housing quality (building materials) with annual income confirmed the fact that poor households live in poorly built and inadequately maintained housing, which are more likely to be destroyed or damaged by flooding. For example, 53.3\% of households at Milaboni compared with $36.7 \%$ at Dzingahe have used mud/dirt as predominant materials for the external walls of their main houses/huts. The same falls within the poorest fifth (R400-6 868) quintile. The same trend is observed for floor and roofing materials. A high proportion of households in both villages have used mud/dirt and grass for flooring and roofing respectively. Although the local government at Milaboni village

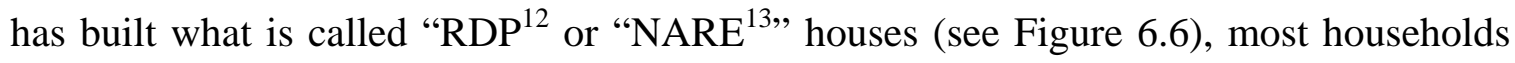
did not regard them as the main dwelling units, partly because they are small and uniform. This type of RDP housing puts household identity and pride at risk, because of the stigma associated with them.

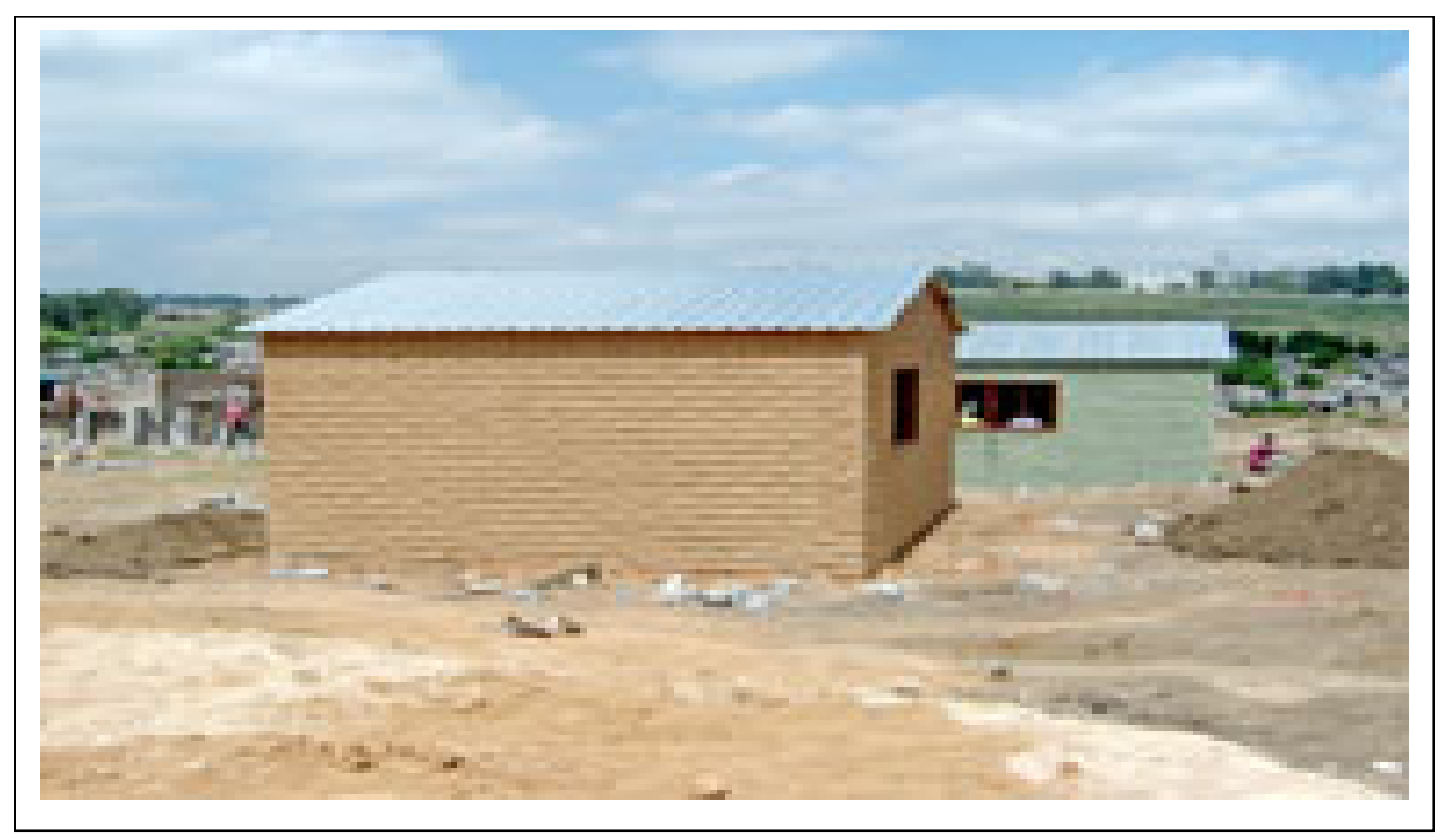

Figure 6.6: A Typical RDP Housing Structure

\footnotetext{
${ }^{12}$ RDP means Reconstruction and Development Program.

13، Nare": name of the construction company that built them.
} 
In terms of amenities, Table 6.2 (b) indicates that a higher proportion in both villages used wood, paraffin (kerosene) and candles for cooking and lighting purposes. Electricity is also a predominant source of power for $40 \%$ households at Dzingahe and $37 \%$ at Milaboni villages. Heavy reliance on wood as a source of energy does not necessarily mean lack of electricity, since most households combine the use of wood with electricity to cut down on electric bills. Communal water tap on streets supply most of the water needs of households in both study sites. Other forms of water supply such as boreholes or fountains ranked less with most of the households, because fountains have disappeared in most rivers and boreholes are usually dry as ground water levels drop below the levels of the pump intakes.

\subsubsection{Household Assets}

Another good indicator of household flood vulnerability is the asset-holding of the household. The assets owned and controlled by households in the study area are presented in Table 6.3. These include livestock, land, car, and home and personal electronics such as TV, radio, computer and cell-phones. These assets have direct utility values as a means of household survival. In terms of home and personal electronics, radio ownership is the highest in the surveyed villages, followed by the cell-phone and the television sets, especially for those with access to electricity. In general, households in both villages have more than basic facilities including the cell-phones. One expected finding though, is the differentiation of assets by gender, especially, livestock. The ownership of livestock by male-headed households is higher than that of the femaleheaded households (see Table 6.3). Significant differences also exist in as far as land ownership is concerned. Land tenure systems in these villages, though communal, often favor men than women. However, women can either acquire land if married 'in community of property' or as an inherited estate of their late husbands. These patriarchal practices usually limit women's access to and control of land as an important resource. 
Table 6.3: Multiple Response Table of Household Assets by gender

\begin{tabular}{|c|c|c|c|c|c|c|}
\hline \multirow{2}{*}{\multicolumn{4}{|c|}{$\begin{array}{c}\text { Dzingahe } \\
\mathrm{N}=30 \text { cases }\end{array}$}} & \multicolumn{3}{|c|}{ VILLAGES } \\
\hline & & & & & $\begin{array}{l}\text { boni } \\
N=30 \text { cases) }\end{array}$ & \\
\hline Household Assets & \begin{tabular}{|c|} 
Male \\
Responses \\
(\% of Cases)
\end{tabular} & \begin{tabular}{|c|} 
Female \\
Responses \\
(\% of Cases)
\end{tabular} & $\begin{array}{c}\text { Total } \\
\text { Responses } \\
\text { (\% of Cases) }\end{array}$ & $\begin{array}{c}\text { Male } \\
\text { Responses } \\
\text { (\% of Cases) }\end{array}$ & $\begin{array}{c}\text { Female } \\
\text { Responses } \\
\text { (\% of Cases) }\end{array}$ & $\begin{array}{c}\text { Total } \\
\text { Responses } \\
\text { (\% of Cases) }\end{array}$ \\
\hline Cattle & $17(56.7 \%)$ & $3(10 \%)$ & $20(66.7 \%)$ & $11(36.7 \%)$ & $9(30 \%)$ & $20(66.7 \%)$ \\
\hline Goats & $16(53.3 \%)$ & $10(33.3 \%$ & $26(86.7 \%)$ & $11(36.7 \%)$ & $6(20 \%)$ & $17(56.7 \%)$ \\
\hline Sheep & ---- & ---- & --- & $3(10 \%)$ & ---- & $2(6.7 \%)$ \\
\hline Orchard & $9(30 \%)$ & $4(13.3 \%)$ & $13(43.3 \%)$ & $6(20 \%)$ & $7(23.3 \%)$ & $13(43.3 \%)$ \\
\hline Plot of arable land on stand & $2(6.7 \%)$ & $6(20 \%)$ & $8(26.7 \%)$ & $7(23.3 \%)$ & $2(6.7 \%)$ & $9(30 \%)$ \\
\hline Field outside stand & $14(46.7 \%)$ & $3(10 \%)$ & $17(56.7 \%)$ & $8(26.7 \%)$ & $2(6.7 \%)$ & $10(33 \%)$ \\
\hline Modern House & $8(26.7 \%)$ & $8(26.7 \%)$ & $16(53.3 \%)$ & $11(36.7 \%)$ & $3(10 \%)$ & $14(46.7 \%)$ \\
\hline Car/truck/van & $10(33.3 \%)$ & $6(20 \%)$ & $16(53.3 \%)$ & $7(23.3 \%)$ & $3(10 \%)$ & $10(33.3 \%)$ \\
\hline Tractor & $1(3.3 \%)$ & $3(10 \%)$ & $4(13.3 \%)$ & $2(6.7 \%)$ & ---- & $2(6.7 \%)$ \\
\hline Computer & $6(20 \%)$ & $2(6.7 \%)$ & $8(26.7 \%)$ & $6(20 \%)$ & $1(3.3 \%)$ & $7(23.3 \%)$ \\
\hline TV & $12(40 \%)$ & $9(30 \%)$ & $21(70 \%)$ & $16(53.3 \%)$ & $7(23.3)$ & $23(76.7 \%)$ \\
\hline Cell-phone & $12(40 \%)$ & $12(40 \%)$ & $24(80 \%)$ & $15(50 \%)$ & $10(33 \%)$ & 25 (83.3\%) \\
\hline Radio & 16 (53.3\%) & $14(46.7 \%)$ & $30(100 \%)$ & $17(56.7 \%)$ & $13(43.3 \%)$ & $30(100 \%)$ \\
\hline Fridge & $12(40 \%)$ & $6(20 \%)$ & $18(60 \%)$ & $12(40 \%)$ & 8 (26.7\%) & $20(66.7 \%)$ \\
\hline None & ---- & ---- & ---- & ---- & ---- & $2(6.7 \%)$ \\
\hline Other & ---- & ---- & 4 (13.3\%) & $4(13.3 \%)$ & $4(13.3 \%)$ & $8(26.7 \%)$ \\
\hline
\end{tabular}

Communities in these villages do not own much sophisticated gadgets but one gadget most owned is the cell-phone. Mobile telephones have revolutionized communication systems in these villages more than landline telephone systems. Cell phone ownership is high even amongst households with low annual income. Eighty percent of households at Dzingahe and 83\% at Milaboni owned a mobile phone compared to 27\% (Dzingahe) and 23\% (Milaboni) that own a computer. In these communities, the mobile telephone is more important than the computer for social and community organization. 
Focus group discussions confirmed the importance of cell-phones as a communication link between those at home and those migrants that are in remote urban areas. Logistical arrangements pertaining to remittances are also communicated over by cell-phones. More importantly, the fact that a "Pay as you go" subscriber does not pay for incoming calls and has free "Please call me" privileges, elevates the importance of this communication device in these rural communities. Focus group participants also indicated the role of cell-phone communication during any crisis, including floods, mostly because of the free "Please call me" feature.

Table 6.3 indicates that 53\% of households at Dzingahe and 33\% at Milaboni villages have access to a vehicular mode of transport. A considerable proportion of households without private means of transport reported that they use public transport or hitch-hike to work or the market for those engaged in informal businesses. Lack of private means of transport implies slow reaction towards the heeding of evacuation warnings or buying enough food supplies that can sustain the household during flood emergencies. Lack of emergency supplies further means that households often tend to buy necessities at exorbitant rates, since those with means of transport and money often buy goods in bulk during flood emergencies and re-sell them at higher than normal prices.

Livestock such as cattle, goats and sheep becomes important assets as forms of coping with flood crisis. Likewise, TV and radios could be disposed during family flood crisis and they are important as carriers of flood warning messages, especially the battery or solar /air operated radios.

\subsubsection{Perceived Economic Pressure}

The overall obligation of the head of household in an African setting is to provide for the whole family. However, the pendulum of responsibility is shifting from men being the main provider to a shared balance of responsibilities. This shift is largely due to a form of marriage that brings the property of the spouses together in a joint estate and an increasing participation of women in the workforce. Differential perceived economic 
pressure is a function of the absence or presence of family support to make ends meet. Householders were asked to rate a list of characteristics that might describe their family situations on a Likert scale from 1 (strongly disagree) to 5 (strongly agree). These ratings were used as indicators for assessing perceived differential household flood coping capacity. The results of these ratings are presented in Tables 6.4 (a; b). In general, householders in both villages perceive themselves as incapable of buying a house in the nearby town. Hence, they did not have an option of moving into a nearby urban area. However, differential responses exist within the villages themselves. At both villages, for instance, although 57\% felt they did not have enough financial capital to procure a house, only $20 \%$ of this total felt very strongly about this.

Similar differential trends were observed regarding all other economic pressure indicators listed in Table 6.4 (a). Although householders in these villages indicated sustained economic hardships as reflected in their respective responses on issues such as inadequate bank savings, lack of capacity to survive a crisis, inaccessibility to land and electricity, most households strongly disagreed that they were poorer than before and that they were starving and as such relied on neighbors for basic needs. It is common for male-headed households not to report their poverty, starvation, and dependence situations, especially if they detected no immediate assistance, like in this case.

The majority of households in both villages indicated heavy reliance on wood and electricity at the same time. As explained elsewhere, the relationship between households' dependence on wood and electric energy is not straightforward. Heavy reliance on wood in these communities does not necessarily mean that there is no electricity provision, because households tend to depend on both sources of energy for different purposes at different times. 
Table 6.4 (a): Likert Scale Response Table of Perceived Household Economic Pressure

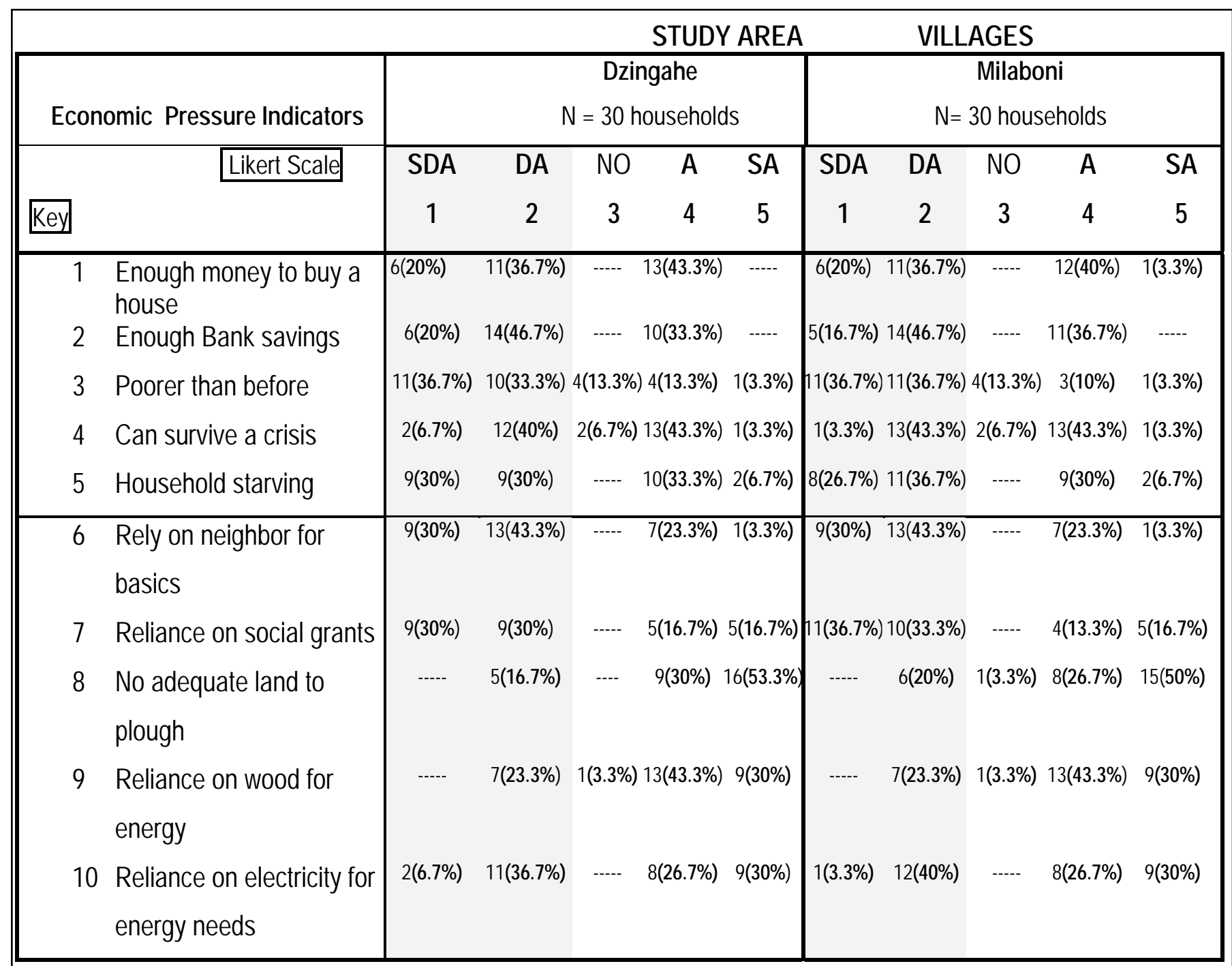

Key: 1. SDA = Strongly Disagree; 2. DA= Disagree; 3. NO = No Opinion; 4. A = Agree; 5. SA = Strongly Agree 
Table 6.4 (b): Means and Standard Deviations of Perceived Household Economic Pressure

\begin{tabular}{|c|c|c|c|c|c|c|c|c|c|c|c|}
\hline \multicolumn{12}{|c|}{ STUDY AREA VILLAGES } \\
\hline \multicolumn{2}{|c|}{ Economic Pressure Indicators } & \multicolumn{5}{|c|}{$\begin{array}{l}\text { Dzingahe } \\
N=30\end{array}$} & \multicolumn{5}{|c|}{$\begin{array}{l}\text { Milaboni } \\
\mathrm{N}=30\end{array}$} \\
\hline \multirow{2}{*}{\multicolumn{2}{|c|}{ Key }} & \multirow{2}{*}{$\begin{array}{c}\text { Sum } \\
1\end{array}$} & \multirow{2}{*}{$\begin{array}{c}\text { Mean } \\
2\end{array}$} & \multirow{2}{*}{$\begin{array}{c}\mathrm{SD} \\
3\end{array}$} & \multicolumn{2}{|c|}{ SkewKurtosis } & \multirow{2}{*}{$\begin{array}{c}\text { Sum } \\
1\end{array}$} & \multirow{2}{*}{$\begin{array}{c}\text { Mean } \\
2\end{array}$} & \multirow{2}{*}{$\begin{array}{c}\mathrm{SD} \\
3\end{array}$} & \multicolumn{2}{|c|}{ Ske Kurtosis } \\
\hline & & & & & 4 & 5 & & & & $\begin{array}{l}w \\
4\end{array}$ & 5 \\
\hline & $\begin{array}{l}\text { Enough money to buy a } \\
\text { house }\end{array}$ & 80 & 2.67 & 1.24 & -.004 & -1.74 & 81 & 2.70 & 1.29 & .09 & -1.58 \\
\hline 2 & Enough Bank savings & 74 & 2.47 & 1.17 & .37 & -1.42 & 77 & 2.57 & 1.17 & .25 & -1.54 \\
\hline 3 & Poorer than before & 64 & 2.13 & 1.17 & .84 & -.21 & 62 & 2.10 & 1.11 & .99 & .36 \\
\hline 4 & Can survive a crisis & 89 & 2.97 & 1.13 & -.09 & -1.45 & 90 & 3.0 & 1.1 & .00 & -1.55 \\
\hline 5 & Household starving & 77 & 2.57 & 1.41 & .29 & -1.52 & 76 & 2.53 & 1.36 & .412 & -1.33 \\
\hline 6 & $\begin{array}{l}\text { Rely on neighbor for } \\
\text { basics }\end{array}$ & 68 & 2.27 & 1.23 & .76 & -.70 & 68 & 2.27 & 1.23 & .76 & -.70 \\
\hline 7 & Reliance on social grants & 74 & 2.47 & 1.55 & .64 & -1.23 & 72 & 2.4 & 1.52 & .77 & -.99 \\
\hline 8 & $\begin{array}{l}\text { No adequate land to } \\
\text { plough }\end{array}$ & 126 & 4.2 & 1.10 & -1.27 & .31 & 122 & 4.1 & 1.17 & -.96 & -.59 \\
\hline 9 & $\begin{array}{l}\text { Reliance on wood for } \\
\text { energy }\end{array}$ & 114 & 3.8 & 1.13 & -.66 & -.90 & 114 & 3.8 & 1.13 & -.66 & -.89 \\
\hline & $\begin{array}{l}\text { Reliance on electricity for } \\
\text { energy needs }\end{array}$ & 101 & 3.4 & 1.43 & -1.7 & -1.63 & 102 & 3.4 & 1.38 & .12 & -1.71 \\
\hline
\end{tabular}


Overall, as indicated by the arithmetic means in Table 6.4 (b), households in the study sites disagreed pretty much with many of the economic pressure indicators with the exception of the last three indicators (nos. 8 - 10) in Tables 6.4 (a; b). The mean values of the latter indicators range from 3.4 to 4.2, indicating on a Likert scale a shift from "no opinion" to some form of "agreement" with the indicators as explained in the preceding paragraphs. Figures 6.7 (a; b) illustrate the distribution of the means, standard deviations, skewness and kurtosis for each of the perceived economic pressure indicators in the study sites. Skewness characterizes the degree of asymmetry (positive or negative) of a distribution around its mean while kurtosis characterizes the relative peakness (positive kurtosis) or flatness (negative kurtosis) of a distribution compared to the normal or a bellshaped distribution.

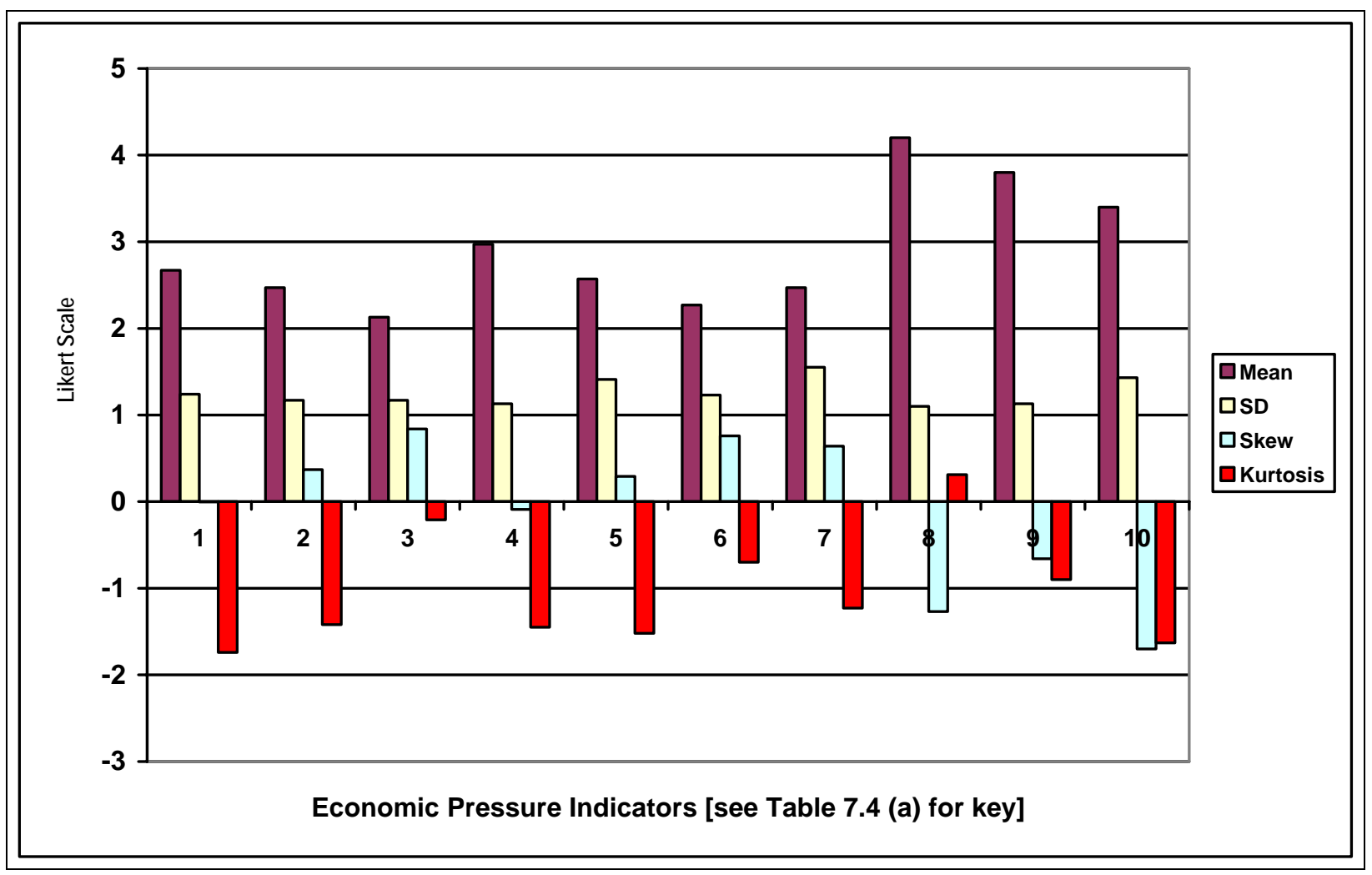

Figure 6.7 (a): Means, Standard Deviations, Skewness and Kurtosis of Perceived Household Economic Pressure: Dzingahe village 


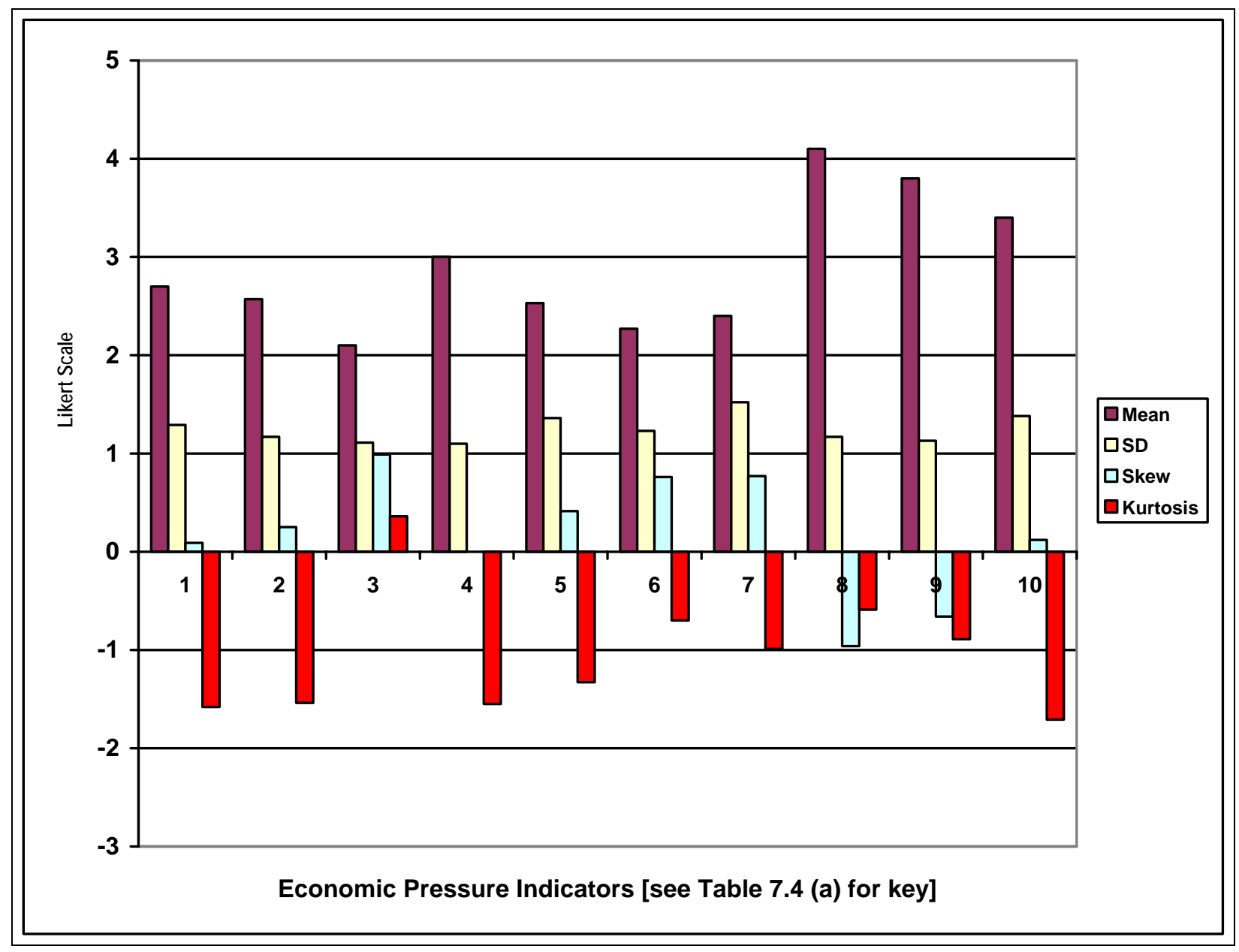

Figure 6.7 (b): Means, Standard Deviations, Skewness and Kurtosis of Perceived Household Economic Pressure: Milaboni village

Considering the distribution of each of the ten economic pressure indicators at the study sites, one can observe that many of the indicators have a positive asymmetry in that their skewness statistics is positive. However, the kurtosis statistics of many indicators in both villages shows a distribution that is too flat. What this means is that with the exception of indicators numbers 8 to 10, with Likert mean scores of above three, all the mean values of the remaining seven indicators have mean scores of three and below (see Figures 6.7 a; b). Overall the distribution of the perceived household economic pressure indicators is flat and negatively skewed. What this means is that householders have negative perceptions about their economic resilience and their ability to cope during flooding, hence more vulnerable. 


\subsubsection{Human and Personal resources}

Limited economic and material resources are not the only indicators of differential household vulnerability to floods. Human and personal resources such as health, age, physical disability within the household and household living arrangements are also critical factors that have produced differential flood vulnerability in the study area.

\subsubsection{Health status of householders}

Health is an important variable that explains differential flood vulnerability patterns in these villages. Figures 6.8 (a; b) show age distributions by health status of the householders at Milaboni and Dzingahe villages. Health is strongly and positively correlated with age at Milaboni $\left(\chi^{2}=18.351\right.$; $\mathrm{df}=12, \mathrm{p}=0.05$; Cramer's $\left.\mathrm{V}=.452\right)$ and Dzingahe villages ( $\chi^{2}=25.182 ; \mathrm{df}=9 ; \mathrm{p}=0.05$; Cramer's $\mathrm{V}=.529$ ). The strength of that correlation is denoted by Cramer's V (.452 at Milaboni and .529 at Dzingahe). What this means is that at Milaboni village $45 \%$ of flood vulnerability patterns compared to $53 \%$ at Dzingahe, are explained by these two variables. Other important variables discussed earlier (e.g. income, education, housing quality) explain the rest.

Overall, a reasonable segment (43.3\%) of householders across different age groups at Milaboni village compared with $30 \%$ at Dzingahe, have poor health outcomes. Health outcomes in both study sites also vary significantly by age. A closer analysis of data in Figures 6.8 (a, b) indicate that one third (30\%) of older householders (age groups 45-50 and above), at Dzingahe and 23\% at Milaboni, have average to poor health outcomes. This does not mean that all the elderly who belong to this age group are frail and weak. However, it is important to know their locations and their circumstances for effective evacuation and sheltering. The poor health outcomes and their attachment to their homes tend to explain why they might be reluctant to move during evacuation emergencies. 30\% of households at Dzingahe and $43 \%$ at Milaboni have at least one member of the household with some form of physical or mental disability. The elderly and the physically and mentally disabled need more flood hazard assistance than any other social group. 


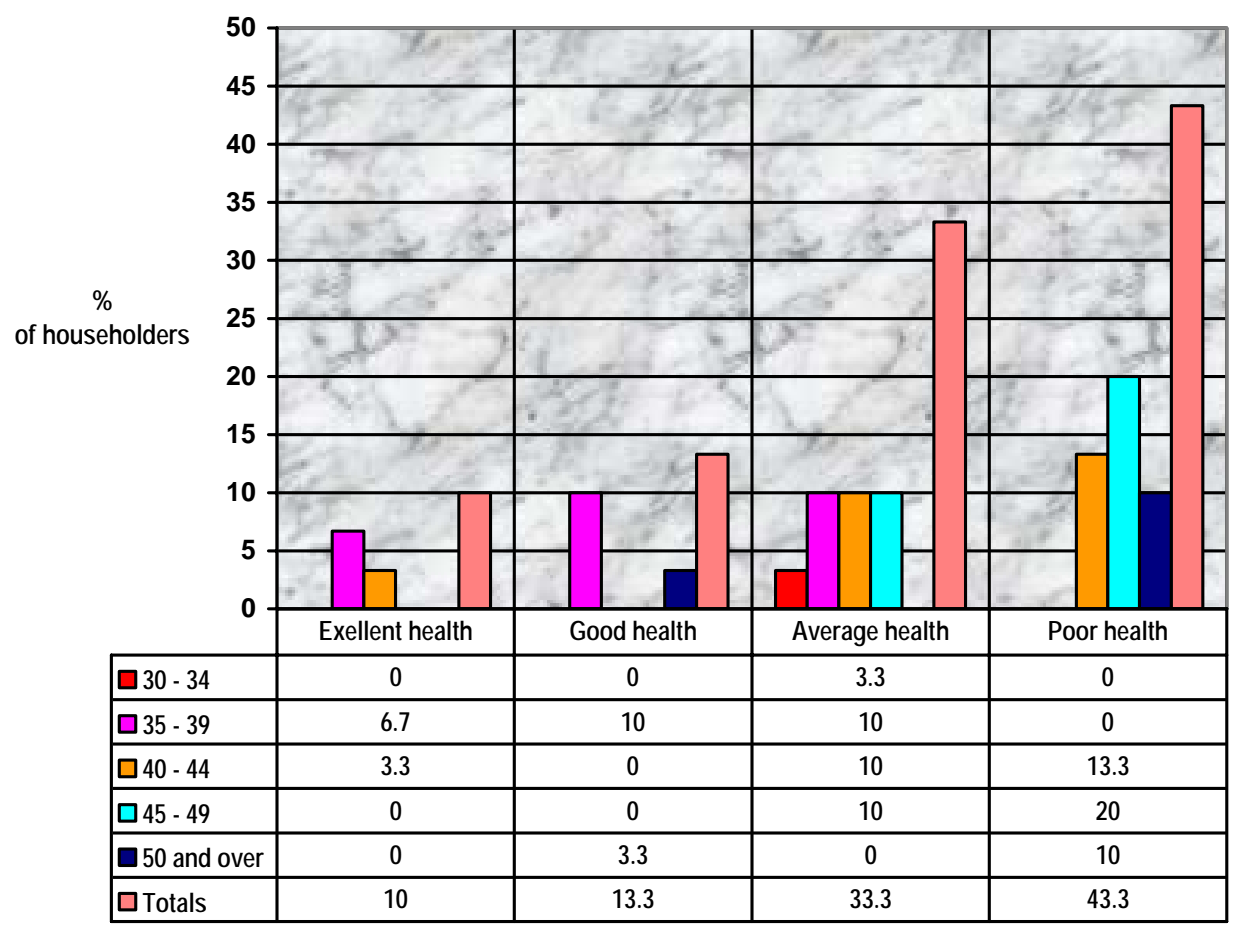

Figure 6.8 (a): Age distribution by health status of the householder: Milaboni village

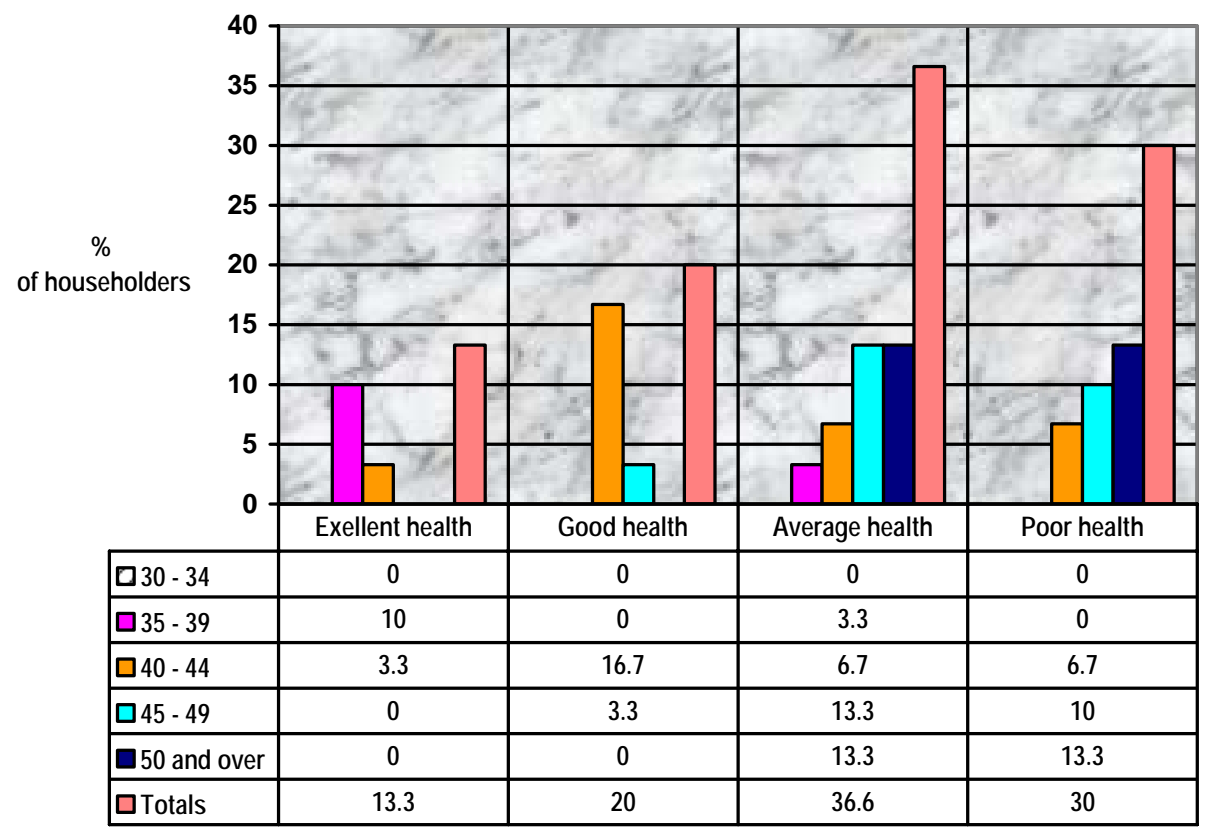

Figure 6.8 (b): Age distribution by health status of the householder: Dzingahe village 


\subsubsection{Household living arrangements}

Household living arrangements have consequences that are flood-related. For example, the type of housing ownership, cultural norms regarding family size, dependency ratios, marital status, form of marriage and monogamous/polygamous arrangements are critical determinants of household flood vulnerability. The empirical results of this research indicate that households in these villages own their houses even though they do not have title deeds to their property. Land ownership in these villages is administered through communal land tenure systems, under the custodian of a chief or a headman. A patriarchal system operates in these villages and this explains why it is difficult for women to access land. In addition, patriarchy also defines gender roles in the household. Householders when asked if men and women were engaged as equal partners in family and community decision-making reported unequal power relations between men and women in decision-making. For example, $40 \%$ in both study sites reported that women were never engaged as equal partners. However, over $60 \%$ of respondents did not agree that there were institutional and ideological constraints limiting women's engagement. Reasons given included the fact that the current government has been empowering women and as such women were free to take part in family and community decisions. Some respondents believed that the emancipation of women is practical and acceptable in the workplace, not at home. As one respondent at Dzingahe village reported: "A 50-50 scenario might work well in the workplace, but not at home. Men and women with the same qualification should be treated equal and receive equal salary but at home the wife should be submissive to the husband as the Bible demands (Focus Group Discussion, November, 2005).

Cultural norms regarding family size also play an important role in determining flood vulnerability. As evident in Figure 6.8, more households (27) at Dzingahe than at Milaboni (20) have between 2 and 3 children. The estimated average number of children is three at Dzingahe (2.6) and Milaboni (3.1) villages. The overall household size (i.e. children plus other dependents) is five (5.3) at Dzingahe and almost six (5.7) persons at Milaboni village. This finding implies that the overall typical family type is extended 
rather than nucleated. Households with many dependents and children are likely to encounter greater financial obstacles than smaller families when coping with flood impacts. Coupled with other variables described earlier, high dependency ratios affect negatively the capacity of the household to secure sustainable livelihoods and the recovery after flood hazards. However, not all large families are liabilities during the times of flood crisis, because they may provide be a source of important social support systems. Similarly, not all smaller families cope well with flood impacts, because some lack adequate economic and human resources to deal with flood impacts, and hence become vulnerable.

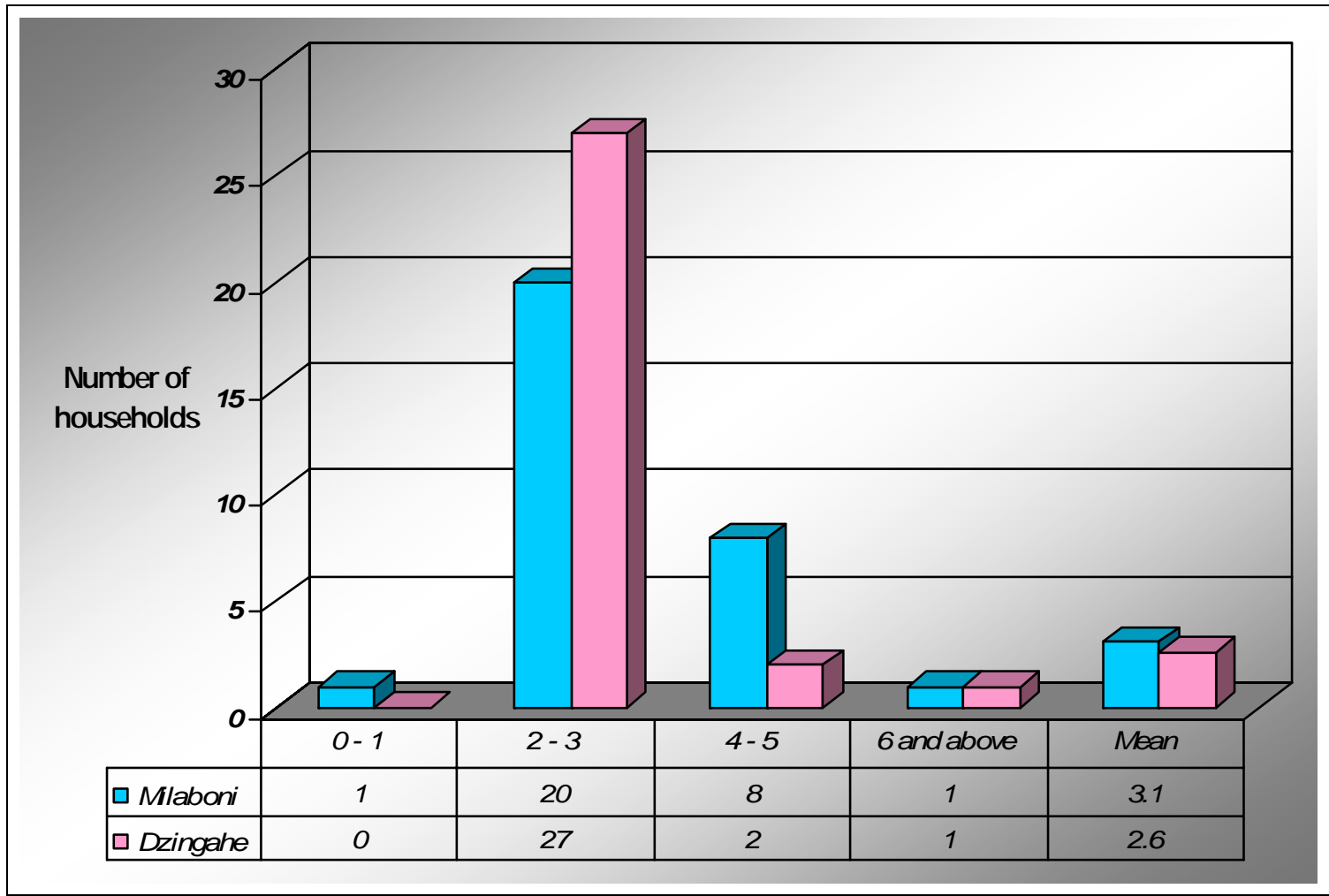

Figure 6.9: Children distribution at Dzingahe and Milaboni households 
In terms of marriage and its forms, both monogamous/polygamous and in community of property / customary marriage practices are acceptable in the study sites. In this regard, married householders were asked to provide the number of spouses as well as the type of marriage in place. The majority of respondents in both villages indicated that they had one spouse, meaning that monogamy is more preferred than polygamy. An interesting observation relates to the high proportion of those who selected the "Not applicable" category. It has to be noted that most people in these villages are not comfortable about disclosing marital/sex-related affairs to a stranger or somebody younger. This might account for a minor variation between monogamous and polygamous families. This finding is contrary to normal expectations regarding this variable. However, the majority of householders at Dzingahe (60\%) compared to Milaboni (46.7\%) were in customary marriages as opposed to other forms of marriages. Considerable proportions (27\%) in both villages were married in the community of property regime. This might be attributed to the role of Christianity which bas become the dominant religion in these areas.

\subsubsection{Social Capital}

According to Putman (1995:66) social capital consists of those "features of social-life networks, norms (including reciprocity) and trust that enable participants to act together more effectively." In his research in Italy, Putman examined social capital using indicators such as the extent of one's civic involvement and faith in public institutions to deliver expected community outcomes. As such, social capital consists of both family and social resources.

\subsubsection{Family and social networks}

Family and social resources are valuable indicators of flood vulnerability and hence they form an important part of flood hazard-related assistance for many households in the Limpopo Province. Lack of family and social networks can be a limiting factor towards effective response during and after flood hazards. For example, households with closeknit networks of friends and relatives are likely to cope better than those without this 
form of support system. Similarly, social support systems such as institutions of government, businesses and NGOs are very critical source of help during the times of flood crisis.

Households were asked if friends and relatives significantly assist during and after flooding. As can be seen from Figure 6.10 households from both villages possess some significant form of kinship bond and support, even though the support is not always provided. Such bonds serve as protective mechanisms during times of need. An insignificant proportion of householders reported they seldom or never received any form of help from friends and relatives. This proportion represents isolated households whose lifestyles are individualistic and autonomous due to different socio-economic status and political influence. It is not uncommon for weaker ties to exist between members of family or friends.

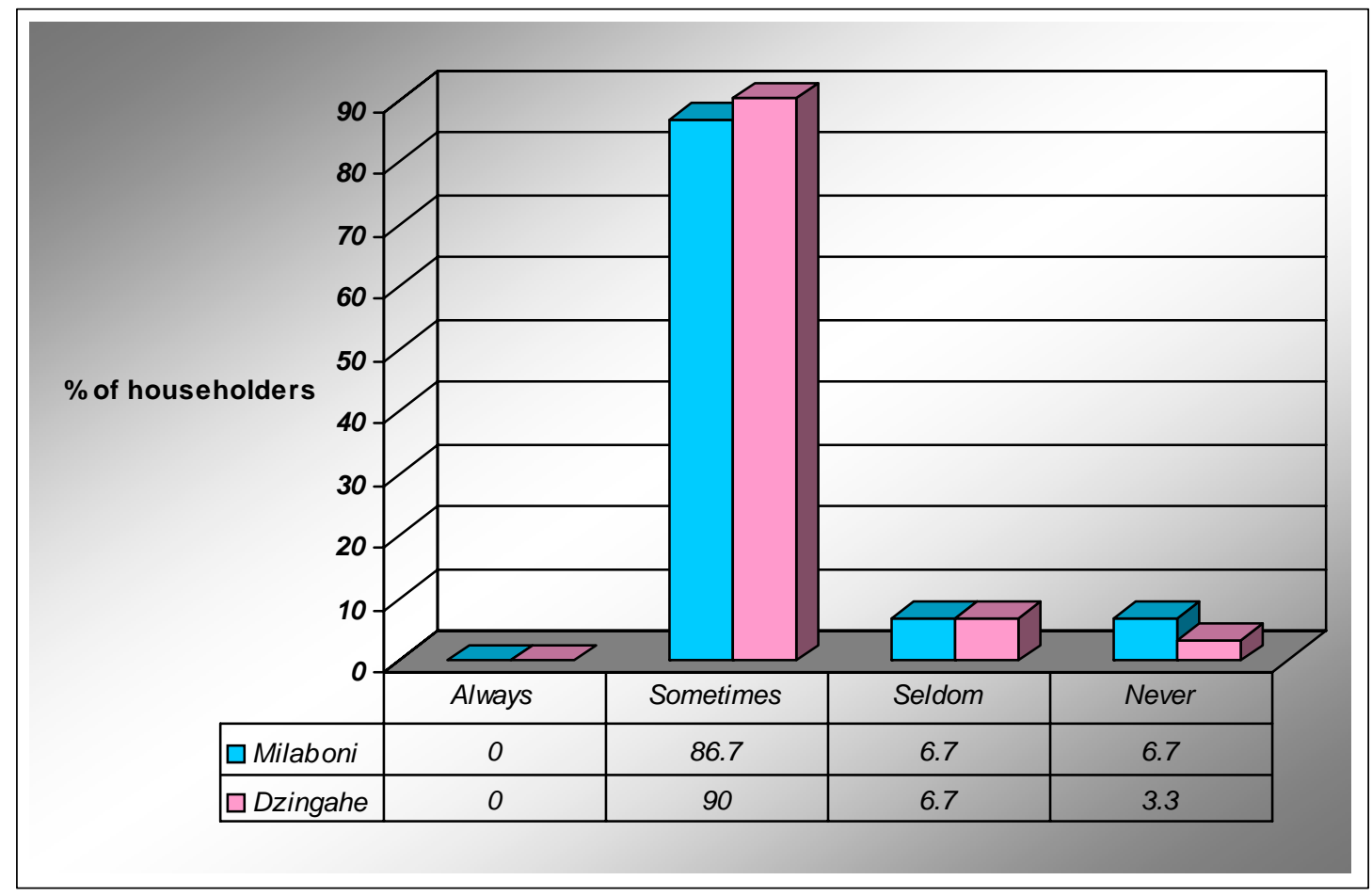

Figure 6.10: Perceived flood-related assistance from relatives and friends 
In addition to family resources, institutions such as civic organizations, local government and businesses are critical sources of flood-related assistance. These institutions are perceived as rendering assistance "sometimes" by the majority of households at both villages. In fact, institutions of chieftaincy, government and NGOs, and disaster-related policies offer humanitarian assistance as a way to temporarily assist flood victims during flood hazards. In fact, all of the households surveyed in both villages were not aware of policies or processes meant to enhance flood coping capacity in their community or elsewhere. Disaster-related policies do not adequately address processes which place people at flood risk, since they are not regarded as part of disaster emergencies.

\subsubsection{Perceived Social Capital Measure}

In order to measure how households perceive their levels of social capital, indicators in the form of statements (from 1-15) were administered as part of the household survey. Households were asked to rate these statements (indicators) on a Likert scale from 1 (strongly disagree) to 5 (strongly agree). The results of household ratings are presented in Table 6.5 (a). The means and standard deviations for each indicator (statement) are shown in Table 6.5 (b).

In terms of social capital, $87 \%$ of householders at Dzingahe and Milaboni villages indicated the existence of strong community bond when dealing with flood crisis (Table 6.5a). They can voucher for their community acceptance and the fact that their community is a caring one. In addition, householders also perceived a strong sense of belonging to the community through participation in solving problems and thereby being known by their neighbors. This form of community integration is an important component of social capital. Social capital is also measured by the degree to which one participates in civic associations, worker's union religious groups and burial societies. A considerable majority in both villages belong to burial societies compared to over $60 \%$ that do not belong to any religious group. However, most of these households have some form of indigenous attachment to spiritual deities or supernatural being, even if they do not go to church. Generally, positive social capital exists in these households. This social 
capital bond can be an important agent for transmitting information or flood-related assistance before, during or after flood crisis.

Table 6.5(a): Likert Scale Response Table of Perceived Household Social Capital

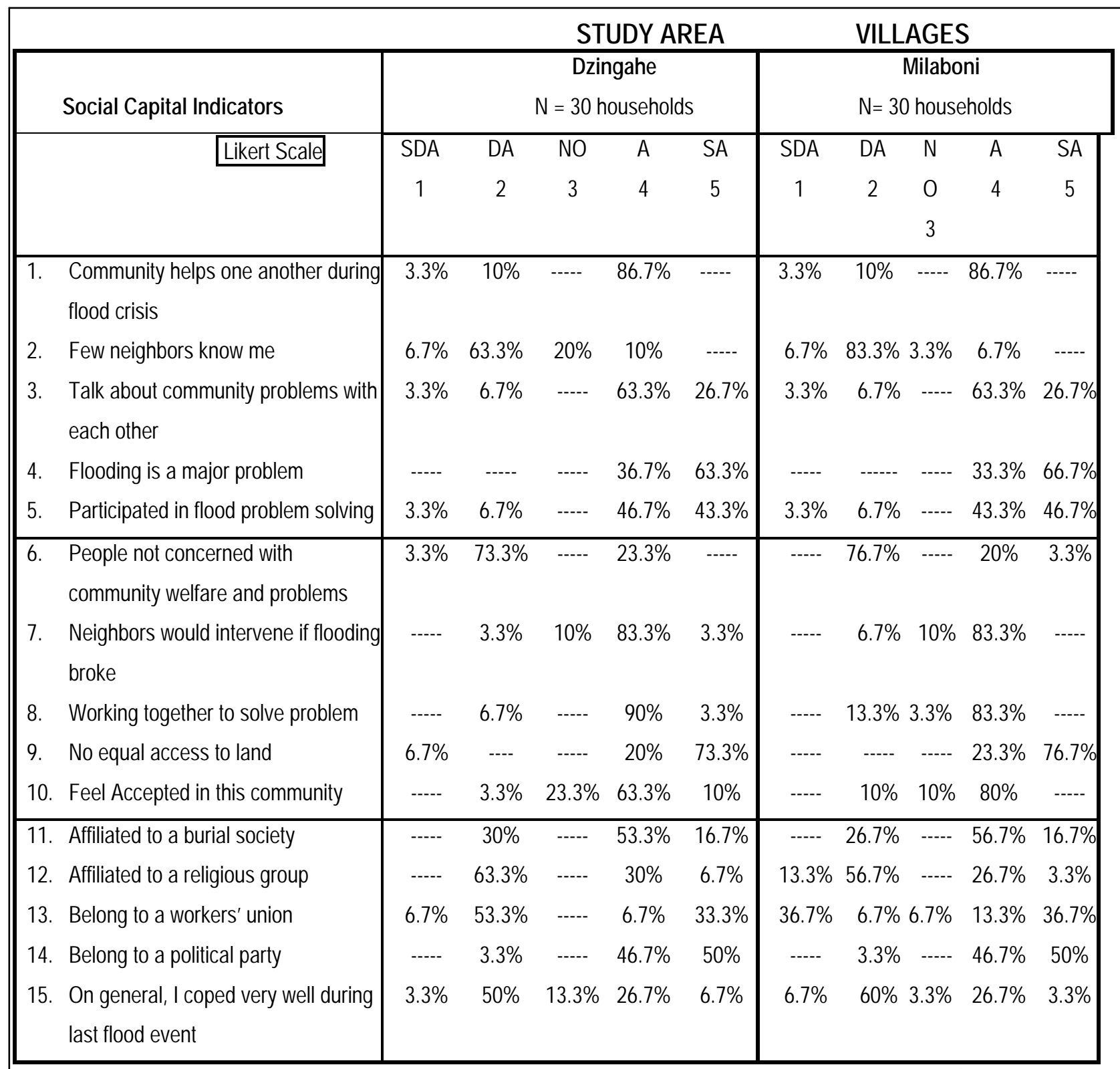

Key: 1. SDA = Strongly Disagree; 2. DA= Disagree; 3. NO = No Opinion; 4. A = Agree; 5. SA = Strongly Agree 
Table 6.5 (b): Means and Standard Deviations of Perceived Household Social Capital

\begin{tabular}{|c|c|c|c|c|c|c|c|c|c|c|}
\hline \multirow{4}{*}{ Social Capital Indicators } & \multicolumn{10}{|c|}{ STUDY AREA VILLAGES } \\
\hline & \multicolumn{5}{|c|}{$\begin{array}{l}\text { Dzingahe } \\
\mathrm{N}=30\end{array}$} & \multicolumn{5}{|c|}{$\begin{array}{c}\text { Milaboni } \\
\mathrm{N}=30\end{array}$} \\
\hline & Sum & Mean & SD & Skew & Kurtosis & Sum & Mean & $\begin{array}{l}\mathrm{SD} \\
\end{array}$ & Skew $\mathrm{K}$ & Kurtosis \\
\hline & 1 & 2 & 3 & 4 & 5 & 1 & 2 & 3 & 4 & 5 \\
\hline $\begin{array}{l}\text { 1. Community helps one another during flood } \\
\text { crisis }\end{array}$ & 111 & 3.70 & .79 & 2.49 & .83 & 111 & 3.70 & .79 & -2.49 & 5.02 \\
\hline 2. Few neighbors know me & 70 & 2.33 & .76 & .87 & .63 & 63 & 2.10 & .61 & 1.94 & 5.90 \\
\hline 3. Talk about community problems with each other & 121 & 4.03 & .93 & -1.73 & 3.86 & 121 & 4.03 & .93 & -1.73 & 3.87 \\
\hline 4. Flooding is a major problem & 139 & 4.63 & .49 & -.58 & -1.78 & 140 & 4.67 & .48 & -.75 & -1.56 \\
\hline 5. Participated in flood problem solving & 126 & 4.20 & .99 & -1.77 & 3.42 & 127 & 4.23 & 1.01 & -1.81 & 3.44 \\
\hline $\begin{array}{l}\text { 6. People not concerned with community welfare and } \\
\text { problems }\end{array}$ & 73 & 2.43 & .89 & 1.13 & -2.56 & 75 & 2.50 & .94 & 1.48 & .55 \\
\hline 7. Neighbors would intervene if flooding broke & 116 & 3.87 & .51 & -1.96 & 6.58 & 113 & 3.77 & .57 & -2.43 & 5.04 \\
\hline 8. Working together to solve problem & 117 & 3.90 & .55 & -2.78 & 9.64 & 111 & 3.70 & .70 & -2.06 & 2.57 \\
\hline 9. No equal access to land & 130 & 4.53 & 1.04 & -2.84 & 7.95 & 143 & 4.77 & .43 & -1.33 & -.26 \\
\hline 10. Feel Accepted in this community & 114 & 3.80 & .66 & -.51 & .93 & 111 & 3.70 & .65 & -2.02 & 2.79 \\
\hline 11. Affiliated to a burial society & 107 & 3.57 & 1.10 & -.51 & -1.17 & 109 & 3.63 & 1.07 & -.65 & -.89 \\
\hline 12. Affiliated to a religious group & 84 & 2.80 & 1.10 & .76 & -1.18 & 75 & 2.50 & 1.14 & .68 & -.78 \\
\hline 13. Belong to a workers' union & 92 & 3.07 & 1.51 & .39 & -1.71 & 104 & 3.47 & 2.35 & .59 & -.04 \\
\hline 14. Belong to a political party & 133 & 4.43 & .68 & -1.51 & 4.07 & 133 & 4.43 & .68 & -1.51 & 4.07 \\
\hline $\begin{array}{l}\text { 15. On general, I coped very well during last flood } \\
\text { event }\end{array}$ & 85 & 2.83 & 1.11 & .53 & -.97 & 78 & 2.60 & 1.07 & .72 & -.77 \\
\hline
\end{tabular}


Householders on general reported they did not cope well during the last flood event. The benefits of social capital are contestable since social capital may not necessarily enhance flood coping capacity, especially in poor rural communities which are characterized by unequal power relations.

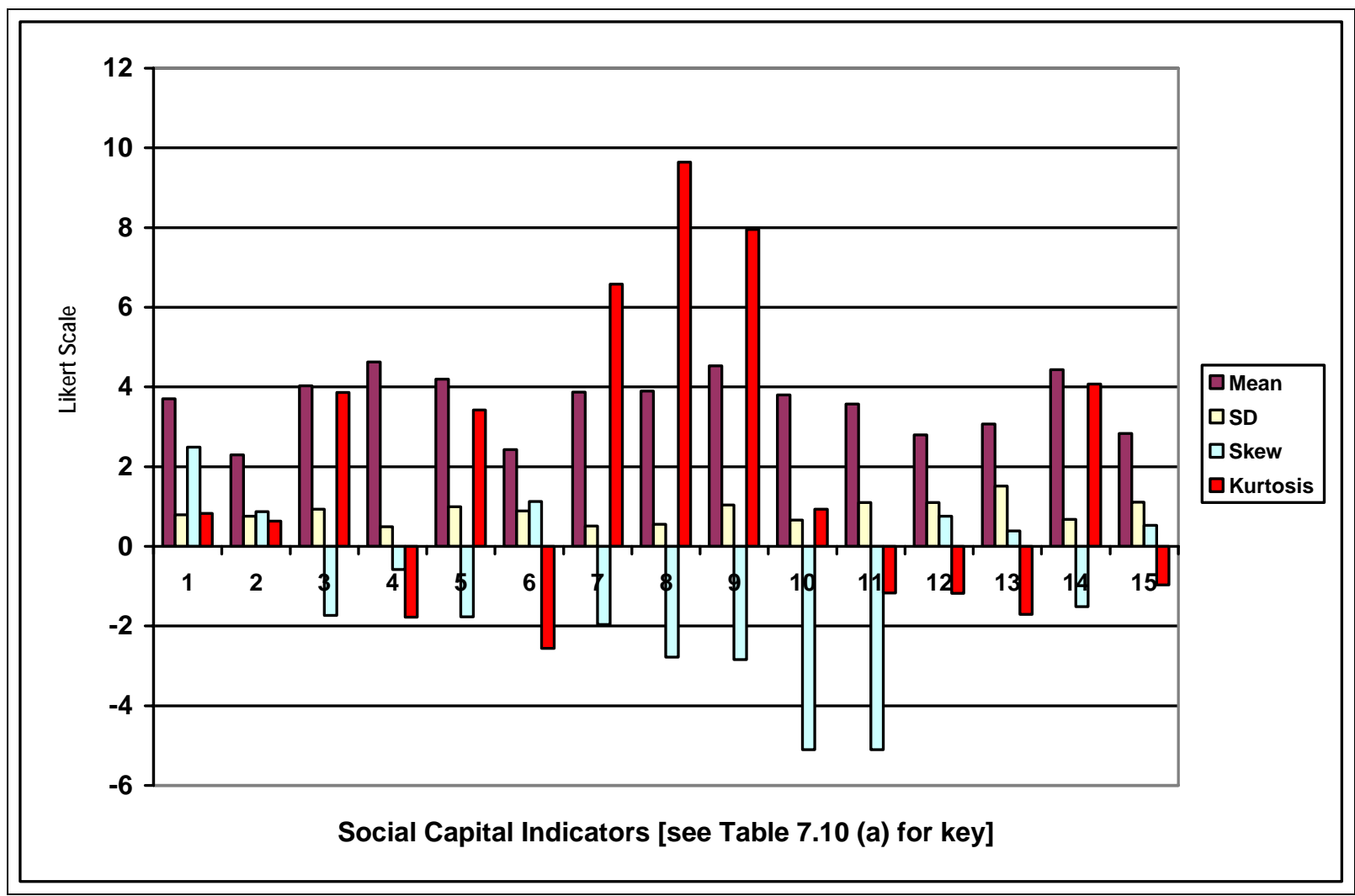

Figure 6.11 (a): Means, Standard Deviations, Skewness and Kurtosis of Perceived Household Social Capital: Dzingahe village

The arithmetic means in Table 6.5 (b) indicate that households in the study sites agreed pretty much with many of the social capital indicators with the exception of five indicators (nos. 2, 6,12,13 and 15) in Tables 6.5 (a; b). The mean values of the latter indicators range from 2.33 to 3.07 , indicating on a Likert scale continuum a shift from "disagree" to some form of "no opinion" about the indicators as explained above. Figures 6.10 (a; b) illustrate the distribution of the means, standard deviations, skewness and kurtosis for each of the perceived social capital indicators in the study sites. The concepts 
of skewness and kurtosis are described elsewhere in the preceding sections. Considering the distribution of each of the fifteen social capital indicators at the study sites, one can observe that many of the indicators have a negative asymmetry in that their skewness statistics is negative. However, the kurtosis statistics of many indicators in both villages shows a distribution that has a positive kurtosis (Figures $6.10 \mathrm{a}$; b). Overall the householders have a positive social capital.

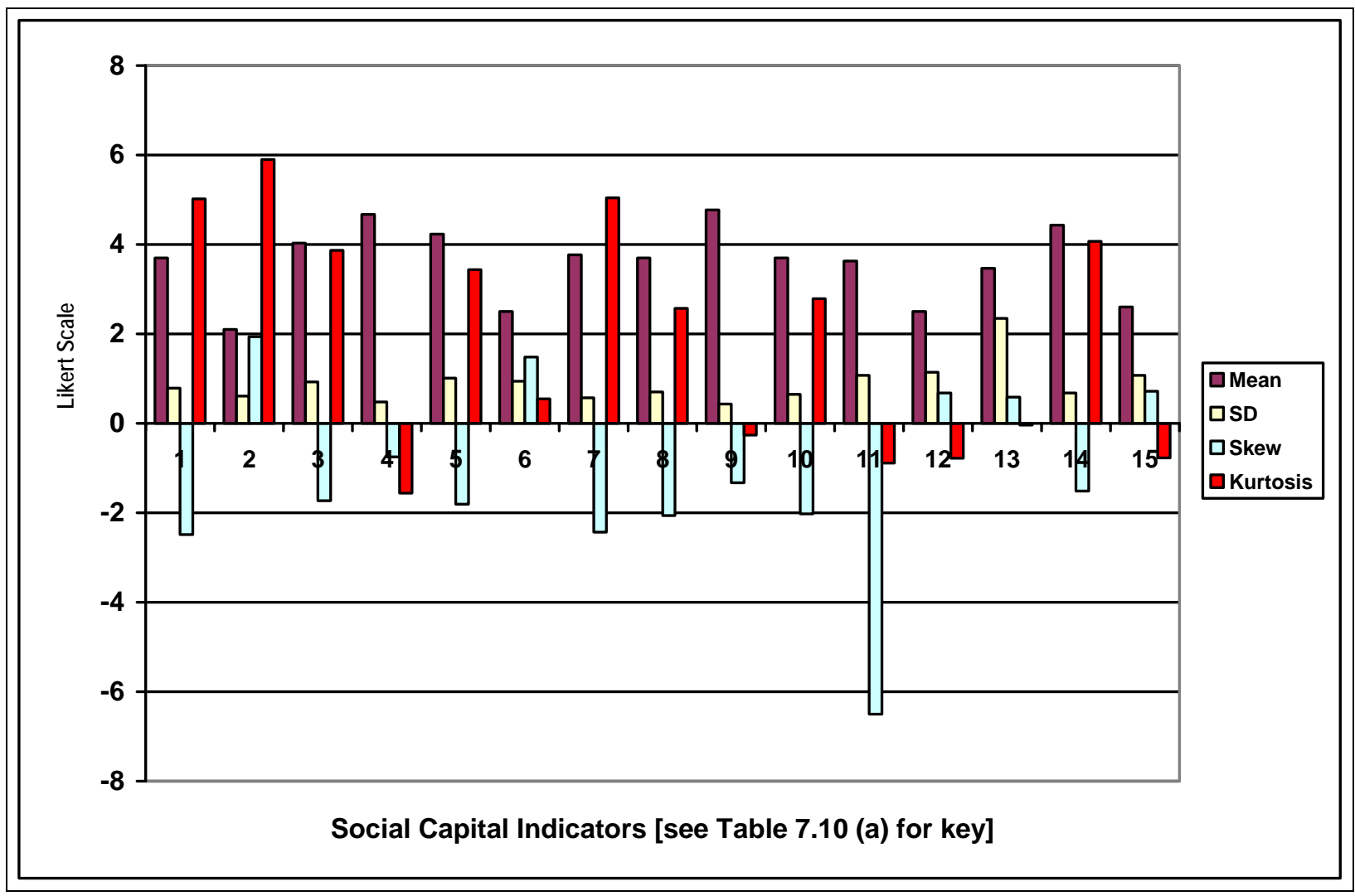

Figure 6.11 (b): Means, Standard Deviations, Skewness and Kurtosis of Perceived Household Social Capital: Milaboni village

\subsubsection{Political resources}

Political resources include power relationships (i.e. assumptions and structures about who is in control and who has power over others) and autonomy. This also includes freedom to express one's opinion and grievances. Lack of choice and control over circumstances and resources is an important power-related factor that determines household coping 
capacity and resilience. Power structures determine (1) the allocation of infrastructure such as water resources, roads and land; (2) determines who is invisible or visible enough to be heard; and (3) determines how the allocation of relief aid is done. Political resources, therefore, remain one of the most important indicators of household flood vulnerability.

An overwhelming majority of householders a in both villages were affiliated to a political party (see Table 6.5a). However, 97\% of householders at Dzingahe and 87\% at Milaboni villages had reported that they had never involved in any overt grassroots activism as part of registering their concerns to political structures. For example, Milaboni village, in addition to being surrounded on the northern and eastern sides by Thononda Mountains, has Tshikombani and Mudunungu villages bordering its western, southwestern and southern sides. The political significance of these borders is that the contested spaces identified by the residents of Milaboni village in the previous chapter represent some of the land conflicts between Milaboni and its neighbors. Inaccessibility to adjacent land parcels has further implications for environmental degradation and the future growth of Milaboni village, which is currently confined to the mountains.

Unequal power relations are also evident in the distribution of disaster aid and household resources, especially land. Regarding access to land, householders in both study sites strongly agreed to the fact that land is unequally distributed (see Table 6.5 a) between men and women. Patriarchal structures in these villages control who is allocated land and who is not. Furthermore, limited household resources combined with poor connections with those in power make some unable to access land while others do. There are also structural constraints regarding the distribution of disaster assistance. Seventy seven percent of householders in both study sites reported that local community is "sometimes" involved in the distribution of disaster aid. However, they mentioned that policies governing the distribution of aid are not transparent. In certain cases some flood affected victims whose children are working do not qualify for disaster aid while others who fall in the same category do receive aid. Most flood affected communities are invisible in that their perspectives are not taken into account by powerful groups. Since most 
municipalities use flood relief aid for normal road maintenance works, the relief aid is mostly used to repair major bridges and transport routes. This tendency generally results in low levels of flood preparedness by local and municipal structures of governance in these rural villages.

\subsection{Conclusion}

Empirical results from the household survey indicate differential household resources in terms of capacities, social networks and political resources in both villages. These socioeconomic dimensions linked with historical and physical processes, provide a useful assessment of whether households are resilient or vulnerable to flooding. It is also evident that local capacity in the form of inherent skills or those not acquired from formal institutions is currently ignored. There is, therefore, need to assert such capacity if vulnerability is to be reduced. Furthermore, a considerable proportion of householders depends on an unstable informal sector for their annual income, and hence are more vulnerable to flooding, especially when spatial interaction is disrupted during flooding. Despite conventional thinking that regard elders as vulnerable due to lack of mobility, they are however, very resourceful in these villages due to financial and social support they render to households.

This research has produced divergent interpretations about the relationship between gender and flood vulnerability in both villages. Qualitative evidence from narratives, focus group discussions and descriptive statistics indicates that female-headed households are more vulnerable than male-headed households. They have limited economic and material resources in terms of income and important assets (e.g. livestock, cars, television sets and other electronic equipment) that can buffer them from negative flood impacts. Hence, household positionality in patriarchal relations represents one of the mechanisms by which male-headed-households are resilient while female-headed are vulnerable to flooding. However, inferential statistics in contrast, indicates that gender is statistically insignificant in explaining differential vulnerability between male-headed and female-headed households. This does not necessarily mean that gender is not an 
important variable, but it only means that according to quantitative analysis the contribution of gender to differential vulnerability is small. Within the sample, male- and female-headed households show insignificance differences in terms of household resources. This finding could be attributed to small sample size in addition to developing trends towards gender equalities in these villages and beyond. Different gender relations in these two villages lead to different relationships between gender and vulnerability. For example, women at Dzingahe village are more progressive than those at Milaboni whose patriarchal relations are still traditional.

Flood vulnerability is also differentiated by housing conditions and living arrangements. It has been found that the housing quality index is positively correlated with income and a considerable proportion of traditional housing structures are in minimal to poor conditions due poor building materials and workmanship. Households in poorly maintained traditional units are at a significantly greater flood risk than those with small RDP housing units, even if the latter are poorly conditioned for hot weather conditions. Furthermore, high costs of electricity often results in heavy dependency on wood despite installation of electricity. This has negative implications for environmental degradation. In terms of household living arrangements cultural norms prefer customary forms of marriage while western forms of "In community of Property" marriage regime is typical for younger members of society. The extended family system which is characterized by a higher dependency ratio is a typical living arrangement in these villages.

In terms of perceived social capital, households in these villages display strong social bonds that help them deal with flood crises. Overall, householders have positive social capital but have negative perceptions about their economic resilience, though differences exist at individual levels. The majority of householders are affiliated to a political party. However, unequal power relations and little influential power characterize political relations in these villages. Political autonomy and freedom of speech should be privileged over just affiliation to political parties. 


\section{CHAPTER 7}

\section{PGIS Representations of Differential Flood Vulnerability}

\subsection{Introduction}

Flood vulnerability assessment cannot be divorced from the experiences and narratives of local people. Furthermore, their modes of production, ideology about nature and exploitation of natural resources remain vital for sustaining their livelihoods. In light of this background, the aim of this chapter is to further explore ways in which local experiences, narratives and knowledges about flood vulnerability can be captured and analyzed in a Participatory Geographic Information System. In this case, a PGIS methodology is ideally suited to the task of representing differential flood vulnerability for four reasons. First, PGIS brings participatory dialogues to issues impacting flood vulnerability. Second, local communities are offered an opportunity to map local politics, power and the distribution of natural resources. Third, PGIS is an approach that takes into account connections between historical and contemporary perspectives in understanding flood vulnerability. Finally, it is about engaging people's experiences, perceptions and knowledge in issues they feel and regard as important. PGIS is, therefore, a "forum around which issues, information, alternative perspectives and decisions evolve” (Weiner \& Harris, 1999:8). A PGIS methodology recognizes that communities understand their environment and how to cope in hazardous situations. It also realizes the need for some form of advocacy to help communities understand and map processes that make them vulnerable and to integrate their coping strategies within a wider socio-economic and political context. Mechanisms of advocacy can help them "move things around" for their benefit. In this way, PGIS can disrupt and change local political relations for the better. 
In terms of their ideology about nature, people in these communities tend to view themselves in harmony rather than in opposition with nature. As such, they associate their vulnerability to flooding with socio-economic and political processes rather than nature itself. However, notwithstanding the degrading effects of their economic activities, evidence from the community mental mapping workshops indicate that these people see their mountainous cultivation as part of an enforced interaction with nature. Although this assertion is debatable, it does highlight the role of historical processes in contributing towards the current flood vulnerability status of the two study sites.

Overall, PGIS acknowledges that people's experiences, perceptions and knowledges are intimately related to issues of local power and politics. Therefore, it is necessary to understand and represent their diverse narratives about landscape in order to understand the social production of differential flood vulnerability. In addition, PGIS can help us understand and analyze flood vulnerability by merging community mental maps with other "expert" spatial information. Participatory methods embedded in PGIS ensure that local perspectives about flood vulnerability are captured and hence, bottom-up representations of flood vulnerability are emphasized. Local mapping by communities themselves can help researchers and flood hazard planners locate where high risk groups are concentrated. Participatory discussions could provide local perspectives about processes that make people vulnerable in the study sites. In this research, local perspectives were documented through community mental maps which were based on the topographical map sheets and vertical aerial photographs of the study sites. These were then digitized and geo-referenced for integration with other data sets.

\subsection{Community perspectives on flood vulnerability in the study sites}

Flood vulnerability is inter alia, a matter of people's perceptions and hence, adequate consideration should be given to the views of affected people in order to learn how they cope and take flood hazard-related decisions. This section explores people's perceptions and experiences of flood vulnerability from an historical perspective. This approach to flood vulnerability assessment is important because flood vulnerability is not only about 
present or future conditions, but it is also about understanding the past. The historical analysis provides the context and root causes of flood vulnerability (Blaikie et al., 1994; Oliver-Smith, 1986). In the study sites, flood vulnerability is cast in people's political history and power relations. The root causes of flood vulnerability are embedded in a long history of unequal distribution of land. Associated with this highly skewed distribution of land are insecure land tenure systems and the geography of forced removals. It is, therefore, the purpose of this chapter to addresses four issues related to flood vulnerability within a political ecology conceptual framework and PGIS methodology. These conceptual issues are: the historical geography of forced removals; perspectives on contested spaces; perceptions on flood-prone areas; and, perspectives about forces shaping natural resource access, control and ownership. These conceptual issues are meant to shed some light on the underlying social and political processes that produce differential flood vulnerability.

\subsubsection{The historical geography of forced removals and insecurity of land- tenure}

Changes to traditional economic processes in South African communities through the influences of colonialism, apartheid planning, forced removals and land tenure practices, have alienated people from resources they had depended on for many years (Levin \& Weiner, 1997; Tapela, 1999; Omara-Ojungu, 1999). For example, forced removals through legislations for national and private parks, commercial farms and plantations, and apartheid betterment planning, restricted the right of access and use of land, yet offered few alternative means of survival (Levin \& Weiner, 1997; Wisner, 1999). At Milaboni and Dzingahe villages, forced removals were due to the expansion of commercial farms mostly owned by whites in the Levubu area and pine plantations at Khalavha and Thathe Vondo areas (see Figure 7.1). Forced removals combined with betterment planning have led to overcrowding in densely populated settlements with fragile ecosystems. The result has been the deforestation of such settings, particularly in mountainous environments (Omara-Ojungu, 1992). 
Due to unequal access to land, communities at these villages have resorted to mountainous and riparian cultivation. A closer analysis of Figure 7.2 (a) shows visible scars of mountaintop agriculture at Milaboni village. However, households at the study sites have different understandings of why they are involved in riparian and mountainous cultivation. "We cultivate along the river because there is water nearby to irrigate the crops and maize cultivated at river banks does well even when there is no rain. Lack of land is the reason why we cultivate on mountain slopes, but we build stone-walls to protect soils from being washed away by rain” (Milaboni Mental Mapping Workshop, December 2005).

Similarly, households at Dzingahe village support this view:

I do not think that we spoil the environment like those in big farms and plantations. Look at the dams, they take much water from the river in order to irrigate their farms and pine and coffee trees that consume a lot of water and who benefits from those farms? People who work there get very little wages and tea and coffee they grow is sold overseas (Dzingahe Mental Mapping Workshop, January 2006).

Mountainous and riparian cultivation is attributed to water availability near local rivers and lack of arable land. These communities feel that they are not largely implicated in environmental degradation because their farming practices are subsistence and they adopt terracing systems to combat soil erosion. In order to support this discourse they also argue that their activities contribute to land degradation less than the activities of the commercial farming and forestry in the area (Figure 7.1). Despite the validity of this local discourse, narratives from focus group discussions suggest that both commercial farmers and local communities are implicated in processes that degrade the environment, although the former do so to a greater extent. The poor are implicated through their desperate and sometimes inappropriate use of land or overuse of a few resources available to them. Inappropriate land use activities degrade environments and place households in harm's way, largely through the lack of reasonable alternatives for daily 
survival. Participants of mental mapping workshops were asked to explore on the map the history and geography of forced removals. However, the historical information lacked approximation of important dates relating to when they were forcefully removed. Nevertheless, the participants had vivid perceptions about where they were forcefully removed.

In the study area, processes of forced removals and resettlements in the 1960s were facilitated by the apartheid system of insecure land tenure. Insecurity of land tenure combined with social and political factors has furthermore mediated flood vulnerability in the study sites. Community perceptions of forced removals as indicated in Figure 7.1 show forced removals at both local and regional scales of analysis. At both scales the construction of dams (C), towns (B), prison development (D) and development of commercial farms and plantations (A; E) have involved displacement of people and human rights violations. The displacement process highlights the political vulnerability of communities in the study area. Due to insecurity of tenure, community participation could hardly influence or block policies or laws that were meant to harm them.

Overall, the relationship between flood vulnerability and the history of apartheid in South Africa extends beyond the unequal distribution of land as a resource. Certain segments of the population are often situated in more hazardous settings than others due to the historical consequences of political, economic and social processes. In particular, the geography of apartheid has meant that poverty has affected some people more than others. In the study sites, the poor and those with no formal education in particular, were confined to low income jobs and were most affected by unemployment and landlessness. 


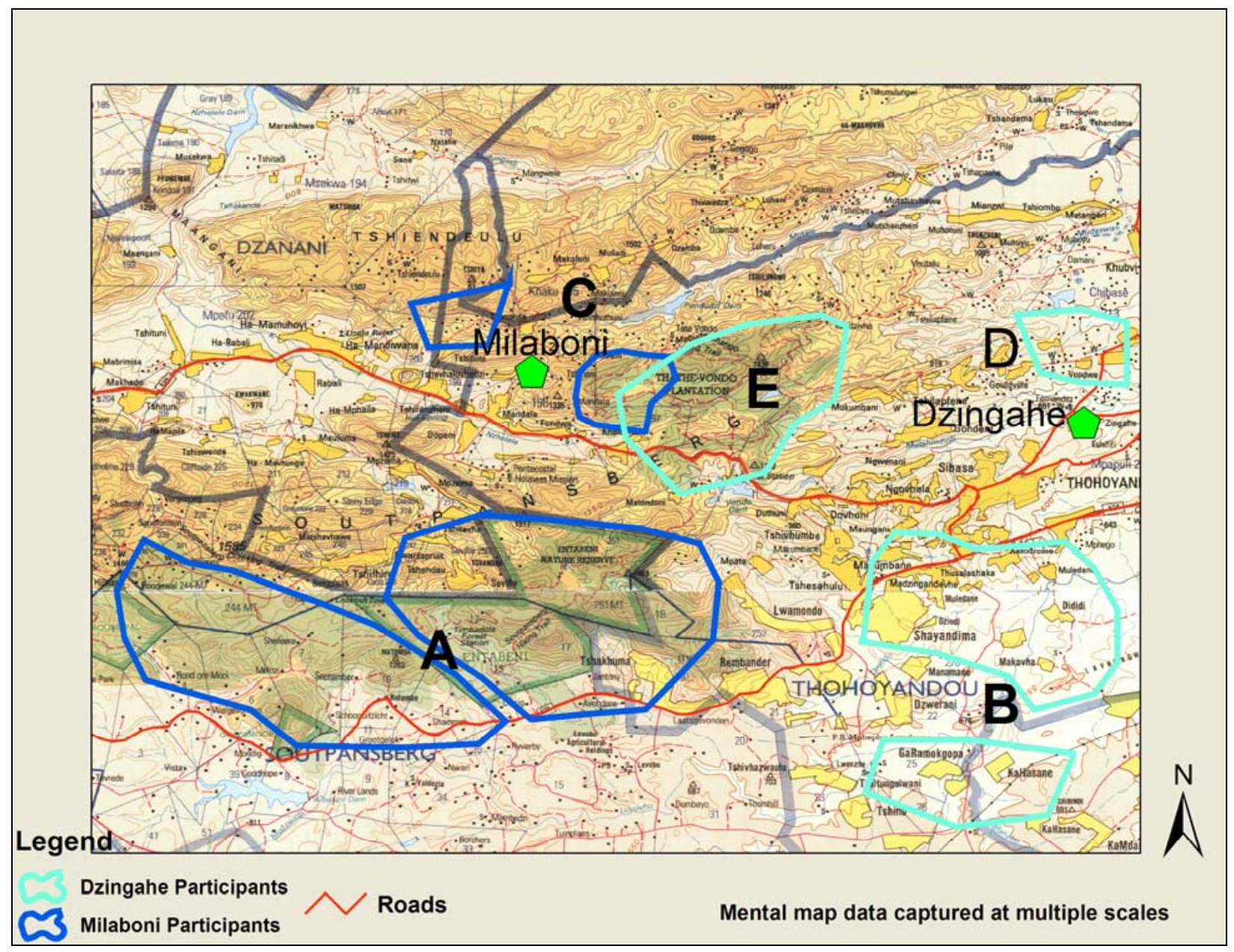

Figure 7.1: Mental Map of Forced Removals at Dzingahe and Milaboni villages

This was not an historical accident, but the result of deliberate apartheid policies that deprived people of their land, kept them out of skilled work and confined them to poverty. Though the situation has gradually changed, the legacy of the apartheid system throughout the province remains as millions of people still could not meet their basic needs for housing, water, sanitation, food, health care and education. This means that for some people the nature of flood vulnerability is changing and intensifying while their ability to cope has diminished (Oliver-Smith, 2007). 


\subsubsection{Perspectives on contested spaces}

Flood vulnerability among other things, is constructed through local politics and power relations. In the study area, power relations are manifested through contested spaces which indicate power struggles over environmental resources. Figure 7.2 (a) indicates two broadly demarcated regions of contested spaces at Milaboni village. The two locally contested spaces fall under Tshivhase tribal authority, affecting the neighboring Tshikombani and Mudunungu villages. Tshikombani is a typical example of a settlement whose morphology has been influenced by topography and the geography of flood vulnerable settings. To avoid such unsafe locations, Tshikombani village has grown into the formerly uninhabited territory of Milaboni village. Land in this territory was used for pastures and agriculture, in addition to gathering of wild fruit, vegetables and building materials. Although people at Milaboni village were not displaced from the contested spaces in Figure 7.2 (a), they feel that the political system has not observed territorial boundary and thus not protected their traditional use of resources such as water and grazing land.

A workshop participant at Milaboni village observed:

Mudunungu and Tshikombani villages have not observed the river as a boundary. It is like Mudunungu is pushing Tshikombani village which in turn pushes our village (Milaboni village) to the mountain. I think the problem is that our village is small and does not have adequate schools and clinics, so we get all these facilities from other villages. This is the problem. It is like they are blackmailing us (Mental Mapping Workshop, December 2005). 


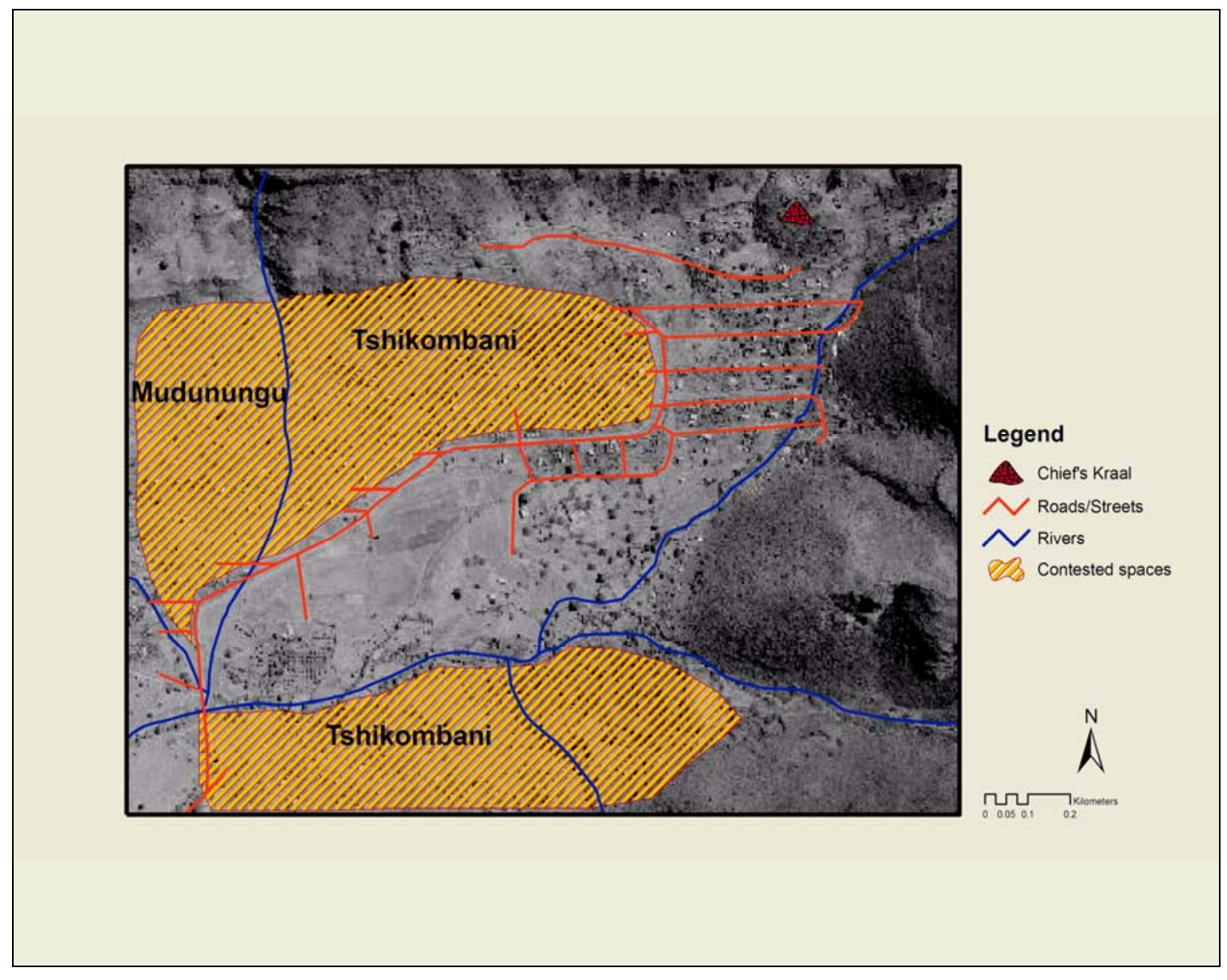

Figure 7.2(a): Mental map of contested spaces at Milaboni village

All these two villages have furthermore exerted development pressure at Milaboni village. From the group discussions, participants indicated diplomatic and covert acts of resistance as more effective ways of dealing with this conflict than overt resistant behavior. Covert resistance is preferred as a strategy to maintain positive social capital and connections with ruling political structures. Another participant at Milaboni clarified this point:

What can you do? The Chief knows about land problem and the Civic Organization knows it too. We cannot fight them because our children go to their schools. It is a give and take situation. You need to address this issue in a diplomatic way. That's what local politics is about (Focus Group Discussions, December 2005). 
As indicated by this narrative, positive social capital and connections are not only important survival strategies but they can open up access to other social and physical infrastructure outside the village boundary. For example, Milaboni village does not currently have a high school but has only one dilapidated primary school (Figure 5.4). It is currently serviced by Mudunungu village for its secondary educational needs. Lack of medical, social and commercial facilities such as clinics, community crèche and a grinding mill would mean that Milaboni village will continue to depend on its neighboring villages for such needs. This type of relationship constitutes unequal power relations at the village scale. However, this infrastructural dependency might come in the way of any prospective land-related activism that Milaboni village might direct to its neighboring villages. These people are likely to be marginalized and hence might require advocacy and support if they are to deal with these conflicts effectively.

In contrast, land-related conflicts at Dzingahe village are largely induced by development programs, especially the establishment of Thohoyandou Correctional facility (prison) situated on land that formerly belonged to Dzingahe village (A). Evidence from key informant interviews and focus group discussions indicated how the homeland government established a well-defined buffer zone around the prison facility as a safety measure between the village and the prison facility. The buffer zone demarcation contributed to the forced removals of Dzingahe residents to the new location as a dormitory village to supply labor to Sibasa and Thohoyandou urban areas. This process took place during the 1960s. An interview at Dzingahe village with one of the key informants substantiated the point:

When they removed us from the area where the prison is currently situated, they said it was for our safety. The buffer zone was necessary because if prisoners were to escape, they might hurt you. That's what the government officials said. We lost our land like that and we cannot claim it anymore; to where will they move the prisoners? Our burial sites are left unattended there (Individual Interviews, October, 2005). 
In addition to the fact that Dzingahe villagers have limited access to the correctional facility, local politics and power relations have not considered the local cultural identities of Dzingahe people in the naming of the facility. Instead, the prison was named "Thohoyandou Correctional facility" to reflect the identity of the former homeland capital and not that of the village. The community seems to resent this form of cultural appropriation in order to keep their customs and resources to themselves. The resentment is attributed to the fact that beneficiaries were supposed to be the people of Dzingahe village but in this case the area's identity is defined by outsiders. These 'outsiders' include institutions and power structures beyond the village that continue to govern the Correctional facility. Hence, Dzingahe community members perceive it as an imposed structure on them. In this way villagers feel marginalized and powerless.

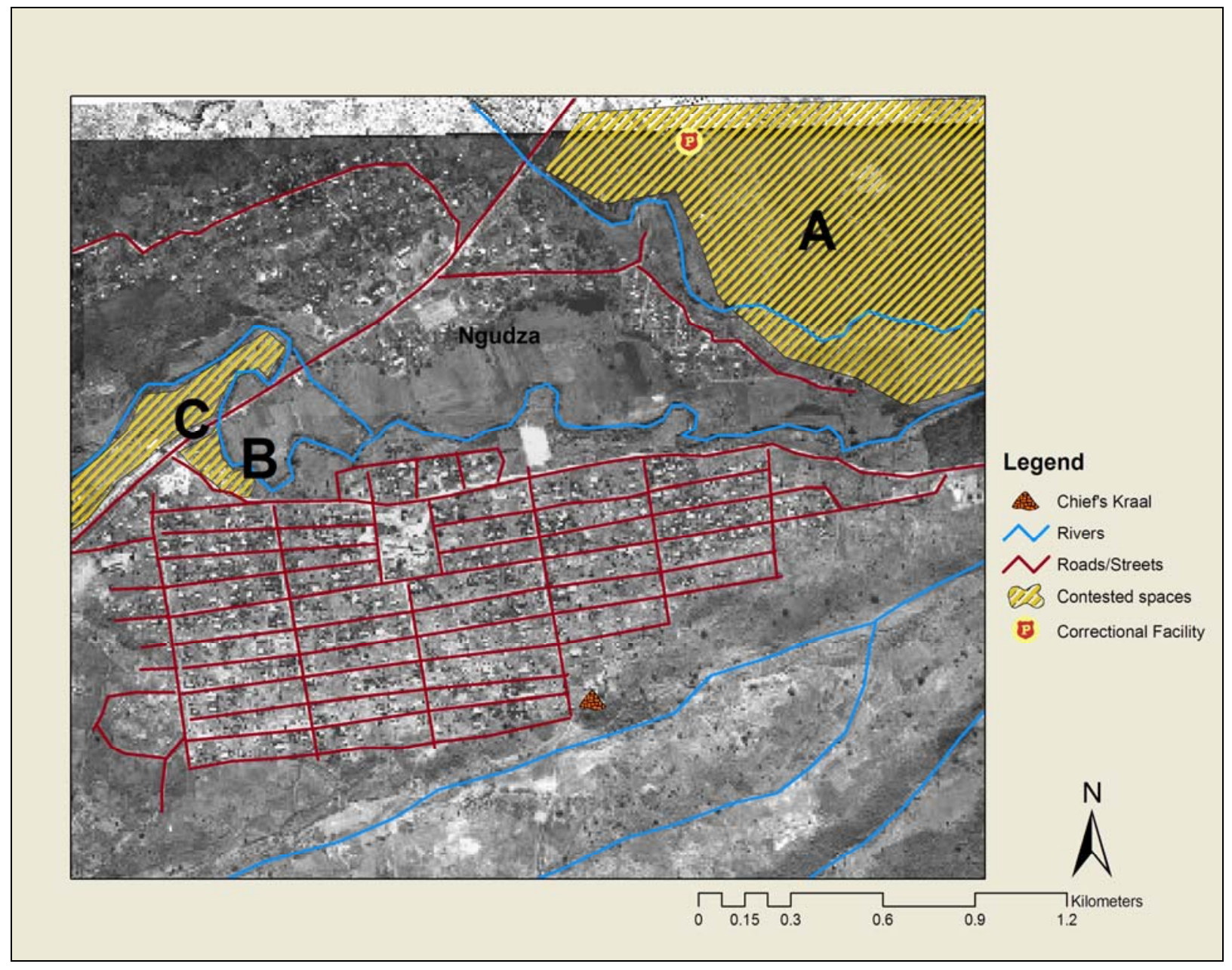

Figure 7.2(b): Mental map of contested spaces at Dzingahe village 
In addition to development related conflicts, social conflicts at Dzingahe are also about some form of political tensions between Tshivhase and Mphaphuli tribal authorities. In contrast to Milaboni village which is under the jurisdiction of one authority (i.e. Tshivhase), some of the households and commercial infrastructure at Dzingahe village are under Tshivhase while others are under Mphaphuli tribal authorities. However, the majority of households, social and commercial infrastructure at Dzingahe are under Mphaphuli territorial authority. From the historical narrative, the problem lies with the contested spaces identified in Figure 7.2 (b). In addition, the pockets of business clusters (C; B) belong to Ngudza territory. However, villagers regard that territory as theirs. This represents another land-related conflict arising out of the fact that physical barriers such as rivers were not considered in the demarcation of village boundaries. Instead, the territorial ownership was considered and that land belongs to Tshivhase territory. The implication is that people at Dzingahe village feel alienated from riparian resources due to these territorial conflicts. However, they do not have alternatives because they do not have access to structures of power that control the zoning of land in this village.

\subsubsection{Communities' perspectives on flood-prone areas}

In this exercise, participants were asked to use their experiences and knowledges to define and demarcate flood vulnerability in terms of a geographic space (i.e. indicating where vulnerable people and places are located) and a social space (i.e. who or what in that place is vulnerable). This task entailed the mapping of areas in the study sites that are prone to flooding (Figures $7.3 \mathrm{a}$; b). The whole process is consistent with the idea that flood vulnerability should be defined by vulnerable people. Evidence from the community mental mapping workshop and focus group discussions indicate that there is not vernacular usage of the term "vulnerability" although local communities understand the scientific meaning translated to them. However, participants were aware of flood relief assistance given to them during the great flood of 2000, although none of them were aware of any policy in place that deals with flood hazard in the area. 
Figure 7.3 (a) indicates the areas at Dzingahe village which are considered flood-prone by the participants of the mental mapping workshop. These are mostly, areas along the main transportation routes and along main rivers in the area. It is interesting to note that participants did not only demarcate areas in their own village but also included the neighboring Ngudza village. These neighboring rural villages have social links and shared experiences such as tragedy, death or sorrows. Hence, participants perceive flood crisis as a broader communal and societal responsibility.

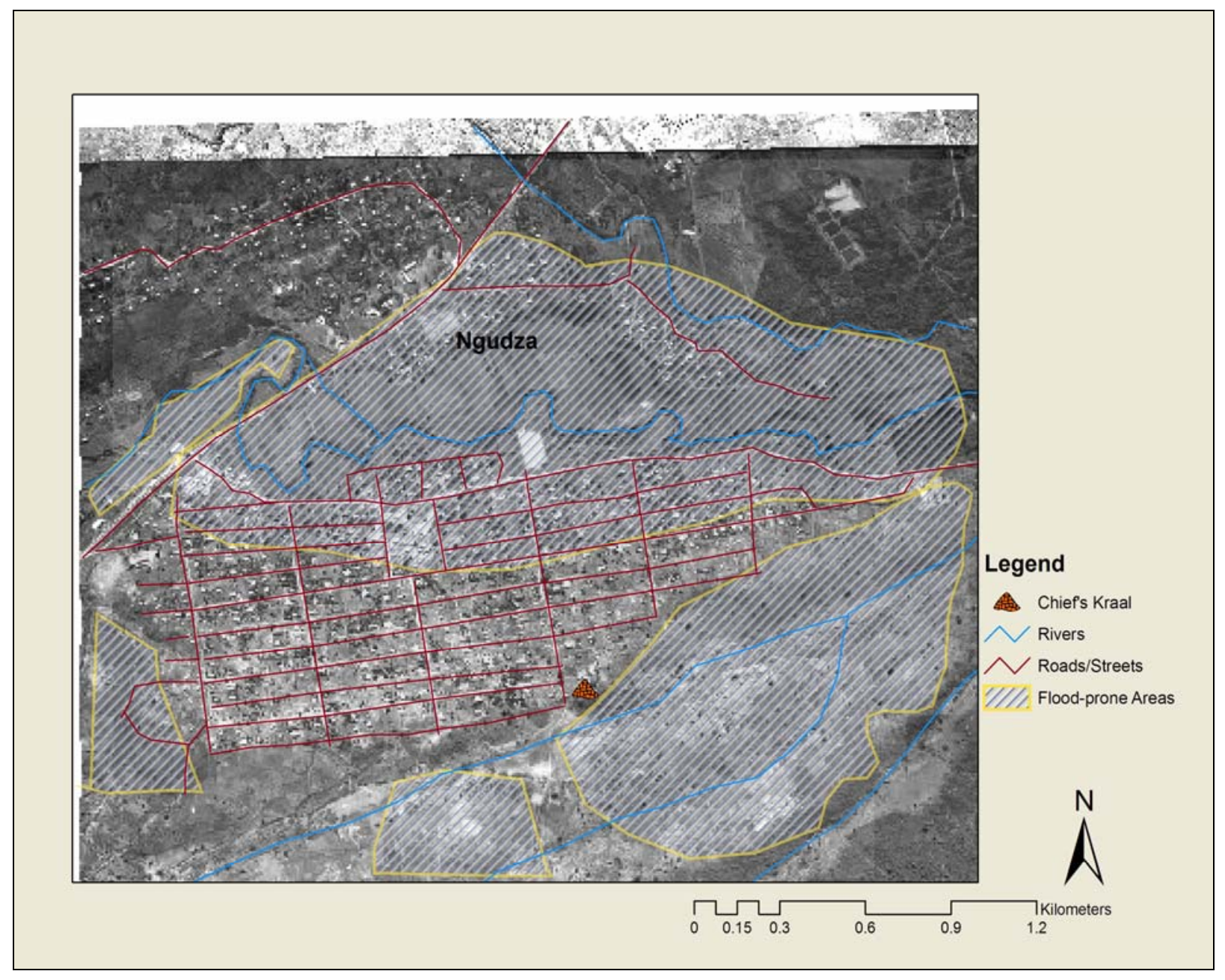

Figure 7.3(a): Mental map of flood-prone areas at Dzingahe village 
Flood vulnerability areas reconstructed through mental maps at Milaboni and Dzingahe villages consist of zones of low-lying, flood-prone land in the vicinity of main river streams and small farming areas in the floodplain (Figure 7.3 b). Participants at Milaboni village have a generalized view of the perceived flood zone which includes only two flood-prone zones. These cognitive maps of flood-prone areas confirm the discourse that regards the floodplains and other low-lying areas as dangerous places. In this case, flood vulnerability is linked to these locations. However, evidence from the household survey indicates the prevalence of vulnerable households even beyond the flood-plain. Vulnerability profiles of households within the community demarcated flood zones are addressed in the next section to demonstrate the integration of "local" and expert" knowledges to assess differential flood vulnerability.

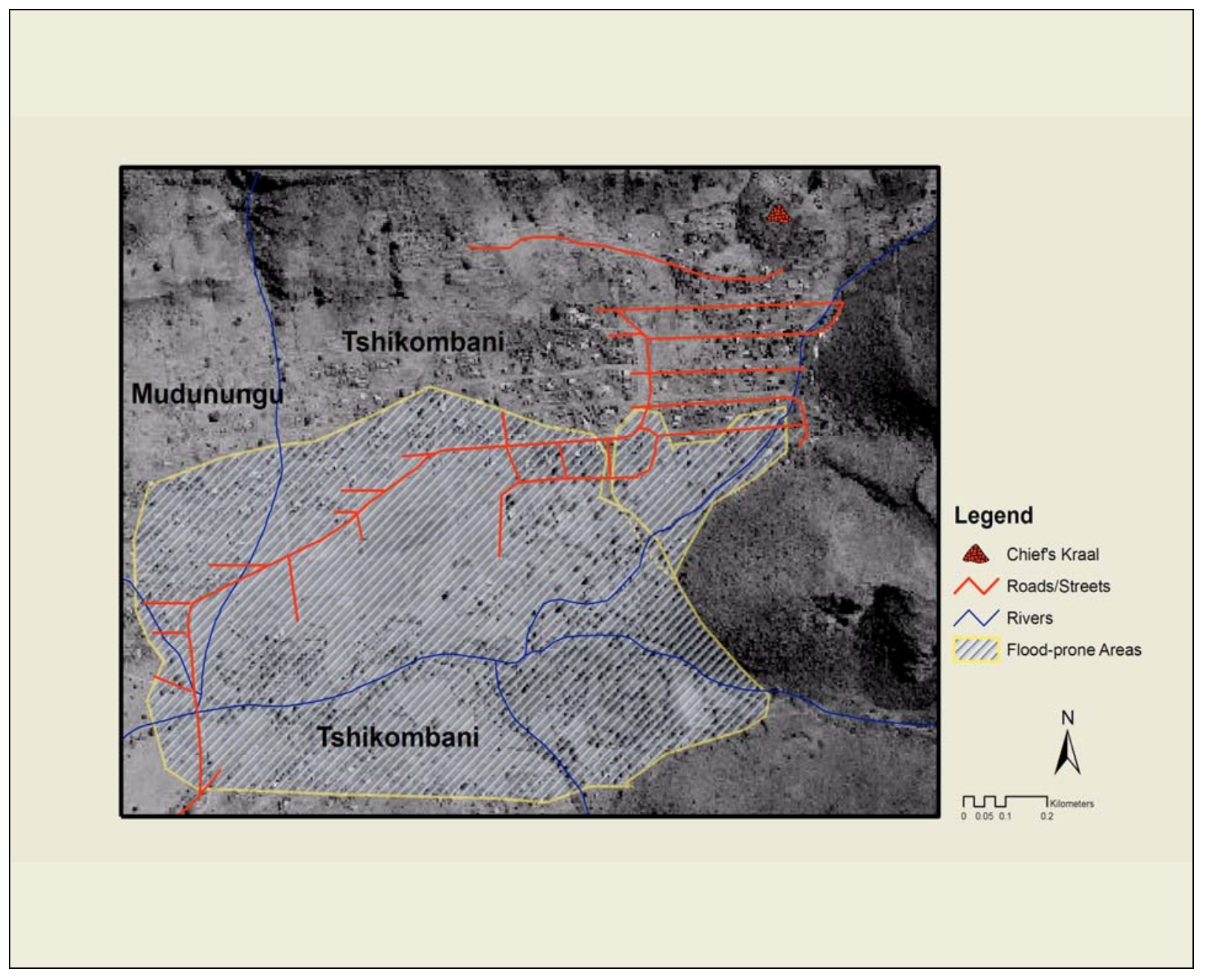

Figure 7.3(b): Mental map of flood-prone areas at Milaboni village 
Land conflicts affect mostly the poor because once they lose infrastructure and resources they originally owned, it becomes difficult to obtain, recover or replace them. Tributes are often paid to acquire land resources even under communal land ownership. Local knowledge of flood-prone areas has been an important input into the "expert" DEM modeling of flood vulnerable space. The output of the integration of the "local" and "expert" knowledges about the geography of flood vulnerability was then used as a backdrop upon which the social, economic and political space of vulnerability was based.

\subsubsection{Perspectives on historical and contemporary resource access and use}

Mental mapping workshop participants at Dzingahe and Milaboni areas were also asked to identify historical and contemporary natural resource use and ownership patterns. Identifying what and where resources exist, who has access to such resources, and who controls them, is important for capacity building and for developing flood vulnerability reduction strategies that are sensitive to local needs. Figures 7.4 (a; b) represent the historical and contemporary natural resource access areas identified for both study sites. The two maps suggest that the resource access area before used to be larger than the area now. Over-exploitation of resources from this smaller area, in the form of deforestation, digging of soils for wall ornaments is likely to cause irreversible environmental stress.

In South Africa, the Communal Land Rights Act of 2004 contains a group titling procedure that transfers title to land in the former reserves to 'communities.' According to the Act, all uninhabited land without statutory tiles belongs to the state, under communal ownership. What this means is that the resource access areas demarcated in Figures 7.4 (a; b) are under communal ownership. This type of ownership is ambiguous and may be wrongly interpreted to mean that all natural resources such as water, grazing, fruit and wild vegetables, wood and building materials in the communal land are available to every resident of that community. The concept of communal ownership allows for a considerable overlap in rights and entitlements. Hence, chiefs who have political and ritual powers claim some kind of sovereignty over the land. Currently, most of the control of communal resources is granted to locals who are able to pay tribute to be 
granted usufruct in the area. In other cases, large area of land is put on lease to state plantation companies and that alienated the local community from using the resources in the plantation.

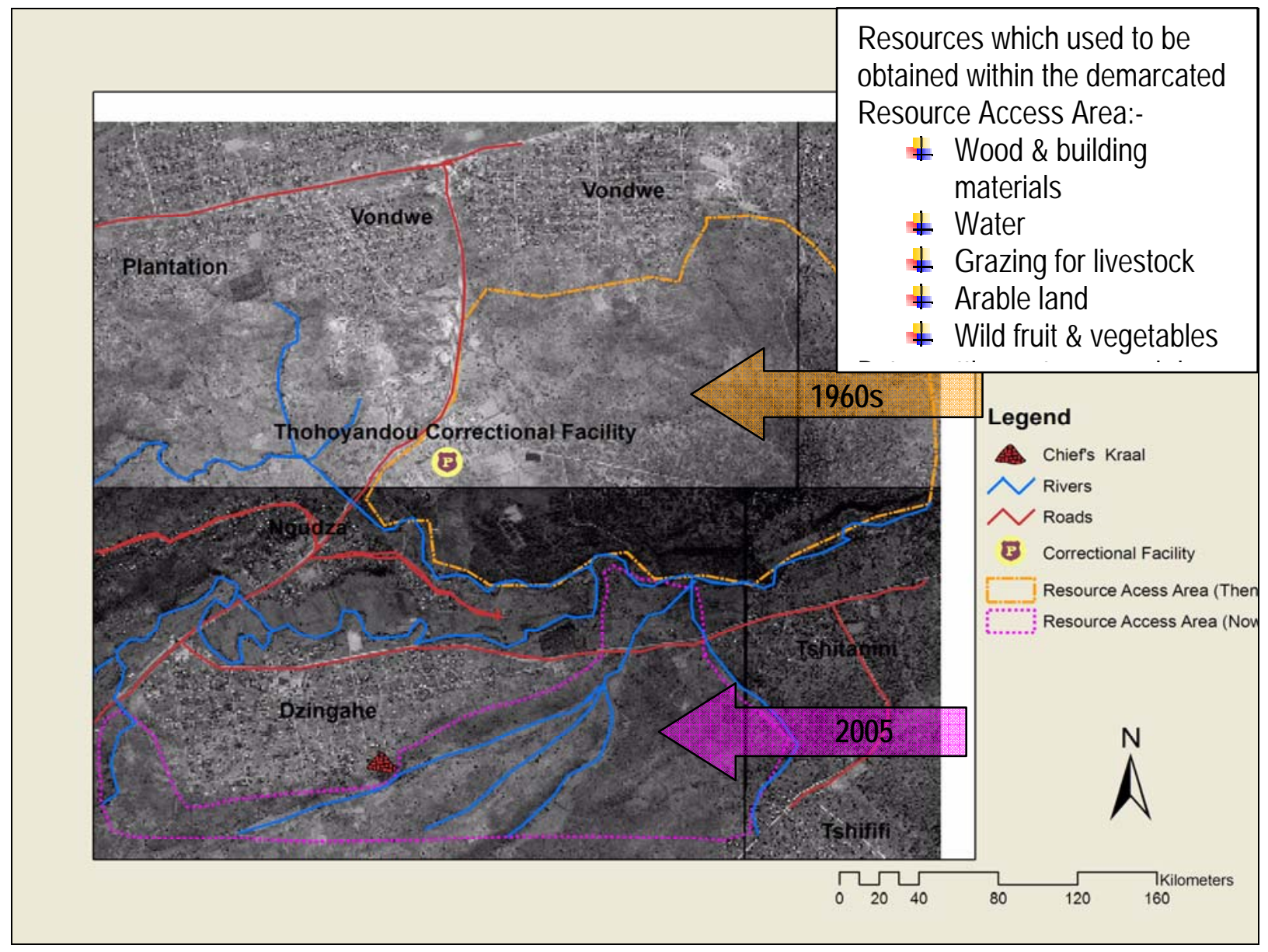

Figure 7.4 (a): Historical and contemporary natural resource use at Dzingahe village

In the case of Dzingahe village, it was the homeland government which issued a permit for the establishment of a prison facility in the area demarcated in Figure 7.4 (a). This competitive land tenure system has proliferated the unequal access to land resources under communal ownership. Hence, social, political and economic power relations are inscribed through ownership practices in the communal land. For example, plantations 
and farms owned by government and private individuals reflect social, political and economic power. Power relations are also manifested in how the size of the farm or field is determined. Market forces in the form of tributes, political or economic power, earned or ascribed determine the nature of usufruct rights granted. Local politics determines the access, use and distribution of the resources in the communal land. Hence, access and ownership of those resources is differentiation by social status and other contextual factors in place.

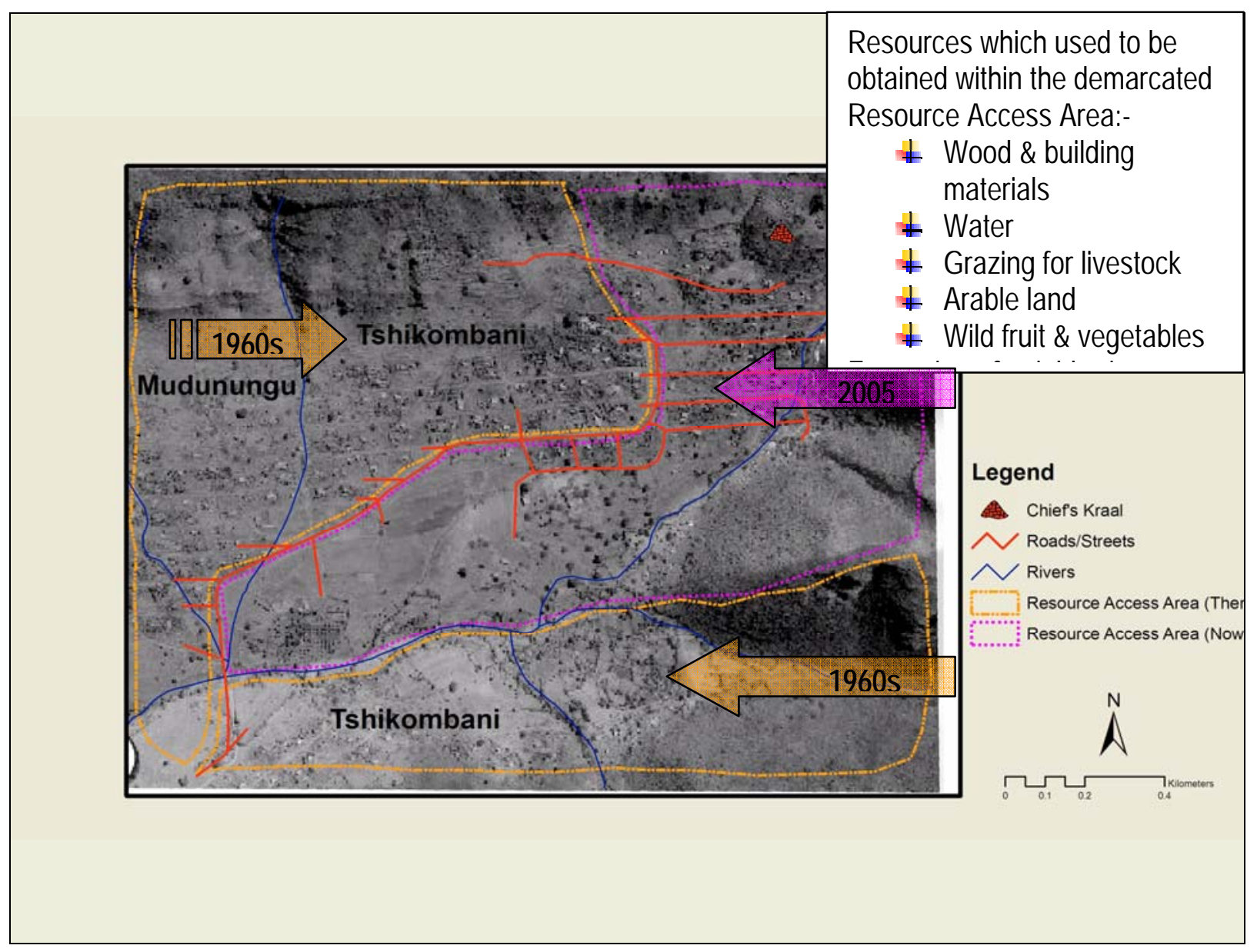

Figure 7.4 (b): Historical and contemporary natural resource use at Milaboni village 


\subsection{Integration of Local and Expert Knowledge}

This section integrates "local" and "expert" knowledge to assess flood vulnerability based on geographic location, socio-economic and political space. Physical or geographic vulnerability surfaces were constructed for both villages on the basis of "local" and "expert" perspectives of flood-prone areas. Then the geographic space was populated with household, infrastructural and socio-economic data to assess differential flood vulnerability. Income, gender and assets, including land were the socio-economic indicators which were used to demonstrate the contribution of PGIS to the analysis of flood vulnerability. Comprehensive analyses of socio-economic indicators of vulnerability were conducted in the previous chapter. The following section provides the background of how the flood vulnerability surfaces were constructed in an ArcGIS ${ }^{\circledR}$ environment.

\subsubsection{Background}

Physical factors such as geology, rainfall intensity, hydrology, vegetation cover and soil types play an important role in determining differential flood vulnerability. All these factors constitute geographic space and they impart variable flood exposure and vulnerability on people. Spatial variations of flood exposure between the two study sites are contingent upon variations in rainfall regimes, geological composition, vegetation cover and soil types. The role of these factors in determining spatial flood vulnerability is described in chapter 3 . These physical factors can be modeled and aggregated to derive weighted indices that can be integrated with GIS data to produce complex flood vulnerability models. There are also attempts to integrate hydrological run-off models with GIS. One example is a run-off model which examines the effect of soil type, ground cover type, and rainfall amount on the quantity of water runoff and flooding (Gotwals, 1998; Crowley, 2002). However, despite the fact that the modeling of these physical variables is beyond the scope of this research, complex modeling processes are data intensive and more importantly, can mask variability depending on the way data sets are weighted and aggregated. In addition, meaningful analyses of physical factors in a PGIS 
environment demand geo-referenced spatial and attribute data that are accurate and in an appropriate scale. The question of scale is very important because scale determines what is visible and what is not. For example, rainfall and geology data presented in Chapter 3 are at the municipal scale of analysis and hence, could not be scaled down to the village level. Such data sets for Milaboni and Dzingahe villages were not available. In these study sites, there are no gauging stations and hence, no records were available of flood stage data for Mutangwi and Mutshindudi Rivers which drain the two villages respectively. In South Africa, GIS data collection is driven by tender agreements and as such agencies of government, NGOs and private consultancies only collect data that are useful for their purposes.

For example, in 2005/2006, Statistics South Africa embarked on a data collection pilot project to geo-reference dwelling frames for 15 municipalities in South Africa. This project has benefits for service delivery and census related applications for the sampled municipalities. However, despite several attempts to obtain the data sets in GIS formats, I could only access the data through ArcIMS that was slow to load and prone to errors (e.g. ArcSDE ERR 2407) during data loading and query sessions. ${ }^{14}$ Instead, I had to digitize the necessary data for this research. This explains the practical realities of the political economy of GIS data access and commodification in South Africa. In this context where the researcher's questions are not answered by the formal scientific data, the use of other means (e.g. digitizing) including community-based knowledge of historical flood and elevation data is appropriate (see Bayliss \& Reed, 2001; Reed, 2002). According to Ruddle (1994) local knowledge has short horizon, lacks institutional memory and cannot be simply generalized because it is not always directly related to general society (Ruddle, 1994). This view is debatable and is not void of controversy, since the reporting of flood history by the elderly people indicates that their local knowledges can have a long horizon.

\footnotetext{
${ }^{14}$ ArcIMS is ESRI ${ }^{\circledR}$ software that delivers dynamic maps and GIS data and services via the Web.
} 
In view of this background, the question that remains is how best to describe the physical landscape of flood vulnerability in the study sites. The answer to this question lies in the objective at hand --- which in this case, is to model a flood vulnerability surface or geographic space based on the elevation data of two study sites and the local community experiences of flood-prone areas. Physical factors described in Chapter 3 and land use activities are part of this geographic space and they also interact with it. Local people know and have experienced and modified this geographic space. These experiences and knowledges even though based on the intuitive and not an inscribed source are valid and have therefore, informed the development of flood vulnerability surfaces represented in Figures $7.6(\mathrm{a} ; \mathrm{b})$.

\subsubsection{The construction of flood vulnerability surfaces}

By using elevation data of the two study sites, Digital Elevation Models that could drape raster and vector data sets were created in ArcGIS ${ }^{\circledR}$ using the 3D Analyst Raster Interpolation function. On the basis of community's estimation of flood-prone areas, discussion with villagers and the ground inspection, three scenarios of combined river proximity and flood vulnerability surfaces were constructed [Figures 7.5 (a; b)]. These scenarios are not comprehensive flood-forecasting models but they are useful tools in places where there are no flood-maps to identify elements at risk and suggest possible flood mitigation strategies.

Figures 7.5 (a; b) indicate the delineated "local” and "expert” flood-prone areas in both villages. These are mainly in the low-lying areas. In terms of the construction of 'expert" vulnerability surfaces, different elevation breakpoints or pixel values from an interpolated raster surface were selected for Milaboni and Dzingahe villages, mainly because of variations in elevation and location of community perceived ("local') flood-prone areas. For Milaboni village, the estimated elevation breakpoints from the community mental maps, for both three scenarios range from $949 \mathrm{~m}$ for the worst case scenario (i.e. scenario 1) to $900 \mathrm{~m}$ above sea level. In contrast, the estimated elevation breakpoints for Dzingahe village are between 580 and $548 \mathrm{~m}$ above sea level. The differences in the breakpoints for 
scenarios in each village are attributed to variations in elevation, valley configuration and different flood experiences and perceptions of these two communities.

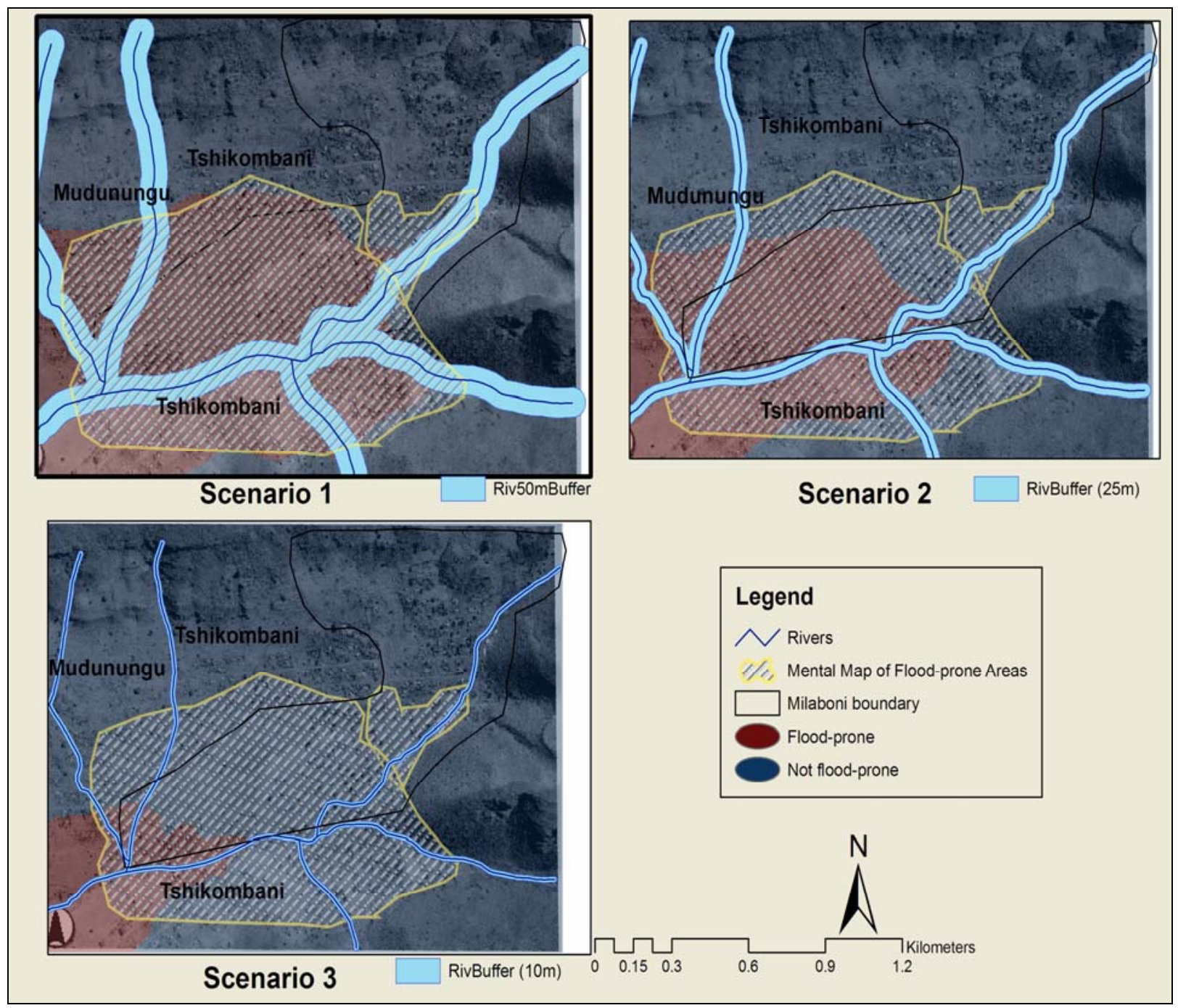

Figure 7.5 (a): Raster Interpolated Flood vulnerability Surfaces: Scenarios 1-3 at Milaboni

In addition, proximity analysis was factored into the construction of 'expert" floodvulnerability surfaces. In this case, locations of elements at risk were analyzed by measuring the distance between them and the river. It is assumed on the basis of spatial autocorrelation that features closer to the river are likely to be more vulnerable than those 
far away depending on the magnitude of flooding. For proximity analysis, 50, 30 and 10 meter buffer zones from the river were delineated. The choice of the cut-off distance points were informed by the community mental maps which demarcated flood-prone areas [(Figures 7.3 (a; b)]. Taking into account the extent of coverage, flood scenario 1 was selected for both study sites. This scenario in both villages assumes severe flood impacts, an emergency that may last couple of weeks and slow recovery phase due to sheer extensive damage. This is an example of a worst-case scenario characterized by severe flood impacts - a typical representation of the 'great' flood of 2000 in the study sites.

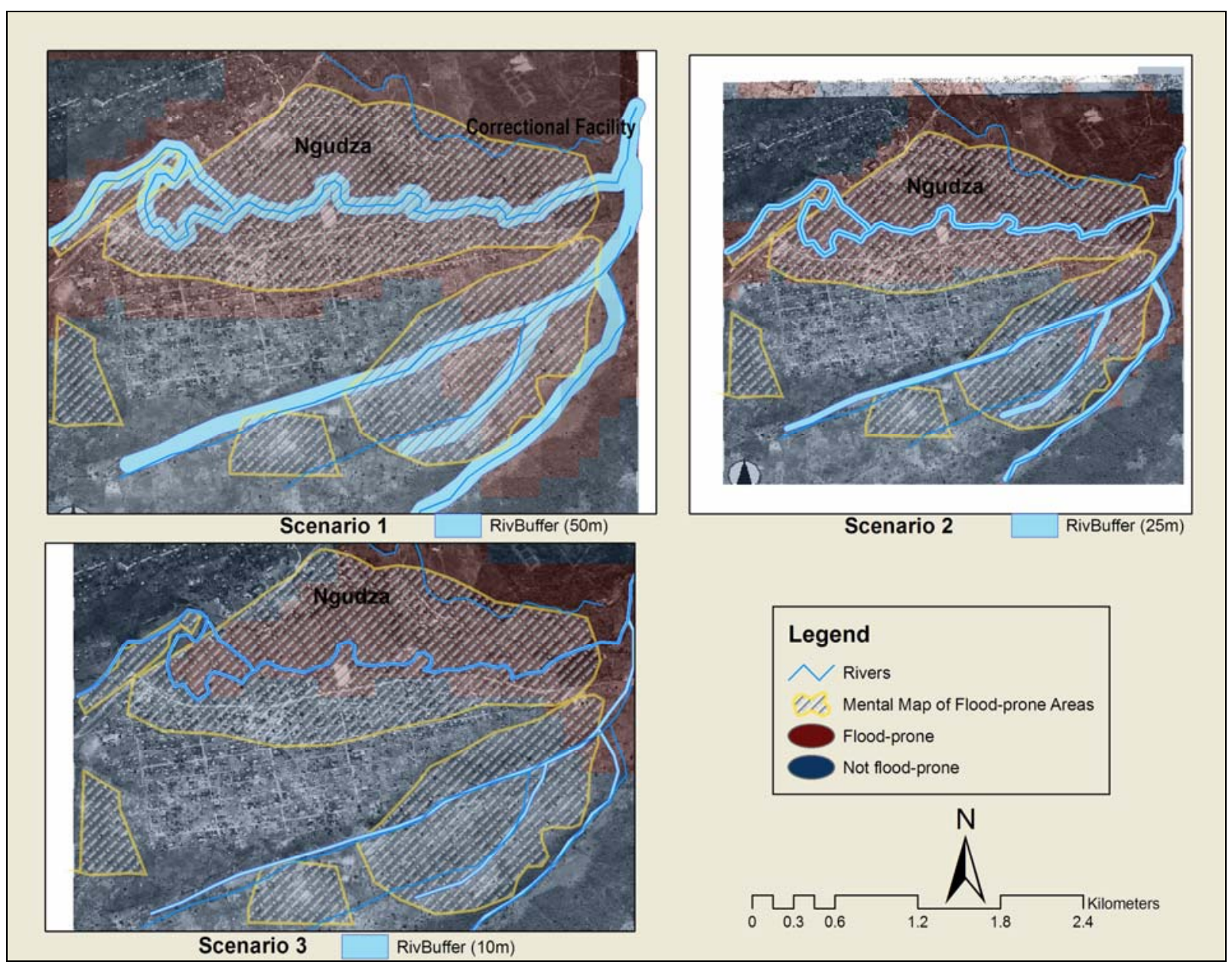

Figure 7.5 (b): Raster Interpolated Flood vulnerability Surfaces: Scenarios 1-3 at Dzingahe 
Flood vulnerability scenarios are meant in this research to evaluate various vulnerability surfaces which were developed on the basis of "local" and 'expert' knowledge" as explained earlier. The evaluation is done to arrive at a more reliable geographic space of flood vulnerability which takes into account of both community and expert inputs. The geographic flood-prone space amongst the three scenarios in each village decreases as various elevation parameters and buffer distance change. This three scenario model in each village represents flood vulnerability as a dynamic and complex phenomenon. The models simulate the fact that as the geographic space in terms of physical exposure changes, so does flood vulnerability. It is also evident in Figures $7.5(\mathrm{a} ; \mathrm{b})$ that the community's mental maps of flood-prone areas omitted vulnerable areas identified by the letter "C". This omission indicates areas outside activity spaces of the workshop participants. This observation justifies the importance of integrating local and expert knowledge for complementary outcomes.

A closer analysis of the physical terrains of Milaboni and Dzingahe villages reveals that in addition to socio-economic factors, a combination of factors such as rugged topography, heavy orographic rainfall, upstream watershed and a vast floodplain are some of the critical factors that are likely to explain flood vulnerability. However, slight differences in topography influence rainfall variability between the two study sites. Physical parameters such as soil characteristics and the valley configuration explain to a significant extent flood vulnerability in terms of exposure in these villages. These factors were addressed in Chapter 3. However, it is the combination of physical and socioeconomic parameters that best explain what, why and who are vulnerable to flooding.

\subsubsection{Analyzing differential flood vulnerability for the study sites}

\subsubsection{Background}

Flood vulnerability as illustrated earlier in Figure 2.2 is a function of exposure (physical location) and coping capacity. This implies that understanding flood vulnerability requires an assessment of how affected people are exposed to flooding. It also requires an 
insight into their perceptions, knowledge about hazards and different forms of coping. The latter issues were addressed in the preceding sections. The earlier conceptualization of vulnerability (Blaikie, et al., 1994:14) privileged coping capacity over exposure, because the conventional explanation of flood risk has always linked hazards and its impacts to the physical domain at the expense of socio-economic, historical and political processes that make people vulnerable to hazards. However, the current explanation of vulnerability emphasizes coping capacity and acknowledges the role of geographic space and physical forms of vulnerability that include areas, buildings and agricultural systems (Bankoff \& Hilhorst, 2007). This conceptualization of vulnerability highlights complexities associated with understanding vulnerability. The point remains though, that flood vulnerability is socially constructed, even though it has a relationship to physical or geographic space. Flood vulnerability is distributed as a reflection of social, political and economic power relations. These power relations are inscribed through material practices in the built environment. This section therefore addresses the physical flood exposure and coping capacity as two critical elements of flood vulnerability. An attempt to answer questions on the location, who is exposed, why they are exposed and their associated coping capacity is done on the basis of the household data. Statistical analyses of these household socio-economic data were done in the previous chapter. This chapter provides the spatial interaction of the physical and human factors that produced differential vulnerability.

\subsubsection{Physical and Human Geographies of Differential Flood vulnerability}

Flood vulnerability in the study sites is differentiated by geographic location and socioeconomic conditions. Households and other elements at risk are usually located on floodplains and other vulnerable locations (Figures 7.5 a; b). Similarly, there are physical and social attributes that make them vulnerable to flooding. Figures $7.6(a$; b) indicate how "local" and "expert" knowledges have augmented each other to delineate floodprone areas. These maps indicate the extent of geographic area, households and other physical infrastructure that are vulnerable to flooding on the basis of geographic location. Analyses of potential relationships between data sets in Figures 7.6 (a; b) indicate that 
elements at risk are located on low-lying areas (A; B) which are likely to be inundated in the event of a flood hazard.

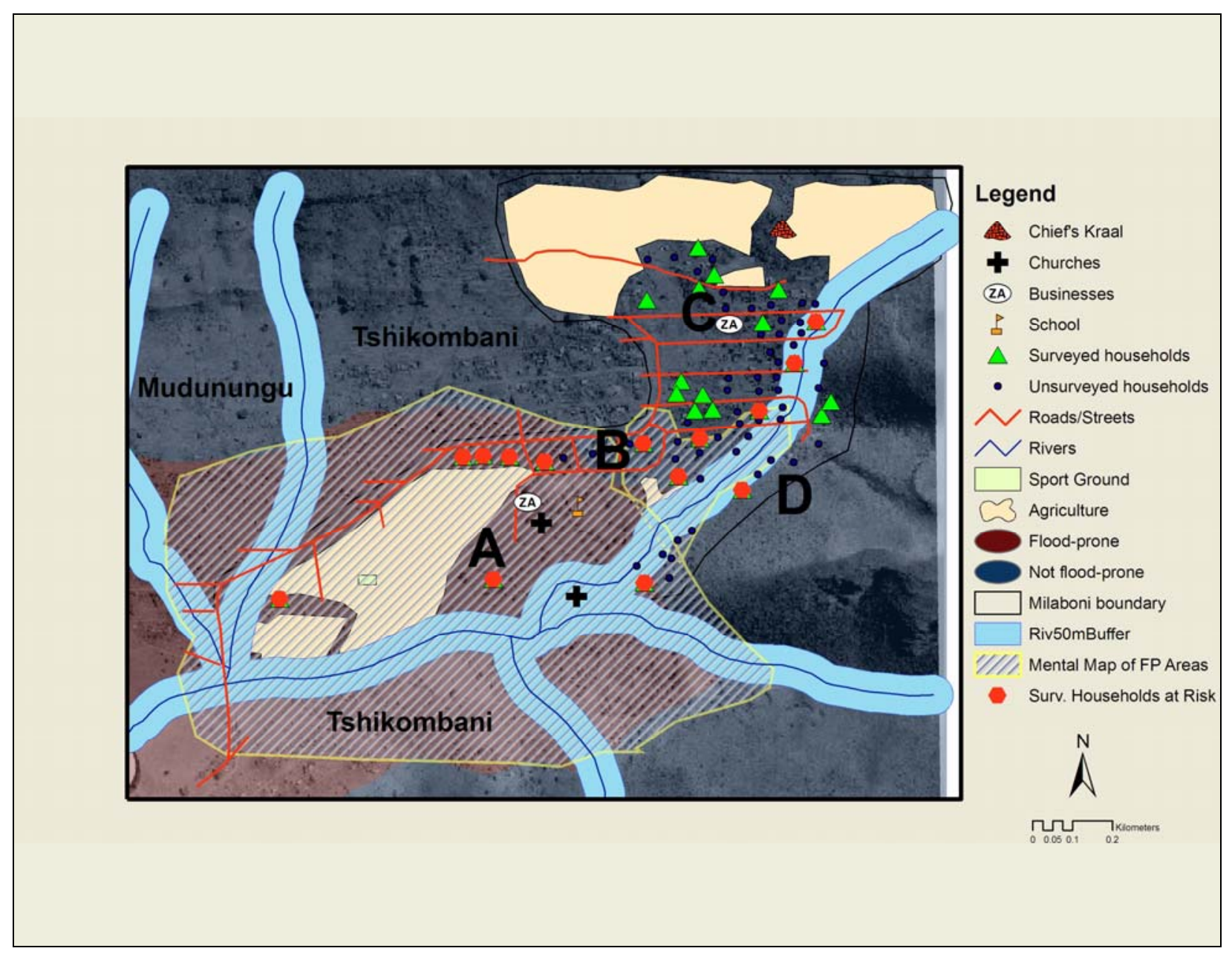

Figure 7.6 (a): Flood vulnerability at Milaboni village

When participants of mental mapping workshops were asked to delineate flood-prone areas as indicated on the map, they also verbally depicted vivid memories of flood impacts from the year 2000, in terms of how their houses were damaged as well as how their corn fields and other riparian crops were washed away by the Mutangwi and Mutshindudi Rivers. Differential flood vulnerability based on location is evident on the 
maps in Figures 7.6 (a; b). At Milaboni village, households that are on higher elevations (C; D) are less vulnerable than those on the valley floor (A; B).

It is also interesting to observe limited use of flood-plains at Milaboni despite the fact that no flood-plain zoning rules exist that might place restrictions on their use. This might be a direct response to the flood of year 2000 and can reduce the cost of future flood damage. Furthermore, this represents the proactive measure of villagers towards a move away from the vulnerable floodplains. Instead, the flood plain is mostly inhabited by the land use and development activities such as subsistence farming, commercial and social infrastructure (such as a retail business), a sporting ground, a primary school and two churches (Figure 7.6 a).Survey households at flood risk are also indicated on the map. Another significant observation at Milaboni village is that there are certain households within the river buffer zone in the vicinity of the letter " $\mathrm{C}$ " that were not included in the mental maps of flood-prone areas. These households might be outside the activity spaces of the workshop participants. This is a good indication that participants from those households were not represented in the workshop. Hence, integration of the buffer model and the mental maps spatially broadens the risk profile of households.

Similarly, at Dzingahe village, areas in the vicinity of "B" were beyond the activity spaces of workshop participants. The elements at flood risk include, riparian subsistence agriculture, individual households, a clinic and commercial sites which have inhabited the flood zone (Figure $7.6 \mathrm{~b}$ ). The prevailing development patterns of commercial sites and clinic in this flood-prone zone are associated with main transport routes and as such this location is attractive due to ease of access. Individual householders as indicated in Figure 7.7 (b) have limited resources, although variations exist between male and female headed households. There is significant difference in terms of the "local" and "expert" boundaries of flood zones at Dzingahe village. This implies that the "expert" boundary has included more elements at flood risk than the mental map boundary [Figure 7.6 (b)]. This zone has included in addition, three additional churches, a school with its sport ground, a business premise and a number of surveyed and unsurveyed households. Unsurveyed households are those households that were not part of the study sample, but 
few have been included on the map to emphasize in terms of spatial coverage the significance flood vulnerability in these two villages.

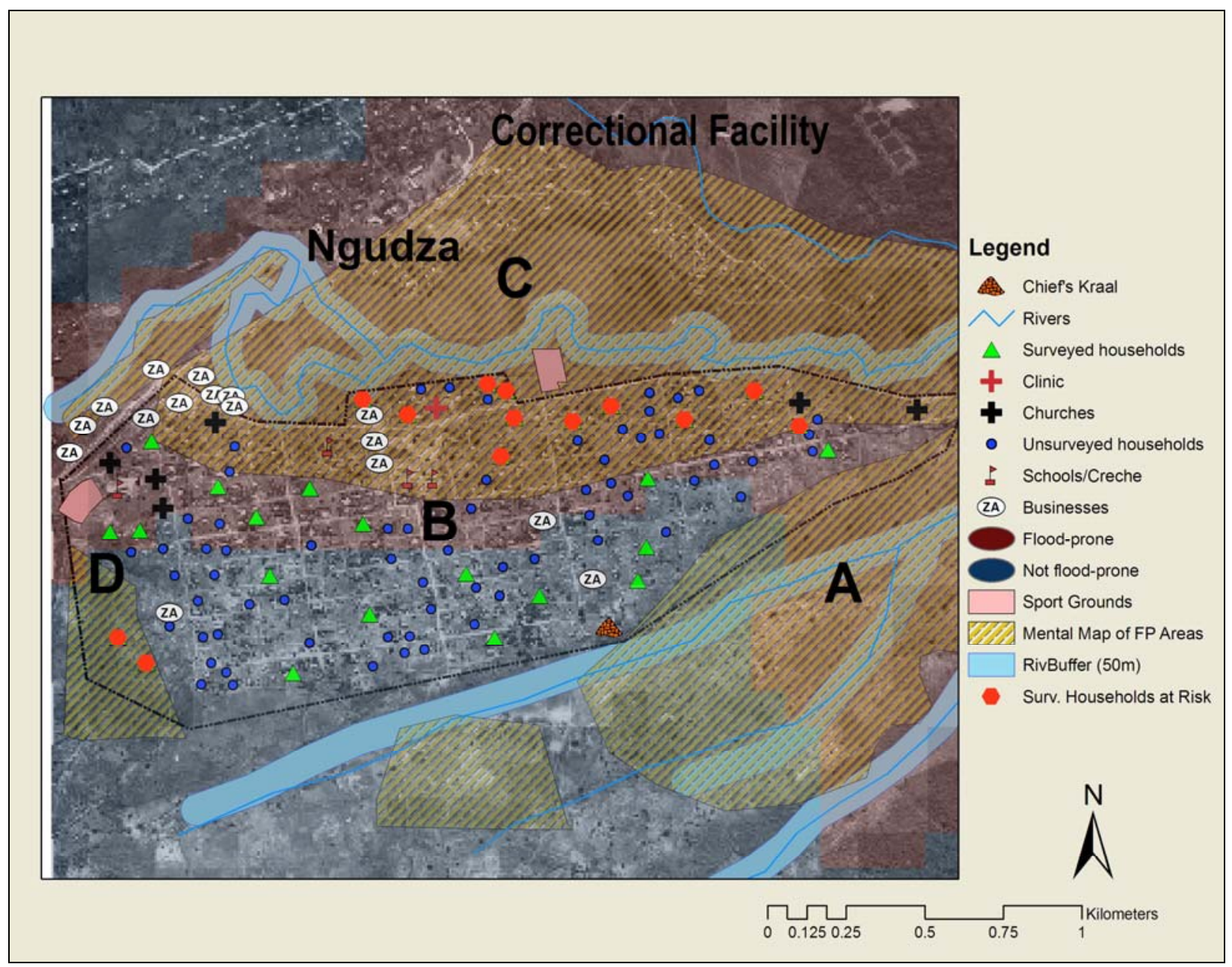

Figure 7.6 (b): Flood vulnerability at Dzingahe village

Figures 7.7 (a; b) further explore differential flood vulnerability on the basis of socioeconomic indicators such as income and gender. Income differentials are evident according to gender of the head of the household in both study sites. As evident from the household survey (see chapter 6), gender shapes human responses to flood hazards. Women are directly and indirectly hard-hit by the social impacts of flood hazards. 
Unstable informal businesses which form the mainstay economy of these two villages are mostly run by women. Hence, the direct destruction of home-based and informal businesses, and the disruption by floods of spatial connectivity to markets in towns make women-headed families more vulnerable.

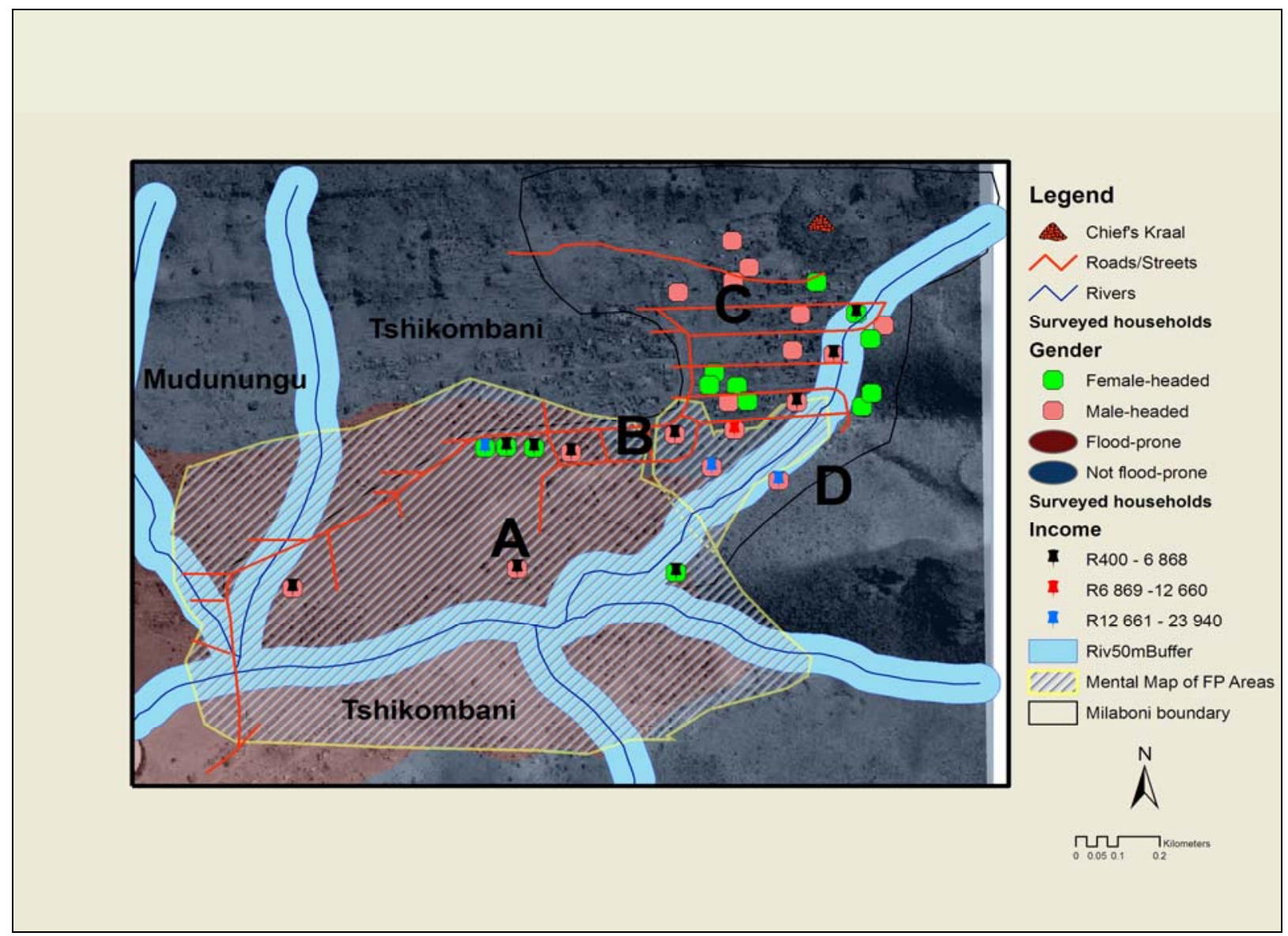

Figure 7.7 (a): Distribution of households by gender and income of householders: Milaboni

At Milaboni village, of those vulnerable households that fall within the "local and expert" demarcated flood zones, as identified in 7.6 (a), the ratio between male and femaleheaded households is 9:5 (Figure 7.7 a). Household flood vulnerability is increasingly differentiated by household assets, income, social status and gender (Tables 7.1; 7.2). These variables impart differential capabilities and varied modes of household flood coping. In terms of income, four of the five female-headed households located in floodprone area belong to the low income category (R400 - 6 868), compared to six of the 
nine male-headed households that fall in the same income quintile. However, one femaleheaded compared to two male-headed households were in the lower middle income category (R12 661 to R23 940). As evident in Table 7.1, the head of the household (ID \#12) in the income category between R12 661 and R23 940 is a female widow, with 2 dependents, 2 dwelling units and has 14 years and above of educational training (i.e. has college/tertiary qualification). Within the sample households that inhabit the demarcated flood zone, only one male-headed household falls under the income category of R6 869 12 660. These findings imply that not all male-headed households in the flood zone have the same coping capacity. Similarly, there are female-headed households that have enhanced flood coping capacity as compared to their male counterparts.

Table 7.1: Attribute data for identified households at risk: Milaboni village

\begin{tabular}{|c|c|c|c|c|c|c|c|c|c|c|c|c|c|}
\hline ID | UNT Cender & r|Marital\$ & Income & Depend| & Children Land & Ouncell & Owncar & OwnComp & OwnRadio & OwnTV & Ftamad & d Assets & Educ_1 & AMarriage \\
\hline $4 \quad 1$ Nale & Whowed & RAOO-6868 & 2 & $4 \mathrm{Nb}$ & Yes & $\mathrm{Nb}$ & Yes & Yes & Yes & Yes & Nodern House & $9-13 y r s$ & Qustomary \\
\hline 63 Fenale & Nerried & RAOO- 6868 & 2 & $5 \mathrm{Nb}$ & $\mathrm{Nb}$ & $\mathrm{Nb}$ & $N$ & Yes & $\mathrm{Nb}$ & Yes & Catlle & $>=5 y$ ys & hommunity \\
\hline 73 Nale & Nerried & R6869-12660 & 2 & $3 \mathrm{Nb}$ & Yes & $\mathrm{Nb}$ & $\mathrm{Nb}$ & Yes & Yes & $\mathrm{Nb}$ & NodernHtouse & 9-13yrs & Qustomery \\
\hline $8 \quad 1$ Nale & Nerried & R12661-23940 & 2 & 2 Yes & Yes & $\mathrm{Nb}$ & $N$ & Yes & $\mathrm{Nb}$ & Yes & Poto d landon & 9-13yrs & astomery \\
\hline 102 Fenale & Nerried & RAOO- 6868 & 3 & $3 \mathrm{Nb}$ & Yes & Yes & $\mathrm{Nb}$ & Yes & Yes & $N$ & Cattle & $\Leftrightarrow=14 y$ rs & Qustomary \\
\hline 122 Fenale & Wdowed & R12661 - 23940 & 2 & $O N B$ & Yes & Yes & $N b$ & Yes & Yes & Yes & Cattle & $<=14 y r s$ & Qustomery \\
\hline 132 Fenale & Divorced & RAOO- 6868 & 2 & $3 \mathrm{Nb}$ & Yes & $\mathrm{Nb}$ & Yes & Yes & $\mathrm{Nb}$ & $\mathrm{Nb}$ & Sheep & 9-13yrs & NA \\
\hline 183 Nale & Nerried & RAOO- 6868 & 2 & 4 Yes & Yes & $\mathrm{Nb}$ & Yes & Yes & Yes & Yes & Cattle & 9-13yrs & Qustomery \\
\hline 151 Fenale & Single & RAOO- 6868 & 2 & $3 \mathrm{Nb}$ & Yes & Yes & $\mathrm{Nb}$ & Yes & $\mathrm{Nb}$ & Yes & Cattle & 9-13yrs & NA \\
\hline $27 \quad 2$ Nale & Nerried & RAOO- 6868 & 2 & $2 \mathrm{Nb}$ & Yes & $\mathrm{Nb}$ & Yes & Yes & Yes & $N$ & Sheep & $>=5 y$ ys & Qustomery \\
\hline 292 Nale & Nerried & RAOO- 6868 & 3 & 2 Yes & $\mathrm{Nb}$ & $\mathrm{Nb}$ & $\mathrm{Nb}$ & Yes & $\mathrm{Nb}$ & $\mathrm{Nb}$ & Sheep & $6-8 y r s$ & astomary \\
\hline 52 Nale & Nerried & RAOO- 6868 & 2 & $3 \mathrm{Nb}$ & Yes & $\mathrm{Nb}$ & $N b$ & Yes & Yes & $\mathrm{Nb}$ & Catlle & 6-8yrs & h cormunity \\
\hline 2 Nale & Nerried & RAOO- 6868 & 3 & $3 \mathrm{Nb}$ & Yes & $\mathrm{Nb}$ & $N$ & Yes & Yes & $N b$ & Cattle & 9-13yrs & astomery \\
\hline 1 Nale & Nerried & $R 12661-23940$ & 3 & 3 Yes & Yes & Yes & Yes & Yes & Yes & Yes & Cattle & $<=14 y r s$ & hcormunity \\
\hline
\end{tabular}

Differential vulnerability based on gender and income is more evident at Dzingahe than at Milaboni villages [Figure 7.7 (b)]. Of the thirteen households located in the flood zones, eight are female-headed and five male-headed households (Table 7.2). Similarly, 
there are income variations among and between male- and female-headed households. Five of the female- headed households fall within the low income category (R400- 6 866) and three with an income range of between R12 661 and R52 800. Of the five femaleheaded households, two are divorced, one is single, one is widowed and one is married under customary law. Of the three householders one whose income ranges from R12 661 to R23 940 is single. Of the two remaining householders one was married in community of property and the other was widowed during the time of the survey. Hence, their marital status entitled them to equal share of the property and other assets and the inheritance including land that is passed on during the death of the husband.

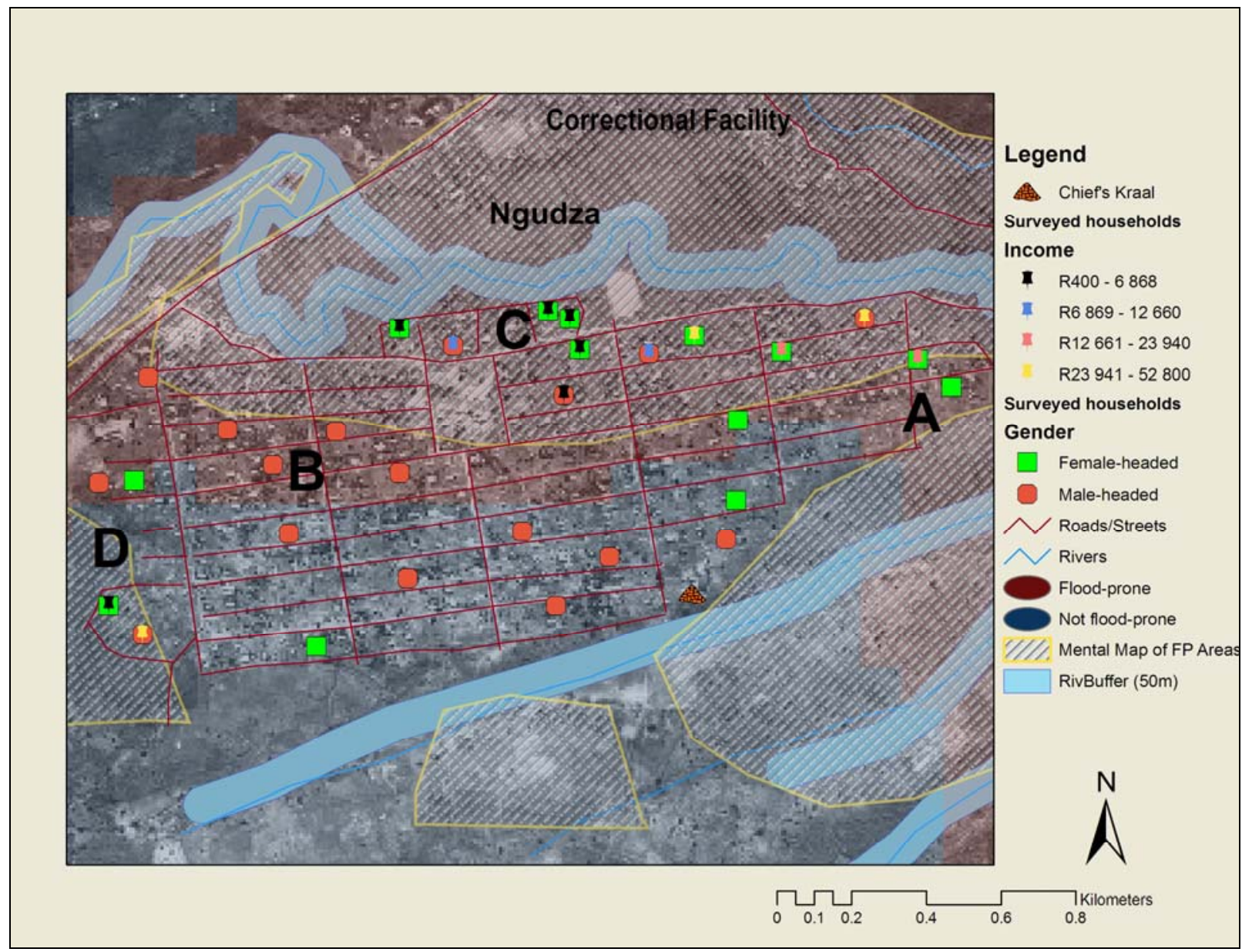

Figure 7.7 (b): Distribution of households by gender and income of householders: Dzingahe 
Table 7.2: Attribute data for identified households at risk: Dzingahe village

\begin{tabular}{|c|c|c|c|c|c|c|c|c|c|c|c|c|c|c|}
\hline Id Cender & Marital S & s) Income & Depend & d Children & a Land & Ouncel & $\|$ OwnCa & a) OwnComp & p OwnRadio & OWnTV & Famad & d Assets & Educ_1 & Alariage \\
\hline 1 Nale & Nerined & $168669-12600$ & 2 & 2 & 2 Yes Y & Yes & Yes & $\mathrm{Nb}$ & Yes & Yes & $\mathrm{Nb}$ & Cattle & $>=5 y / s$ & Qsstomary \\
\hline 2 Fermale & Wdowed & RAOO- 6868 & 2 & 3 & $3 \mathbb{B b}$ & Yes & Ab & Nb & Yes & Yes & Yes & Pdof landon & n 9-13yis & NA \\
\hline 3 Fende & Divorced & RAOD- 68680 & 2 & 2 & $2 A B$ & Yes & Ab & Nb & Yes & Yes & Yes & Goats & $>=5 y$ is & astomery \\
\hline 4 Fende & Single & RAOO- 6868 & 2 & 3 & $3 \mathrm{NB}$ & Yes & Ab & Nb & Yes & N & Yes & Modern House & e9-13y/s & NA \\
\hline 5 Fendle & Divorced & RAOD- 6868 & 2 & 2 & $2 \mathrm{Bb}$ & Yes & Yes & Nb & Yes & N & N & Sheep & $<=14 y$ rs & incomunity \\
\hline 6 Nble & Single & RR3941-52800 & 2 & 2 & $2 \mathrm{Mb}$ & Yes & $\mathrm{Ab}$ & $\mathrm{Nb}$ & Yes & Nb & Yes & Pdof landon & n 9-13y/s & NA \\
\hline 7 Fende & Nerried & RAOO- 6868 & 2 & 6 & 6Yes 1 & & Yes & Yes & Yes & Yes & $\mathrm{Nb}$ & Cattle & $\Leftrightarrow=14 y$ rs & astomery \\
\hline 16 Nale & Neried & RAOO-6868 & 2 & 3 & 3 Yes 1 & $\mathrm{Nb}$ & $\mathrm{Ab}$ & Nb & Yes & Yes & $\mathrm{Nb}$ & Cattle & $>=5 y$ ys & Qustomery \\
\hline 22 Fermle & Single & $\mathrm{R} 12661-23940$ & 2 & 2 & $2 \mathrm{NB} Y$ & & Yes & $\mathrm{Nb}$ & Yes & Nb & Yes & Goats & 6-8yrs & NA \\
\hline 23 Fermale & Nerried & $R \mid 2661-23940$ & 2 & 2 & 2 Yes $Y$ & & Nb & Yes & Yes & Yes & $\mathrm{Nb}$ & Cattle & $<=14 y$ rs & hcomnint \\
\hline 24 Nale & Wdowed & RR3941-52800 & 2 & 2 & $2 N B$ & & Ab & N & Yes & b & Yes & Sheep & 9-13yrs & astomery \\
\hline 27 Fende & Wdowed & RR3941-52800 & 2 & 3 & $3 \mathrm{NB}$ & Yes & Ab & N & Yes & Yes & b & Catlle & 9-13yss & astomery \\
\hline 28 Nale & Wdowed & $1168609-12660$ & 3 & 3 & 3 Yes Y & Yes & Yes & Yes & Yes & Yes & $\mathrm{b}$ & Catlle & $<=14 y$ rs & Oustomery \\
\hline
\end{tabular}

This positionality provides them with sufficient financial resources to take care of unexpected impacts of flood hazards. In most cases, however, for women married under customary law often share inheritance with other members of the extended family including the brothers and sisters of the deceased. This factor combined with poor access to land and income contributes to low resilience levels of female-headed households and consequently they might find it harder to recover from flood impacts. However, as demonstrated earlier, women are not universally impacted by flood hazards. Widows and single women, functionally illiterate and those not formally employed constitute the vulnerable group. Similarly, there are differential incomes of the male-headed households that are located within the flood-zone. The income of the five sampled male-headed households range between R400 and R52 800 . These households fall within the low, lower and upper middle income categories. Those male-headed households with low flood vulnerability might cope well due to variations in socioeconomic characteristics. 


\subsection{A composite landscape of differential household flood vulnerability}

Figures 7.8 (a; b) illustrate the combined role of physical and socio-economic characteristic in determining flood vulnerability in the study sites. This combined role emphasizes the need to look beyond physical geographical vulnerability to understand how social, economic and political processes place people at flood risk and to ensure that current flood mitigation policies are addressing important factors that make people more or less vulnerable to flooding. These composite maps were developed to isolate flood vulnerable households on the basis of household location, income, gender and access to assets including land.

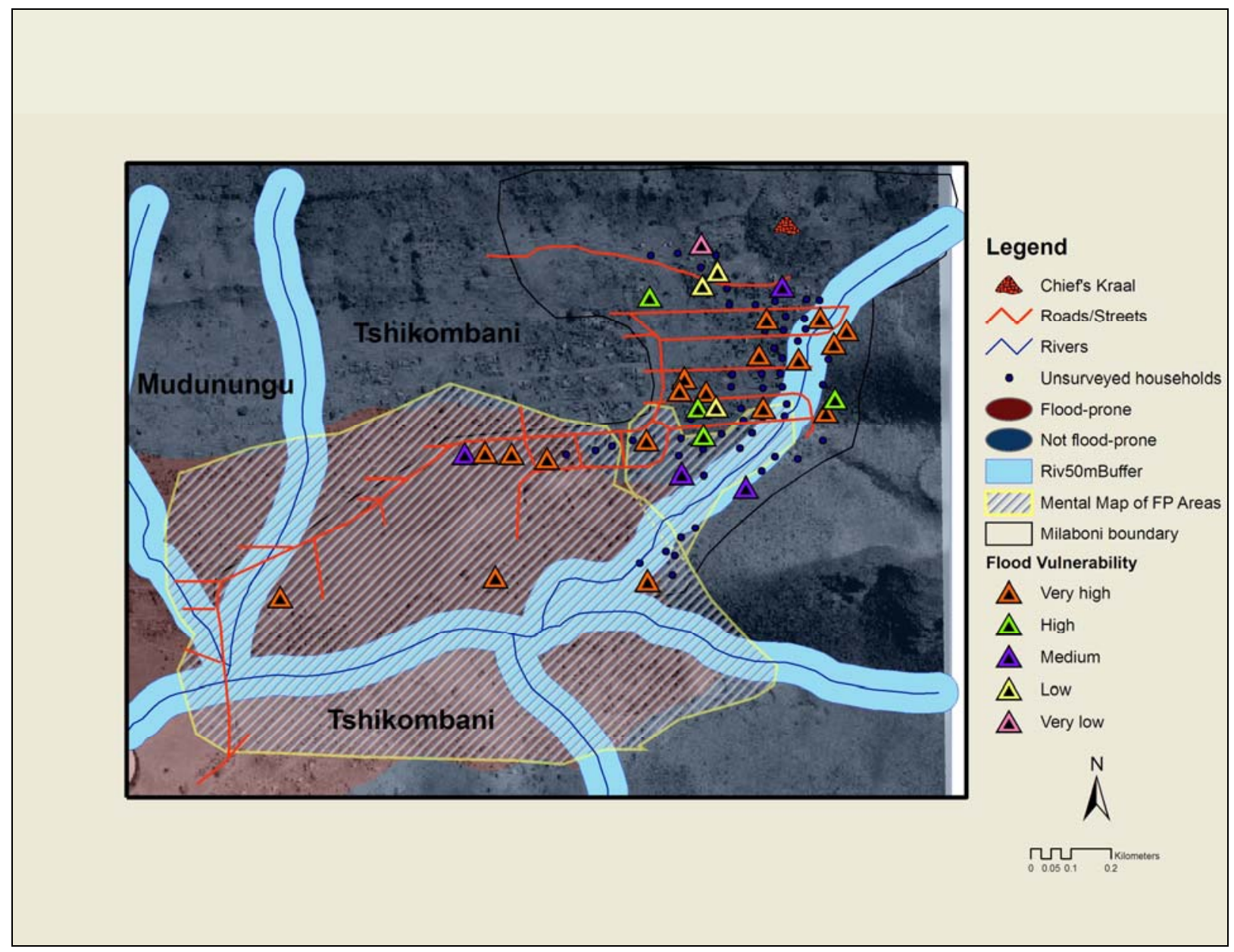

Figure 7.8 (a): A composite map of household flood vulnerability: Milaboni village 


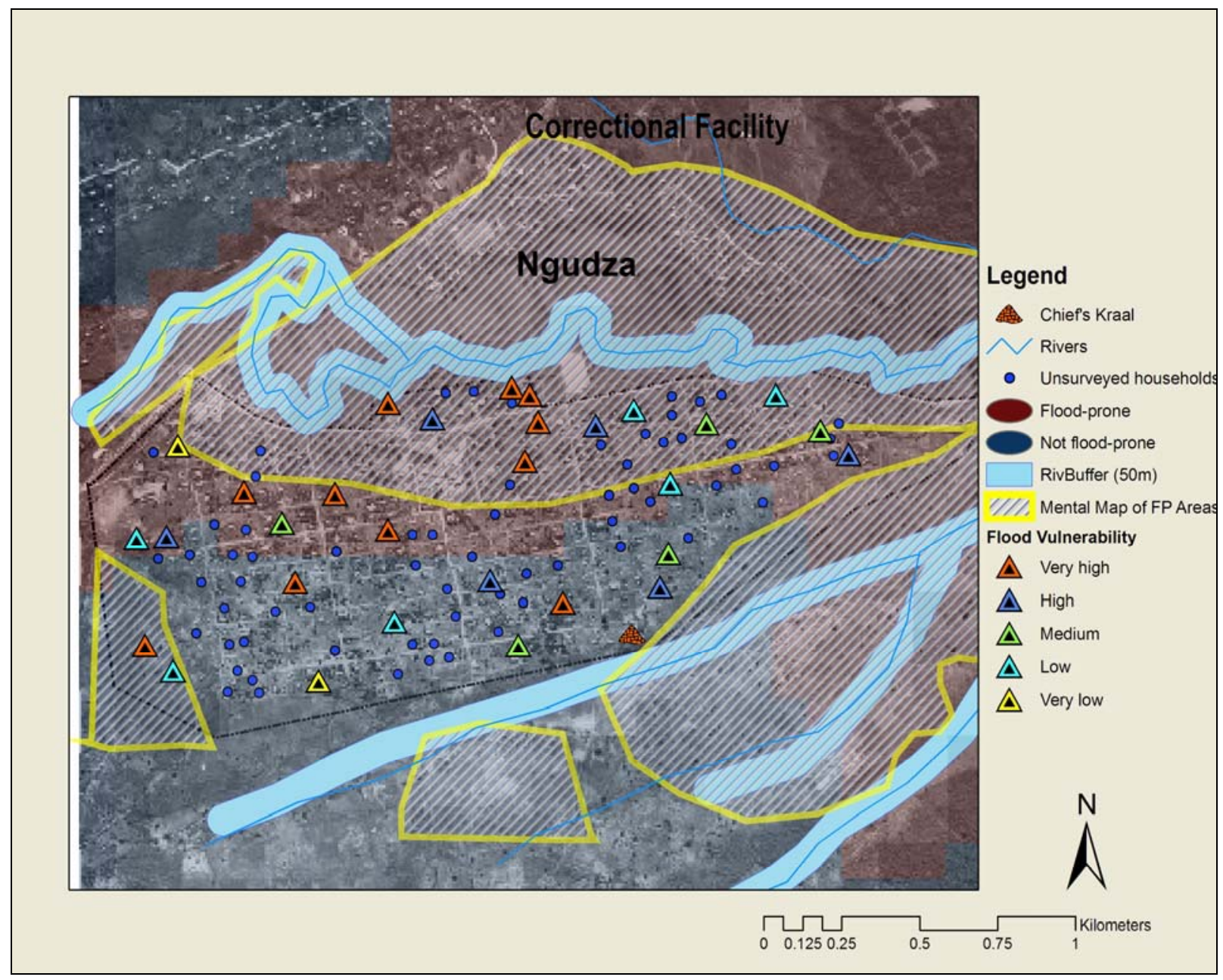

Figure 7.8 (b): A composite map of household flood vulnerability: Dzingahe village

The role of these individual factors in producing household flood vulnerability has been addressed in chapter 6. Physical parameters of flood hazards indicate that flood threat exists. Likewise, socio-economic indicators of flood vulnerability highlight the preexisting conditions of vulnerability (i.e. vulnerability context). Separately, each set of information does not make us understand critical forces that make people vulnerable and thus, does not raise our understanding of flood vulnerability. In addition, a separate analysis does not help decision-makers identify appropriate actions to take to reduce vulnerability. But together, these critical sets of information can help both flood vulnerable groups and the decision-makers see a powerful perspective of the likely impacts of flood hazards on different people and places. Composite maps in Figures 7.8 
(a; b), indicate differential flood vulnerability on the basis of physical location and the socio-economic parameters, particularly income. On the basis of income, therefore, households occupying the same geographic space are differentially vulnerable to flooding due variations in coping capacity.

Many households are rendered vulnerable by location such as those in the floodplains. These households are often situated in these vulnerable locations due to historical consequences of social, economic and political processes that have produced differential coping capacity. Households that are not located in flood-prone settings might become vulnerable due to limited economic resources that enhance a speedy recovery after flood crisis. As can be seen in Figures 7.8 (a; b) there are pockets of vulnerability which are intensifying across geographic space. Socio-economic and political parameters indicated that not all households living in the same surveyed villages live exactly the same way. Neither do they have the same flood coping capacity. As indicated on the maps (Figures $7.8 \mathrm{a}$; b) and Tables 7.1 and 7.2 some households are able to cope better than others based on the differential household resources. Not all people in a flood impacted area will need the same level of assistance. By highlighting who is vulnerable and how, this helps identify appropriate areas of response for decision-makers and helps develop appropriate flood vulnerability mitigation strategies before and after flood events.

\subsection{Conclusion}

Community mental maps have a cognitive dimension and are largely dependent on participants' knowledges, experiences and impressions. Therefore, these maps should be linked to activity spaces of these communities and should not be taken as absolute maps of flood vulnerability. In other words, mental maps reflect a person's activity space including what is accessible to his or her rounds of daily activities. Hence, flood vulnerability mental maps should be viewed as relative representations of vulnerability by those participants of the mental mapping workshop. A different group of participants could have come up with maps that represent differently the underlying causes of flood vulnerability and unsafe conditions at Milaboni and Dzingahe villages. If participants 
were divided according to gender the outcome might have been a different representation. Nevertheless, mental maps and community narratives represent the critical steps towards understanding differential flood vulnerability in these villages. Community perceptions, knowledges and power relations provide both the means and the explanation that link people through vulnerability to hazards and development. The integration of local and expert knowledge has the capability to spatially broaden the risk profile of households and communities beyond the buffer. However, Euclidean distance alone cannot adequately define flood vulnerability but factors such as elevation and ground inspection can enhance the usefulness of a buffer model.

The extent to which household location plays in flood vulnerability analysis has been examined. However, flood vulnerability at Dzingahe and Milaboni villages is produced by the interaction of both the physical and social factors that make households in these communities vulnerable. Such an interaction is increasingly complex and controversial. In these study sites, vulnerable people are those at flood risk, not simply because they are exposed to hazards, but as a result of marginality that makes them vulnerable. This "marginality" has increasingly become linked to access to income and local natural resources.

There is need in the study sites to restructure the apartheid space economy by developing programs that will increase the asset base of the vulnerable groups. Furthermore, the geographic dislocation between livelihoods, assets and infrastructure of the poor must be reduced by ensuring that people, jobs and infrastructure are closer together. Flood hazards in the study area sites are increasing not because of an increase in flood magnitude and frequency but because of increasing social vulnerability. It is both the level of development and the way society is structured that determines income and access to resources. Consequently, these factors impact people's differential coping capacity. Flood vulnerability assessment is still a conflict-ridden activity in a society. Understanding the human dimensions of flood vulnerability is critical to designing flood mitigation programs that target the most vulnerable groups. Socio-economic information helps assess how quickly or slowly vulnerable people may recover from flood impacts. 


\section{CHAPTER 8}

\section{Summary and Conclusions}

This dissertation research employed a Participatory Geographic Information System to examine social and spatial differentiation of flood vulnerability in the Limpopo Province of South Africa. Political ecology was the conceptual framework. Vulnerability was assessed at three scales of analysis: the household; village; and, intra-household. Milaboni and Dzingahe villages are case studies in the Thulamela municipality that illustrate how differential flood vulnerability is embedded within a wider socioeconomic, political and historical context. This chapter provides a summary of the main research findings and provides overall conclusions.

The first question of this research concerned key historical and contemporary household flood coping strategies in order to highlight how these strategies shape our understanding of differential flood vulnerability in general and household flood coping mechanisms in particular. In this case, the primary unit of analysis was the household. This scale acknowledges the fact that people often deal with flooding as a household by pooling resources and social capital together in order to buffer flood impacts. However, the analytical framework also included intra-household village scales of analysis. The empirical evidence from individual interviews, household surveys and focus group discussions at Milaboni and Dzingahe villages identified significant shifts from historical to contemporary flood coping strategies. These changes are dynamic and have both ecological and socio-economic dimensions. Historical flood coping strategies among other things include a change in cropping patterns and eating habits, evacuation to upland environments, and, natural resource extraction. These were mainly resource-based because they were shaped by access to natural resources. For example, evacuating to upland environments was contingent upon the availability of land. Similarly, the extraction of common property resources such as gathering of wild fruits and vegetables, 
and other forest products, was dependent upon natural resource endowments. An important conclusion drawn from this finding relates to reduced household reliance on natural resources as a flood coping mechanism. The tendency of relying heavily on the extraction of natural resources is often a risk-averse mechanism for these households when resources are available. However, this strategy becomes problematic when natural resources are depleted. In addition, historical processes and prevailing policies and institutions could disrupt the enabling environment for maintaining livelihoods. These factors link household flood vulnerability to the availability of and access to natural resources. The main conclusion based on these findings is that there is a transition from community-based resource management strategies to household and individual income dependent strategies. Therefore, the scale of risk is shifting from community to individual households.

The second question is linked to the first and involves an historical analysis of how household flood coping strategies evolved and the consequent development of contemporary flood coping strategies. The assumption here is that household flood vulnerability changes if flood coping mechanisms change. Similarly, shifts in the physical, socio-economic and cultural factors shaping particular coping strategies are likely to cause significant changes in household flood vulnerability. At the household level, flood vulnerability is a key concept to understanding household flood coping and how they have changed over time. Such changes of flood coping strategies have constantly evolved through homeland government historical processes and power struggles over land. The results of the study indicated that betterment planning was one of the historical factors that contributed to a shift in historical forms of flood coping. Betterment planning which was an important component of apartheid spatial planning contributed to unequal distribution of resources, especially land in the study area. Its implementation was characterized by processes of forced removals and relocation which disrupted socio-political organization and resulted in overcrowding, landlessness, deforestation, soil erosion and the development of commercial farms, national parks and pine plantations in the former "homeland" areas. These contributed to the erosion of livelihoods for the majority of poor rural people in the study sites. 
Consequently, due to betterment planning most of the historical forms of coping became ineffective and hence, abandoned. Contemporary strategies included amongst other things asset disposal, remittances, informal sector activity, income, levees and terraces, wage labor and financial borrowing. These flood coping strategies, which developed out of the crisis of historical forms of coping, emphasized financial income as the most important flood coping mechanism. Within that context, the dynamics of social differentiation of vulnerability have shifted from access to natural resources to income. Land, however, remains an important natural resource which continues to support livelihoods in the study sites. It was also demonstrated that contemporary flood coping strategies tend to overlap with some of the historical forms of coping. Hence, not all historical flood coping strategies are abandoned in these communities. It is their relative importance which is diminishing due to poor environmental resource endowment and lack of access.

It was also demonstrated that the importance of remittances is diminishing as younger members of the households as potential contributors become established in nuclear families in urban areas. As a result, old age pensions are increasingly an important source of livelihoods in these villages. The elderly are no longer perceived as an economic liability but important asset- group for household livelihoods maintenance. Therefore, changes in coping strategies and the importance of remittances, and the economic burden carried by the elderly have intensified social and spatial differentiation of flood vulnerability.

The third question examined critical factors that have produced differential household flood vulnerability in the study area sites. It was demonstrated that flood vulnerability varies over space and among people depending on both the physical exposure and household coping capacity and resilience levels. In this way, changes in the physical environment brought about by land use activities such as grazing, cultivation and building, become very important. Socio-economic conditions of households interacting with physical factors produce differential flood vulnerability. 
The relationship between gender and vulnerability is complex because of changes in the patriarchal system of marriage and inheritance, especially at Dzingahe village which is closer to Thohoyandou town. At the intra-household level of analysis, female-headed households are more vulnerable due to poor socio-economic conditions and by inhabiting more vulnerable location, when compared with male-headed households. However, marital status and improved women's access to income and education have redefined their vulnerability position. For example, some women who are widowed, divorced or have formal education were found to have improved access to resources that were traditionally inaccessible to them such as land, because of changing inheritance processes that entitle them to their husbands' heritage. They also have income generating activities in the form of informal businesses which have improved their financial reserves and help them cope with flooding. Despite the predominance of patriarchal social relations in these villages, some women's positionality within this context strengthens their copying capacity and resilience. However, this is an unexpected finding and cannot be generalized since the majority of female-headed households are still in abject poverty.

The other significant finding relates to the importance of household economic and personal resources, housing type and quality, social capital and political resources. In terms of household economic resources, household flood vulnerability is differentiated by income. In addition, households are also vulnerable due to limited personal and political resources. An important conclusion in this regard is that vulnerability due to social status and political power is dynamic. Hence, those households that are more vulnerable due to the latter factors might be less vulnerable in future if their socio-economic and political circumstances change. It has also been determined by the Housing Quality index that the majority of vulnerable households live in grass-thatched huts whose outside walls are made of dirt. These housing conditions coupled with heavy rains from tropical cyclones and /or located in flood-prone settings are more susceptible to flood damage. The Household Quality Index in these study sites indicates that social stratification is reflected by the range and quality of village houses/huts. In addition, households are more vulnerable by location and by socio-economic or political characteristics. 
The study also demonstrated the importance of social capital involving networks of friends and relatives in enhancing the coping ability of households with floods. Such networks of reciprocity play an important role in rebuilding lives after flood events. Political power and autonomy have been found to be more symbolic rather than functional in the sense that although the majority of householders belong to a political party, they do not have power to influence decisions that impact their lives. For example, community members at both study sites are not directly involved in land use allocation and land use rights decisions. They do not have power to control resources and they lost their access rights during forced removals. An interesting finding is that chiefs are custodians of common resources and as such can authorize usufruct access to all resources but they have very limited political power to change the current land tenure system.

The fourth question of this dissertation research concerned the role of PGIS and political ecology in locating and understanding differential flood vulnerability in the study area. PGIS with its participatory dimension provides an opportunity for local communities to voice and document their experiences and knowledges about flood vulnerability in their area. Political ecology offers an historical and contemporary analysis of power relations that have spatially produced their vulnerability. PGIS also provides an opportunity for local representations of power, politics and resource management in the study area. At the community level, as indicated by community's mental maps, vulnerability is linked to historical processes of apartheid and development outcomes that weakened people's coping capacity and resilience levels. Flood vulnerability is thus, linked to failed development that did not take into account the aspirations and the interests of rural people. PGIS analyses and mapping of community perspectives about underlying factors, historical contemporary processes of flood vulnerability has shed some light on how local knowledge can contribute to science. As demonstrated in the previous chapter, local knowledge through narratives, mental maps of forced removals, contested spaces and historical and current resource use and distribution has identified structures and processes that have transformed household livelihoods and produced differential flood vulnerability. Intra-village land related conflicts about contested spaces and resource use 
have encompassed different stakeholders with unequal social and power relationships. However, at the community level, mental mapping workshops have promoted interaction and often mobilized previously divided communities.

The political ecology framework acknowledges that flood vulnerability does not stem from unexpected events but are the predictable results of the interactions among three major systems: the physical environment which includes flood events; the social and demographic characteristics of the communities that experience floods; and the buildings, roads, bridges, and other components of the constructed environment. An assessment of differential vulnerability challenges the idea of homogeneity that aggregate groups of vulnerable people either by geographic location or by social status alone. Such tendencies often miss the heterogeneity and critical analyses at household, intra-household and village levels shown by participatory approaches offered by PGIS and political ecology. Using a political ecology framework, resource access and land control rights are addressed.

In conclusion, flood vulnerability assessment is more than a matter of academic interest. It has practical implications for the development of meaningful hazard mitigation strategies. The relative success of strategies to reduce flood vulnerability is contingent upon initiatives that take into account local perceptions, experiences and capacity. Furthermore, strategies associated with power shifts and a more even distribution of resources are likely to build local capacity which will help for a more rapid recovery from flood events. Such strategies should be sensitive to social and spatial differentiation of flood vulnerability at various scales. This would facilitate interventions that target impacted households, individuals and members of the community.

The integration of local and expert knowledge with a Participatory GIS has been demonstrated to be very useful for assessing flood hazards within their geographic, socioeconomic and political context. PGIS is, therefore, an effective technology and methodology for assessing social and spatial vulnerability of flood-prone communities and for studying landscape politics and power relations and the structures and institutions 
that produce differential flood vulnerability. In other words PGIS is useful for studying the political ecology of flood hazards because it helps to understand and visualize the politics of power relationships that create such vulnerability in a local landscape. 


\section{REFERENCES}

Abbot, J., Chambers, R., Dunn, C., Harris, T., De Merode, E., Porter, G., Townsend J. \& Weiner, D. 1998. Participatory GIS: Opportunity or oxymoron, PLA Notes 33: 27-34.

Adger, W. N., Brooks, N., Bentham, G., Agnew, M. \& Eriksen, S. 2004. New indicators of vulnerability and adaptive capacity. Tyndall Centre Technical Report 7, Tyndall Centre or Climate Change Research Norwich, UK. Available online at: http://www.tyndall.ac.uk/publications/tech_reports/tech_reports.shtml Accessed, February 2006.

Ahmed, S. 1992. Disaster Management: Socio-Economic Perspectives. In Cyclone Disaster Management and Regional/Rural Development Planning: UNCRD- CIRDAP Seminar, Phase III, 27-29 January, 1992, Chittagong, Bangladesh, 47- 66. Nagoya, Japan: UNCRD.

Aitken, S.C. and Michel, S. 1995. Who Contrives in the "Real" in GIS? Geographic Information, Planning and Critical Theory. Cartography and Geographic Information Systems, 22(1): 17-29.

Alexander, D. 1991. Natural Disasters: A Framework for Research and Teaching. Disasters 15(3):209 - 226.

Alexander, D. 1993. Natural Disasters. London: UCL Press Limited. 1997. The Study of Natural Disasters, 1977-1997: Some Reflections on a Changing Field of Knowledge. Disasters, 21(4): 284-304. 
Anderson, M.A. (1994) Understanding the Disaster-Development Continuum: Gender Analysis is the Essential Tool. In Walker, B. (ed.) Women and Emergencies. Oxfam, Oxford.

Anderson, M.B. \& Woodrow, P.J. 1991. Reducing Vulnerability to Drought and Famine: Development Approaches to Relief. Disasters, 15(1): 43-54.

Aron, J. \& Muellbauer, J. 2006a. Estimates of Household Sector Wealth for South Africa, 1970 - 2003. Review of Income and Wealth, 52 (2): 285 - 308.

Atkinson, A. 1990. Principles of Political Ecology. London: Belhaven Press.

Aysan, Y. \& Davis, I. (eds.) 1993 Disasters and the Small Dwelling. London: James \& James Science Press.

Bankoff, G., Frerks, G. \& Hilhorst, D. (eds.) 2004. Mapping Vulnerability: Disasters, Development and People. London: Eathscan.

Bayliss, A.C. \& Reed, D.W. 2001. The Use of historical data in flood frequency estimation. Report to Ministry of Agriculture, Fisheries and Flood (MAFF), Centre for Ecology \& Hydrology, Natural Environment Research Council.

Bernhagen, P. 2002. Power: making sense of an elusive concept. Paper based upon the work supported by the German Academic Exchange Service (DAAD under the HSP-III Doctoral Scholarship Program.

Bernstein, H., Crow, B. \& Johnson, H. 1992. Rural Livelihoods: Crises and Responses. Oxford: Oxford University Press.

Blaikie, P. 1985. The Political Economy of Soil Erosion in Developing Countries. London: Longman. 
Blaikie, P. 2004. Vulnerability and Disasters. In Desai, V. \& Potter, R.B (eds.) The Companion to Development Studies. New York: Arnold.

Blaikie, P. \& H. Brookfield 1987. Measuring land degradation. In P. Blaikie \& H. Brooksfield (eds.) Land Degradation and Society. London \& New York: Methuen

Blaikie, P., Cannon, T., Davis, I. \& Wisner, B. 1994. At Risk: Natural Hazards, People's Vulnerability and Disasters. London: Routledge.

Bolin, R.C. Household and Community Recovery after Earthquakes. Institute of Behavioral Science, University of Colorado, Boulder.

Bovin, M. \& Manger, L. (eds.) 1990. Adaptive Strategies in African Arid Lands. Proceedings from a Seminar at the Scandinavian Institute of African Studies, Uppsala, Sweden, April, 1989.

Bryant, E.A. 1991. Natural Hazards. Cambridge: Cambridge University Press.

Bryant, R.L. and Bailey, S. 1997. Third World Political Ecology. London \& New York: Routledge and Taylor \& Francis.

Burby, R.J. 1998. Co-operating with Nature: Confronting Hazards with Land-use Planning for Sustainable Communities. Washington D.C.: John Henry Press.

Burton, I. \& Kates, R.W. 1964. Perceptions of Natural Hazards in Resource Management Natural Resources Journal, 3:412-41.

Burton, I, Kates, R.W. \& White, G.F. 1978. The Environment as Hazard. Oxford: Oxford University Press. 
Burton, I, Kates, R.W. \& White, G.F. 1993. The Environment as Hazard, $2^{\text {nd }}$ Edition. New York \& London: The Guilford Press.

Cameroon, J. 2000. Focusing on the focus group. In Hay, I.(ed.). Qualitative Research Methods in Geography. New York: Oxford University Press.

2005. Focusing on the focus group. In Hay, I.(ed.). Qualitative Research Methods in Geography, $2^{\text {nd }}$ edition. New York: Oxford University Press.

Cannon, T. 1994. Vulnerability Analysis and the Explanation of Natural Disasters. In Varley, A. Disasters, Development and Environment. New York: John Wiley \& Sons.

Carney, D. 1998. Implementing the Sustainable Rural Livelihoods Approach. In Carney, D (ed.), Sustainable Rural Livelihoods: What Contribution Can We Make? London: Department of International Development.

Carver, S. 2003. The future of participatory approaches using geographic information: Developing a research agenda for the 21st century. Urban and Regional Information Systems Association (URISA) Journal 15, APA I, 61-72. Available online at http://www.urisa.org/Journal/APANo1/carver.pdf (accessed 10 October 2005).

Clark, G., Moser, S., Ratick, S., Dow, K., Meyer, W., Emani, S., Jin, W., Kasperson, J., Kasperson, R. and Schwarz, H. E. 1998. Assessing the vulnerability of coastal communities to extreme storms: the case of Revere, MA., USA. Mitigation and Adaptation Strategies for Global Change, 3, 59-82.

Cockburn, A. \& Ridgeway, J. (eds.) 1979. Political Ecology. Times Books: New York.

Cohen, C. \& Werker, E. 2004. Towards an understanding of the Root causes of Forced Migration: The Political Economy of Natural Disasters. Working Paper \# 25. 
Craig, W.J., T.M. Harris \& D. Weiner. (eds.). 2002. Community Participation and Geographic Information Systems. London \& New York.

Crimp, S.J.; van Heever, S.C.; D’Aberton, P.C.; Tyson, P.D. \& Mason, S.J. 1997. Mesoscale Modelling of Tropical-Temperate Troughs and Associated Systems over Southern Africa. WRC Report 595/1/97, 395.

Croley, T.E. 2002. Large Basin Runoff Model. In: Singh, V., Frevert, D \& Meyer, S (eds.) Mathematical Models of Large Watershed Hydrology (II). Water Resources Publications: Littleton, Colorado.

Cutter, S.L. (ed.) 1993. Environmental Risks and Hazards. New Jersey: Prentice Hall.

1996. Vulnerability to environmental hazards. Progress in Human Geography, 529-39.

Daanish, M. 2002. To each according to his power? Participation, access, and vulnerability in irrigation and flood management in Pakistan. Environment and Planning D: Society and Space, 20(6): 737-753.

Dow, K. 1992. Exploring differences in our common future(s): the meaning of vulnerability to global environmental change. Geoforum, 23, 417-436.

Du Plesis, L.A. 2000. A Review of effective flood forecasting, warning and response system for application in South Africa. Water SA, 28 (2): 129-137.

Du Plessis, L.A. \& Viljoen, M.F. 1999. Calculation of the secondary effects of floods in the Lower Orange River: A GIS approach. Water SA, 25(2): 197-203.

Dymon, U.J. 1993. Map use during and after Hurricane Andrew. Final Report to the Natural Hazards Research and Applications Information Center. Boulder Colorado. 
Ellis, F. 2000. Rural Livelihoods and Diversity in Developing Countries. New York \& Oxford: Oxford University Press.

Elwood, S. \& Leitner, H.1998. GIS and community-based planning: exploring the diversity of neighborhood perspectives and needs. Cartography and Geographic Information Systems, 25(2): 77-88.

Emel, J. \& Peet, R. 1989.Resource management and natural hazards. In Peet, R \& Thrift, N. (eds.) New models in geography: the political economy perspective. Volume 2. London: Unwin Hyman.

Enzensberger, H.M. 1974. A Critique of political ecology. New Left Review, 84:3-31.

Erskine, J.M. 1993. Ecology and Land Usage in Southern Africa: A Survey of Present Day Ties, Problems and Opportunities. London: Island Press.

Fairhurst, U.J., Musyoki, A., Saidi, T. \& Wilson, G.D.H. (eds.). 2000. Integrating Environment and Society: The Thohoyandou Environs, Northern Province, South Africa. Pretoria \& Venda: Universities of Pretoria \& Venda.

Fothergill, Alice. 1996. Gender, risk, and disaster. International Journal of Mass Emergencies and Disasters, 14 (1): 33-56.

Foster, H.D.1992. Health, Disease \& the Environment. London: Belhaven Press.

Forsyth, T. 2003. Critical Political Ecology: The Politics of Environmental Science. London \& New York: Routledge and Taylor \& Francis.

Frerks, G. \& Bender, S. 2004. Conclusion: Vulnerability Analysis as a Means of Strengthening Policy Formulation and Policy Practice. In Bankoff, G., Frerks, G. \& 
Hilhorst, D (eds.). Mapping Vulnerability: Disasters, Development and People. London: Eathscan.

Goss, J. 1995a. We know who you are and we know where you live: The instrumental rationality of geo-dermographic information systems. Economic Geography, 71: 171-98.

Grossman, L.S. 1998. The Political Ecology of Bananas: Contracting Farming, Peasants, and Agrarian Change in the Eastern Caribbean. Chaphill: The University of Carolina Press.

Handmer, J. \& Penning-Rowsell, E. (eds.) 1990. Hazards and the Communication of Risk. Aldershot: Gower Publishing.

Harris, T.M., Weiner, D., Warner, T. and Levin, R. 1995. Pursuing social goals through Participatory GIS: Redressing South Africa's historical political ecology. In Pickles, J. (ed.), Ground truth; the social implications of geographic information Systems. New York: Guilford.

Harris, T.M. \& Weiner, D. 1996. GIS and Society: The social implications of how people, space and environment are represented in GIS. NCGIA Technical Report 96-97. Scientific Report for Initiative 19 Specialist Meeting, South Haven, Minn., March 2-5, 1996.

2002. Implementing a Community-integrated GIS: perspectives from South African fieldwork. In: Craig, W.J., Harris, T.M. \& Weiner, D. (eds.). Community Participation and Geographic Information Systems. London \& New York: Taylor \& Francis.

Hecht, S.B., Anderson, A.B. \& May, P. 1988. The Subsidy from Nature: Shifting Cultivation, Successional Palm Forests and Rural Development. Human Organization, 47(1): 25-35. 
Hewitt, K. 1983. The Idea of Calamity in a Technocratic Age. In K. Hewitt (ed.) Interpretations of Calamity: From the Viewpoint of Human Ecology. Allen \& Unwin, London.

(ed.) 1983. Interpretations of Calamity: From the Viewpoint of Ecology. London \& Sydney: Allen \& Unwin.

1997. Regions of risk: a geographical introduction to disasters. Essex: Addison Wesley Longman Ltd.

Holloway, A \& von Kotze, A. 1996. Reducing Risk: Participatory Learning Activities for Disaster Mitigation in Southern Africa. UK/I: Oxfam.

Horlick-Jones, T. Sime, J \& Pidgeon, N. 2003. The social dynamics of environmental risk perception: implication for risk communication research. In Pidgeon, N., Kasperson, R.E. Slovic, P. (eds.) 2003. The Social Amplification of Risk. Cape Town \& New York: Cambridge University Press.

Howe, G.M. 1980. The Environment: Its Influences and Hazards to Health. In G.M. Howe (ed.) Environmental Medicine. London: Heinemann Medical Books.

Howitt, R. 2003. Scale. In Agnew, J., Mitchell, K \& Toal, G. A Companion to Political Geography. MA: Blackwell Publishers Ltd.

Huntington, E. 1945. Mainsprings of civilization. New York: Wiley.

Johnston, R.J., Gregory, D., Pratt, G. and Watts, M. (eds.) 2000. The Dictionary of Human Geography, $4^{\text {th }}$ edition. Oxford \& Massachusetts: Blackwell Publishers Ltd. 
Jordan, G. \& Shrestha, B. 1999. A Participatory GIS for Community Forestry User Groups in Nepal: Putting People Before the Technology. Available online at:

$<$ http:www.mtnforum.org/resources/library/jordx99a.htm. Accessed on February, 2005.

Kabanda, T.A. 2004. Climatology of Long-term Drought in the Northern Region of the Limpopo Province of South Africa. Unpublished doctoral dissertation submitted to the Department of Geography and Geo-Information Sciences, University of Venda, South Africa.

Kates, R.W. 1980. Disaster Reduction: Links between Disaster and Development. In Berry, L \& Kates, R.W. (eds.) Making the Most of the Least: Alternative Ways to Development. New York: Holmes \& Meier.

Kates, R.W. \& Kasperson, J.X. 1983. Comparative Risk Assessment of technological hazards. Proceedings: National Academy of Sciences, 80: 7027-7038.

Keller, E.A. 2001. Environmental Geology, $\boldsymbol{8}^{\text {th }}$ edition. Upper Saddle River, New Jersey: Prentice - Hall.

Kelly, P.M. \& Adger, N.W. 1999. Assessing vulnerability to climate change and facilitating adaptation. East Anglia: Centre for Social and Economic Research on the Global Environment, University of East Anglia and University College London.

Khandlhela, M. \& May, J. 2006. Poverty, vulnerability and the impact of flooding in the Limpopo province, South Africa. Natural Hazards, 39: 275-287.

Kyem, P.A.K. 2001 (published 2004) Public participation GIS applications and the community empowerment process: A review of concerns and challenges. Cartographica, 38 (3\&4): 5-17. 
.2002. Promoting local community participation in forest management through a PPGIS application in Southern Ghana. In: Craig, W.J., Harris, T.M. \& Weiner, (eds.). Community Participation and Geographic Information Systems. London \& New York: Taylor \& Francis.

2004. Of intractable conflicts and participatory GIS applications: The search for consensus amidst competing claims and institutional demands. Annals of the Association of American Geographers, 94 (1): 37-57.

Laituri, M. 2002. Ensuring access to GIS for marginal societies. In: Craig, W.J., Harris, T.M. \& Weiner, D. (eds.). Community Participation and Geographic Information Systems. London \& New York: Taylor \& Francis.

Levin, R. \& Weiner, D. (eds.) 1997. No more Tears: Struggles for land in Mpumalanga, South Africa. New Jersey \& Eritrea: Africa World Press.

Liverman, D. 1990. Vulnerability to Global Environmental Change. In Kasperson, R.E., Dow, K., Golding, D and Kasperson, J.X. (eds.). Understanding Global Environmental Change: the contributions of risk analysis and management. Winchester, M.A.: Earth Transformed Program, Clarke University.

Lupton, M. \& Mather, c. 1996. The anti-politics machine: GIS and the reconstruction of the Johannesburg local state. Political Geography, 16(7):565-580.

Maguire, D.J., Goodchild, M.F. \& Rhind, D.W. 1991. Geographical Information Systems (Vol. 1). London \& New York: Longman \& Wiley.

Mamun, M. Z. \& Amin, A. T. M. 2000. Strategic Role of Water Transport Modernization for Safe Settlements Growth in the Erosion-Prone Floodplains of Bangladesh. Regional Development Studies, 6: 111-129. 
McCusker, B. 2002. The impacts of membership in communal property associations on livelihoods in the Northern Province, South Africa. GeoJournal, 56(2), 113-122.

McCusker, B. \& Weiner, D. 2003. GIS Representation of Nature, Political Ecology, and the study of land-use and land cover change in South Africa. In Zimmerer, K.S and Bassett, T.J. (eds.), Political Ecology: An Integrative Approach to Geography and Environment- Development Studies. New York: Guilford Press.

McCusker, B. \& Oberhauser, A. 2006. An assessment of women's access to natural resources through communal projects in South Africa. GeoJournal, 66: 325-339.

McLafferty, S.L. 2002. Mapping women's worlds: Knowledge, power and the bounds of GIS. Gender, Place and Culture, 9(3): 263-269.

Merriam, S.B.1991.Case Study research in education: A qualitative approach. San Francisco: Jossey -Bass.

Messner, F \& Meyer, V. 2006. Flood damage, vulnerability and risk perception challenges for flood damage research. In: Schanze, J., Zerman, E., Marsalek, J. (Eds.) Flood Risk Management - Hazards, Vulnerability and Mitigation Measures. Nato Science Series: Springer Publisher.

Mitchell, J.K. 1998. Hazards in changing cities. Applied Geography, 18:1-6.

Mitchell, J.K. \& Cutter, S.L. 1999. Global change and environmental hazards: is the world becoming disastrous? Available online at:

$<$ http://www.aag.org/HDGC/www/hazards/units/unit1/html/bkgound.html. Accessed December 2004.

Mileti, D.S.1999. Disasters by Design: A Reassessment of Natural Hazards in the United States. Washington D.C.: Joseph Henry Press. 
Miller, E.W. \& Miller, R.M. 2000. Natural Disasters: Floods. New York: ABC-Clio.

Mgquba, S.K. \& Vogel, C. 2004. Living with Environmental Risks and Change in Alexandra Township. South African Geographical Journal, 86(1): 30-38.

Morrow, B.H. 1999. Identifying and Mapping Community Vulnerability. Disasters, 23(1):1-18.

Morse, S. \& Stocking, M. (eds.) 1995. People and environment. Vancouver: UBC Press.

Mufamadi, T.A. 2003. Limpopo State of the Environment Overview Report. Government Printers: Polokwane.

Oberhauser, A.M. \& Pratt, A. 2004. Women's Collective Economic Strategies and Political Transformation in Rural South Africa. Gender, Place and Culture, 11(2):209227.

Obermeyer, N. J.1995. The evolution of public participation GIS. Cartography and Geographic Information Systems, 25(2): 37-52.

O’Keefe, P., Westgate, K. \& Wisner, B. 1976. Taking the naturalness out of natural disasters. Nature, 260:566-7.

Onsrud, H.J. 1995. Identifying unethical conduct in the use of GIS. Cartography and Geographic Information Systems, 22(1): 90 - 97.

Omara-Ojungu, P.H. 2001. Environmental Science in the Management of Mountain Resources. Professional Inaugural Address, University of Venda. 
1999. Resource Management issues in the former homelands of South Africa.

The 1999 International Symposium on Society and Resource Management. University of Queensland, Brisbane, Australia. July 7-10.

Palm, R.I. 1990. Natural Hazards: An Integrative Framework for Research and Planning. Baltimore: John Hopkins University Press.

Peet, R. \& Watts, M. (eds.) 1996. Liberation Ecologies: Environment, Development and Social movements. London \& New York: Routledge.

Pelling, M.1998. Participation, social capital and vulnerability to urban flooding in Guyana. Journal of International Development,,10(4): 469-486.

Rambaldi, G., Kwaku Kyem, A.P., McCall, M. \& Weiner, D. 2006. Participatory Spatial Information Management and Communication in Developing Countries. Electronic Journal of Information Systems in Developing Countries, 25(1):1-9.

Reed, D.W. 2002. Reinforcing flood-risk estimation. Phil. Trans. R. Soc. Lond. A, (360): 13731387.

Rodda, A. 1991. Women and the Environment. London \& New Jersey: Zed Books Ltd.

Rosa, E.A. 2003. The logical structure of the social amplification of risk framework (SARF): Metatheoretical foundations and policy implications. In Pidgeon, N., Kasperson, R.E. \& Slovic, P. (eds.) 2003. The Social Amplification of Risk. Cape Town \& New York: Cambridge University Press.

Ruddle, K. 1994. A Guide to the Literature on Traditional Community-Based Fishery Management in the Asia-Pacific Tropics. Rome: FAO Fisheries Circular Number 869, FIPP/C869. 
Rundstrum, R.1995. GIS, indigenous peoples, and epistemological diversity. Cartography and Geographic Information Systems, 22(1): 45-57.

Saidi, T. 1999. A synopsis of environmental problems in the former homeland of Venda. In: U.J. Fairhurst et al. (eds.) Integrating Environment and Society: The Thohoyandou Environs, Northern Province, South Africa. Pretoria \& Venda: Universities of Pretoria \& Venda.

Scoones, I.1998. Sustainable Rural Livelihoods: A Framework for Analysis. IDS Working Paper No.72.

Sen, A. 1981. Poverty and famines: an essay on entitlement and deprivation. Oxford: Clarendon Press.

Sieber, R. 2006. Public Participation Geographic Information Systems: A Literature Review and Framework. Annals of the Association of American Geographers, 96(3):491-507.

Smit, B., Burton, I., Klein, R.J.T. \& Street, R.1999. The Science of Adaptation: A Framework for Assessment. Mitigation and Adaptation Strategies for Global Change, 4: 199-213.

Smith, D.J. G. 1981. Guidelines for Assessing Flood damage in South Africa. Bloemfontein and Cape Town: WRC.

Smith, K. 1996. Environmental Hazards: Assessing Risk and Reducing Disaster, $2^{\text {nd }}$ Edition. London and New York: Routledge.

Staeheli, L.A. 2003. Place. In Agnew, J., Mitchell, K \& Toal, G. A Companion to Political Geography. MA: Blackwell Publishers Ltd. 
Stott, P. \& Sullivan, S. (eds.) 2000. Introduction. In Stott, P. \& Sullivan, S. (eds.), Political Ecology: Science, Myth and Power. London and New York: Arnold and Oxford University Press.

Susman, P., O’Keefe, P. \& Wisner, B. 1983. Global disasters, a radical interpretation. In Hewitt, K. (ed.). Interpretations of Calamity: From the Viewpoint of Ecology.

Taljaard, J.J.1994. Atmospheric Circulation Systems, Synoptic Climatology and Weather Phenomena of South Africa. Part 1: Controls of the weather and climate of South Africa. South Africa. Weather Service Technical Paper 27, South Africa Weather Service, Pretoria.

Tapela, B. 1999. Makuleke - A gender sensitive analysis of Community Participation in an Integrated Conservation and Development Programme. In U.J. Fairhurst et al. (eds.) Integrating Environment and Society: The Thohoyandou Environs, Northern Province, South Africa. Pretoria \& Venda.

Tapela, B \& Omara-Ojungu, P. 1999. Towards bridging the gulf between wildlife conservation and rural development in post-apartheid South Africa: The case of the Makuleke community and the Kruger National Park. South African Geographical Journal, 82(1):148-55.

Thomson, D. \& Laurini, R. 1992. Fundamentals of Spatial Information Systems. London: Academic Press.

Tierney, K.J. 1989. Improving Theory and Research on Hazard Mitigation: political economy and organizational perspectives. International Journal of Mass Emergencies and Disasters, 7(3): 367-396. 
Tripathi, N. \& Bhattarya, S. 2004. Integrating Indigenous Knowledge and GIS for Participatory Natural Resource Management: State-of -the Practice. EJISDC, 17(3):113.

Torry, W.I. 1979. Hazards, Hazes and Holes: A Critique of the Environment as Hazard and General Reflections on Disaster Research. Canadian Geographer, 23: 368-383.

Varley, A. (1994) The Exceptional and the Everyday: Vulnerability Analysis in the International Decade for Natural Disaster Reduction. In A. Varley (ed.) Disasters, Development and Environment. Wiley: New York.

Von Kotze, A. 1999. A New Concept of Risk. In Holloway, A. (ed.) Risk, Sustainable Development and Disasters: Southern African perspectives. Cape Town: Periperi Publications.

Waddell, E. 1977. The Hazards of Scientism. Human Ecology, 5: 69-76.

Watts, M. 1983a. On the Poverty of Theory: Natural Hazards Research in Context. In Hewitt, K. (ed.) Interpretations of Calamity: From the Viewpoint of Ecology. London \& Sydney: Allen \& Unwin.

1983b. Silent Violence: Food, Famine and Peasantry in Northern Nigeria. Berkeley: University of California Press.

Watts, M.J. \& Bohle, H.G.1993. The space of vulnerability: the causal structure of hunger and famine. Progress in Human Geography, 17: 43-67.

White, G.F. (ed.) 1974. Natural Hazards: Local, National and Global. New York: Oxford University Press. 
Wijkman, A. \& Timberlake, L. 1984. Natural Disasters: Acts of God or Acts of Man? London \& Washington D.C.: Earthscan.

Wisner, B. 1976. Man-made famine in Eastern Kenya: the interrelationship of environment and development. Institute of Development Studies discussion Paper No.96. Brighton: IDS.

1989. Power and Need in Africa. Trenton, NJ: Africa World Press.

1999. From “Acts of God' to 'Water Wars': The urgent Analytical and Policy Role of Political Ecology in Mitigating Losses from Flood: A view of South Africa from Central America. Paper presented at the IDNDR Symposium on WaterRelated Disasters in Nagoya, Japan, February 17, 1999.

Wolf, E.R. 1972. Ownership and political ecology. Anthropological Quarterly, 45: 201205.

1999. Envisioning Power: Ideologies of Dominance and Crisis. Berkeley \& Los Angeles: University of California Press.

Wu, S. Y., Yarnal, B. and Fisher, A. 2002. Vulnerability of coastal communities to sea level rise: a case study of Cape May County, New Jersey, USA. Climate Research, 22: 255-270.

Yapa, L.S. 1991. Is GIS appropriate technology? International Journal of Geographical Information Systems, 5: 41-58.

Yarnal, B.: 1994, 'Agricultural decollectivization and vulnerability to environmental change: a Bulgarian case study', Global Environmental Change, 4: 229-243. 
Zimmerer, K.S. \& Bassett, T.J. (eds.) 2003. Political Ecology: An Integrative Approach to Geography and Environment - Development Studies. New York: Guilford Press.

\section{Local Newspaper Articles}

Maseko, S. 2001. Shelter for the poor. In: Sowetan, March 2000.

Floods a predictable disaster. In: Mail and Guardian, March 16, 2000.

Flood situation getting worse. In: Sowetan, February 18, 2000.

“Provinsie lamgele deur woedende Sikloon Eilene en haar vloedwaters” In:

Zoutpansberger, March, 3, 2000. 


\section{APPENDIX A}

\section{Statement of Confidentiality}

August, $10^{\text {th }}, 2005$

Dear Research Participant,

\section{RE: STATEMENT OF CONFIDENTIALITY AND NOTE OF APPRECIATION}

My name is Nthaduleni Samuel Nethengwe, a PhD candidate in the Geography program, in the Department of Geology and Geography, at West Virginia University, Morgantown, WV. My PhD project, entitled, "Integrating Participatory GIS and Political Ecology to study Differential Flood vulnerability in Thulamela Municipality of the Limpopo Province of South Africa" demands that I collect data and engage communities in mental mapping workshops to get a better understanding of social and spatial differentiation of flood vulnerability in your village. I am pleased you accepted to participate in this survey, interview and workshop. Your contribution is highly appreciated and I wish to take this opportunity to assure you that I'm committed secure your privacy and confidentiality in as far as your responses are concerned. The information colleted will be for academic purposes only and your name will not be mentioned.

If you have any further questions, please feel free to contact me or my advisor Dr.

Daniel Weiner at:

Department of Geology and Geography

West Virginia University

425 White Hall

P.O Box 6300

Morgantown, WV 26506-6300

USA

Telephone: + (304) 293-5603

Or

Dr. Peter-Omara-Ojungu

Executive Dean, Faculty of Natural and Applied Sciences

University of Venda

P.O Box 5050

Thohoyandou, Limpopo Province, South Africa

0950

Telephone: (015) 9628514

Regards,

Nthaduleni Samuel Nethengwe 


\section{APPENDIX B}

\section{SURVEY DIRECTED TO HOUSEHOLDS AT DZINGAHE \& MILABONI STUDY SITES IN THE VHEMBE DISTRICT MUNICIPALITY - LIMPOPO PROVINCE.}

The overall purpose of this survey is to elicit respondents' socio-economic information, household perceptions and experiences of floods as well as their flood coping strategies. Respondents also provide information about their affiliation to institutions and their perceptions of such institutions in terms of their usefulness before, during and after flood event. The individual information collected in this survey is confidential and will only be used for academic and related purposes. The questionnaire survey will be administered only to heads of households (both male and female participants).

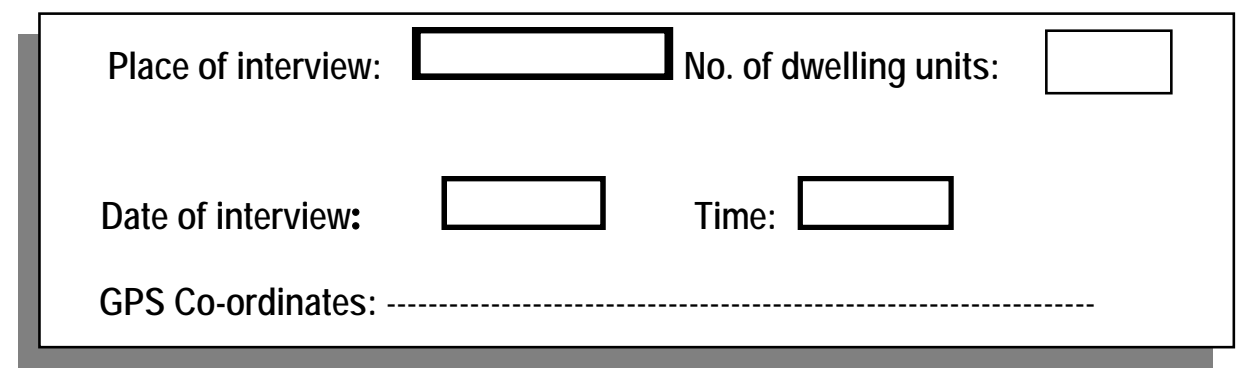

A. DEMOGRAPHIC CHARACTERISTICS

1. ID \#:

2. Gender of the head of the household:
1. Male
2.
Female

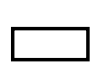

3. Age of the head of household:

4. Your health status:

1. Excellent heath

2. Good health

3. Average health

4. Poor health

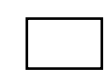
(1) 


\section{Marital Status:}

1. Married

2. Divorced

5. Separated

3. Single

4. Widowed

6. Other (please specify)

6. If married, how many spouses do you have?

\section{Form of marriage:}

1. In Community of property

2. Customary

3. Out of Community of Property

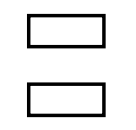

4. Other (specify)......

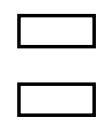

8. How many children do you have?

9. Number of people dependent on your income (excluding your children)?

10. How many of your dependents have some form of disability?

11. What is the highest level of education you reached (in terms of years of education)?

1. Less or equal 5 yrs

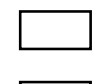

2. 6 - 8 yrs

3. $9-13 \mathrm{yrs}$

4. 14 yrs and above

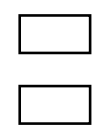

12. Do you have any other educational/ professional training?

1. Yes

2. No

3. Specify (if any):
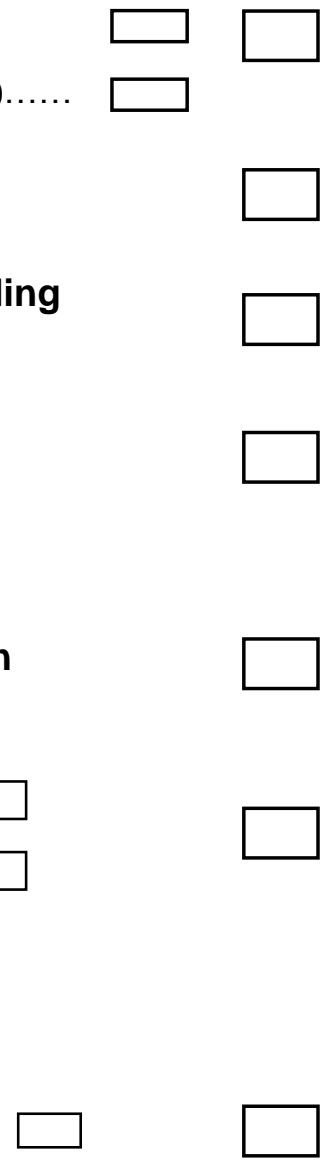

13. Other personal skills that you have.

1. Art-crafting (sewing, pot-making, mat-making, etc)

2. Building 3. Singing/ musical instrument playing

4. Traditional beer-making

5. Car mechanic

6. Other (please specify). 
How many children attend school in:-

14. Grade $1-7$

15. Grade 8- 12

16. Tertiary

B. LIVELIHOOD EARNINGS

17. What is the main source of your household income?

1. Informal business

2. Old -age pension

3. Remittances from migrant labour

4. Formal employment

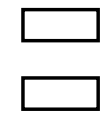

5. Other (specify)

18. What is your annual household income including that from the informal sector?

1. R400 - R6 868

3. R12 $661-\mathrm{R} 23940$

5. R52 $801+$

2. R6 $869-R 12660$

4. R23 $941-$ R52 800

19. Are you formally employed?

1. Yes

2. No

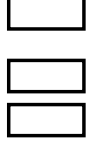

$\square$

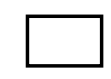


22. Mean hours worked per week for those formally employed.

23. Mean hours worked per week for those engaged in informal sector.

24. What other source (s) of income does your family have?

1. Spouse's contribution

3. Growing maize and vegetables

5. Other (specify).
2. Old -age pension

4. None
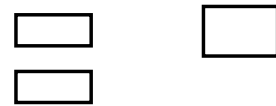

25. Indicate any assets that you have:

1. Cattle (Estimate \#)

3. Sheep (Estimate \#)

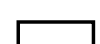

5. Plot of land on stand

7. Other (specify)
2. Goat (Estimate \#)

4. Modern House

6. Fruit Farm
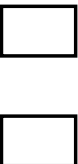


\section{HOUSEHOLD LIVING CONDITIONS}

34. Is your house/ dwelling unit

1. rented

3. other (specify)

2. owned

35. If you don't have access to water inside your yard, what is the average distance from water source?
1. $<100 \mathrm{~m}$
3. $200-<500 \mathrm{~m}$
5. $>1 \mathrm{~km}$

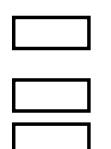

2. $100-<200 m$

4. $500 \mathrm{~m}-<1 \mathrm{~km}$
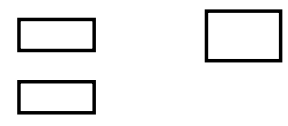

36. If you mainly use wood for cooking and heating, what is the average distance from wood source?
1. $<100 \mathrm{~m}$
3. $200-<500 \mathrm{~m}$
5. $>1 \mathrm{~km}$
2. $100-<200 m$
4. $500 \mathrm{~m}-<1 \mathrm{~km}$
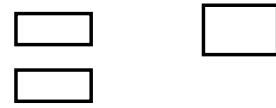
Housing Quality Index (for main house/hut)

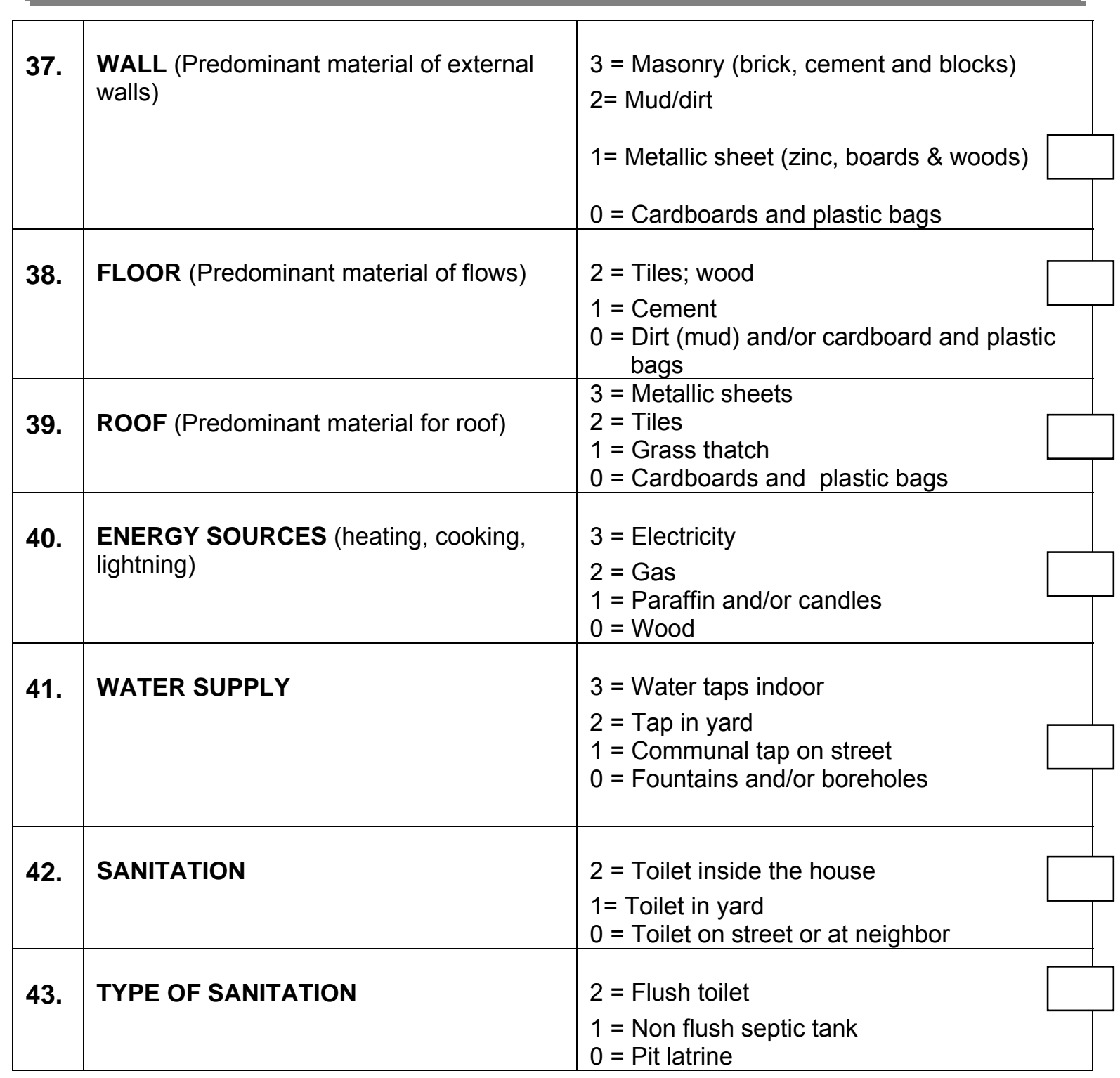




\section{FLOOD EXPERIENCES \& COPING STRATEGIES}

\section{Has your household ever devastated by floods?}

1. Yes

2. No

If you answered 'No' to question 28, proceed to answer question 28 item \#8.

If 'Yes', describe what happened and when did that happen? (3)

How did you cope then? (4)

List the articles/assets (from the most valuable) that were destroyed by the flood.

(5).

Were you able to replace the destroyed items after flooding? (6)

Why were/weren't you able to replace them? (7).

If you answered 'No' to question 28 item \#1 above, what do you attribute the fact that your household was not devastated by floods to? (8).

From what other indirect flood impacts did your household suffer? (9).....

How did you cope from those impacts?(10). 
45. For how long have you been staying here?

46. If the next flood comes would you approach flood mitigation differently? Yes

2. No

If Yes, what would you do differently? (3).

If No, why not change your strategies? (4)

47. Which activity (human /physical) do you think is the major cause of flooding in your village?

1. Forest clearing for agriculture/wood

2. Cultivation on steep slopes

3. Overgrazing

4. Heavy rains

5. Other (please specify)

48. Of the following flood coping strategies indicate the ones your household adopted or can adopt as a way to cope with flood impacts.

\begin{tabular}{|c|c|}
\hline 1. & Borrow money from relatives or informal lenders \\
\hline 2. & Access savings from the bank \\
\hline 3. & Evacuate to places of safety \\
\hline 4. & Work in nearby farms, towns or elsewhere \\
\hline 5. & Engage in informal sectoral activities \\
\hline 6. & Sell some assets including livestock \\
\hline 7. & Building protective walls around home and terraces in fields \\
\hline 8. & Get money from member(s) of family who work(s) elsewhere \\
\hline 9. & Do nothing and wait for neighbors and government to help \\
\hline 10. & Approach local businesses and structures of governance to help \\
\hline 11. & Other (please specify)... \\
\hline
\end{tabular}


49. Why do you think do you think coping strategies identified in question 33 above are so effective?

(1). Have these strategies changed over time and why?

(2). How do these coping strategies compare with the overall coping mechanisms in the Vhembe district and the province as a whole?

\section{E. LOCATIONAL FACTORS/ DECISIONS}

50. Why is your household located here?

\section{If given any option to resettle, would you move?}

1. Yes

2. No

If Yes, why (1) and where (2) will you move to?

(1)

(2).

If No, why wouldn't you move? (3). 
52. In a household situation, who (1) is likely to take the final decision to resettle and why (2) is it like that? (1).

(2).

53. What would you like to change in terms of the roles of taking decisions and household/community level initiatives?

\section{F. PERCEIVED FAMILY ECONOMIC PRESSURE}

This section has a list of situations that one may experience in one's family. Please use these characteristics to describe the family in which you live. Indicate on a scale from 1 to 5, how much you agree or disagree with each of the statements listed below. Indicate [9] if the statement is not applicable to you.

$1=$ Strongly Disagree
$2=$ Disagree
$3=$ No opinion
$4=$ Agree
$5=$ Strongly Agree

Question

Statement

Scale

54. My family has enough money for the kind of home we would like to have.

55. My family has enough money saved in the bank or elsewhere.

56. We are poorer now than we used to.

57. Our household can survive a crisis (e.g. job loss, ill-health of breadwinner, flood, etc. without any problems.

58. We do not have money to feed everyone in the family. 
59. We depend on our neighbors or relatives for most of our basic needs.

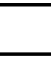

60. We depend on old-age pension or child grant for most our basic needs.

61. We do not have adequate land to plough

62. We rely on wood fuel for cooking and heating

63. We rely on electricity or paraffin for household cooking and/or heating

G. IMPACT OF INSTITUTIONS, SOCIAL NETWORKS/RELATIONS \& DISASTER AID ON COPING CAPACITY

64. Are you aware of policies or laws meant to enhance flood coping capacity within this community?
1. Yes
2.
No

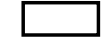

65. What role does the institution of (1) chieftaincy, (2) civic organization and (3) local government play before, during and after flood?

$(1)$

(2).

(3).

66. Do other social networks including friends and relatives help during and after floods?

$\begin{array}{lllll}\text { 1. } & \text { Always } \square & \text { Sometimes } \\ \text { 3. } & \text { Seldom } \square & \text { N. } & \text { Never }\end{array}$

67. Are women and men in your community engaged as equal partners in flood mitigation decisions and community-based planning?
1. Always
2. Sometimes
3. Seldom
4. Never

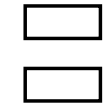


68. Do you think of any institutional and ideological constraints that are likely to limit women's engagement in mitigating the effects of flood in your community?

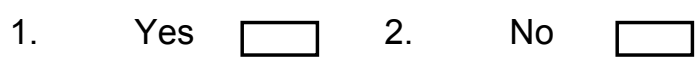

If Yes, what are those constraints? (3).

What do you think should be done to deal with such constraints? (4)

69. What do you think are the root causes of flood disaster vulnerability in this household and the community at large?

70. Have you ever involved in any overt grassroots activism as part of community resistance?
1. Yes
2. No

If No, please specify covert forms of resistance (if any) (3).....

71. What do you think should be done to reduce flood vulnerability at the household and community levels?..(1).....

(2).

72. What is the nature of disaster aid (1) and (2) how is it distributed in the event of flood?(1)

(2) 
73. Is the local community involved in the distribution of disaster aid?
1. Always
2. Sometimes
3. Seldom
4. Never

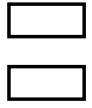

74. Do vulnerable communities adjust after aid or are they left permanently vulnerable?
1. Always
2. Sometimes
3. Seldom
4. Never

75. Do local businesses contribute towards disaster relief fund?
1. Always $\square$
2. Sometimes
3.
Seldom
4. Never

4. Never $\square$

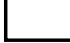

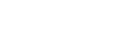

\section{H. PERCEIVED SOCIAL CAPITAL MEASURE}

This section has a list of characteristics that one could find in one's life or society. Please use these characteristics to describe the family in which you live. Indicate on a scale from 1 to 5 , how much you agree or disagree with each of the statements listed below. Indicate [9] if the statement is not applicable to you.

\section{Question}

\section{Statement}

$$
\begin{aligned}
& 1=\text { Strongly Disagree } \\
& 2=\text { Disagree } \\
& 3=\text { No opinion } \\
& 4=\text { Agree } \\
& 5=\text { Strongly Agree }
\end{aligned}
$$

Scale

76. In this community we turn to each other for help when we have a crisis.

77. Few neighbors know me.

78. In the past 12 months I talked with other people in my area about a problem in the community.

79. Flooding is the major environmental problem in the area.

80. During the past years community members have participated in solving flood related- problems in the community. 
81. People are not concerned with community welfare.

82. My neighbors would intervene if flooding broke out in the community

83. We work together to solve any problem in this community.

84. Members of this community do not have equal access to available resources such as land.

85. I feel accepted as a member of this community.

86. I am affiliated to a burial society

87. I am affiliated to a religious group.

88. I belong to a workers union.

89. I belong to a political party.

90. On general I coped very well during previous flood event

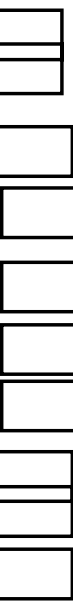

All the information that you have shared here will remain confidential, so please do not write the name of the head of household anywhere on the form. If he or she would like to make any comments or add any information or if they feel we left any important information or facts, please write their comments on the back of the form. For any other issues concerning the study please contact me, Mr. N.S. Nethengwe or Dr. Peter Omara-Ojungu at the Department of Geography and Geo-information Science, University of Venda or Dr. Daniel Weiner at Department of Geology and Geography, West Virginia University, Morgantown, WV, USA.

\section{THANK YOU}




\section{APPENDIX C}

\section{Focus Group Discussion Check List}

\section{STUDY SITES: Milaboni and Dzingahe}

MAIN ISSUE OF DISCUSSION: Flooding of Year 2000: Its Impacts and Future Prospects.

PREAMBLE: Introduction, purpose and confidentiality statement read before any session.

1. Appraising the flooding of year 2000

a. Impacts?

b. Adjustments/ Recovery/ coping strategies?

c. Evaluating the implementation of Disaster Aid -What went right/wrong?

d. How to mitigate future flood impacts- level of preparedness, etc?

2. Accountability of people, processes and institutions.

a. Do you think people, processes and institutions have increased flood susceptibility or have prevented or mitigated its impacts?

b. How did these institutions help the affected people recover from the impacts of floods?

\section{How are the affected people perceived?}

a. As helpless victims or as agents who can cope or avoid disaster together?

b. Can affected people cope or have they coped adequately? How did they cope? Have any other social networks including friends and relatives helped them cope?

4. The issue of Social justice- have
a. the poor rather than the rich,
b. women rather than men
c. the very old rather than the young
d. those with low community status rather than those with higher status; mostly affected by floods?

5. Identify Resources that are important to reduce flood risk. Any other issues of discussion?

EPILOGUE: Appreciation \& closing remarks. 